\title{
Rectal cancer : are we ready for a paradigm shift?
}

Citation for published version (APA):

Maas, M. (2013). Rectal cancer : are we ready for a paradigm shift? [Doctoral Thesis, Maastricht University]. Datawyse / Universitaire Pers Maastricht. https://doi.org/10.26481/dis.20130508mm

Document status and date:

Published: 01/01/2013

DOI:

10.26481/dis.20130508mm

Document Version:

Publisher's PDF, also known as Version of record

\section{Please check the document version of this publication:}

- A submitted manuscript is the version of the article upon submission and before peer-review. There can be important differences between the submitted version and the official published version of record.

People interested in the research are advised to contact the author for the final version of the publication, or visit the DOI to the publisher's website.

- The final author version and the galley proof are versions of the publication after peer review.

- The final published version features the final layout of the paper including the volume, issue and page numbers.

Link to publication

\footnotetext{
General rights rights.

- You may freely distribute the URL identifying the publication in the public portal. please follow below link for the End User Agreement:

www.umlib.nl/taverne-license

Take down policy

If you believe that this document breaches copyright please contact us at:

repository@maastrichtuniversity.nl

providing details and we will investigate your claim.
}

Copyright and moral rights for the publications made accessible in the public portal are retained by the authors and/or other copyright owners and it is a condition of accessing publications that users recognise and abide by the legal requirements associated with these

- Users may download and print one copy of any publication from the public portal for the purpose of private study or research.

- You may not further distribute the material or use it for any profit-making activity or commercial gain

If the publication is distributed under the terms of Article $25 \mathrm{fa}$ of the Dutch Copyright Act, indicated by the "Taverne" license above, 


\section{RECTAL CANCER: Are we ready for A PARADIGM SHIFT?}


ISBN 9789461592194

(C) copyright Monique Maas, Maastricht 2013

Printing: Datawyse / Universitaire Pers Maastricht 


\section{Rectal cancer: are we ready for a paradigm shift?}

\section{PROEFSCHRIFT}

ter verkrijging van de graad van doctor aan de Universiteit Maastricht op gezag van de Rector Magnificus Prof. dr. L.L.G Soete, volgens het besluit van het College van Decanen, in het openbaar te verdedigen

op woensdag 8 mei 2013 om 15:15 uur

$$
\text { door }
$$

\section{Monique Maas}

geboren op 5 januari 1983 te Eindhoven

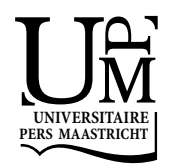


Promotor

Prof. dr. R.G.H. Beets-Tan

Copromotores

Dr. G.L. Beets

Dr. P.J. Nelemans

Beoordelingscommissie

Prof. dr. M.F. von Meyenfeldt (voorzitter)

Prof. dr. Ph. Lambin

Prof. dr. V.C.G. Tjan-Heijnen

Prof. dr. J.E. Wildberger

Prof. dr. J.H.W. de Wilt, UMC St. Radboud 


\section{CONTENTS}

CHAPTER 1 Introduction

7

PART I - PARADIGM SHIFT TO LESS INVASIVE TREATMENT

CHAPTER 2 Long-term outcome in patients with a pathologic

complete response after chemoradiation for

rectal cancer: a pooled analysis of 3105 patients

19

CHAPTER 3 Wait-and-see policy for clinical complete

responders after chemoradiation for rectal cancer

45

CHAPTER 4 Long-term follow-up features on rectal MRI

during wait-and-see policy after a clinical complete

response in rectal cancer patients treated with

chemoradiotherapy

63

PART II - PARADIGM SHIFT FROM LOCAL TO DISTANT CONTROL

CHAPTER 5 Modern multidisciplinary treatment of rectal cancer based on staging with MRI leads to excellent

local control, but distant control remains a challenge

CHAPTER 6 Neoadjuvant chemoradiation for rectal cancer:

defining subgroups who may benefit from

further adjuvant chemotherapy after resection

CHAPTER 7 What is the most accurate whole-body imaging

modality for assessment of local and distant

recurrent disease in colorectal cancer? A meta-analysis.

PART III - A PATIENT'S PERSPECTIVE

CHAPTER 8 Patiënteninterview

CHAPTER 9 Discussion

Summary

Dutch summary

Dankwoord

Curriculum vitae 



\title{
CHAPTER 1
}

\author{
Introduction
}


CHAPTER 1 


\section{Introduction}

Every year approximately 10000 new cases of colorectal cancer are diagnosed in The Netherlands, of which 3300 are located in the rectum. ${ }^{1}$ Diagnosis is usually established by history taking, physical examination, followed by multiple additional investigations (laboratory, colonoscopy, (contrast-enhanced) pelvic MRI, abdominal and chest CT or chest X-ray). These modalities are used for both local and distant staging of the rectal cancer. ${ }^{2}$

Local recurrence has been one of the main problems after treatment of rectal cancer. The risk for local recurrence has been reported to be as high as $40 \%$, mainly caused by a suboptimal surgical technique in which the mesorectal envelope was bluntly resected, leading to incomplete resections and tumour spill. ${ }^{3}$ With the introduction of the total mesorectal excision (TME), resulting in an accurate dissection of the whole mesorectal envelope along the mesorectal fascia or 'the holy plane', the local recurrence rate reduced substantially to $10 \%$ in some expert centres. ${ }^{4}$

As a local recurrence is often associated with debilitating symptoms, requiring, if resectable at all, extensive salvage surgery, efforts were made to further improve the local recurrence rate. The Swedish rectal cancer trial and Dutch TME trial assessed the influence of neoadjuvant 5x5 gray (Gy) radiation additional to surgery on local recurrence and found that preoperative radiation significantly reduced local recurrence rates from $26-27 \%$ in the non-irradiated group to $9-11 \%$ in the irradiated group. ${ }^{5,6}$ Subgroup analyses in the Dutch TME trial revealed that patients with stage I disease (T1-2No) did not benefit from neoadjuvant 5x5 Gy radiation, because their risk for local recurrence already is very low. Furthermore, patients with stage III disease $(\mathrm{TxN}+)$ benefited from preoperative radiation, but still had a relatively high risk for local recurrence in spite of the radiation $(11.2 \%) .{ }^{6}$ For these high-risk patients more intensive neoadjuvant treatment could be considered, such as combined chemo- and radiotherapy (chemoradiation). Sauer et al. randomized patients between preoperative and postoperative chemoradiation and found that preoperative chemoradiation reduced the risk for local recurrence significantly from $13 \%$ in the postoperative group to $6 \%$ in the preoperative group. ${ }^{7}$ In summary, these studies show that preoperative (chemo)radiation significantly reduces the risk for local recurrence in patients with intermediate and high risk tumours.

Based on the results of the aforementioned studies patients can be stratified into three risk groups: (1) the low-risk tumours, which are confined to the bowel wall (T1-2) without nodal metastases (No), (2) the intermediate-risk tumours, which are T3 tumours without mesorectal fascia (MRF) involvement and maximally 3 nodal metastases $(\mathrm{N} 1)$ or very distal $\mathrm{T} 2-3 \mathrm{Nx}$ tumours and (3) the high risk or locally advanced T3-4Nx tumours, which threaten or involve the MRF and/or tumours with more than 3 nodal metastases (N2). The treatment can be based on these risk groups. 
The low risk patients undergo immediate TME without any neoadjuvant treatment. The patients with an intermediate risk for local recurrence undergo neoadjuvant 5x5 Gy radiation with subsequent TME and the high risk group undergoes a long course of chemoradiation followed by TME or more extensive surgery after an interval of 6-8 weeks. Within the group of low risk tumours there is the prognostically favourable small T1 tumour, which may be treated with transanal endoscopic microsurgery (TEM). The only T1 tumours that are eligible for local treatment with TEM are well to moderately differentiated, do not show lymphatic or venous invasion and invasion depth into the submucosa must be restricted to the superficial two thirds. ${ }^{1,}{ }^{8}$ Staging of rectal cancer is generally performed with MRI and/or endoscopic ultrasound.

With a total mesorectal excision (TME) the rectum is resected with the mesorectum, the surrounding fat containing the mesorectal lymph nodes. This surgical treatment is associated with high rates of surgical complications, morbidity and mortality. The most common complications are infection, abscess, ileus or anastomotic leakage (11-20\%). Long term morbidity includes urinary incontinence (3-15\%), sexual dysfunction (5-70\%), faecal incontinence or stoma (temporary or permanent). ${ }^{9}$ Average peri-operative mortality rate is $4 \%$, but in the elderly this rate increases up to $12 \%{ }^{10}$

Following surgical resection some centres administer adjuvant chemotherapy to patients with an increased risk for distant metastases, e.g. patients with metastatic nodes, T4 tumours or tumours with a poor differentiation grade, lymphatic or venous invasion at histopathology. However, the evidence for adjuvant chemotherapy in rectal cancer is relatively weak and there is a high variability in the administration of adjuvant chemotherapy between different centres and countries.

\section{Response to neoadjuvant chemoradiation}

Neoadjuvant chemoradiation induces downsizing or even downstaging of rectal cancer. Downsizing is a volume reduction of the tumour while downstaging is an improvement of the $\mathrm{T}, \mathrm{N}$ and/or M-stage due to substantial response of the cancer to the chemoradiation. Downstaging can be determined clinically, radiologically and/or histologically. After neo-adjuvant chemoradiation the degree of response (i.e. downsizing and/or downstaging) is evaluated with MRI, CT and/or endoscopy (+/biopsy). A complete response of the tumour and lymph nodes (i.e. no residual tumour) is encountered in 15-20\% of patients. A complete response is traditionally defined after surgery as absence of viable tumour and tumoural lymph nodes in the resected specimen, a so called pathologic complete response (pCR). ${ }^{11}{ }^{12}$ Although it is generally believed that patients with a pCR have a good prognosis, individual studies give conflicting results with some studies reporting failure to detect significantly improved survival. 


\section{Treatment after neoadjuvant chemoradiation}

\section{Local treatment}

Current practice is to treat all patients with radical surgery (TME), regardless of the response to chemoradation. The rationale is twofold. First, there is the uncertainty that a small percentage of patients who are clinically diagnosed as having complete or good response may actually have residual viable tumour at histological examination. Second, there are currently only a limited number of studies available that evaluated less invasive treatment after chemoradiation. An often discussed option in case of a good or complete response to chemoradiation is a local excision or transanal endoscopic microsurgery (TEM). Generally, a TEM is reserved for adenomas or T1 tumours with favourable prognosis, as mentioned earlier. Several studies have suggested and evaluated the use of TEM after CRT, with promising results. The largest (randomized) study to date has compared laparoscopic TME with TEM for small residual tumours after CRT and reported a local recurrence and distant metastasis rate after 5 years of $7 \%$ in both treatment groups. ${ }^{13}$

Another option is the so-called wait-and-see policy, as first introduced by HabrGama et al. ${ }^{14-16}$. This study is the only one that describes the long-term clinical outcome after omission of surgery in clinical complete responders. In this study patients with suspected clinical complete response (cCR), as defined by digital rectal examination, endoscopy and CT, did not undergo surgical intervention but a wait-andsee policy with intensive follow-up. All patients without clinical complete response underwent surgery. Habr-Gama et al. found that there was no significant difference between the patients undergoing a wait-and-see policy on the one hand and operatively managed patients on the other hand, regarding the risk for local failure or survival. The local failure rate after wait-and-see-policy was $18 \%$ after a median follow-up period of 4 years and 3 months. The majority of local failures (85\%) occurred in the first year. An issue in the study by Habr-Gama is that of the 122 patients that had a cCR 6-8 weeks after chemoradiation, only 99 had a sustained cCR after one year. These 99 patients were defined as 'true cCR' and included in the wait-and-see policy group. The 23 patients that did not have sustained $\mathrm{cCR}$ and were operated, were included in the control group (surgery). The design and results of this study lead to a number of considerations. ${ }^{14-18}$ First, there is the question whether with current up-to-date imaging the results can be reproduced or even improved. Improvement of selection of complete responders would probably lead to a decrease in the proportion of patients with tumour regrowth during the first year after chemoradiation. Therefore, the question arises whether the selection and follow-up procedures can be optimised. Second, there is currently no evidence on the extent of improvement in quality of life with wait-and-see policy compared to standard surgery.

\section{Prevention and detection of metastasis}

Despite all the advances in local treatment of rectal cancer, so far only one study could demonstrate an improvement in overall survival of patients with rectal cancer. ${ }^{19}$ 
The lack of substantial survival benefit from the improvement of local treatment strategies can probably be attributed to the incidence of distant metastasis in rectal cancer patients; at diagnosis up to $25 \%$ of patients have synchronous metastartic disease and another $25 \%$ of patients develop metachronous metastases later on. ${ }^{20}$ The cornerstone in the reduction of metachronous metastatic disease after surgical treatment in many solid tumours is adjuvant chemotherapy. The use of adjuvant chemotherapy in rectal cancer is mainly based on extrapolation of results from trials in patients with colon cancer only or trials in which only a minority of patients had rectal cancer. Therefore, the strength of evidence for adjuvant chemotherapy in rectal cancer is weaker than in colon cancer. Moreover, there is a lack of evidence for the use of adjuvant chemotherapy in patients who have been treated with neoadjuvant chemoradiation. In these patients chemoradiation-induced downstaging changes the very basis that guides the decision-making about administration of adjuvant chemotherapy; the downstaging may mask the presence of prognostically unfavourable factors at diagnosis, which harbours a risk for undertreatment of patients. Basing the decision about adjuvant chemotherapy on primary staging is not very reliable either, because primary staging is only moderately accurate. Therefore, more evidence on the value of adjuvant chemotherapy in patients treated with neoadjuvant chemoradiation is needed. Also, it is necessary to evaluate the magnitude of benefit across subgroups with different response to chemoradiation.

Another important aspect in the management of distant metastases is early and accurate detection. Major progress has been made and is still being made in the curative operative treatment of distant metastasis. Therefore, it becomes increasingly important to exactly determine the presence and extent of metastatic disease, both at diagnosis and during follow-up, in order to select potential candidates for curative treatment. Currently, follow-up of patients who have been treated with curative intent for their rectal cancer, consists of regular carcinoembryogenic antigen measurements, ultrasound or computed tomography (CT) of the liver and a chest X-ray or CT. ${ }^{1}$ Computed tomography is mainly accurate for the detection of liver metastasis, while a substantial part of patients develops recurrent disease in other localisations, such as the the pelvis or the thoraxor in nodes located outside the mesorectum. For these types of recurrence CT is not accurate enough. Thus, there is a strong need for an accurate imaging modality to screen the whole body for local and/or distant recurrence.

\section{Aims of this thesis}

The main aims of this thesis are (1) to evaluate the feasibility of a shift towards less invasive local treatment of rectal cancer in patients with complete response to neoadjuvant chemoradiation and (2) to identify areas for further improvement of the 
prognosis of patients with rectal cancer. To accomplish these aims, the following objectives are addressed in this thesis:

- To establish the prognosis of patients with a complete response after chemoradiation and surgery and to compare it with prognosis of patients with residual tumour.

- To evaluate the prognosis and quality of life of patients who have convincing evidence of clinical complete response after chemoradiation and are managed with a wait-and-see policy with intensive follow-up.

- To acquire knowledge about (changes in) the MR morphology of the rectum in patients with a complete response who follow a wait-and-see policy, which can help a radiologist in early and accurate identification of a recurrence.

- To describe the short and long-term results of the use of MRI as a tool for stratification of treatment for patients with rectal cancer.

- To determine whether and which patients benefit from adjuvant chemotherapy after chemoradiation for locally advanced rectal cancer.

- To establish the most accurate whole-body imaging modality to detect recurrence during follow-up for (colo)rectal cancer.

\section{Outline of this thesis}

Chapter 2 will discuss the results of a pooled analysis of individual patient data to establish whether complete responders after chemoradiation have a better prognosis compared to incomplete responders. In chapter 3 the first results on both functional outcome and long-term oncological outcome of a pilot study on wait-and-see policy for complete responders after chemoradiation are reported and compared to patients with a complete response who did undergo surgery. Chapter 4 describes the MRI follow-up features of the rectum during wait-and-see policy. Chapter 5 reports the short and longterm results of a prospective multicentre study in patients who were treated based on their risk for local recurrence as assessed with MRI. These results were compared with those of the Dutch TME trial. One objective was to verify that local control is good, when MRI is used as a selection tool. A second objective was to evaluate the magnitude of the problem with respect to distant metastasis. In chapter 6 the benefit of adjuvant chemotherapy is evaluated according to response to chemoradiation with a pooled analysis of individual patient data. Chapter 7 describes the results of a meta-analysis that compares the diagnostic performance of whole-body staging modalities for the 
detection of local or distant recurrence in patients with colorectal cancer. Chapter 8 describes an interview with a patient who follows a wait-and-see policy in order to give insight into a patient's perspective of this new and rather controversial treatment strategy. Finally, in chapter 9 the content of this thesis is discussed and recommendations for clinical practice and future research are given. 


\section{References}

1. Landelijke_Werkgroep_Gastro-Intestinale_Tumoren. Landelijke Richtlijn Rectumcarcinoom (versie 2.1). www.oncoline.nl 2008 .

2. Richtlijn Rectumcarcinoom. www.oncoline.nl 2009.

3. Quirke P, Durdey P, Dixon MF, Williams NS. Local recurrence of rectal adenocarcinoma due to inadequate surgical resection. Histopathological study of lateral tumour spread and surgical excision. Lancet 1986;2(8514): 996-999.

4. Heald RJ, Ryall RD. Recurrence and survival after total mesorectal excision for rectal cancer. Lancet 1986;1(8496): 1479-1482.

5. Improved survival with preoperative radiotherapy in resectable rectal cancer. Swedish Rectal Cancer Trial. N Engl J Med 1997;336(14): 980-987.

6. Kapiteijn E, Marijnen CA, Nagtegaal ID, Putter H, Steup WH, Wiggers T, Rutten HJ, Pahlman L, Glimelius B, van Krieken JH, Leer JW, van de Velde CJ. Preoperative radiotherapy combined with total mesorectal excision for resectable rectal cancer. N Engl J Med 2001;345(9): 638-646.

7. Sauer R, Becker H, Hohenberger W, Rodel C, Wittekind C, Fietkau R, Martus P, Tschmelitsch J, Hager E, Hess CF, Karstens JH, Liersch T, Schmidberger H, Raab R. Preoperative versus postoperative chemoradiotherapy for rectal cancer. N Engl J Med 2004;351(17): 1731-1740.

8. Tytherleigh MG, Warren BF, Mortensen NJ. Management of early rectal cancer. Br $J$ Surg 2008;95(4): 409-423.

9. Rectal Cancer. www.emedicine.com.

10. Marijnen CA, Kapiteijn E, van de Velde CJ, Martijn H, Steup WH, Wiggers T, Kranenbarg EK, Leer JW. Acute side effects and complications after short-term preoperative radiotherapy combined with total mesorectal excision in primary rectal cancer: report of a multicenter randomized trial. $J$ Clin Oncol 2002;20(3): 817-825.

11. Guillem JG, Chessin DB, Cohen AM, Shia J, Mazumdar M, Enker W, Paty PB, Weiser MR, Klimstra D, Saltz L, Minsky BD, Wong WD. Long-term oncologic outcome following preoperative combined modality therapy and total mesorectal excision of locally advanced rectal cancer. Ann Surg 2005;241(5): 829-836.

12. Ruo L, Tickoo S, Klimstra DS, Minsky BD, Saltz L, Mazumdar M, Paty PB, Wong WD, Larson SM, Cohen AM, Guillem JG. Long-term prognostic significance of extent of rectal cancer response to preoperative radiation and chemotherapy. Ann Surg 2002;236(1): 75-81.

13. Lezoche G, Baldarelli M, Guerrieri M, Paganini AM, De Sanctis A, Bartolacci S, Lezoche E. A prospective randomized study with a 5-year minimum follow-up evaluation of transanal endoscopic microsurgery versus laparoscopic total mesorectal excision after neoadjuvant therapy. Surg Endosc 2008;22(2): 352-358.

14. Habr Gama A, Perez RO, Nadalin W, Nahas SC, Ribeiro U, Jr., Silva E Sousa AH, Jr., Campos FG, Kiss DR, Gama Rodrigues J. Long-term results of preoperative chemoradiation for distal rectal cancer correlation between final stage and survival. J Gastrointest Surg 2005;9(1): 90-99.

15. Habr Gama A, Perez RO, Nadalin W, Sabbaga J, Ribeiro U, Jr., Silva e Sousa AH, Jr., Campos FG, Kiss DR, Gama Rodrigues J. Operative versus nonoperative treatment for stage o distal rectal cancer following chemoradiation therapy: long-term results. Ann Surg 2004;240(4): 71 1-717.

16. Habr Gama A, Perez RO, Proscurshim I, Campos FG, Nadalin W, Kiss D, Gama Rodrigues J. Patterns of Failure and Survival for Nonoperative Treatment of Stage co Distal Rectal Cancer Following Neoadjuvant Chemoradiation Therapy. J Gastrointest Surg 2006;10(10): 1319-1329. 
17. Habr Gama A, de Souza PM, Ribeiro U, Jr., Nadalin W, Gansl R, Sousa AH, Jr., Campos FG, Gama Rodrigues J. Low rectal cancer: impact of radiation and chemotherapy on surgical treatment. Dis Colon Rectum 1998;41(9): 1087-1096.

18. Gavioli M, Luppi G, Losi L, Bertolini F, Santantonio M, Falchi AM, D'Amico R, Conte PF, Natalini $\mathrm{G}$. Incidence and clinical impact of sterilized disease and minimal residual disease after preoperative radiochemotherapy for rectal cancer. Dis Colon Rectum 2005;48(10): 1851-1857.

19. Group SRC. Improved survival with preoperative radiotherapy in resectable rectal cancer. Swedish Rectal Cancer Trial. N Engl J Med 1997;336(14): 980-987.

20. Glynne-Jones R, Mathur P, Elton C, Train ML. The multidisciplinary management of gastrointestinal cancer. Multimodal treatment of rectal cancer. Best Pract Res Clin Gastroenterol 2007;2 1(6): 1049-1070. 

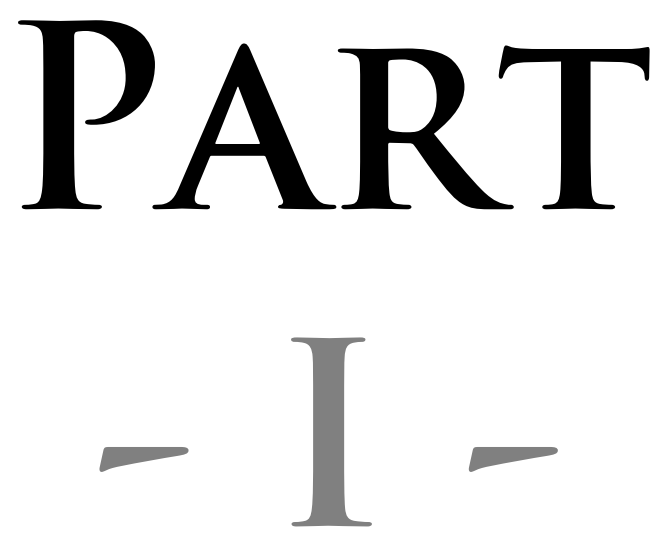

Paradigm shift to less invasive treatment 



\title{
CHAPTER 2
}

Long-term outcome in patients with a pathologic complete response after chemoradiation for rectal cancer: a pooled analysis of 3105 patients

\author{
M. Maas \\ P.J. Nelemans \\ V. Valentini \\ P. Das \\ C. Rödel \\ L.J. Kuo \\ F.A. Calvo \\ J. García-Aguilar \\ R. Glynne-Jones \\ K. Haustermans \\ M. Mohiuddin \\ S. Pucciarelli \\ W. Small \\ J. Suárez \\ G. Theodoropoulos \\ S. Biondo \\ R.G.H. Beets-Tan \\ G.L. Beets
}




\begin{abstract}
Background. Locally advanced rectal cancer is usually treated with preoperative chemoradiation. After chemoradiation and surgery, $15-27 \%$ of the patients have no residual viable tumour at pathology: a pathologic complete response (pCR). The purpose of this study is to determine whether patients with pCR have better long-term outcome than patients without pCR.
\end{abstract}

Methods. In Medline and Embase 27 articles were identified regarding long-term outcome of patients with and without pCR. These 27 articles were based on 17 different datasets. 14 authors agreed to share individual patient data. All patients underwent chemoradiation and total mesorectal excision. Primary outcome was 5-year diseasefree-survival (DFS). Kaplan-Meier survival functions were computed and hazard ratios (HR) with $95 \%$ confidence intervals (95\%CI) were calculated, using the Cox proportional hazards model. Subgroup analyses were performed to test for effect modification by other predicting factors. Interstudy heterogeneity was assessed for DFS and overall survival (OS) with forest plots and the Q-test.

Findings. 484 of 3105 included patients had pCR. Median follow-up for all patients was 48 months (range 0-277). 5-year crude DFS is $83.3 \%$ and $65.6 \%$ for patients with and without $\mathrm{pCR}$, respectively $(\mathrm{p}<0.0001)$. The $\mathrm{Q}$-test and the forest plots did not suggest significant interstudy variation. The adjusted HR for pCR for failure is 0.54 (95\%CI:0.40-0.73), indicating that pCR-patients have a significantly increased probability of DFS. The adjusted HR for DFS for administration of adjuvant chemotherapy was 0.91 (95\%CI:0.73-1.12). The effect of pCR on DFS was not modified by other prognostic factors.

Conclusions. Patients with pCR have better long-term outcome than patients without pCR. pCR might be indicative of a prognostically favourable biological tumour profile with less propensity for local and/or distant recurrence and better survival. Further research should aim at evaluation of the relationship between biological tumour characteristics and response to chemoradiation and prognosis 


\section{Introduction}

Locally advanced rectal cancer is usually treated with preoperative chemoradiation treatment (CRT) followed by total mesorectal excision (TME). ${ }^{1}$ The majority of patients show substantial downsizing, and in $15-27 \%$ no residual viable tumour cells can be found in the resected specimen., ${ }^{2,3}$ Several studies have suggested that this pathological complete response (pCR) is associated with a favourable outcome with regard to local control, distant recurrence, disease-free survival and overall survival.4-8 Such a finding is clinically relevant because it relates to the question whether or not to omit further adjuvant treatment for good responders, or to intensify treatment in nonresponders. Additionally, it can play a role in the current discussion whether patients who respond very well to chemoradiation would benefit from less invasive strategies such as local excision or even wait-and-see policy..$^{9,10}$

Until now published studies have reported a trend towards a favourable prognosis for patients with a pCR, but this trend was often not statistically significant, probably due to small sample sizes. ${ }^{3,11}$ Censoring of subjects in survival analyses even aggravated this problem, as fewer patients were left for analysis after longer follow-up periods. Moreover, most studies compared responding to non-responding patients and did not make a distinction between pCR and other degrees of response.,7,12 A pooled analysis of a large set of individual patient data can solve the aforementioned methodological problems: it allows for a large sample size, differences in baseline characteristics between patients with and without pCR can be adjusted with multivariate analyses and the definition of pCR can be standardised.

For these reasons, we decided to perform a pooled analysis of studies, in which data were reported on the diagnosis, treatment and prognosis of patients with and without pCR after chemoradiation. The objective was to evaluate whether a pCR is associated with improved 5-year rates of local control (LC), distant-metastasis-free (DMFS), disease-free (DFS) and overall survival (OS) compared with patients who did not achieve a pCR.

\section{Methods}

\section{Search strategy and selection criteria}

PubMed, Medline and Embase were searched for relevant articles published from 1980 through January 2009 with the following search terms: "rectal cancer", "response", “radiotherap*”, “chemotherap*”, "chemoradiation”, "radio(-)chemo*”, "chemo(-)radio*”, "chemo-radiotherapy”, "radio-chemotherapy”, "regression”, "patholog*”, "survival”, "sphincter", "progn*", "Dworak” and/or "Mandard”. Inclusion criteria were as follows: (1) the study had to be published in English, German or Dutch language, (2) patients had to have primary rectal cancer treated with preoperative chemoradiation followed by surgery, (3) the surgical procedure had to be low anterior 
resection (LAR), abdominoperineal resection (APR) or a more extended resection, (4) data and time to event for local recurrence, metastases and/or death had to be provided, and (5) data on pathologic response had to be available.

One reviewer (MM) checked the titles and abstracts of the identified studies in order to select studies potentially meeting the inclusion criteria. Two reviewers (MM and PN) independently studied full text copies of the selected studies to decide which studies met the inclusion criteria. Additional studies were traced by checking the reference lists of the selected studies.

Finally, 55 eligible studies were identified, of which 28 were excluded for the following reasons: 12 studies included patients who were treated preoperatively with radiotherapy only ${ }^{13-24}$, 10 studies did not provide data separately for different pathologic response groups ${ }^{25-34}, 3$ studies concerned patients who had local excision or did not have surgery because of good response or comorbidity ${ }^{10,35,36}$, and 3 studies duplicated the results of another publication by the same group ${ }^{8,37,38}$. No study was excluded based on language.

\section{Selection of individual patient data}

The corresponding authors of the 27 included studies were invited to participate in a collaborative analysis. ${ }^{2-7,11,12,39-57}$ Author contact revealed that the papers were based on 17 different study datasets. Fourteen authors decided to participate and provided individual patient data. ${ }^{2-6,11,12,39,43,45,47,50,55,56}$ Characteristics and results from the 3 nonincluded studies are shown in table 1 (originally published as a webappendix). Most datasets included variables about age at diagnosis, gender, clinical and pathological $\mathrm{T}$-, $\mathrm{N}$ - and M-category, type of chemoradiation, radiation dose, date and type of surgery (LAR, APR or other surgery consisting of Hartmann's procedure, anterior, posterior or total pelvic exenteration, hemicolectomy or colectomy), radicality of the resection, and administration of adjuvant chemotherapy. Data were also available for one or more of the following clinical endpoints: local recurrence, distant recurrence, disease-free survival, overall survival, and dates to events and/or follow-up times.

All relevant data from the individual datasets were combined into one dataset. Some authors provided datasets with more patients than originally reported in their publications. Individual patients were excluded from these datasets if they had synchronous metastasis, a radiation dose of $\leq 25$ gray, recurrent disease, incomplete resection, or radiation treatment only.

pCR was defined as ypToNoMo. Three authors provided data on pCR without giving the required data on ypTNM-stage. ${ }^{11,50,55}$ The published manuscript or author contact revealed that pCR was also defined as ypToNoMo in these 3 datasets.

The primary outcome measure of the present study was the cumulative probability of DFS after 5 years in patients with a pCR compared to patients without a pCR. Secondary outcomes were the cumulative 5-year probabilities of LC, DMFS and OS. 


\section{Statistical analyses}

The comparison between patients with $\mathrm{pCR}$ and patients without pCR was of primary interest in this pooled analysis. Baseline characteristics between pCR- and non-pCR patients were compared. Differences were tested for significance using the independent samples T-test for the comparison of means, and the Pearson's Chi-square test for the comparison of proportions.

Heterogeneity between studies was tested using the $Q$ test. Forest plots were used to display the study-specific hazard ratios (HRs).

Cumulative probabilities of 5-year LC, DMFS, DFS and OS were compared for patients with pCR and without pCR using Kaplan-Meier survival methods. The logrank test was used to test for statistically significant differences. LC was defined as the absence of pelvic recurrence, DMFS was defined as the absence of distant metastasis outside the pelvis. DFS was defined as the absence of a local and/or distant recurrence or death from any cause, whichever came first. OS was defined as the absence of death from any cause. Duration of follow-up was calculated as the time from surgery to the event of interest or to the last follow-up that was used as a date of censoring. Adjustment for differences in baseline characteristics between pCR and non-pCR patients was performed using multivariate Cox proportional hazards models with stratification for study centre. The proportional hazard assumption was explored by graphical methods.

Hazard ratios with $95 \%$ confidence intervals (95\%CI) were calculated. All HRs corresponding with the $\mathrm{pCR}$ variable represent the relative risks of having an event during follow-up for patients with pCR compared with patients without pCR. A HR below 1 indicates that patients with pCR have a higher probability of LC, DMFS, DFS and OS than patients without pCR. Additionally, we performed subgroup analyses to test the hypothesis that unfavourable prognostic factors might compromise the prognosis in such a way that pCR would no longer have an effect on long-term outcome. Analyses were performed with Statistical Packages for Social Science 15.0 (SPSS) and Stata, release 10; StataCorp, College Station, TX. P-values <0.05 were considered statistically significant. 


\begin{tabular}{|c|c|c|c|c|c|}
\hline so & 紊 & 总 & ஃ̊ & 高 & 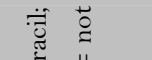 \\
\hline 常 & శ్ర్ల & 兽 & வீ & 吕 & 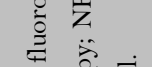 \\
\hline$\sum$ & 立苛 & $\stackrel{\circ}{\Gamma}$ & $\tilde{z}$ & 苹 & 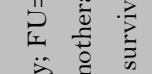 \\
\hline 离 & $\underset{2}{\tilde{Z}}$ & @̊ & $\tilde{z}$ & $\stackrel{\Re}{z}$ & 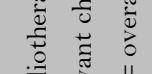 \\
\hline th & 立 & $\frac{q}{z}$ & ळ & 咅 & 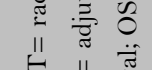 \\
\hline 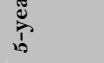 & శ్ & 艺 & 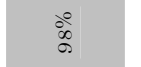 & 总 & 记 \\
\hline ב & 立 & ळ̊ & 苹 & ฏे & 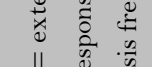 \\
\hline 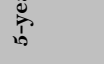 & శ్ర & @̊ & $\tilde{z}$ & $\stackrel{\infty}{\infty}$ & 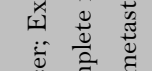 \\
\hline 惫总 & & $\approx$ & & $\approx$ & 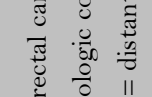 \\
\hline D & & $\infty$ & 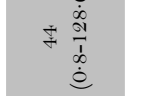 & t & 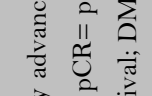 \\
\hline క气 & & 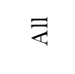 & is & 妾 & 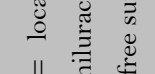 \\
\hline : & & $a \stackrel{\circ}{a}$ & ¥ & $\therefore \frac{\widehat{\circ}}{a}$ & 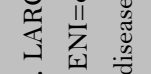 \\
\hline 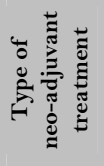 & & 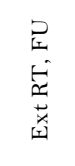 & 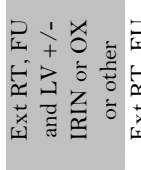 & 至 & 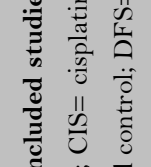 \\
\hline$\Sigma$ & & مْ & \%ั & 惑 & 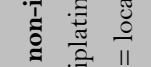 \\
\hline 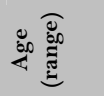 & & 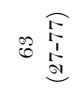 & 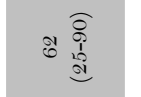 & 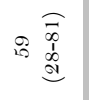 & 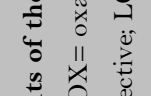 \\
\hline z & & gे & ฐิ & $\exists$ & 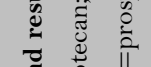 \\
\hline 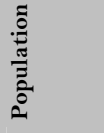 & & 5 & 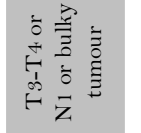 & 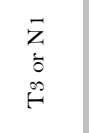 & 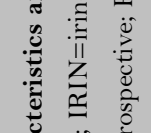 \\
\hline ¿्र & & : & 悹 & $\vec{\circ}$ & 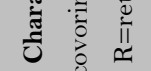 \\
\hline 竞 & & 웅 & 豆 & & 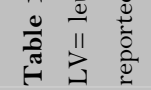 \\
\hline
\end{tabular}




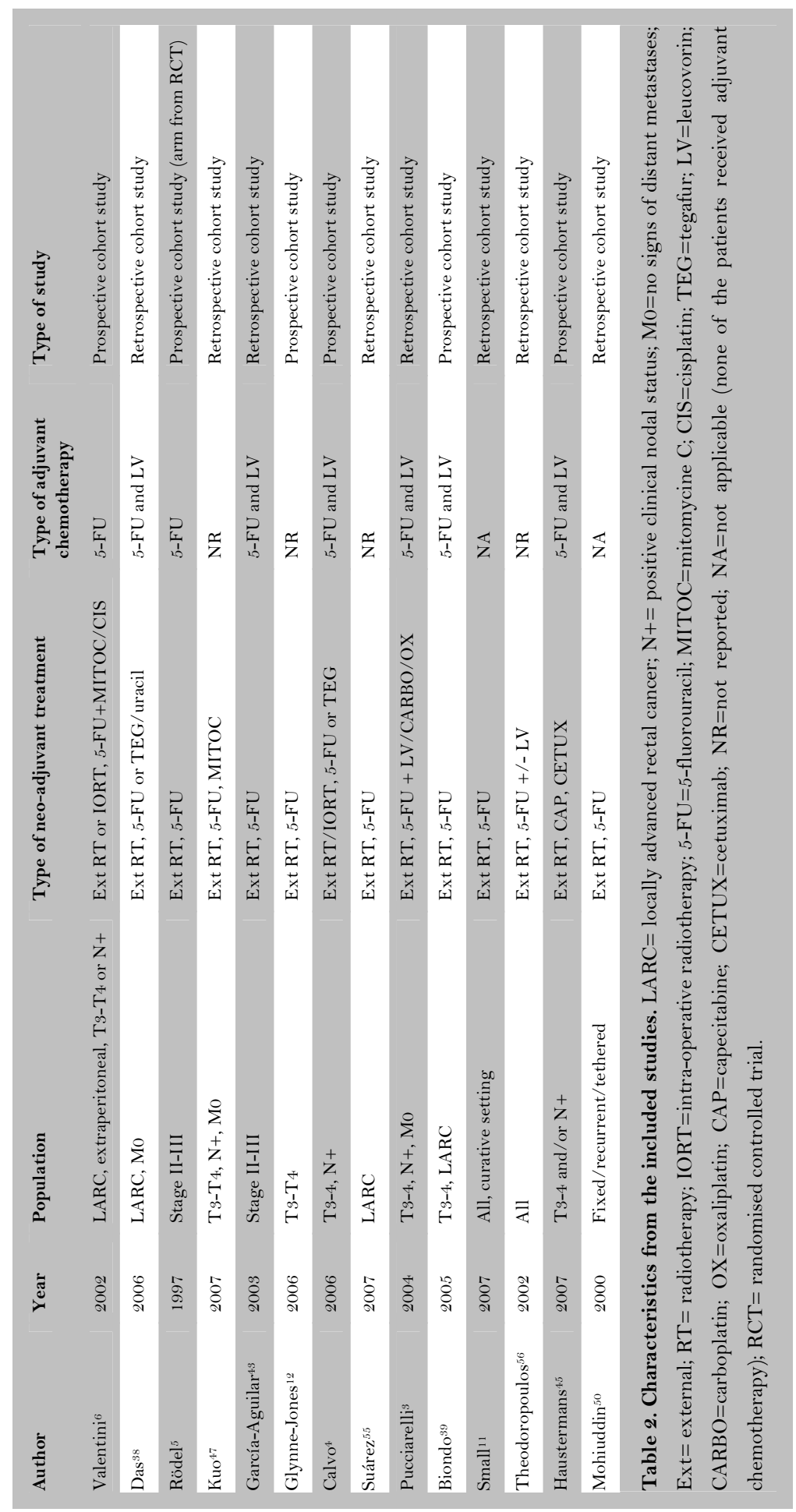




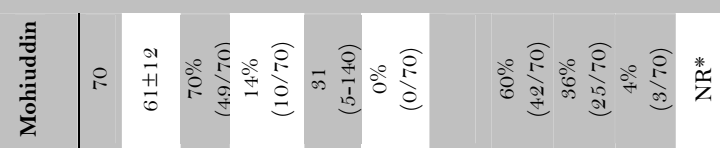

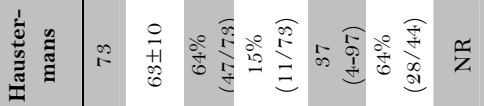

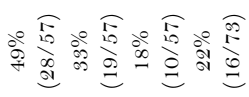

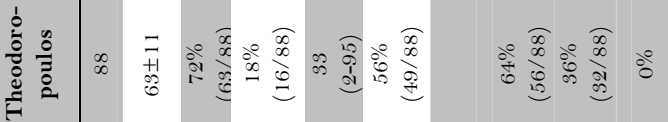

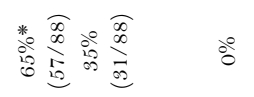

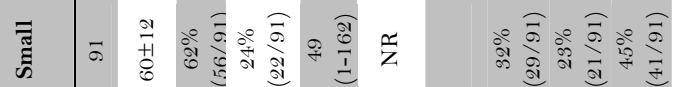

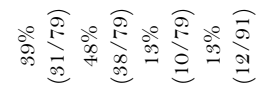

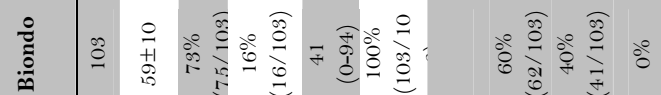

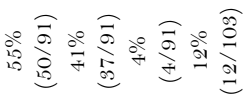

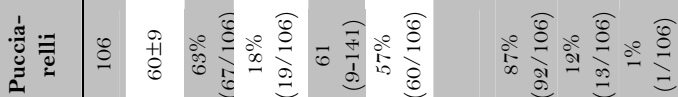

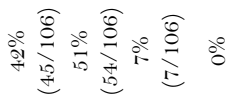

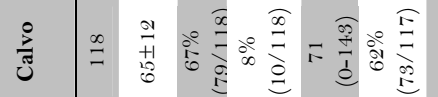

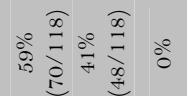

市

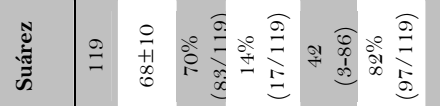

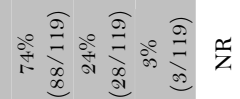

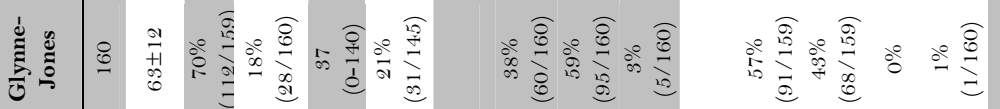

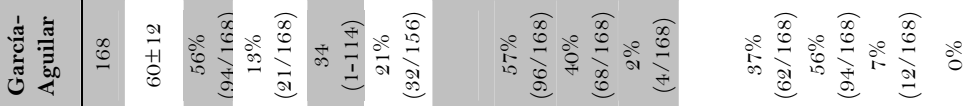

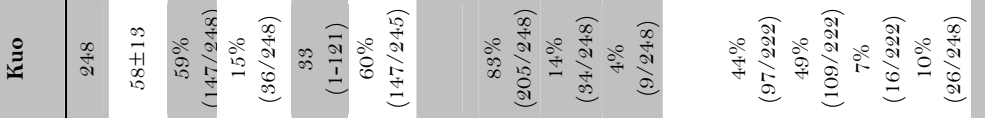

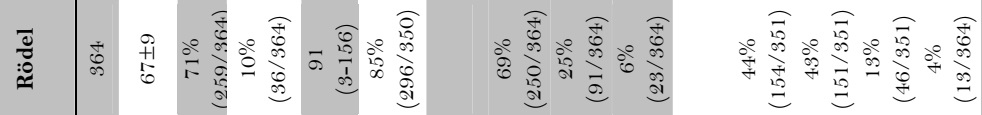

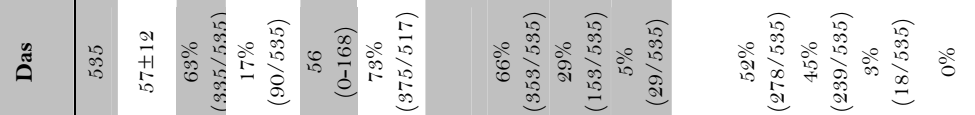

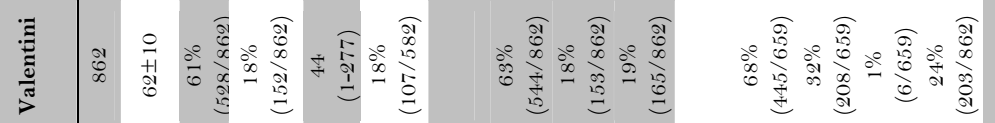

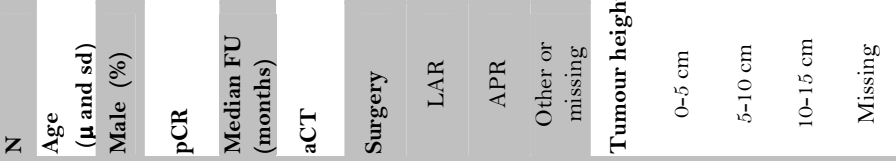




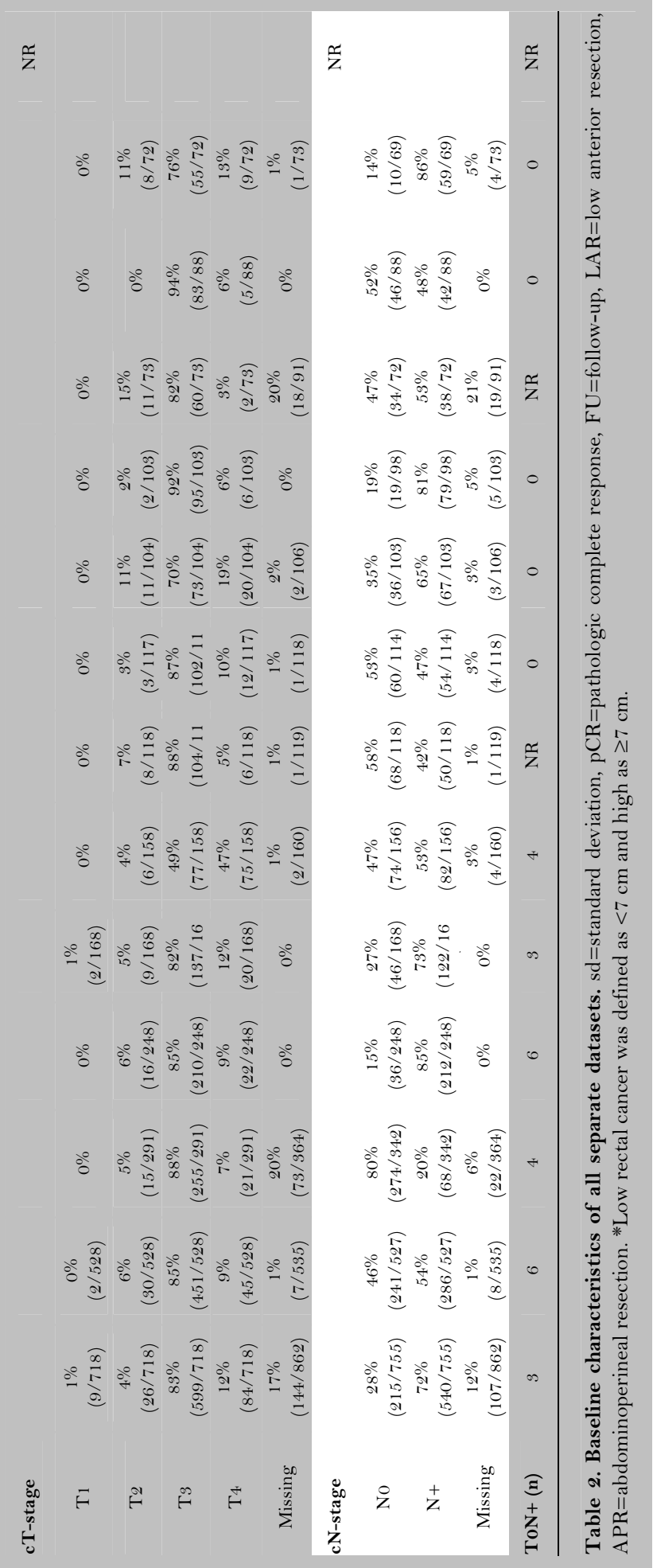




\section{Results}

Table 2 gives details about the 14 studies that were included for the meta-analysis.

A total of 3105 patients were included of which 484 had a pCR. Chemoradiation consisted of 45-50.4 Gray in 25 to 28 fractions of 1.8 Gray with 5-flourouracil (5-FU) based chemotherapy in most studies. The interval between chemoradiation and surgery was 6-8 weeks in almost all studies. Table 3 provides the characteristics of the included datasets separately. Table 4 presents the baseline characteristics for all patients, for patients with $\mathrm{pCR}$ and for patients without pCR. Mean age $( \pm \mathrm{SD})$ was $61 \pm 12$ years and $64 \%(1994 / 3104)$ of patients were male. pCR rates ranged from $9 \%$ to $24 \%$ in the individual studies. The pooled prevalence of pCR was 16\% (484/3105). 25 of 509 patients $(5 \%)$ with ypTo had positive lymph nodes at pathologic examination. Median follow-up was 46 months (range: $0-187$ ) for patients with pCR and 48 months (range: 0-277) for patients without pCR. Clinical staging was generally performed with computed tomography and/or endorectal ultrasound. Three studies used magnetic resonance imaging (MRI). ${ }^{11,12,47}$ The T-stage before CRT was significantly more often a cT1 or cT2 tumour in the patients with pCR. Patients with pCR had clinical T1 and T2 tumours significantly more often than patients without pCR ( $11 \%$ vs. $4 \%$, $\mathrm{p}<0.0001)$. The percentages of patients with a clinically positive lymph node status were similar for patients with and without pCR. LAR was performed significantly more often than APR in patients with pCR (69\% vs. 63\%, p=0.030). Adjuvant chemotherapy was administered significantly less often to patients with pCR (39\% vs. $56 \%$, p $<0.0001)$. Additional information about the proportions of patients with $\mathrm{pCR}$ according to different tumour and treatment characteristics is shown in table 5 (originally published as a webappendix).

Study-specific hazard ratios for DFS and OS were available for 11 and 12 studies, respectively. Two studies ${ }^{47,50}$ did not provide data on DFS and in one study, due to absence of events in the pCR group ${ }^{56}$, neither the HR for DFS nor the HR for OS could be calculated. For the same reason the HR for OS could not be calculated in another study. ${ }^{45}$ The p-value from the Q-test for OS was non-significant (0.62), but for DFS the $\mathrm{p}$-value was near 0.05 ( $\mathrm{p}=0.052)$. However, the forest plots for DFS and OS (figure 1) do not suggest significant interstudy variation among the estimated hazard ratios. 


\begin{tabular}{|c|c|c|c|c|}
\hline Parameter & All & $\begin{array}{l}\text { Pathologic } \\
\text { complete } \\
\text { response }\end{array}$ & $\begin{array}{l}\text { No pathologic } \\
\text { complete } \\
\text { response }\end{array}$ & p-value \\
\hline Mean age (years) & $61 \pm 12$ & $62 \pm 11$ & $61 \pm 12$ & $\mathrm{p}=0.79$ \\
\hline Missing & $2 \%(49 / 3105)$ & $2 \%(9 / 484)$ & $2 \%(40 / 2621)$ & \\
\hline Gender (male \%) & $64 \%(1994 / 3104)$ & $65 \%(315 / 484)$ & $64 \%(1679 / 2620)$ & $\mathrm{p}=0.24$ \\
\hline Missing & $0 \%(1 / 3105)$ & $\mathrm{O} \%(\mathrm{O} / 484)$ & $0 \%(1 / 2621)$ & \\
\hline \multicolumn{5}{|l|}{ Clinical T-stage } \\
\hline $\mathrm{T} 1$ & $0 \%(12 / 2785)$ & $2 \%(7 / 462)$ & $0 \%(5 / 2323)$ & \multirow{5}{*}{$\mathrm{p}<0.0001$} \\
\hline $\mathrm{T} 2$ & $5 \%(145 / 2785)$ & $9 \%(41 / 462)$ & $4 \%(104 / 2323)$ & \\
\hline Т3 & $83 \%(2301 / 2785)$ & $81 \%(374 / 462)$ & $83 \%(1927 / 2323)$ & \\
\hline $\mathrm{T} 4$ & $12 \%(327 / 2785)$ & $9 \%(40 / 462)$ & $12 \%(287 / 2323)$ & \\
\hline Missing & $10 \%(320 / 3105)$ & $5 \%(22 / 484)$ & $11 \%(298 / 2621)$ & \\
\hline \multicolumn{5}{|l|}{ Clinical N-stage } \\
\hline $\mathrm{N}+$ & $59 \%(1699 / 2858)$ & $59 \%(277 / 466)$ & $59 \%(1422 / 2392)$ & \multirow[t]{2}{*}{$\mathrm{p}=0.10$} \\
\hline Missing & $8 \%(247 / 3105)$ & $4 \%(18 / 484)$ & $9 \%(229 / 2621)$ & \\
\hline \multicolumn{5}{|l|}{ Distance ab ano } \\
\hline $0-5 \mathrm{~cm}$ & $52 \%(1327 / 2533)$ & $56 \%(237 / 421)$ & $52 \%(1090 / 2112)$ & \multirow{4}{*}{$\mathrm{p}=0.15$} \\
\hline $5-10 \mathrm{~cm}$ & $42 \%(1071 / 2533)$ & $40 \%(167 / 421)$ & $43 \%(904 / 2112)$ & \\
\hline$>10 \mathrm{~cm}$ & $5 \%(135 / 2533)$ & $4 \%(17 / 421)$ & $6 \%(118 / 2112)$ & \\
\hline Missing & $18 \%(572 / 3105)$ & $13 \%(63 / 484)$ & $19 \%(509 / 2621)$ & \\
\hline \multicolumn{5}{|l|}{ Type of surgery } \\
\hline Low anterior resection & $64 \%(1947 / 3029)$ & $69 \%(326 / 473)$ & $63 \%(1621 / 2556)$ & \multirow{4}{*}{$\mathrm{p}=0.030$} \\
\hline $\begin{array}{l}\text { Abdominoperineal } \\
\text { resection }\end{array}$ & $26 \%(802 / 3029)$ & $22 \%(102 / 473)$ & $27 \%(700 / 2556)$ & \\
\hline Other & $9 \%(280 / 3029)$ & $10 \%(45 / 473)$ & $9 \%(235 / 2556)$ & \\
\hline Missing & $2 \%(76 / 3105)$ & $2 \%(11 / 484)$ & $2 \%(65 / 2621)$ & \\
\hline Adjuvant chemotherapy & $53 \%(1398 / 2642)$ & $39 \%(155 / 402)$ & $55 \%(1243 / 2240)$ & \multirow[t]{2}{*}{$\mathrm{p}<0.0001$} \\
\hline Missing & $15 \%(463 / 3105)$ & $17 \%(82 / 484)$ & $15 \%(381 / 2621)$ & \\
\hline $\begin{array}{l}\text { Median follow-up time } \\
\text { (months) }\end{array}$ & $48(0-277)$ & $46(0-187)$ & $48(0-277)$ & $\mathrm{p}=0.058$ \\
\hline Missing & $3 \%(96 / 3105)$ & $4 \%(17 / 484)$ & $3 \%(79 / 2621)$ & \\
\hline
\end{tabular}



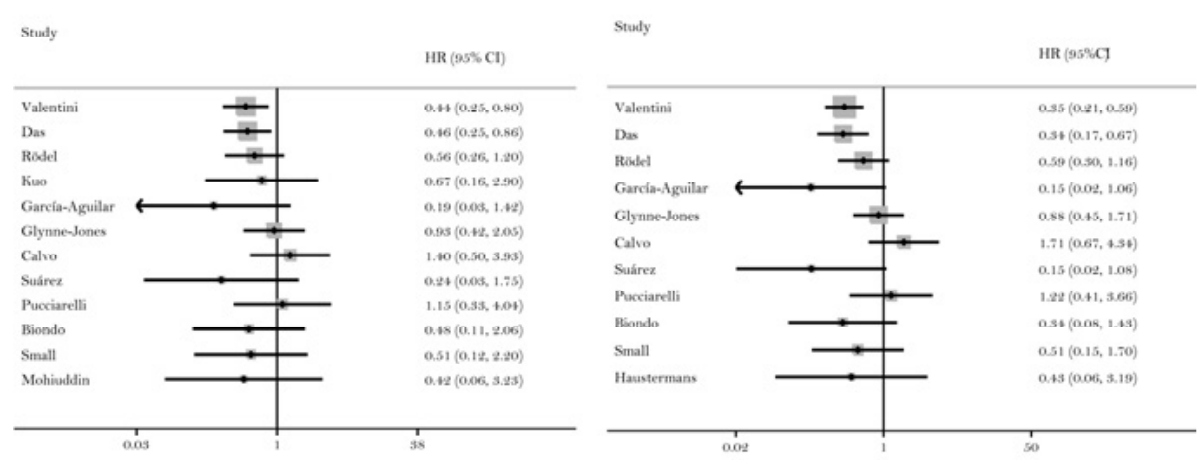

Figure 1. Forest plot with the hazard ratios and $95 \%$ CI for DFS (left) and OS (right) for each individual study.

\section{Univariate analyses}

Kaplan-Meier survival functions for LC, DMFS, DFS and OS for patients with and without pCR are shown in figure 2. Because not all datasets evaluated and/or provided all 4 outcome measures, the number of patients at risk can differ between outcome measures.

pCR after chemoradiation is associated with a lower risk for local recurrence. In the group with pCR 12/455 local recurrences were found, compared to 202/2478 in the non-pCR group. The 5-year risk for local recurrence was $2.8 \%$ in the pCR group and $9.7 \%$ in the non-pCR group ( $<<0 \cdot 0001)$. The crude HR was 0.33 (95\%CI: 0.19-0.60) in favour of pCR patients.

5-year DMFS was $88.8 \%$ for patients with pCR and $74.9 \%$ for patients without pCR (p<0.0001) with a crude HR of 0.40 (95\%CI: 0.29-0.55). 38/419 pCR patients had distant metastasis vs. $512 / 2257$ patients in the non-pCR group.

5-year DFS was $83.3 \%$ and $65.6 \%$ for pCR and non-pCR, respectively $(\mathrm{p}<0.0001)$. The crude HR for DFS was 0.44 (95\%CI: 0.34-0.57), which is in favour of pCR patients. Disease recurred in 61/419 pCR-patients and in 747/2263 non-pCR patients.

5 -year OS was $87.6 \%$ for pCR (53 deaths in 465 patients) and $76.4 \%$ (614 deaths in 2538 patients) for non-pCR patients $(\mathrm{p}<0.0001)$. The crude HR for OS was 0.51 (95\%CI: 0.38-0.67) in favour of pCR patients.

\section{Multivariate analyses}

Table 6 presents the results from a multivariate Cox proportional hazards model with stratification for study centre. Only 8 authors $(n=2416$ patients) provided data on all relevant baseline characteristics, such as clinical $\mathrm{T}$ - and $\mathrm{N}$-stage, distance from the anal verge, type of surgery and administration of adjuvant chemotherapy. Therefore, the multivariate analyses were based on data from these 8 centres. ${ }^{2-6,12,39,43}$ 
A Local recurrence free survival

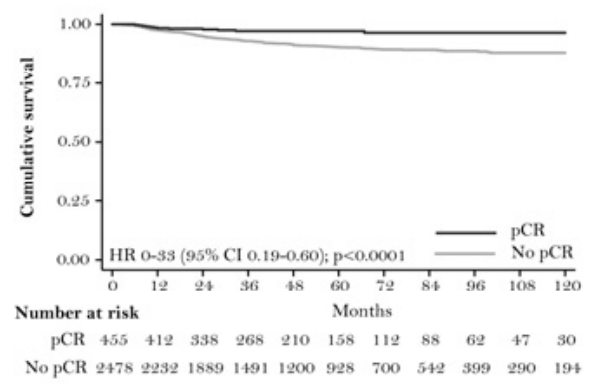

C Disease-free survival

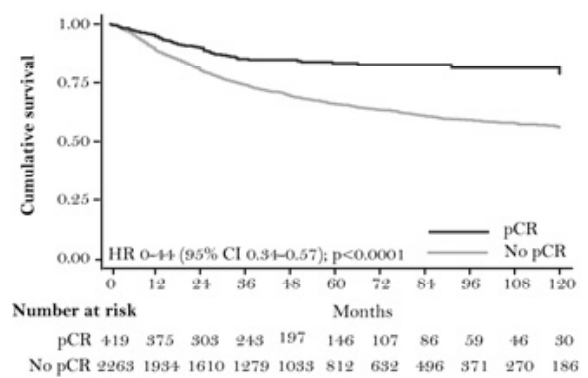

B Distant metastasis free survival

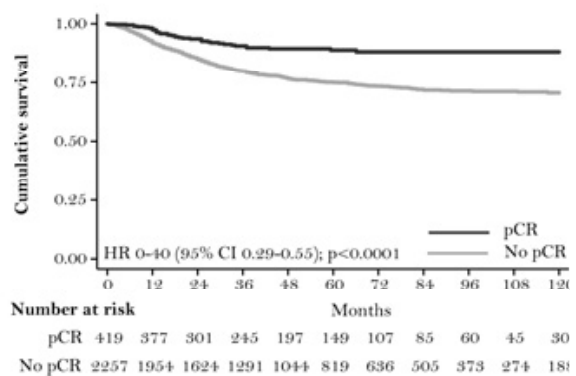

D Overall survival

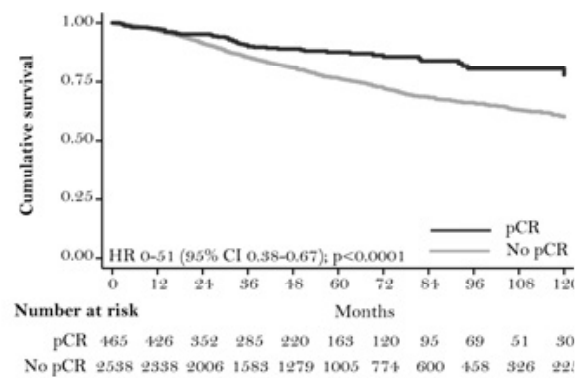

Figure 2. Kaplan-Meier survival curves for patients with (pCR) and without pathologic complete response (non-pCR). A: local-recurrence free survival, B: distant-metastasis free survival, C: disease-free survival, D: overall survival. Not all study centres provided data for all 4 outcome measures, which explains the discrepancies of numbers at risk between outcome measures. Pvalues were determined by log-rank test. $\mathrm{HR}=$ hazard ratio, $95 \% \mathrm{CI}=95 \%$ confidence intervals.

The adjusted HR of 0.54 (95\%CI: 0.40-0.73) for DFS indicates that after adjustment for other relevant prognostic factors, patients with pCR still have a significantly higher probability of DFS than patients without pCR. The adjusted HR for LC is 0.41 (95\%CI: 0.21-0.81), for DMFS the adjusted HR is 0.49 (95\%CI: 0.34-0.71), and for OS it is 0.65 (95\%CI: 0.47-0.89), all indicating that pCR-patients have better prognosis than nonpCR patients. 


\begin{tabular}{|c|c|c|c|c|}
\hline Parameter & All & $\begin{array}{c}\text { Pathologic } \\
\text { complete } \\
\text { response }\end{array}$ & Missing & p-value \\
\hline Clinical T-stage & & & & \\
\hline $\mathrm{T} 1$ & $0 \%(12 / 2785)$ & $58 \%(7 / 12)$ & \multirow{4}{*}{$10 \%(320 / 3105)$} & \multirow{4}{*}{$\mathrm{p}<0.0001$} \\
\hline $\mathrm{T} 2$ & $5 \%(145 / 2785)$ & $28 \%(41 / 145)$ & & \\
\hline T3 & $83 \%(2301 / 2785)$ & $16 \%(374 / 2301)$ & & \\
\hline $\mathrm{T} 4$ & $12 \%(327 / 2785)$ & $12 \%(40 / 327)$ & & \\
\hline \multicolumn{5}{|l|}{ Clinical N-stage } \\
\hline No & $41 \%(1159 / 2858)$ & $16 \%(189 / 1159)$ & \multirow[b]{2}{*}{$8 \%(247 / 3105)$} & \multirow[b]{2}{*}{$\mathrm{p}=0.10$} \\
\hline $\mathrm{N}+$ & $59 \%(1699 / 2858)$ & $16 \%(277 / 1699)$ & & \\
\hline \multicolumn{5}{|l|}{ Distance $a b$ ano } \\
\hline $0-5 \mathrm{~cm}$ & $52 \%(1327 / 2533)$ & $18 \%(237 / 1327)$ & \multirow{3}{*}{$18 \%(572 / 3105)$} & \multirow{3}{*}{$\mathrm{p}=0.15$} \\
\hline $5-10 \mathrm{~cm}$ & $42 \%(1071 / 2533)$ & $16 \%(167 / 1071)$ & & \\
\hline$>10 \mathrm{~cm}$ & $5 \%(135 / 2533)$ & $13 \%(17 / 135)$ & & \\
\hline \multicolumn{5}{|l|}{ Type of surgery } \\
\hline Low anterior resection & $64 \%(1947 / 3029)$ & $17 \%(326 / 1947)$ & \multirow{3}{*}{$2 \%(76 / 3105)$} & \multirow{3}{*}{$\mathrm{p}=0.030$} \\
\hline $\begin{array}{l}\text { Abdominoperineal } \\
\text { resection }\end{array}$ & $26 \%(802 / 3029)$ & $13 \%(102 / 802)$ & & \\
\hline Other & $9 \%(280 / 3029)$ & $16 \%(45 / 280)$ & & \\
\hline
\end{tabular}

Table 5. Proportions of patients with pCR according to tumour and treatment characteristics.

Additional analyses with the separate components of pCR: ypTo and ypNo. To evaluate whether the favourable prognosis of pCR is due to the ypNo component only we performed an additional multivariate analysis with the 2 components of pCR (ypTo and ypNo) entered separately in the model instead of the variable pCR. The adjusted hazard ratio for disease-free survival for ypTo was 0.65 (95\% CI 0.48-0.87) and for ypNo the adjusted hazard ratio for disease-free survival was 0.41 (95\% CI 0.34-0.49). This reflects that both ypTo and ypNo attribute to the favourable effect of pCR on disease-free survival. 


\begin{tabular}{|c|c|c|c|c|}
\hline Factor & $\begin{array}{c}\text { Disease-free } \\
\text { survival } \\
\text { Hazard Ratio } \\
(95 \% \mathrm{CI})\end{array}$ & $\begin{array}{c}\text { Local control } \\
\text { Hazard Ratio } \\
\text { (95\% CI })\end{array}$ & $\begin{array}{c}\text { Distant } \\
\text { metastasis free } \\
\text { survival } \\
\text { Hazard Ratio } \\
(95 \% \mathrm{CI})\end{array}$ & $\begin{array}{c}\text { Overall Survival } \\
\text { Hazard Ratio (95\% } \\
\text { CI) }\end{array}$ \\
\hline \multicolumn{5}{|l|}{ Pathologic response } \\
\hline Residual disease & 1.00 (ref) & 1.00 (ref) & 1.00 (ref) & 1.00 (ref) \\
\hline $\begin{array}{l}\text { Pathologic } \\
\text { complete response }\end{array}$ & $0.54(0.40-0.73)$ & $0.41(0.21-0.81)$ & $0.49(0.34-0.71)$ & $0.65(0.47-0.89)$ \\
\hline Age & $0.99(0.99-1.00)$ & $0.99(0.98-1.01)$ & $0.98(0.98-0.99)$ & $1.01(1.00-1.02)$ \\
\hline \multicolumn{5}{|l|}{ Gender } \\
\hline Male & 1.00 (ref) & 1.00 (ref) & 1.00 (ref) & 1.00 (ref) \\
\hline Female & $0.87(0.73-1.05)$ & $1.25(0.87-1.78)$ & $0.84(0.68-1.05)$ & $0.83(0.68-1.03)$ \\
\hline \multicolumn{5}{|l|}{ Clinical T-stage } \\
\hline $\mathrm{T} 1$ & $0.89(0.12-6.37)$ & $\mathrm{NE}$ & $1.18(0.16-8.50)$ & $1.39(0.19-9.98)$ \\
\hline $\mathrm{T} 2$ & $0.58(0.33-1.01)$ & $0.55(0.17-1.73)$ & $0.80(0.46-1.39)$ & $0.48(0.25-0.93)$ \\
\hline T3 & $100($ ref $)$ & 1.00 (ref) & $1.00($ ref $)$ & $1.00($ ref $)$ \\
\hline $\mathrm{T} 4$ & $1.51(1.19-1.90)$ & $1.22(0.74-2.02)$ & $1.43(1.07-1.91)$ & $1.44(1.11-1.89)$ \\
\hline \multicolumn{5}{|l|}{ Clinical N-stage } \\
\hline No & 1.00 (ref) & 1.00 (ref) & 1.00 (ref) & 1.00 (ref) \\
\hline $\mathrm{N}+$ & $1.23(1.02-1.50)$ & $1.70(1.10-2.63)$ & $1.20(0.95-1.52)$ & $1.24(1.00-1.53)$ \\
\hline \multicolumn{5}{|l|}{ Distance from anal } \\
\hline$\leq 5 \mathrm{~cm}$ & 1.00 (ref) & 1.00 (ref) & 1.00 (ref) & 1.00 (ref) \\
\hline$>5 \mathrm{~cm}$ & $1.19(0.99-1.45)$ & $0.90(0.60-1.35)$ & $1.11(0 \cdot 88-1.40)$ & $1.28(1.03-1.59)$ \\
\hline \multicolumn{5}{|l|}{ Type of Surgery } \\
\hline $\begin{array}{l}\text { Low anterior } \\
\text { resection }\end{array}$ & 1.00 (ref) & 1.00 (ref) & 1.00 (ref) & 1.00 (ref) \\
\hline $\begin{array}{l}\text { Abdominoperineal } \\
\text { resection }\end{array}$ & $1.50(1.21-1.85)$ & $1.45(0.94-2.23)$ & $1.54(1.20-1.98)$ & $1.83(1.45-2.32)$ \\
\hline Other & $1.72(1.17-2.54)$ & $2.05(0.99-4.24)$ & $1.36(0.84-2.22)$ & $2.11(1.38-3.23)$ \\
\hline \multicolumn{5}{|l|}{ Adjuvant chemotherapy } \\
\hline No & 1.00 (ref) & 1.00 (ref) & 1.00 (ref) & 1.00 (ref) \\
\hline Yes & $0.91(0.73-1.12)$ & $0.98(0.63-1.51)$ & $1.03(0.80-1.34)$ & $0.68(0.54-0.86)$ \\
\hline
\end{tabular}

Table 6. Adjusted hazard ratios with $95 \%$ confidence intervals (95\%CI) from multivariate Cox proportional hazards model.

A hazard ratio below 1 indicates that patients have a lower probability of an unfavourable event. ref=reference variable; $\mathrm{NE}=$ not estimable; $\mathrm{cm}=$ centimetres.

Table 6 also provides information on the independent effect of other prognostic factors on the studied endpoints. The multivariate analyses with respect to DFS show that patients with clinical $\mathrm{T} 4$ stage have a significantly higher risk of disease recurrence $(\mathrm{HR}=1.5195 \% \mathrm{CI}: 1.19-1.90)$, compared to patients with clinical T3 stage. Patients with a clinically positive nodal status also have a significantly increased risk of disease recurrence $(\mathrm{HR}=1.23,95 \% \mathrm{CI}$ : 1.02-1.50). Type of surgery is significantly 
associated with prognosis as well: compared with low anterior resection, the prognosis of patients who have had APR or another type of surgery is poorer $(\mathrm{HR}=1.5095 \% \mathrm{CI}$ : 1.21-1.85 and HR=1.72 95\% CI 1.17-2.54, respectively). The administration of adjuvant chemotherapy did not have an additional favourable effect on DFS (HR=0.91 95\%CI: 0.73-1.12), although it was associated with significantly improved OS (HR 0.68, 95\%CI: 0.54-0.86). We performed an additional multivariate analysis with addition of the variable 'tumour length' (as a proxy for tumour volume), which was provided by 3 datasets $(n=1189) .{ }^{6,12,43}$ The adjusted HR for DFS was 0.51 (95\%CI: 0.33-0.80), in favour of patients with pCR. Furthermore, to evaluate whether the favourable effect of pCR on prognosis was due to either the ypTo or ypNo component in pCR only we performed an additional multivariate analyses with ypTo and ypNo as separate factors in the model instead of the pCR variable. This analysis revealed that both ypTo and ypNo attribute significantly to the improved disease-free survival in patients with pCR (more details are supplied in the webappendix).

\section{Subgroup analyses}

The results of the subgroup analyses (figure 3) indicate that the favourable effect of pCR on prognosis was not modified by baseline characteristics or treatment variables.

\section{Discussion}

This pooled analysis of individual patient data from multiple study centres shows that patients with a pCR after chemoradiation have a significantly improved long-term outcome in terms of LC, DMFS, DFS and OS compared to patients with residual disease. The effect of pCR on long-term outcome was not influenced or modified by clinical $\mathrm{T}$ - or N-category, administration of adjuvant chemotherapy, distance from the anal verge or type of surgery.

One of the earliest studies reporting that patients with a pCR or good response after chemoradiation for rectal cancer had better long-term outcome than patients with little or no response was published by Chari et al. ${ }^{8}$ Since then, several reports have confirmed these findings, but some studies reported similar or worse outcome for patients with a pCR. ${ }^{2,47,51}$ A recent long-term analysis in a large population of 566 patients with a pCR by Capirci et al. contributed evidence that patients with a pCR have a favourable prognosis with 5-year rates of DFS and OS of $85 \%$ and $92 \%$, respectively. Their study, however, did not compare outcome with a control group of patients with residual disease. ${ }^{58}$ Our pooled analysis confirms the high 5-year DFS and OS in patients with pCR. 


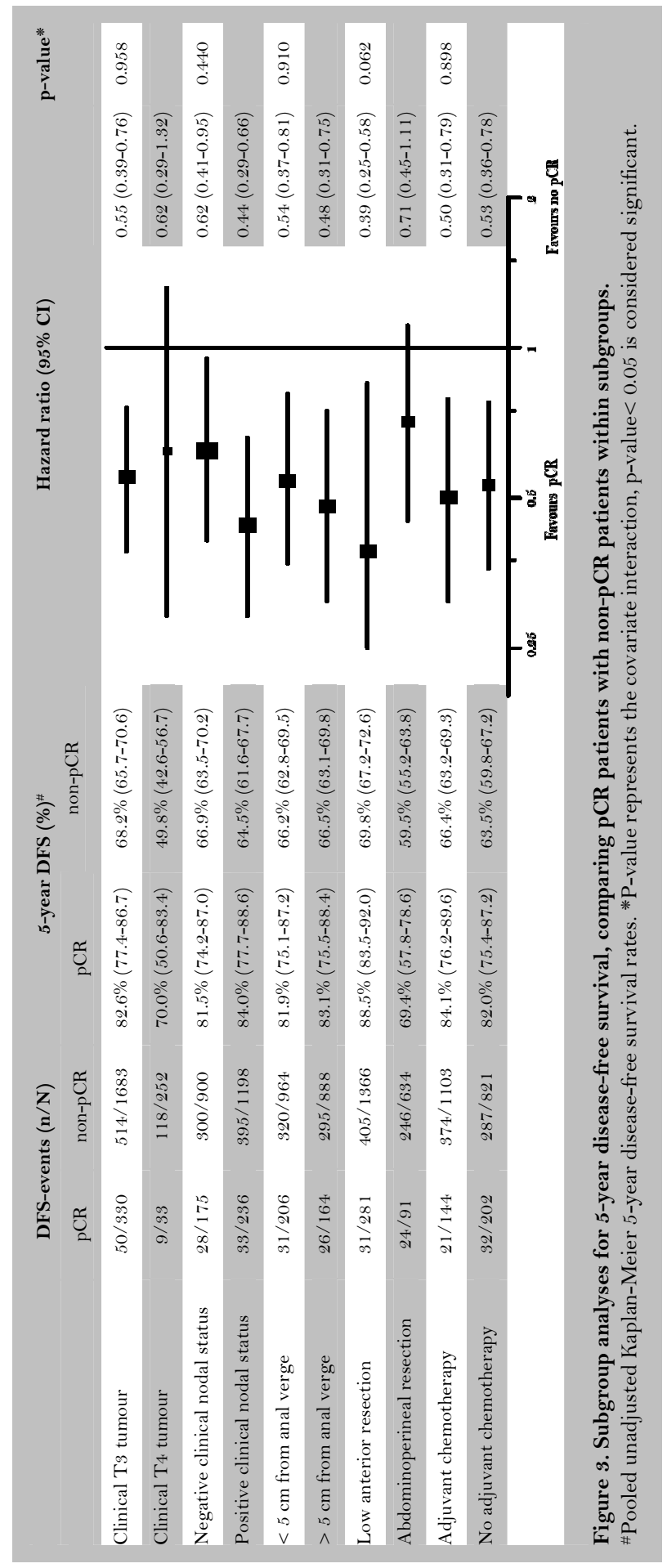


One appealing explanation for the good prognosis after pCR is that a pCR after chemoradiation is indicative of a prognostically favourable biological tumour profile with less propensity for local recurrence, distant metastases and a better survival compared with patients with less response. Several efforts have been made to identify tumour markers that can predict response to chemoradiation. Rödel et al. reported that the pre-treatment apoptotic index (percentage of apoptotic tumour cells in the total number of tumour cells) may be a predictor of pCR. ${ }^{59}$ Other biological factors that have been evaluated as potential predictors of response and long-term outcome, are, among others, p53, EGFR, Ki-67, p21, and Bax/bcl-2. Finally, microarray studies of genetic profiles have been compared between responding and non-responding tumours. ${ }^{60}$ Although these studies are promising, the results are still premature and the studies were conducted in small samples.

An alternative hypothesis is that the favourable effect of pCR on prognosis might be explained by a strong correlation between pCR and a small pre-treatment volume. ${ }^{61}$ However, after we entered tumour length together with the other relevant prognostic variables the multivariate analysis showed that $\mathrm{pCR}$ was still significantly associated with better DFS (HR 0.51, 95\%CI: 0.33-0.80). Based on this finding, it seems unlikely that the favourable effect of pCR on prognosis is due to a correlation with smaller pretreatment volume. However, this analysis was performed with data from 3 datasets $(n=1189)$ only and thus the result should be interpreted with caution.

In this analysis pCR was defined as ypToNoMo. Nevertheless, local recurrence still occurred in 12 patients with pCR after surgery, corresponding with a 5-year risk of local recurrence of $2.8 \%$. The individual data of these 12 patients did not reveal any clinical clues to explain these local recurrences. The pCR in these 12 patients can be considered as errors in pCR assessment. This can be due to evaluation errors by the pathologist, or because tumour was left behind in the patient at surgery (e.g. lateral lymph nodes). The reported interobserver agreement for histological examination of rectal cancer specimens after chemoradiation is good, ranging from 0.64 to 0.74 , with the best agreement for determination of pathologic complete response. ${ }^{62,63}$ Irrespective of the exact cause of the local recurrences after pCR, the finding indicates that a pCR does not guarantee a zero risk of local recurrence.

\section{Clinical implications}

The finding that patients with a pCR have a more favourable prognosis than patients with residual disease raises the question whether achieving a pCR should be a goal in the treatment of rectal cancer. More aggressive neoadjuvant treatment, such as higher radiation doses and boosts, continuous venous infusion of concurrent chemotherapy ${ }^{29,64}$, additional neoadjuvant chemotherapy ${ }^{65}$, and more potent radiosensitizers ${ }^{66,67}$ could be considered for this purpose. Another more simple option for increasing pCR rates is to lengthen the interval between chemoradiation and surgery. ${ }^{68,69}$ The finding in this study that a pCR is associated with a good prognosis, however, is based on data from studies which evaluated response at 6-8 weeks after 45- 
50.4 Gy radiation with 5-FU based chemotherapy. The question whether patients that achieve a pCR after different neoadjuvant regimens also have a favourable prognosis cannot be answered by this pooled analysis and remains a subject for further study. Furthermore, as long as the long-term outcome of patients who achieve a pCR after more aggressive types of neoadjuvant treatment is not clarified, we risk overtreating and exposing patients to additional morbidity when implementing more aggressive neoadjuvant treatments to obtain a higher pCR rate.

A good response after chemoradiation offers opportunities for more sphincter sparing procedures, but more controversial organ sparing options such as local excision of the tumour or a wait-and-see approach (i.e. omission of surgery) in case of a clinical complete response could also be considered, provided complete responders can be accurately selected with imaging and endoscopy. Even though current and future studies have to provide definite evidence about the oncological safety, these less invasive alternative options offer obvious functional benefits compared to standard TME. With regard to long-term oncological outcome, the new aforementioned less invasive treatments will have to compete with the excellent prognosis of pathological complete responders after standard resection.

Patients with a pCR received adjuvant chemotherapy less often than patients without a pCR $(39 \%$ versus $56 \%, \mathrm{p}<0 \cdot 0001)$ and still had a better prognosis than patients without a pCR. This raises the question whether patients with a pCR benefit from adjuvant chemotherapy. The results of the multivariate analyses indicate that after adjustment for other prognostic factors the administration of adjuvant chemotherapy had no independent effect on DMFS or DFS. However, administration of adjuvant chemotherapy was associated with significantly better OS (HR 0.68, 95\%CI 0.54-0.86). These puzzling findings may be explained by so-called confounding by indication, a well-known problem in non-randomized studies. This confounding by indication can result in lack of comparability of prognosis between patients who received adjuvant chemotherapy and those who did not. Maybe the decision whether or not to administer adjuvant chemotherapy was also guided by patient factors that were not incorporated in the multivariate analyses, such as comorbidity. In the subgroup of patients with pCR we repeated the multivariate analyses for DFS and found that the HR for adjuvant chemotherapy was 0.88, 95\%CI 0.39-2.02. Because of the wide confidence interval it is difficult to draw conclusions on the benefit of adjuvant chemotherapy for patients with pCR. Collette et al. reported on a study that randomized patients to undergo adjuvant chemotherapy or not after (chemo)radiation and surgery for rectal cancer. They found an overall HR for adjuvant chemotherapy of 0.85 for DFS, comparable to our findings. In a subgroup analysis the degree of downstaging modified the effect of adjuvant chemotherapy on DFS: patients with ypTo-2 tumours benefited from adjuvant chemotherapy, whereas patients with ypT3-4 tumours did not. The authors explained this interesting finding by the hypothesis that tumours that respond well to preoperative 5-FU based chemoradiation will also be sensitive to 5 -FU based adjuvant chemotherapy. ${ }^{70}$ At present there is no definite 
evidence on the benefit of adjuvant chemotherapy after a complete response. Both our study and the study from Capirci et al. suggest little or no benefit of chemotherapy. ${ }^{58}$ Until further evidence becomes available, it is up to the clinicians how to decide for an individual patient. In practice, the decision will often be based on risk factors for local or distant recurrence, such as the clinical pre-treatment staging (usually cN-status) or the response to chemoradiation.

\section{Limitations}

There are some limitations to this analysis. First, although we identified 17 individual datasets in our search, authors from 14 datasets participated. Two of three studies that declined participation reported similar results. ${ }^{44,46}$ The other study reported no difference in 5-year LC and DFS between pCR and non-pCR and a nonsignificant difference in 5-year overall survival in favour of patients with pCR. ${ }^{51}$ However, as stated by the authors, due to limited sample size the power to find a statistically significant difference was only $25 \%$. Therefore it is unlikely that noninclusion of these 3 studies has introduced bias. Additionally, two very recent papers that were published after our search and analyses are in agreement with our main findings. Although lacking the statistical power, both the studies of Roh et al. and Chua et al. report better outcomes for complete responders. ${ }^{65,71}$ A second limitation of this meta-analysis is that there are differences between studies caused by variations between centres in approaches to diagnosis and treatment. Although pathologic examination was performed in accordance with the TNM staging system in all studies, it cannot be guaranteed that pathological examination and pCR evaluation was uniform in all studies. In the analysis we accounted for these differences in diagnosis and treatment by stratification by centre.

\section{Conclusion}

Patients with a pCR after chemoradiation have improved long-term outcome compared to patients with residual pathologic disease. We believe that a pCR after chemoradiation is indicative of a prognostically favourable biological tumour profile with less propensity for local or distant recurrences and a better survival than for patients with tumours that respond less. This hypothesis needs to be substantiated by studies on the relationship between biological tumour characteristics and response to chemoradiation and prognosis. 


\section{References}

1. Sauer R, Becker H, Hohenberger W, Rodel C, Wittekind C, Fietkau R, Martus P, Tschmelitsch J, Hager E, Hess CF, Karstens JH, Liersch T, Schmidberger H, Raab R. Preoperative versus postoperative chemoradiotherapy for rectal cancer. N Engl J Med 2004;351(17): 1731-1740.

2. Janjan NA, Khoo VS, Abbruzzese J, Pazdur R, Dubrow R, Cleary KR, Allen PK, Lynch PM, Glober G, Wolff R, Rich TA, Skibber J. Tumor downstaging and sphincter preservation with preoperative chemoradiation in locally advanced rectal cancer: the M. D. Anderson Cancer Center experience. Int J Radiat Oncol Biol Phys 1999;44(5): 1027-1038.

3. Pucciarelli S, Toppan P, Friso ML, Russo V, Pasetto L, Urso E, Marino F, Ambrosi A, Lise M. Complete pathologic response following preoperative chemoradiation therapy for middle to lower rectal cancer is not a prognostic factor for a better outcome. Dis Colon Rectum 2004;47(11): 17981807 .

4. Diaz-Gonzalez JA, Calvo FA, Cortes J, Garcia-Sabrido JL, Gomez-Espi M, Del Valle E, MunozJimenez F, Alvarez E. Prognostic factors for disease-free survival in patients with T3-4 or N+ rectal cancer treated with preoperative chemoradiation therapy, surgery, and intraoperative irradiation. Int $J$ Radiat Oncol Biol Phys 2006;64(4): 1122-1128.

5. Rodel C, Martus P, Papadoupolos T, Fuzesi L, Klimpfinger M, Fietkau R, Liersch T, Hohenberger W, Raab R, Sauer R, Wittekind C. Prognostic significance of tumor regression after preoperative chemoradiotherapy for rectal cancer. J Clin Oncol 2005;23(34): 8688-8696.

6. Valentini V, Coco C, Picciocchi A, Morganti AG, Trodella L, Ciabattoni A, Cellini F, Barbaro B, Cogliandolo S, Nuzzo G, Doglietto GB, Ambesi Impiombato F, Cosimelli M. Does downstaging predict improved outcome after preoperative chemoradiation for extraperitoneal locally advanced rectal cancer? A long-term analysis of 165 patients. Int J Radiat Oncol Biol Phys 2002;53(3): 664-674.

7. Vecchio FM, Valentini V, Minsky BD, Padula GD, Venkatraman ES, Balducci M, Micciche F, Ricci R, Morganti AG, Gambacorta MA, Maurizi F, Coco C. The relationship of pathologic tumor regression grade (TRG) and outcomes after preoperative therapy in rectal cancer. Int $J$ Radiat Oncol Biol Phys 2005;62(3): 752-760.

8. Chari RS, Tyler DS, Anscher MS, Russell L, Clary BM, Hathorn J, Seigler HF. Preoperative radiation and chemotherapy in the treatment of adenocarcinoma of the rectum. Ann Surg 1995;221(6): 778-786; discussion 786-777.

9. Borschitz T, Wachtlin D, Mohler M, Schmidberger H, Junginger T. Neoadjuvant chemoradiation and local excision for T2-3 rectal cancer. Ann Surg Oncol 2008;15(3): 712-720.

10. Habr-Gama A, Perez RO, Nadalin W, Sabbaga J, Ribeiro U, Jr., Silva e Sousa AH, Jr., Campos FG, Kiss DR, Gama-Rodrigues J. Operative versus nonoperative treatment for stage o distal rectal cancer following chemoradiation therapy: long-term results. Ann Surg 2004;240(4): 711-717; discussion $717-718$.

11. Shivnani AT, Small W, Jr., Stryker SJ, Kiel KD, Lim S, Halverson AL, Talamonti MS. Preoperative chemoradiation for rectal cancer: results of multimodality management and analysis of prognostic factors. Am J Surg 2007;193(3): 389-393; discussion 393-384.

12. Hughes R, Glynne Jones R, Grainger J, Richman P, Makris A, Harrison M, Ashford R, Harrison RA, Livingstone JI, McDonald PJ, Meyrick Thomas J, Mitchell IC, Northover JM, Phillips R, Wallace M, Windsor A, Novell JR. Can pathological complete response in the primary tumour following pre-operative pelvic chemoradiotherapy for T3-T4 rectal cancer predict for sterilisation of pelvic lymph nodes, a low risk of local recurrence and the appropriateness of local excision? Int $J$ Colorectal Dis 2006;21(1): 11-17.

13. Ahmad NR, Nagle D. Long-term results of preoperative radiation therapy alone for stage T3 and T4 rectal cancer. Br J Surg 1997;84(10): 1445-1448. 
14. Berger C, de Muret A, Garaud P, Chapet S, Bourlier P, Reynaud Bougnoux A, Dorval E, de Calan L, Huten N, le Folch O, Calais G. Preoperative radiotherapy (RT) for rectal cancer: predictive factors of tumor downstaging and residual tumor cell density (RTCD): prognostic implications. Int J Radiat Oncol Biol Phys 1997;37(3): 619-627.

15. Bujko K, Nowacki MP, Nasierowska Guttmejer A, Michalski W, Bebenek M, Pudelko M, Kryj M, Oledzki J, Szmeja J, Sluszniak J, Serkies K, Kladny J, Pamucka M, Kukolowicz P. Sphincter preservation following preoperative radiotherapy for rectal cancer: report of a randomised trial comparing short-term radiotherapy vs. conventionally fractionated radiochemotherapy. Radiother Oncol 2004;72(1): 15-24.

16. Kaminsky Forrett MC, Conroy T, Luporsi E, Peiffert D, Lapeyre M, Boissel P, Guillemin F, Bey P. Prognostic implications of downstaging following preoperative radiation therapy for operable T3T4 rectal cancer. Int J Radiat Oncol Biol Phys 1998;42(5): 935-941.

17. Rouanet P, Fabre JM, Dubois JB, Dravet F, Saint Aubert B, Pradel J, Ychou M, Solassol C, Pujol H. Conservative surgery for low rectal carcinoma after high-dose radiation. Functional and oncologic results. Ann Surg 1995;22 1(1): 67-73.

18. Ruo L, Tickoo S, Klimstra DS, Minsky BD, Saltz L, Mazumdar M, Paty PB, Wong WD, Larson SM, Cohen AM, Guillem JG. Long-term prognostic significance of extent of rectal cancer response to preoperative radiation and chemotherapy. Ann Surg 2002;236(1): 75-81.

19. Tsujinaka S, Kawamura YJ, Konishi F, Aihara H, Maeda T, Mizokami K. Long-term efficacy of preoperative radiotherapy for locally advanced low rectal cancer. Int $J$ Colorectal Dis 2008;23(1): 6776.

20. Vermaas M, Ferenschild FT, Nuyttens JJ, Marinelli AW, Wiggers T, van der Sijp JR, Verhoef C, Graveland WJ, Eggermont AM, de Wilt JH. Preoperative radiotherapy improves outcome in recurrent rectal cancer. Dis Colon Rectum 2005;48(5): 918-928.

21. Maingon P, Guerif S, Darsouni R, Salas S, Barillot I, d'Hombres A, Bone Lepinoy MC, Fraisse J, Horiot JC. Conservative management of rectal adenocarcinoma by radiotherapy. Int $J$ Radiat Oncol Biol Phys 1998;40(5): 1077-1085.

22. Rengan R, Paty P, Wong WD, Guillem J, Weiser M, Temple L, Saltz L, Minsky BD. Distal cT2No rectal cancer: is there an alternative to abdominoperineal resection? J Clin Oncol 2005;23(22): 49054912 .

23. Wiig JN, Larsen SG, Dueland S, Giercksky KE. Clinical outcome in patients with complete pathologic response (pTo) to preoperative irradiation/chemo-irradiation operated for locally advanced or locally recurrent rectal cancer. J Surg Oncol 2005;92(1): 70-75.

24. Ceelen W, Pattyn P, Boterberg T, Peeters M. Pre-operative combined modality therapy in the management of locally advanced rectal cancer. Eur J Surg Oncol 2006;32(3): 259-268.

25. Benzoni E, Intersimone D, Terrosu G, Bresadola V, Cojutti A, Cerato F, Avellini C. Prognostic value of tumour regression grading and depth of neoplastic infiltration within the perirectal fat after combined neoadjuvant chemo-radiotherapy and surgery for rectal cancer. J Clin Pathol 2006;59(5): 505-512.

26. Bosset JF, Magnin V, Maingon P, Mantion G, Pelissier EP, Mercier M, Chaillard G, Horiot JC. Preoperative radiochemotherapy in rectal cancer: long-term results of a phase II trial. Int $J$ Radiat Oncol Biol Phys 2000;46(2): 323-327.

27. Grann A, Feng C, Wong D, Saltz L, Paty PP, Guillem JG, Cohen AM, Minsky BD. Preoperative combined modality therapy for clinically resectable uT3 rectal adenocarcinoma. Int J Radiat Oncol Biol Phys 2001;49(4): 987-995. 
28. Grann A, Minsky BD, Cohen AM, Saltz L, Guillem JG, Paty PB, Kelsen DP, Kemeny N, Ilson D, Bass Loeb J. Preliminary results of preoperative 5-fluorouracil, low-dose leucovorin, and concurrent radiation therapy for clinically resectable T3 rectal cancer. Dis Colon Rectum 1997;40(5): 515-522.

29. Mohiuddin M, Regine WF, John WJ, Hagihara PF, McGrath PC, Kenady DE, Marks G. Preoperative chemoradiation in fixed distal rectal cancer: dose time factors for pathological complete response. Int J Radiat Oncol Biol Phys 2000;46(4): 883-888.

30. Onaitis MW, Noone RB, Hartwig M, Hurwitz H, Morse M, Jowell P, McGrath K, Lee C, Anscher MS, Clary B, Mantyh C, Pappas TN, Ludwig K, Seigler HF, Tyler DS. Neoadjuvant chemoradiation for rectal cancer: analysis of clinical outcomes from a 13-year institutional experience. Ann Surg 2001;233(6): 778-785.

31. Pucciarelli S, Friso ML, Toppan P, Fornasiero A, Carnio S, Marchiori E, Lise M. Preoperative combined radiotherapy and chemotherapy for middle and lower rectal cancer: preliminary results. Ann Surg Oncol 2000; 7(1): 38-44.

32. Valentini V, Coco C, Cellini N, Picciocchi A, Genovesi D, Mantini G, Barbaro B, Cogliandolo S, Mattana C, Ambesi Impiombato F, Tedesco M, Cosimelli M. Preoperative chemoradiation for extraperitoneal T3 rectal cancer: acute toxicity, tumor response, and sphincter preservation. Int $J$ Radiat Oncol Biol Phys 1998;40(5): 1067-1075.

33. Videtic GM, Fisher BJ, Perera FE, Bauman GS, Kocha WI, Taylor M, Vincent MD, Plewes EA, Engel CJ, Stitt LW. Preoperative radiation with concurrent 5-fluorouracil continuous infusion for locally advanced unresectable rectal cancer. Int J Radiat Oncol Biol Phys 1998;42(2): 319-324.

34. Wiltshire KL, Ward IG, Swallow C, Oza AM, Cummings B, Pond GR, Catton P, Kim J, Ringash J, Wong CS, Wong R, Siu LL, Moore M, Brierley J. Preoperative radiation with concurrent chemotherapy for resectable rectal cancer: effect of dose escalation on pathologic complete response, local recurrence-free survival, disease-free survival, and overall survival. Int J Radiat Oncol Biol Phys 2006;64(3): 709-716.

35. Bonnen M, Crane C, Vauthey JN, Skibber J, Delclos ME, Rodriguez Bigas M, Hoff PM, Lin E, Eng C, Wong A, Janjan NA, Feig BW. Long-term results using local excision after preoperative chemoradiation among selected T3 rectal cancer patients. Int J Radiat Oncol Biol Phys 2004;60(4): 1098-1105.

36. Lim L, Chao M, Shapiro J, Millar JL, Kipp D, Rezo A, Fong A, Jones IT, McLaughlin S, Gibbs P. Long-term outcomes of patients with localized rectal cancer treated with chemoradiation or radiotherapy alone because of medical inoperability or patient refusal. Dis Colon Rectum 2007;50(12): 2032-2039.

37. Janjan NA, Crane C, Feig BW, Cleary K, Dubrow R, Curley S, Vauthey JN, Lynch P, Ellis LM, Wolff R, Lenzi R, Abbruzzese J, Pazdur R, Hoff PM, Allen P, Brown T, Skibber J. Improved overall survival among responders to preoperative chemoradiation for locally advanced rectal cancer. $\mathrm{Am} J$ Clin Oncol 2001;24(2): 107-112.

38. Das P, Lin EH, Bhatia S, Skibber JM, Rodriguez-Bigas MA, Feig BW, Chang GJ, Hoff PM, Eng C, Wolff RA, Delclos ME, Krishnan S, Janjan NA, Crane CH. Preoperative chemoradiotherapy with capecitabine versus protracted infusion 5 -fluorouracil for rectal cancer: a matched-pair analysis. Int $J$ Radiat Oncol Biol Phys 2006;66(5): 1378-1383.

39. Biondo S, Navarro M, Marti Rague J, Arriola E, Pares D, Del Rio C, Cambray M, Novell V. Response to neoadjuvant therapy for rectal cancer: influence on long-term results. Colorectal Dis 2005;7(5): 472-479.

40. Brown CL, Ternent CA, Thorson AG, Christensen MA, Blatchford GJ, Shashidharan M, Haynatzki GR. Response to preoperative chemoradiation in stage II and III rectal cancer. Dis Colon Rectum 2003;46(9): 1189-1193. 
41. Chan R, Reddy M, Freeman DH. Correlation of different 5-FU regimens and time to surgery with pathological complete response in locally advanced rectal cancer patients treated by pre-operative chemo-radiation. J La State Med Soc 2005;157(4): 196-201.

42. Ferrigno R, Novaes PE, Silva ML, Nishimoto IN, Nakagawa WT, Rossi BM, Ferreira Fde O, Lopes A. Neoadjuvant radiochemotherapy in the treatment of fixed and semi-fixed rectal tumors. Analysis of results and prognostic factors. Radiat Oncol 2006;1: 5 .

43. Garcia-Aguilar J, Hernandez de Anda E, Sirivongs P, Lee SH, Madoff RD, Rothenberger DA. A pathologic complete response to preoperative chemoradiation is associated with lower local recurrence and improved survival in rectal cancer patients treated by mesorectal excision. Dis Colon Rectum 2003;46(3): 298-304.

44. Gavioli M, Luppi G, Losi L, Bertolini F, Santantonio M, Falchi AM, D'Amico R, Conte PF, Natalini $\mathrm{G}$. Incidence and clinical impact of sterilized disease and minimal residual disease after preoperative radiochemotherapy for rectal cancer. Dis Colon Rectum 2005;48(10): 1851-1857.

45. Goethals L, Haustermans K, Perneel C, Bussels B, D'Hoore A, Geboes K, Ectors N, Van Cutsem E, Van den Bogaert W, Penninckx F. Chemo-radiotherapy versus radiotherapy alone in the preoperative treatment of resectable rectal cancer. Eur J Surg Oncol 2005;31(9): 969-976.

46. Guillem JG, Chessin DB, Cohen AM, Shia J, Mazumdar M, Enker W, Paty PB, Weiser MR, Klimstra D, Saltz L, Minsky BD, Wong WD. Long-term oncologic outcome following preoperative combined modality therapy and total mesorectal excision of locally advanced rectal cancer. Ann Surg 2005;241(5): 829-836.

47. Kuo LJ, Liu MC, Jian JJ, Horng CF, Cheng TI, Chen CM, Fang WT, Chung YL. Is final TNM staging a predictor for survival in locally advanced rectal cancer after preoperative chemoradiation therapy? Ann Surg Oncol 2007;14(10): 2766-2772.

48. Losi L, Luppi G, Gavioli M, Iachetta F, Bertolini F, D'Amico R, Jovic G, Bertoni F, Falchi AM, Conte PF. Prognostic value of Dworak grade of regression (GR) in patients with rectal carcinoma treated with preoperative radiochemotherapy. Int $J$ Colorectal Dis 2006;2 1(7): 645-651.

49. Minsky BD, Cohen AM, Enker WE, Saltz L, Guillem JG, Paty PB, Kelsen DP, Kemeny N, Ilson D, Bass J, Conti J. Preoperative 5-FU, low-dose leucovorin, and radiation therapy for locally advanced and unresectable rectal cancer. Int J Radiat Oncol Biol Phys 1997;37(2): 289-295.

50. Mohiuddin M, Hayne M, Regine WF, Hanna N, Hagihara PF, McGrath P, Marks GM. Prognostic significance of postchemoradiation stage following preoperative chemotherapy and radiation for advanced/recurrent rectal cancers. Int J Radiat Oncol Biol Phys 2000;48(4): 1075-1080.

51. Onaitis MW, Noone RB, Fields R, Hurwitz H, Morse M, Jowell P, McGrath K, Lee C, Anscher MS, Clary B, Mantyh C, Pappas TN, Ludwig K, Seigler HF, Tyler DS. Complete response to neoadjuvant chemoradiation for rectal cancer does not influence survival. Ann Surg Oncol 2001;8(10): 801-806.

52. Quah HM, Chou JF, Gonen M, Shia J, Schrag D, Saltz LB, Goodman KA, Minsky BD, Wong WD, Weiser MR. Pathologic stage is most prognostic of disease-free survival in locally advanced rectal cancer patients after preoperative chemoradiation. Cancer 2008;113(1): 57-64.

53. Rich TA, Skibber JM, Ajani JA, Buchholz DJ, Cleary KR, Dubrow RA, Levin B, Lynch PM, Meterissian SH, Roubein LD, et al. Preoperative infusional chemoradiation therapy for stage T3 rectal cancer. Int J Radiat Oncol Biol Phys 1995;32(4): 1025-1029.

54. Stipa F, Chessin DB, Shia J, Paty PB, Weiser M, Temple LK, Minsky BD, Wong WD, Guillem JG. A pathologic complete response of rectal cancer to preoperative combined-modality therapy results in improved oncological outcome compared with those who achieve no downstaging on the basis of preoperative endorectal ultrasonography. Ann Surg Oncol 2006;13(8): 1047-1053. 
55. Suarez J, Vera R, Balen E, Gomez M, Arias F, Lera JM, Herrera J, Zazpe C. Pathologic response assessed by Mandard grade is a better prognostic factor than down staging for disease-free survival after preoperative radiochemotherapy for advanced rectal cancer. Colorectal Dis 2008;10(6): 563-568.

56. Theodoropoulos G, Wise WE, Padmanabhan A, Kerner BA, Taylor CW, Aguilar PS, Khanduja KS. T-level downstaging and complete pathologic response after preoperative chemoradiation for advanced rectal cancer result in decreased recurrence and improved disease-free survival. Dis Colon Rectum 2002;45(7): 895-903.

57. Vauthey JN, Marsh RW, Zlotecki RA, Abdalla EK, Solorzano CC, Bray EJ, Freeman ME, Lauwers GY, Kubilis PS, Mendenhall WM, Copeland EM, 3rd. Recent advances in the treatment and outcome of locally advanced rectal cancer. Ann Surg 1999;229(5): 745-752; discussion 752-744.

58. Capirci C, Valentini V, Cionini L, De Paoli A, Rodel C, Glynne-Jones R, Coco C, Romano M, Mantello G, Palazzi S, Mattia FO, Friso ML, Genovesi D, Vidali C, Gambacorta MA, Buffoli A, Lupattelli M, Favretto MS, La Torre G. Prognostic value of pathologic complete response after neoadjuvant therapy in locally advanced rectal cancer: long-term analysis of 566 ypCR patients. Int $J$ Radiat Oncol Biol Phys 2008;72(1): 99-107.

59. Rodel C, Grabenbauer GG, Papadopoulos T, Bigalke M, Gunther K, Schick C, Peters A, Sauer R, Rodel F. Apoptosis as a cellular predictor for histopathologic response to neoadjuvant radiochemotherapy in patients with rectal cancer. Int J Radiat Oncol Biol Phys 2002;52(2): 294-303.

60. Kuremsky JG, Tepper JE, McLeod HL. Biomarkers for response to neoadjuvant chemoradiation for rectal cancer. Int J Radiat Oncol Biol Phys 2009;74(3): 673-688.

61. Kim NK, Baik SH, Min BS, Pyo HR, Choi YJ, Kim H, Seong J, Keum KC, Rha SY, Chung HC. A comparative study of volumetric analysis, histopathologic downstaging, and tumor regression grade in evaluating tumor response in locally advanced rectal cancer following preoperative chemoradiation. Int J Radiat Oncol Biol Phys 2007;67(1): 204-210.

62. Bateman AC, Jaynes E, Bateman AR. Rectal cancer staging post neoadjuvant therapy--how should the changes be assessed? Histopathology 2009;54(6): 713-721.

63. Ryan R, Gibbons D, Hyland JM, Treanor D, White A, Mulcahy HE, O'Donoghue DP, Moriarty M, Fennelly D, Sheahan K. Pathological response following long-course neoadjuvant chemoradiotherapy for locally advanced rectal cancer. Histopathology 2005;47(2): 141-146.

64. Mohiuddin M, Winter K, Mitchell E, Hanna N, Yuen A, Nichols C, Shane R, Hayostek C, Willett C. Randomized phase II study of neoadjuvant combined-modality chemoradiation for distal rectal cancer: Radiation Therapy Oncology Group Trial 0012. J Clin Oncol 2006;24(4): 650-655.

65. Chua YJ, Barbachano Y, Cunningham D, Oates JR, Brown G, Wotherspoon A, Tait D, Massey A, Tebbutt NC, Chau I. Neoadjuvant capecitabine and oxaliplatin before chemoradiotherapy and total mesorectal excision in MRI-defined poor-risk rectal cancer: a phase 2 trial. Lancet Oncol 2010;11(3): 241-248.

66. Debucquoy A, Haustermans K, Daemen A, Aydin S, Libbrecht L, Gevaert O, De Moor B, Tejpar S, McBride WH, Penninckx F, Scalliet P, Stroh C, Vlassak S, Sempoux C, Machiels JP. Molecular response to cetuximab and efficacy of preoperative cetuximab-based chemoradiation in rectal cancer. $J$ Clin Oncol 2009;27(17): 2751-2757.

67. Valentini V, De Paoli A, Gambacorta MA, Mantini G, Ratto C, Vecchio FM, Barbaro B, Innocente R, Rossi C, Boz G, Barba MC, Frattegiani A, Lupattelli M, Doglietto GB. Infusional 5-fluorouracil and ZD1839 (Gefitinib-Iressa) in combination with preoperative radiotherapy in patients with locally advanced rectal cancer: a phase I and II Trial (1839IL/0092). Int J Radiat Oncol Biol Phys 2008;72(3): 644-649.

68. Kerr SF, Norton S, Glynne-Jones R. Delaying surgery after neoadjuvant chemoradiotherapy for rectal cancer may reduce postoperative morbidity without compromising prognosis. $\mathrm{Br} J \mathrm{Surg}$ 2008;95(12): 1534-1540. 
69. Tulchinsky H, Shmueli E, Figer A, Klausner JM, Rabau M. An interval $>7$ weeks between neoadjuvant therapy and surgery improves pathologic complete response and disease-free survival in patients with locally advanced rectal cancer. Ann Surg Oncol 2008;15(10): 2661-2667.

70. Collette L, Bosset JF, den Dulk M, Nguyen F, Mineur L, Maingon P, Radosevic-Jelic L, Pierart M, Calais G. Patients with curative resection of cT3-4 rectal cancer after preoperative radiotherapy or radiochemotherapy: does anybody benefit from adjuvant fluorouracil-based chemotherapy? A trial of the European Organisation for Research and Treatment of Cancer Radiation Oncology Group. $J$ Clin Oncol 2007;25(28): 4379-4386.

71. Roh MS, Colangelo LH, O'Connell MJ, Yothers G, Deutsch M, Allegra CJ, Kahlenberg MS, BaezDiaz L, Ursiny CS, Petrelli NJ, Wolmark N. Preoperative multimodality therapy improves diseasefree survival in patients with carcinoma of the rectum: NSABP R-03. J Clin Oncol 2009;27(31): 51245130. 


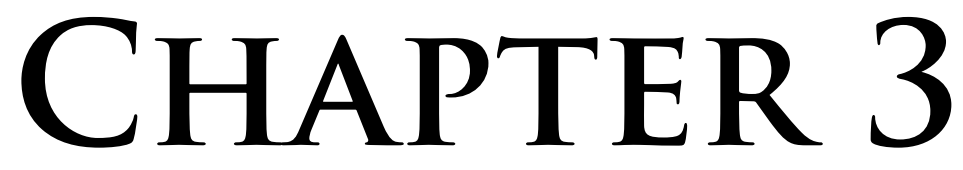

\section{Wait-and-see policy for clinical complete responders after chemoradiation for rectal cancer}

M. Maas

R.G.H. Beets-Tan

D.M.J. Lambregts

G. Lammering

P.J. Nelemans

S.M.E. Engelen

R.M. van Dam

R.L.H. Jansen

M. Sosef

J.W.A. Leijtens

K.W.E. Hulsewé

J. Buijsen

G.L. Beets

Journal of Clinical Oncology 201 1;10:4633-4640 


\begin{abstract}
Background. Neoadjuvant chemoradiation for rectal cancer can result in complete disappearance of tumour and involved nodes. In these patients without residual tumour on imaging and endoscopy (complete clinical response, cCR) wait-and-see-policy (omission of surgery with follow-up) might be considered instead of surgery. The purpose of this prospective cohort study was to evaluate feasibility and safety of waitand-see policy with strict selection criteria and follow-up.

Methods. Patients with a cCR after chemoradiation were prospectively selected for wait-and-see policy with MRI and endoscopy+biopsies. Follow-up was performed 3-6 monthly and consisted of MRI, endoscopy and CT. A control group of patients with a pathologic complete response (pCR) after surgery was identified from a prospective cohort study. Functional outcome was measured with the MSKCC bowel function questionnaire and Wexner incontinence score. With Kaplan-Meier curves long-term outcome was estimated.
\end{abstract}

Findings. 21 patients with cCR were included for wait-and-see policy. Mean follow-up is $25( \pm 19)$ months. One patient developed a local recurrence, which could be salvaged with surgery. The other 20 patients are alive without disease.

The control group consisted of 20 patients with a pCR after surgery, who had a mean follow-up of $35( \pm 23)$ months. Cumulative probabilities of 2-year disease-free survival and overall survival are $93 \%$ and $91 \%$, respectively.

Conclusions. Wait-and-see policy with strict selection criteria, modern imaging and follow-up is feasible and results in promising outcome, which is at least as good as that of patients with a pCR after surgery. The proposed selection criteria and follow-up could form the basis for future randomized studies. 


\section{Introduction}

In approximately $15-20 \%$ of the patients who undergo neoadjuvant chemoradiation (CRT) for locally advanced rectal cancer, no residual tumour is reported at histology after a standard resection: a pathologic complete response (pCR). ${ }^{1}$ Whether in these patients surgery could have been omitted was an intriguing but mostly theoretical question until Habr-Gama et al. reported their results from their so-called 'wait-andsee policy.' ${ }^{2}$ In this study, patients with low rectal cancer who achieved a clinical complete response after CRT were closely followed, without undergoing surgery. Long-term results were compared with a control group without clinical complete response in whom a total mesorectal excision (TME) was performed. After a mean follow-up of 60 months the results for the wait-and-see group were impressive: a 5 -year overall survival and disease-free survival of $93 \%$ and $85 \%$, respectively. ${ }^{2,3}$

These encouraging results of Habr-Gama were generally viewed with caution, and physicians were reluctant to treat patients non-operatively, mainly because of the lack of a sufficiently accurate technique to identify patients with a clinical complete response, and because no other study has reproduced the results., ${ }^{4,5}$

The aim of this study is to evaluate the safety and the benefits of omission of surgery combined with intensive follow-up (wait-and-see policy) for clinical complete responders after CRT with regard to local recurrence, disease-free survival, overall survival and bowel function compared to patients who achieved a pCR after surgery. A second aim was to evaluate a selection process and follow-up schedule with up-to-date MR-techniques.

\section{Methods}

\section{Patient inclusion and selection}

Since 2004 the option of a wait-and-see policy was discussed with patients with a clinical complete response (ycToNo) after CRT. The wait-and-see policy was presented as experimental and controversial, while it was stressed that a TME is the standard treatment with the best oncological control. All patients who preferred the wait-andsee policy over surgery gave informed consent. In 2009 this pilot was continued in a prospective cohort study, approved by the medical ethical committee and registered in clinicaltrials.gov (NCTO0939666). All previously treated patients were also included.

Treatment stratification was based on primary staging with with MRI, consisting of standard T2-weighted imaging. Additionally, nodal status was evaluated with MRI enhanced with either Ultrasmall Superparamagnetic Particles of Iron Oxide before 2006 or gadofosveset trisodium since 2006. ${ }^{6,7}$ Diffusion-weighted MR imaging (DWI), used to distinguish tumoural tissue (high signal on DWI) from normal rectal wall (low signal on DWI), was added to the staging and restaging protocol in $2006{ }^{8}$ Chemoradiation was indicated for all patients with locally advanced rectal cancer, 
defined as a (1)T4 tumour or a T3 tumour with a threatened/involved mesorectal fascia, and/or (2) > three involved nodes, and/or (3) a very distal tumour with 1-3 involved nodes. Chemoradiation consisted of 28 fractions of 1.8 Gy combined with 2x825 mg/m² capecitabine. Six to eight weeks after chemoradiation response evaluation was performed with the same MRI sequences as above. When on post-CRT MRI no residual tumour or only an area of fibrotic signal was visible (figure 1), an endoscopy was performed to assess the endoluminal tumour remnant.

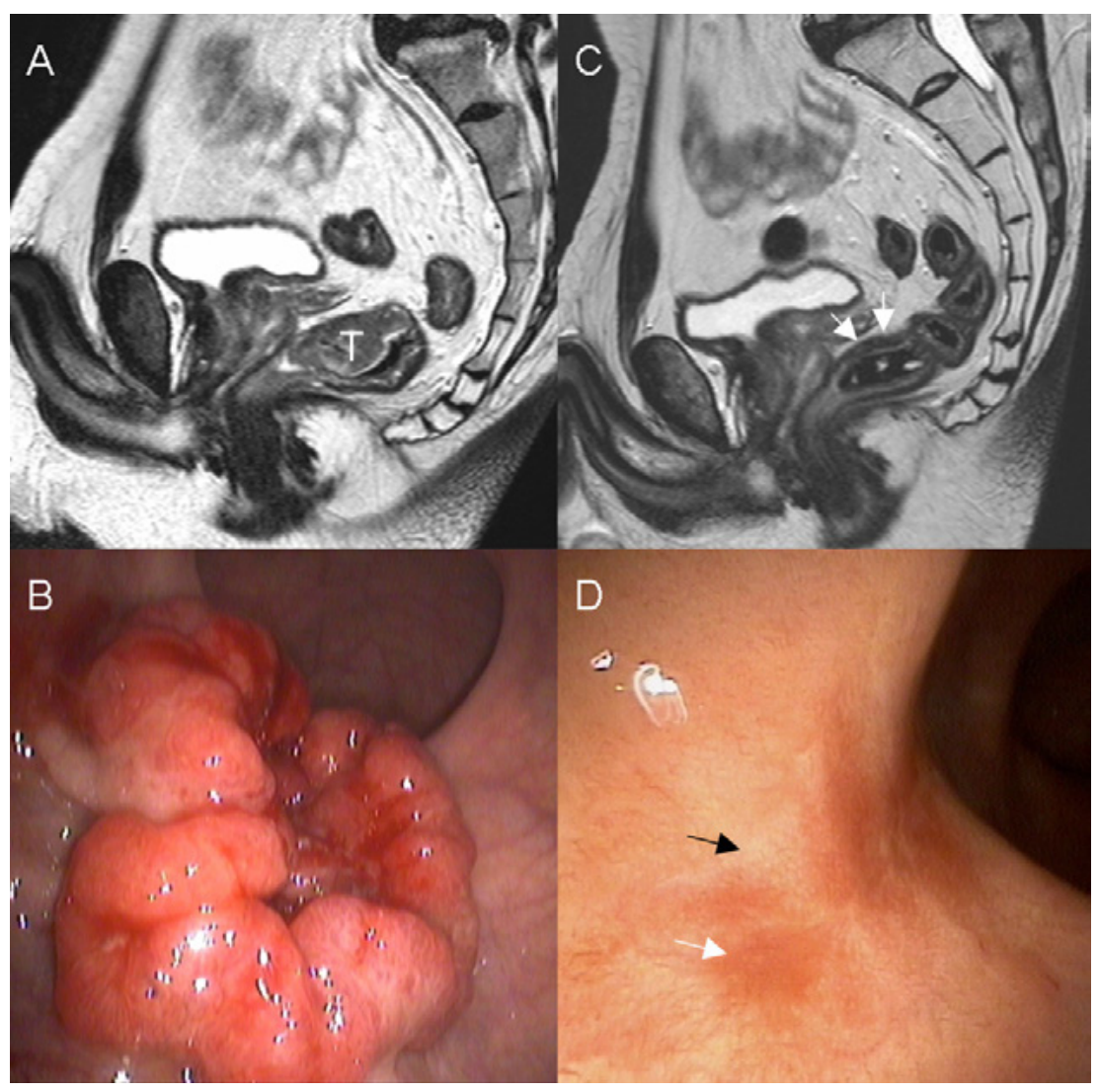

Figure 1. Example of a patient included for wait-and-see policy. 1A: Sagittal T2-weighted image of the primary distally located tumour $(\mathrm{T})$ before treatment. 1B: Tumour at endoscopy before treatment. 1C: Post-chemoradiation sagittal T2-weighted image with the arrows indicating a slightly thickened hypo-intense bowel wall, suggesting fibrosis. 1D: Residual scar after chemoradiation. The black arrow indicates a pale, white area, typical of a clinical complete response. The white arrow marks teleangiectasia, also a typical sign of a clinical complete response. 


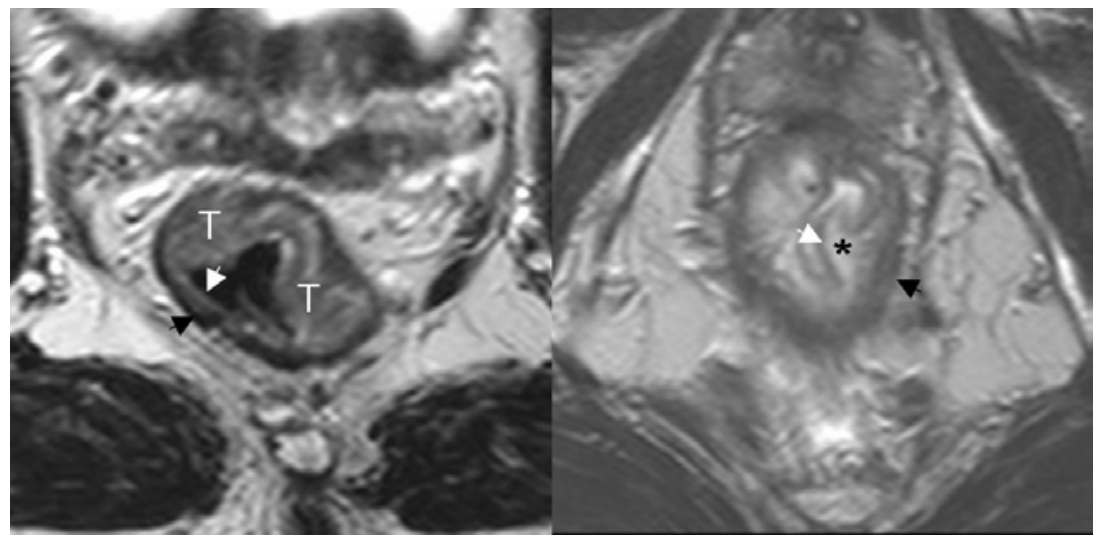

Figure 2. Ventral tumour $(\mathrm{T})$ on a T2-weighted axial image of the distal rectum before chemoradiation (left), showing the mucosa (white arrow) and the muscularis propria (black arrow). After chemoradiation (right image) no residual tumour with iso-intense signal or fibrosis with hypo-intense signal is visible. Again, the white arrow indicates the mucosa and the black arrow indicates the muscularis propria. Now, an additional layer of edema (*) has become visible, the submucosal layer, situated between the mucosa and muscular layer (online only).

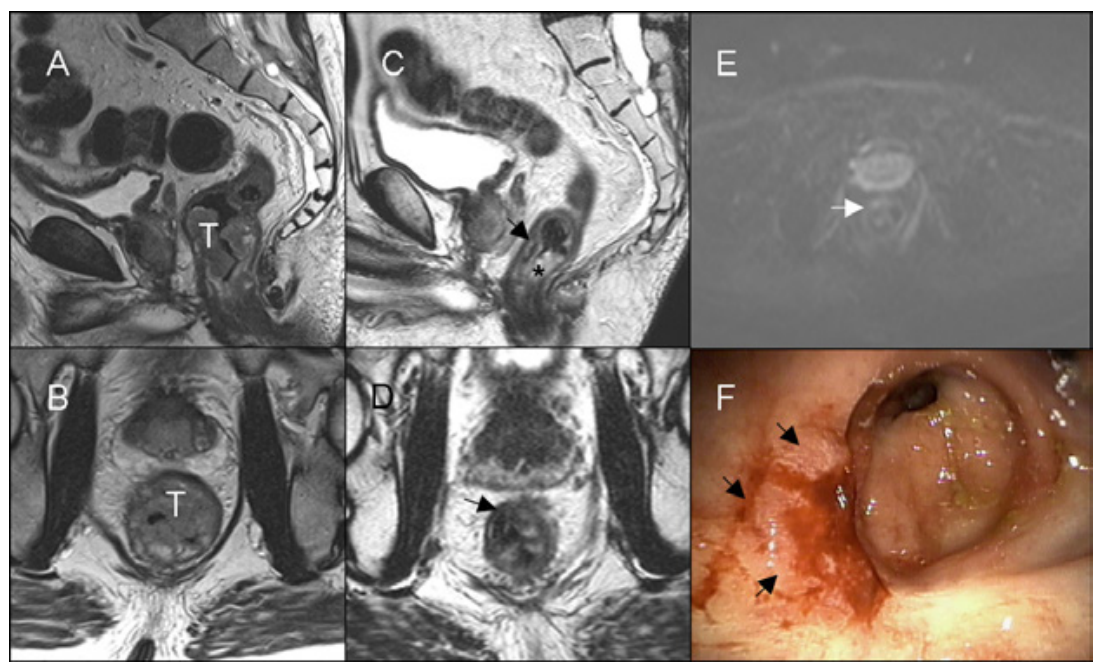

Figure 3. Example of a patient not eligible for wait-and-see policy despite remarkable response on MRI. 3A: Distal tumour (T) before treatment at a T2-weighted sagittal image. 3B: The tumour at an axial T2-weighted image before treatment. 3C: Post-chemoradiation image with edema (*) and a hypointense fibrotic area (black arrow, also on image $3 \mathrm{D}$ ) at the former tumour location. At high b-value diffusion-weighted imaging $(3 \mathrm{E})$ the distinction a small area with higher signal is visible (white arrow), suggestive of residual tumour. $3 \mathrm{~F}$ : Obvious residual tumour at endoscopy after chemoradiation (black arrows). After total mesorectal excision, histology revealed a ypT2No tumour. 
The definition of a clinical complete response was:

1. Substantial downsizing with no residual tumour or residual fibrosis only (with low signal on high b-value DWI, if available), shown in figure 1. Residual wall thickening due to edema only was also an indication for a possible clinical complete response (figure 2), and

2. No suspicious lymph nodes on MRI, and

3. No residual tumour at endoscopy or only a small residual erythematous ulcer or scar (figure 1), and

4. Negative biopsies from the scar, ulcer or former tumour location, and

5. No palpable tumour, when initially palpable with digital rectal examination.

If patients did not meet all of the abovementioned criteria they were regarded as non-complete responders. Figure 3 shows an example of a non-eligible patient for waitand-see policy.

\section{Follow-up}

An intensive follow-up protocol was incorporated into the wait-and see policy, consisting of digital rectal examination, MRI, endoscopy (with biopsy), CT of the chest and abdomen (for distant metastasis imaging) and carcinoembryogenic antigen measurements. The follow-up schedule is shown in table 1.

Patients received 'adjuvant' chemotherapy, consisting of intravenous oxaliplatin $130 \mathrm{mg} / \mathrm{m}^{2}$ on day 1 and capecitabine $1000 \mathrm{mg} / \mathrm{m}^{2}$ twice daily from day $1-14$, when they had a positive nodal status at primary staging. Chemotherapy was administered in 6 (3-week) cycles.

$\begin{array}{lccccc} & \text { CEA } & \text { DRE } & \text { Endoscopy } & \text { MRI* } & \text { CT for distant staging } \\ \text { Year } 1 & 4 \mathrm{x} & 4 \mathrm{x} & 4 \mathrm{x} & 4 \mathrm{x} & 2 \mathrm{x} \\ \text { Year } 2 & 4 \mathrm{x} & 2 \mathrm{x} & 2 \mathrm{x} & 2 \mathrm{x} & 1 \mathrm{x} \\ \text { Year } 3 & 4 \mathrm{x} & 2 \mathrm{x} & 2 \mathrm{x} & 2 \mathrm{x} & 1 \mathrm{x} \\ \text { Year } 4 & 2 \mathrm{x} & 2 \mathrm{x} & 2 \mathrm{x} & 2 \mathrm{x} & 1 \mathrm{x} \\ \text { Year 5 } & 2 \mathrm{x} & 2 \mathrm{x} & 2 \mathrm{x} & 2 \mathrm{x} & 1 \mathrm{x}\end{array}$

Table 1. Follow-up schedule for patients following wait-and-see policy. *indicates that this is different from the standard follow-up after total mesorectal excision.

\section{Control group}

For the comparison of short- and long-term outcome, patients with a pathologic complete response (pCR; ypToNo) after CRT and TME were identified from a multicenter prospective cohort study performed by our research group, in which MRI based tailored treatment for rectal cancer was evaluated. ${ }^{9}$ 


\section{Statistical analysis}

Information on baseline characteristics was collected. Treatment-related complications and morbidity were recorded and classified according to the classification of Dindo et al. ${ }^{10}$ Functional outcome was measured with the Memorial Sloan Kettering Cancer Center (MSKCC) bowel function questionnaire ${ }^{11}$ and the Wexner incontinence score for evaluation of faecal incontinence. ${ }^{12}$ Mean scores were compared between the wait-and-see patients and pCR control group with the independent samples T-test to compare continuous variables and $\chi^{2}$ test to compare proportions.

Cumulative proportions of local recurrence, disease-free and overall survival were evaluated with Kaplan-Meier curves and were compared between patients with waitand-see policy and operated patients with the log rank test. Local recurrence was defined as a recurrence in the pelvis; disease-free survival as the absence of a local and distant recurrence, and death from any cause; and overall survival as the absence of death from any cause. Duration of follow-up was calculated as the time from the MRI after CRT to the event of interest or to the last follow-up date (censoring date).

All statistical analyses were performed with Statistical Package for the Social Sciences (SPSS) version 16.

\section{Results}

From 2004-2010, 192 patients with locally advanced rectal cancer were treated with CRT. Twenty-one patients had a clinical complete response and were included for wait-and-see policy. Fourteen patients $(67 \%)$ were male and the mean age at diagnosis was $65( \pm 9)$ years. Mean time between CRT and response evaluation was $6.5( \pm 3)$ weeks. Mean follow-up is $25( \pm 19)$ months. Patients with a clinical complete response expressed a strong preference for wait-and-see policy over the resection, mostly because of the possibility to avoid major surgery or a permanent colostomy.

The control group consisted of 20 patients who had a pCR after CRT and TME, of which 16 were male $(80 \%)$. Of these patients, five had a suspected complete response at post-CRT imaging, but underwent surgery because in the early study period wait-andsee policy was not always considered. The other fifteen patients were referred for surgery because MRI showed a suspected major residual tumour mass or thickened rectal wall with (partly) iso-intense signal $(n=8$, figure 4), residual involved nodes $(n=2)$, residual spicular stranding into the mesorectal fat or to the mesorectal fascia $(n=4)$ or residual activity on diffusion-weighted MRI $(n=1)$. Mean age was $64( \pm 10)$ years. Mean time between CRT and response evaluation was 6.2 $( \pm 2.1)$ weeks. Mean follow-up is $35( \pm 23)$ months. Baseline (and treatment) characteristics for patients who followed the wait-and-see policy and the pCR control group are shown in table 2 and 3 , respectively. 


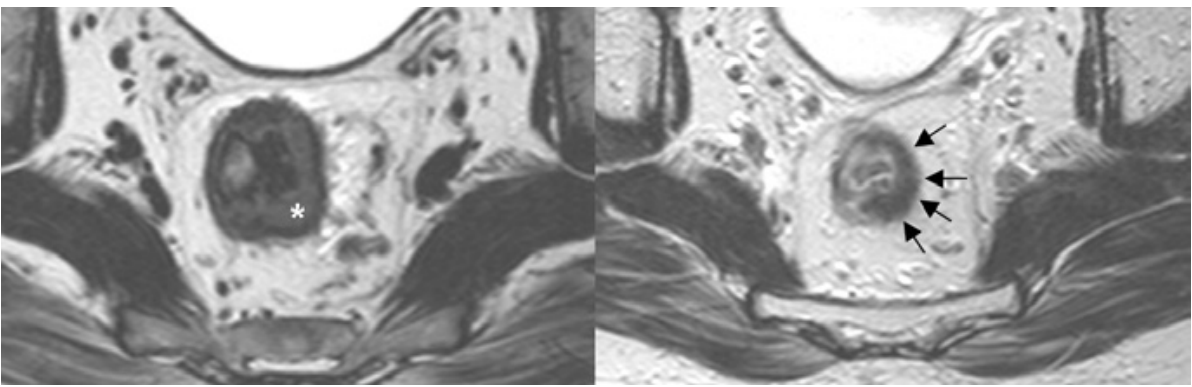

Figure 4. A tumour before chemoradiation (left image, *). After CRT the tumour has been replaced with a residual wall thickening. Because of this fibrotic mass, this was not considered an unequivocal complete response. Histology showed a pathologic complete response.

\begin{tabular}{|c|c|c|c|c|c|c|c|c|}
\hline Patient & Age & Gender & $\begin{array}{c}\text { cT } \\
\text { stage }\end{array}$ & $\begin{array}{l}\mathrm{cN} \\
\text { stage }\end{array}$ & $\begin{array}{c}\text { Distance from } \\
\text { ARJ }(\mathrm{cm})\end{array}$ & $\begin{array}{c}\text { Adjuvant } \\
\text { chemotherapy }\end{array}$ & $\begin{array}{c}\text { FU } \\
\text { (months) }\end{array}$ & $\begin{array}{c}\text { Planned surgical } \\
\text { procedure }\end{array}$ \\
\hline 1 & 70 & Male & 3 & 1 & o & Yes & 67 & APR \\
\hline 2 & 62 & Male & 3 & 2 & 0 & Yes & 60 & APR \\
\hline 3 & 67 & Female & 4 & 1 & o & Yes & 54 & APR \\
\hline 4 & 75 & Male & 2 & 1 & 0 & Yes & 48 & APR \\
\hline 5 & 51 & Male & 3 & 2 & 1 & Yes & 39 & APR \\
\hline 6 & 52 & Male & 3 & 2 & O & Yes & 33 & APR \\
\hline 7 & 65 & Male & 3 & 2 & 5 & Yes & 33 & LAR \\
\hline 8 & 49 & Female & 2 & 2 & 3 & Incomplete & 23 & LAR \\
\hline 9 & 64 & Male & 3 & 0 & 5,5 & Yes & 22 & LAR \\
\hline 10 & 62 & Female & 3 & 2 & 6 & Yes & 19 & LAR \\
\hline 11 & 78 & Female & 3 & o & 8 & No & 15 & LAR \\
\hline 12 & 58 & Female & 4 & 1 & 0 & Yes & 13 & APR \\
\hline 13 & 65 & Male & 3 & 2 & 6,5 & Yes & 13 & LAR \\
\hline 14 & 70 & Male & 3 & 2 & 10 & Yes & 13 & LAR \\
\hline 15 & 56 & Male & 3 & 1 & 3,5 & Yes & 12 & LAR \\
\hline 16 & 61 & Male & 2 & O & 3 & No & 12 & LAR \\
\hline 17 & 60 & Male & 1 & 2 & 4 & Yes & 12 & LAR \\
\hline 18 & 69 & Male & 3 & O & 1,5 & Yes & 12 & APR \\
\hline 19 & 77 & Female & 2 & o & o & No & 10 & APR \\
\hline 20 & 79 & Female & 3 & o & 0 & No & 7 & APR \\
\hline 21 & 65 & Male & 2 & 1 & 3 & Yes & 5 & LAR \\
\hline
\end{tabular}

Table 2. Characteristics of patients following wait-and-see policy. *Planned surgical procedure is the surgical intervention which would have been performed (based on the post-chemoradiation images) when patients would not have followed wait-and-see policy. ARJ= anorectal junction; $F U=$ follow-up time; $A P R=$ abdominoperineal resection; LAR= low anterior resection. 


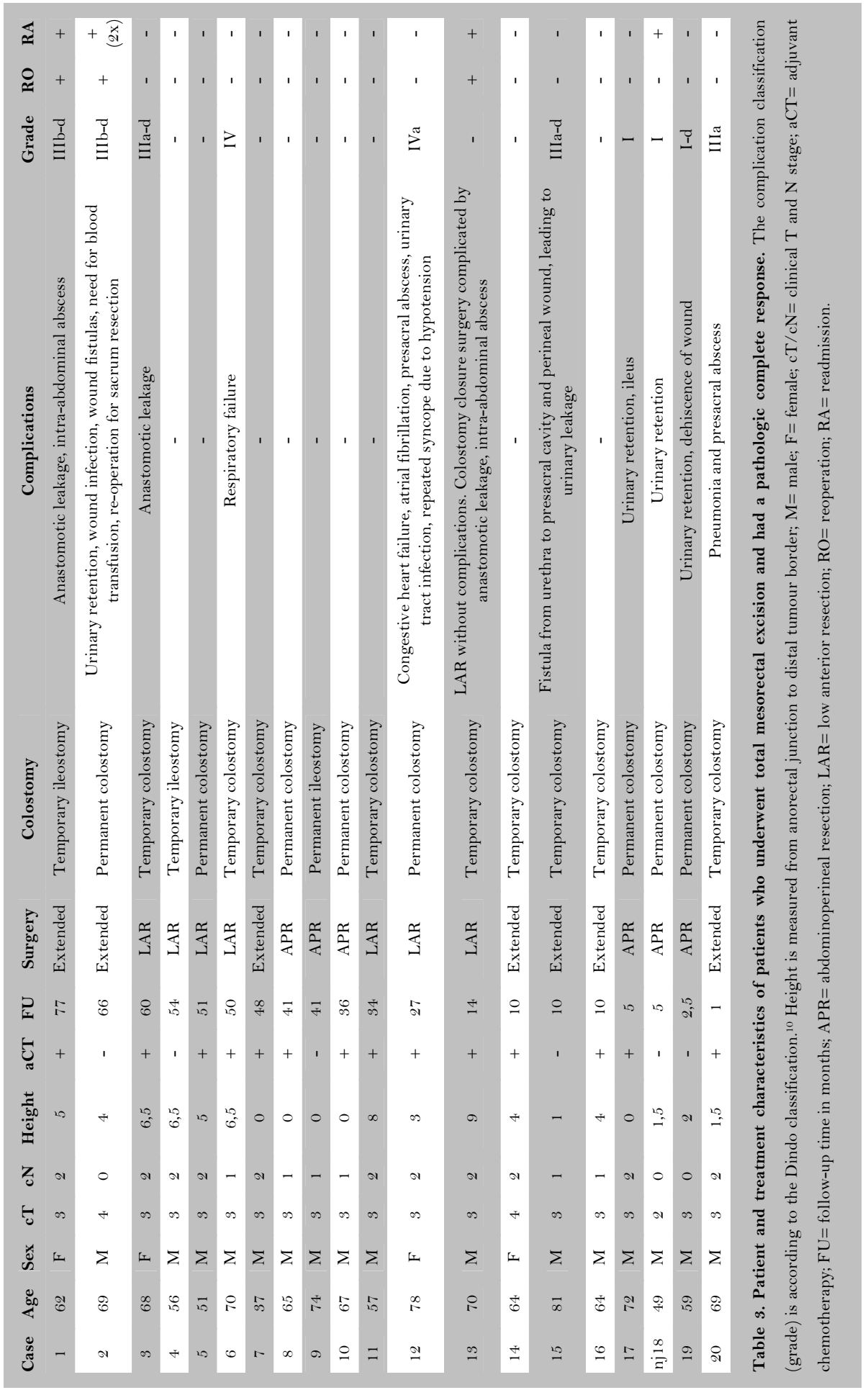




\section{Short-term and functional outcome}

Ten of 21 patients (48\%) initially had distally located tumours which would have required an abdominoperineal resection with a permanent colostomy. In these ten patients this procedure could be avoided with the wait-and-see policy. One patient following wait-and-see policy developed a severe stenosing inflammation in the sigmoid colon after 14 months of follow-up, necessitating an anterior sigmoid resection above the former tumour location in the rectum. This inflammatory stenosis was possibly related to the chemoradiation. The operation was complicated by an anastomotic leakage that eventually healed, and temporary faecal incontinence after ileostomy closure.

Nine patients from the pCR control group required a definitive and 11 a temporary colostomy. In $10 / 20$ patients $(50 \%)$ no complications occurred after surgery. In 7 cases (35\%) major complications occurred, such as anastomotic leakage, intra-abdominal abscess or respiratory failure. In 3 patients (15\%) minor complications occurred, such as urinary retention or wound infection. Data on short-term outcome are shown in table 3.

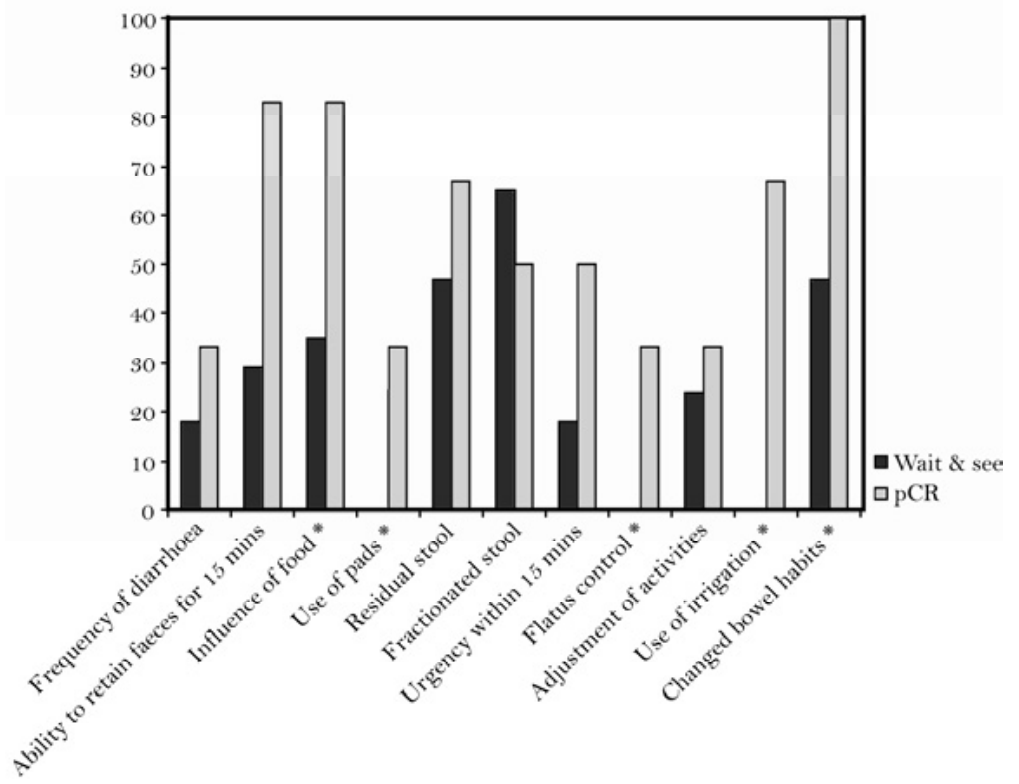

Figure 5. Bowel function based on several items from the MSKCC bowel function questionnaire and the Wexner incontinence score for patients with a clinical complete response following waitand-see policy and patients with a pathologic complete response after total mesorectal excision.

* indicates that the difference was statistically significant.

The MSKCC bowel function score showed a clear difference between patients from the pCR control and the wait-and-see group (figure 5). Bowel function from operated 
patients was significantly more influenced by food intake $(\mathrm{p}=0.043)$, they used pads $(p=0.045)$ and colonic irrigation $(p=0.001)$ more frequently, had less control over flatus $(p=0.036)$ and reported more change in their bowel habits compared to the situation prior to diagnosis than patients undergoing wait-and-see policy ( $p=0.014)$. Furthermore, patients with a wait-and-see policy had a lower mean Wexner incontinence score of 0.8 vs. $3.5(\mathrm{p}=0.182)$ and a lower mean defecation frequency of 1.8/day vs. $2.8 /$ day $(\mathrm{p}=0.323)$ compared to patients from the $\mathrm{pCR}$ control group.

\section{Long-term outcome}

Of the 21 patients following wait-and-see policy one developed a small endoluminal local recurrence without nodal recurrence after 22 months of follow-up (figure 6). Endorectal ultrasound showed a T1 tumour. He was primarily offered a low anterior resection, but eventually preferred transanal endoscopic microsurgery, which resulted in a complete resection of the recurrence. The other 20 patients are alive and diseasefree. The cumulative probability of 2-year disease-free survival (DFS) and 2-year overall survival (OS) are 89\% (95\% confidence interval (CI) 43-98\%) and 100\%, respectively.

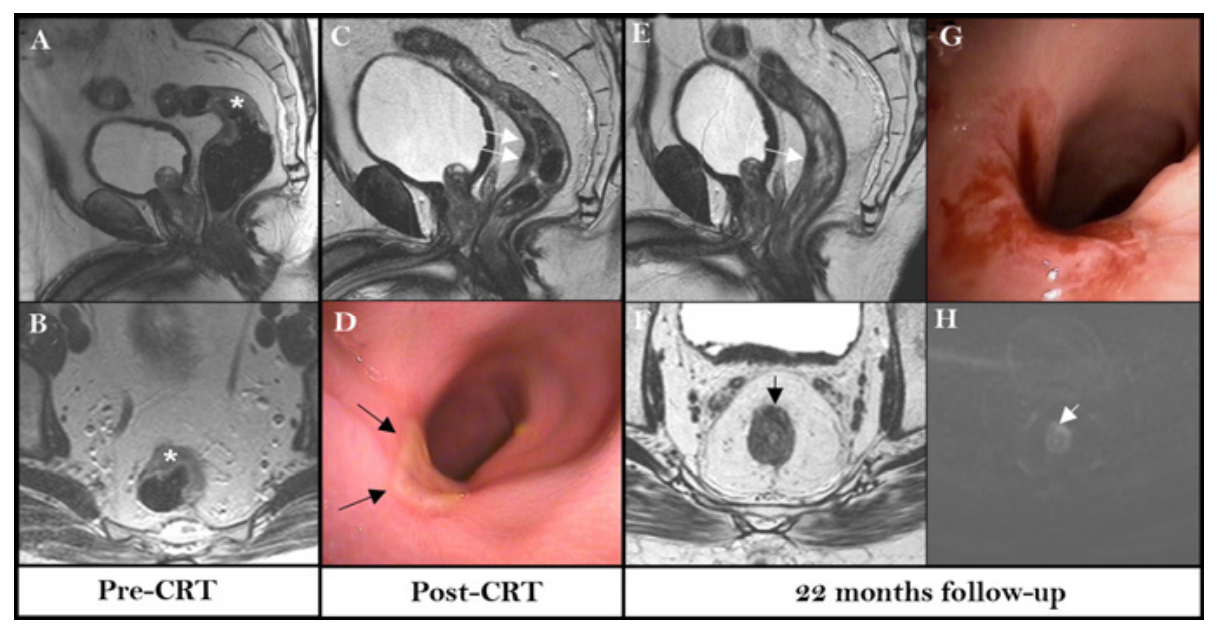

Figure 6. Patient who developed a local recurrence after 22 months of follow-up. Before chemoradiation (A, B) a midrectal T3 tumour (*) is visible. After chemoradiation at MRI (C) a small hypointense area is visible (white arrows) and at endoscopy a small ulcer with yellow covering is visualised (arrow, D). After 22 months of follow-up at T2-weighted MRI (E, F) no change is visualised (black arrows), while at endoscopy $(\mathrm{G})$ and diffusion-weighted imaging $(\mathrm{H})$ there is a suspected recurrence (arrow).

Two of the patients from the pCR control group died. One patient died of complications associated with colostomy closure surgery one year after TME. The other patient died after 5 years of follow-up of metastatic disease, diagnosed after 3 
years of follow-up. None of the operated patients had a local recurrence. Cumulative probability of 2-year DFS is 93\% (95\% CI 59-99\%) and for 2-year OS the cumulative probability is $91 \%$ (95\% CI 59-99\%).

Cumulative probabilities for DFS and OS were not significantly different between the wait-and-see and operated patients $(p=0.770$ and $p=0.228$ for DFS and OS, respectively). Kaplan Meier curves are shown in figure 7.
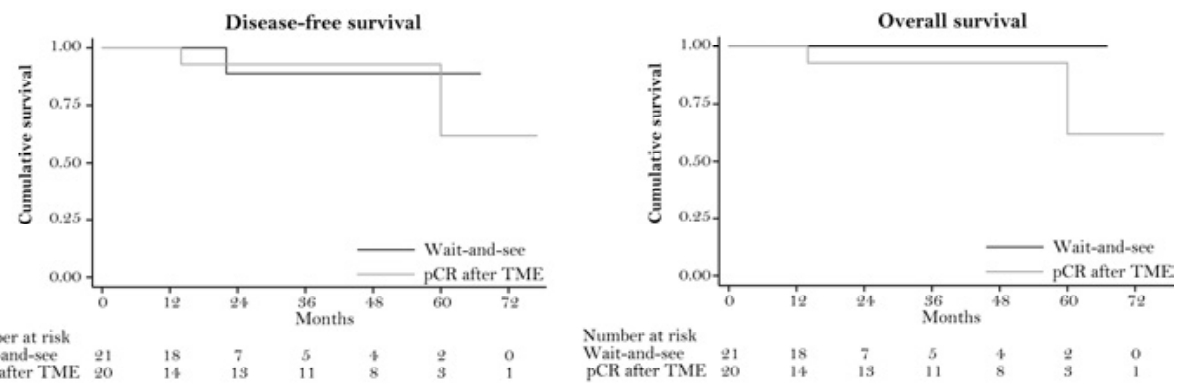

Figure 7. Disease-free (A) and overall survival (B) for patients with a clinical complete response following wait-and-see policy and patients with a pathologic complete response after total mesorectal excision (pCR).

\section{Discussion}

A wait-and-see policy for complete responders after CRT for rectal cancer based on strict selection and follow-up with endoscopy and up-to-date imaging is feasible and appears safe. In this small series, only one small local recurrence was found that could be easily salvaged. No distant metastases were found. The oncological outcome after wait-and-see policy was comparable to that of patients with a pCR after surgery, while functional outcome was significantly better.

To the best of our knowledge this is the second study reporting on a wait-and-see policy after a clinical complete response, and it confirms the good results of Habr-Gama et al. In their first publication they report a local recurrence rate of $19 \%$ in the first year $^{2}$, while we encountered one local recurrence after 22 months of follow-up and none in the first year of follow-up. Although this observation could be caused by chance, it could also result from the restrictive selection. Any sign of residual mass on MRI was considered as possible residual tumour. On the other hand, this restrictive selection led to missing a complete response with MRI in 15 of 20 patients with a pCR after surgery. However, the strict selection criteria may have led to a higher chance of selecting true complete responders.

The one patient with a local recurrence had a very small endoluminal recurrence (figure 7). Initially, after CRT he had a very small shallow depression with a yellow 
covering, thought to be a healing complete response. After 7 months the rectal wall normalised. In retrospect this slow-healing ulcer might have been an indication that the tumour had not disappeared completely. A small number of local recurrences will be inherent to a wait-and-see approach, but a good follow-up enables early detection and treatment with a complete resection. Our follow-up schedule was less intensive than in the Brazilian study. While the follow-up schedule of Habr-Gama et al. mainly focussed on frequent endoscopies with biopsies combined with 6-monthly abdominal CT during the $1^{\text {st }}$ year ${ }^{2}$, the schedule of the present study consisted mainly of MRI and endoscopy at a lower frequency, which resulted in an excellent patient compliance.

Lymph node assessment with MRI played an important role in the selection and follow-up. A recent pooled analysis showed that in ypTo patients, there is still a $5 \%$ incidence of positive lymph nodes. ${ }^{1}$ Therefore, accurate lymph node imaging in both the selection and follow-up is important for prevention and early identification of nodal recurrences. The use of contrast-enhanced MRI has helped in predicting nodal involvement.

Many clinicians argue that a local excision of the residual scar after CRT is a much safer approach than a wait-and-see policy, because it provides reassurance about the presence or absence of residual tumour. While it is undoubtedly true that it provides a more accurate assessment of the tumour remnant, there are some downsides to a local excision. First, there is a small chance of a false pCR finding through a sampling error. Second, there is the reverse problem of the unknown clinical significance of a very small number of tumour cells in the fibrosis. It has been shown that the longer the interval after CRT, the higher the response rate is.13-15 $5^{17-19}$ It is therefore likely that not all patients who have a very limited amount of residual tumour cells after local excision will suffer from a recurrence when treated non-operatively. Another downside of local excision after CRT is that it has a higher complication rate than a primary local excision, with more wound dehiscences, readmissions, bleeding and pain.16-18 $8^{14-16} \mathrm{It}$ may therefore be a better approach not to do a routine local excision in all complete responders but to reserve this procedure for the patients in whom it remains unclear whether or not the response is complete.

As expected, patients who did not undergo surgery had better functional outcome than operated patients. This difference was largest for control over flatus and for the change in bowel habits compared to the situation prior to diagnosis. All the patients with a pCR after surgery had changed bowel habits compared to prior to diagnosis and up to $65 \%$ of patients still had bowel dysfunction at the time of the questionnaire. These results are comparable to results from a recent publication by Pucciarelli et al., who reported that up to $78 \%$ of patients still have problems with bowel function one year after CRT and surgery. ${ }^{19}$

Although in our population no patients died from the primary rectal resection, one patient died of an anastomotic leakage after colostomy closure. Reported mortality after TME is about $4 \%$ for all patients, but with increasing age the postoperative mortality rapidly increases up to $11.8 \%$ for patients $>85$ years. Furthermore, a recent report 
showed that for the elderly the risk of death within 6 months after surgery is even 2-3 times higher than the traditional 1 month mortality. ${ }^{20}$ When evaluating the different treatment options for a given patient, both the oncological outcome and the treatmentrelated morbidity and mortality should be considered. In this regard, wait-and-see policy could be of specific value for the elderly and for patients with comorbidity. In our experience, however, also younger patients have an interest in a wait-and-see approach.

\section{Limitations}

There are some limitations to this study. First, the sample size is small. This is, however, the first study to reproduce results for a wait-and-see policy since the report from Habr-Gama et al. Second, the follow-up is short and late recurrences can occur. ${ }^{3}$ With a mean follow-up over 2 years and 18/21 patients having at least one year of follow-up it can be concluded that the selection procedure and follow-up schedule are feasible and that the preliminary outcome is as good as in the landmark paper. ${ }^{2}$ Last, the evaluation of functional outcome included only a small part of the patients who underwent surgery, because of the presence of a colostomy in the other patients. It is nevertheless clear that the functional results after a wait-and-see policy are better than after standard rectal surgery.

\section{Future perspectives}

Ideally, wait-and-see policy for a clinical complete response should be compared to standard TME through a randomised controlled trial (RCT), evaluating both oncological and functional results. However, some issues might complicate the execution of an RCT. First, a non-inferiority design will have to be used, addressing the primary concern that survival will not be compromised. This requires a very large sample size that will be difficult to achieve. Second, we observed that many patients who have a clinical complete response, even when explicitly informed about the experimental nature of the wait-and-see approach, express a strong preference not to undergo TME. Apparently, patients and doctors have different perceptions of the balance between oncological risk and gain in quality of life. For optimal shared decision-making doctors would like to have more objective high quality evidence, while many patients do not like the loss of control in an RCT over such an important decision. Patient refusal of participation in a RCT might jeopardize its feasibility. 'Second best' evidence can be provided by well documented prospective large cohort studies.

Given the good results of wait-and-see policy in selected patients, it is logical to study how to increase the probability for a clinical complete response after CRT, e.g. by increasing the biological radiation dose to the tumour with an simultaneous integrated boost ${ }^{21}$, or by the use during and after CRT of biological modifiers that sensitize the more radioresistant tumours. ${ }^{22,23}$ However, these intensified approaches should be incorporated into individualized strategies, in which only the predicted non-responding tumours are included in order to avoid overtreatment in those patients with a high 
likelihood for a clinical complete response. Furthermore, a broader inclusion of patients for neoadjuvant CRT - e.g. inclusion of smaller tumours - would probably increase the number of clinical complete responses, since smaller tumour size is an important predictive factor of response. ${ }^{24}$ However, this can also lead to overtreatment with an increased risk of treatment-related morbidity.

\section{Conclusion}

Wait-and-see policy for clinical complete responders after CRT for rectal cancer, with strict selection criteria and follow-up with up-to-date imaging is feasible and safe. Outcome is at least comparable to that of patients with a pCR after surgery. The proposed selection criteria and follow-up can be used in future trials aimed at providing more evidence on wait-and-see policy. 


\section{References}

1. Maas M, Nelemans PJ, Valentini V, Das P, Rodel C, Kuo LJ, Calvo FA, Garcia-Aguilar J, GlynneJones R, Haustermans K, Mohiuddin M, Pucciarelli S, Small W, Jr., Suarez J, Theodoropoulos G, Biondo S, Beets-Tan RG, Beets GL. Long-term outcome in patients with a pathological complete response after chemoradiation for rectal cancer: a pooled analysis of individual patient data. Lancet Oncol 2010;11(9): 835-844.

2. Habr-Gama A, Perez RO, Nadalin W, Sabbaga J, Ribeiro U, Jr., Silva e Sousa AH, Jr., Campos FG, Kiss DR, Gama-Rodrigues J. Operative versus nonoperative treatment for stage o distal rectal cancer following chemoradiation therapy: long-term results. Ann Surg 2004;240(4): 711-717; discussion $717-718$.

3. Habr-Gama A, Perez RO, Proscurshim I, Campos FG, Nadalin W, Kiss D, Gama-Rodrigues J. Patterns of failure and survival for nonoperative treatment of stage co distal rectal cancer following neoadjuvant chemoradiation therapy. J Gastrointest Surg 2006;10(10): 1319-1328; discussion 13281319.

4. Glynne-Jones R, Wallace M, Livingstone JI, Meyrick-Thomas J. Complete clinical response after preoperative chemoradiation in rectal cancer: is a "wait and see" policy justified? Dis Colon Rectum 2008;51(1): 10-19; discussion 19-20.

5. O'Neill BD, Brown G, Heald RJ, Cunningham D, Tait DM. Non-operative treatment after neoadjuvant chemoradiotherapy for rectal cancer. Lancet Oncol 2007;8(7): 625-633.

6. Lahaye MJ, Beets GL, Engelen SM, Kessels AG, de Bruine AP, Kwee HW, van Engelshoven JM, van de Velde CJ, Beets-Tan RG. Locally advanced rectal cancer: MR imaging for restaging after neoadjuvant radiation therapy with concomitant chemotherapy. Part II. What are the criteria to predict involved lymph nodes? Radiology 2009;252(1): 81-91.

7. Lambregts DM, Beets GL, Maas M, Kessels AG, Bakers FC, Cappendijk VC, Engelen SM, Lahaye MJ, de Bruine AP, Lammering G, Leiner T, Verwoerd JL, Wildberger JE, Beets-Tan RG. Accuracy of Gadofosveset-enhanced MRI for Nodal Staging and Restaging in Rectal Cancer. Ann Surg 2011;253: 539-45.

8. Lambregts DM, Vandecaveye V, Barbaro B, Bakers FCH, Lambrecht M, Maas M, Haustermans K, Valentini V, Beets GL, Beets-Tan RGH: Diffusion-weighted MRI for Selection of Complete Responders After Chemoradiation for Locally Advanced Rectal Cancer: A Multicenter Study. Ann Surg Oncol DOI 10.1245/s10434-011-1607-5, Epub Feb 23, 2011

9. Engelen SM, Beets-Tan RG, Lahaye MJ, Lammering G, Jansen RL, van Dam RM, Konsten J, Leijtens JW, van de Velde CJ, Beets GL. MRI after chemoradiotherapy of rectal cancer: a useful tool to select patients for local excision. Dis Colon Rectum 2010;53(7): 979-986.

10. Dindo D, Demartines N, Clavien PA. Classification of surgical complications: a new proposal with evaluation in a cohort of 6336 patients and results of a survey. Ann Surg 2004;240(2): 205-213.

11. Temple LK, Bacik J, Savatta SG, Gottesman L, Paty PB, Weiser MR, Guillem JG, Minsky BD, Kalman M, Thaler HT, Schrag D, Wong WD. The development of a validated instrument to evaluate bowel function after sphincter-preserving surgery for rectal cancer. Dis Colon Rectum 2005;48(7): 1353-1365.

12. Oliveira L, Pfeifer J, Wexner SD. Physiological and clinical outcome of anterior sphincteroplasty. $\mathrm{Br}$ $J$ Surg 1996;83(4): 502-505.

13. Wang Y, Cummings B, Catton P, Dawson L, Kim J, Ringash J, Wong R, Yi QL, Brierley J. Primary radical external beam radiotherapy of rectal adenocarcinoma: long term outcome of 271 patients. Radiother Oncol 2005;77(2): 126-132. 
14. Moore HG, Gittleman AE, Minsky BD, Wong D, Paty PB, Weiser M, Temple L, Saltz L, Shia J, Guillem JG. Rate of pathologic complete response with increased interval between preoperative combined modality therapy and rectal cancer resection. Dis Colon Rectum 2004;47(3): 279-286.

15. Tulchinsky H, Shmueli E, Figer A, Klausner JM, Rabau M. An interval $>7$ weeks between neoadjuvant therapy and surgery improves pathologic complete response and disease-free survival in patients with locally advanced rectal cancer. Ann Surg Oncol 2008;15(10): 2661-2667.

16. Borschitz T, Wachtlin D, Mohler M, Schmidberger H, Junginger T. Neoadjuvant chemoradiation and local excision for T2-3 rectal cancer. Ann Surg Oncol 2008;15(3): 712-720.

17. Marks JH, Valsdottir EB, DeNittis A, Yarandi SS, Newman DA, Nweze I, Mohiuddin M, Marks GJ. Transanal endoscopic microsurgery for the treatment of rectal cancer: comparison of wound complication rates with and without neoadjuvant radiation therapy.Surg Endosc 2009;23(5): 10811087.

18. Perez RO, Habr-Gama A, Sao Juliao GP, Proscurshim I, Neto AS, Gama-Rodrigues J. Transanal endoscopic microsurgery for residual rectal cancer after neoadjuvant chemoradiation therapy is associated with significant immediate pain and hospital readmission rates. Dis Colon Rectum 2011;54(5): 545-551.

19. Pucciarelli S, Del Bianco P, Efficace F, Serpentini S, Capirci C, De Paoli A, Amato A, Cuicchi D, Nitti D. Patient-reported outcomes after neoadjuvant chemoradiotherapy for rectal cancer: a multicenter prospective observational study. Ann Surg,253(1): 71-77.

20. Rutten HJ, den Dulk M, Lemmens VE, van de Velde CJ, Marijnen CA. Controversies of total mesorectal excision for rectal cancer in elderly patients. Lancet Oncol 2008;9(5): 494-501.

21. Seierstad T, Hole KH, Saelen E, Ree AH, Flatmark K, Malinen E. MR-guided simultaneous integrated boost in preoperative radiotherapy of locally advanced rectal cancer following neoadjuvant chemotherapy. Radiother Oncol 2009;93(2): 279-284.

22. Crane CH, Eng C, Feig BW, Das P, Skibber JM, Chang GJ, Wolff RA, Krishnan S, Hamilton S, Janjan NA, Maru DM, Ellis LM, Rodriguez-Bigas MA. Phase II trial of neoadjuvant bevacizumab, capecitabine, and radiotherapy for locally advanced rectal cancer. Int $J$ Radiat Oncol Biol Phys 2010;76(3): 824-830.

23. Pinto C, Di Fabio F, Maiello E, Pini S, Latiano T, Aschele C, Garufi C, Bochicchio A, Rosati G, Aprile G, Giaquinta S, Torri V, Bardelli A, Gion M, Martoni A. Phase II study of panitumumab, oxaliplatin, 5-fluorouracil, and concurrent radiotherapy as preoperative treatment in high-risk locally advanced rectal cancer patients (StarPan/STAR-02 Study). Ann Oncol 2011.

24. Dresen RC, Beets GL, Rutten HJ, Engelen SM, Lahaye MJ, Vliegen RF, de Bruine AP, Kessels AG, Lammering G, Beets-Tan RG. Locally advanced rectal cancer: MR imaging for restaging after neoadjuvant radiation therapy with concomitant chemotherapy. Part I. Are we able to predict tumour confined to the rectal wall? Radiology 2009;252(1): 71-80. 



\section{CHAPTER 4}

\section{Long-term follow-up features on rectal MRI during wait-and-see policy after a clinical complete response in rectal cancer patients treated with chemoradiotherapy}

D.M.J. Lambregts M. Maas

F.C.H. Bakers

V.C. Cappendijk

G. Lammering

G.L Beets

R.G.H. Beets-Tan

Diseases of the Colon and Rectum 2011;54:1521-1528 


\begin{abstract}
Background. A wait-and-see policy instead of standard surgery for rectal cancer patients who achieve a complete tumour response after chemoradiation treatment is highly controversial. It is not clear yet how patients should be monitored once they are managed non-operatively and whether follow-up by MR imaging has any potential role. The aim was to describe the rectal wall MRI morphology during short-term and long-term follow-up in patients with a clinical complete tumour response undergoing a wait-and-see policy without surgical treatment.
\end{abstract}

Methods. As part of an observational study in our center, a cohort of 19 carefully selected patients with a clinical complete response after chemoradiation was managed with a wait-and-see policy and followed regularly (3-6 monthly) by clinical examination, endoscopy + biopsies and a rectal MRI. The MR morphology of the tumour bed was studied on the consecutive MR examinations. The main outcome measure was the morphology of the tumour bed on the consecutive MRI examinations performed during short-term ( $\leq 6$ months) and long-term (> 6 months) follow-up.

Findings. Patients with a complete tumour response after chemoradiation presented with either a normalised rectal wall (26\%) or fibrosis (74\%). In the latter group, three patterns of fibrosis were observed (full thickness, minimal or spicular fibrosis). The morphology patterns of a normalised rectal wall or fibrosis remained consistent during long-term follow-up in 18/19 patients. One patient developed a small, endoluminal recurrence, which was salvaged with transanal endoscopic microsurgery. In $26 \%$ of patients an edematous wall thickening was observed in the first months after chemoradiation, which gradually decreased during long-term follow-up. Median follow-up was 22 months (range 12-60).

Conclusions. Four MR patterns of a persistent complete response of rectal cancer after chemoradiation were identified. These MR features can serve as a reference for the follow-up in a wait-and-see policy. 


\section{Introduction}

The standard treatment for patients with locally advanced rectal cancer consists of a long course of neoadjuvant chemoradiation (CRT) followed by surgical resection. ${ }^{1}$ In recent years there is a highly controversial trend to opt for more conservative, organsaving treatments in patients who show a very good response to neoadjuvant treatment. ${ }^{2-4}$ Observational cohort studies have shown that a wait-and-see policy can be a good alternative to surgery without compromising the outcome in carefully selected patients with clinical evidence of a complete response of both the tumour and lymph nodes. ${ }^{2,5,6}$ There are, however, several issues that need to be addressed in this clinical context. First, it is yet unclear which clinical selection method is the most accurate for identification of clinical complete responders after CRT and whether and how imaging can be of additional benefit. For this purpose ongoing studies are evaluating the potential role of tumour markers, endoscopy +/- biopsies and morphological and functional imaging techniques. ${ }^{7-13}$ Second, there is no evidence yet as to how and how frequently patients should be monitored once they are managed non-operatively. Third, even if imaging proves to be beneficial for the selection and monitoring of the complete responders, information on morphological changes that may occur during long-term follow-up imaging is lacking, making it difficult to understand which of these changes could be indicative of tumour re-growth.

The aim of this study was to establish (changes in) the MR morphology of the rectum in patients with a complete tumour response after non-operative management and follow-up with MRI. The study describes the evolution of tumour morphology on MRI during short-term ( $\leq 6$ months) and long-term ( $>6$ months) follow-up in patients with a clinical complete response who chose a wait-and-see policy in our unit. To the best of our knowledge this is the first report on this subject. We aim to share the MR characteristics of these patients at the moment of their selection (6-8 weeks after completion of CRT) and at regular MRI performed during their clinical follow-up.

\section{Methods}

\section{Study design}

In our unit patients with locally advanced rectal cancer are routinely treated with a preoperative long course of neoadjuvant chemoradiation (50.4 Gy radiation $+2 \times 825$ $\mathrm{mg} / \mathrm{m}^{2} / \mathrm{d}$ capecitabine) when on primary staging MRI there is [1] a T3-4 tumour with a threatened or involved mesorectal fascia, [2] $>3$ metastatic lymph nodes, and/or [3] tumour in the distal rectum ( $\leq 5 \mathrm{~cm}$ from the anorectal junction). Since 2004, in addition to standard rectal cancer surgery, an alternative wait-and-see approach has been offered to rectal cancer patients who show a clinical complete response (ycToNo) after CRT. The response after chemoradiation was assessed with a combination of MRI, endorectal ultrasound, digital examination and endoscopy with biopsies. Patients 
were identified as complete responders when there was [1] substantial tumour downsizing with no residual tumour or with fibrosis only on restaging MRI performed 6-8 weeks after CRT, [2] no suspicious nodes on post-chemoradiation MRI, [3] no residual tumour at endoscopy with negative biopsies, and [4] no palpable tumour at digital rectal examination when palpable at primary presentation. The evaluation of response and the diagnosis of a clinically complete response was established 6-8 weeks after completion of chemoradiation treatment. Patients with a complete response who were offered a wait-and-see policy were well informed on the controversial and investigational nature of this non-operative approach and the associated benefits and risks. All but one patients who were offered the wait-and-see policy chose the wait-andsee policy, mainly because of the opportunity to avoid major surgery and the potential risk of a permanent colostomy. Patients were monitored 3-monthly during the first year and 6-monthly during the following years with clinical examination, serial carcinoembryonic antigen (CEA) measurements, CT for evaluation of distant metastases and endoscopy and rectal MRI for evaluation of local recurrence.

Repetition time / echo time (ms)
Number of slices
$\begin{aligned} & \text { Slice thickness } \\ & \text { Slice gap }\end{aligned}$
$\begin{aligned} & \text { Flip angle (degrees) } \\ & \text { In plane resolution (mm x mm) }\end{aligned}$
$\begin{aligned} & \text { Echotrain length } \\ & \text { Number of signal averages (NSA) }\end{aligned}$
$\begin{aligned} & \text { Acquisition time (min) } \\ & \text { Table 1. 'Standard' rectal MRI protocol: T2W FSE in 3 planes. }\end{aligned}$
$\begin{aligned} & \text { Patients were imaged at 1.5T (Intera; Philips Medical Systems, Best, The Netherlands), using a } \\ & \text { phased array surface coil. Patients did not receive a bowel preparation or spasmolytics. At primary } \\ & \text { staging, the axial images were angled perpendicular to the tumour axis as identified on the sagittal } \\ & \text { MRI. The coronal images were angled parallel to the tumour axis. For the follow-up MRIs, the } \\ & \text { imaging planes from the primary staging MRI were repeated in order to obtain identical imaging } \\ & \text { planes. }\end{aligned}$

\section{MR imaging and image evaluation:}

Patients underwent a standard pelvic MRI (1.5T) as routinely used for the clinical staging of rectal cancer patients. The protocol is described in table 1. As part of ongoing research, patients underwent an additional diffusion-weighted MR sequence (STIR fatsupression, b-values $0,500,1000 \mathrm{~s} / \mathrm{mm}^{2}$, TR/TE $4829 / 70 \mathrm{msec}$, EPI factor 53,4 $\mathrm{NSA}, 2.50 \times 3.11 \times 5.00 \mathrm{~mm}$ acquisition voxel size, 50 slices, 10.37 minutes acquisition 
time). For each patient, the morphology of the tumour was evaluated on the primary staging MRI. The aspect of the tumour bed after chemoradiation was examined on the first restaging MRI performed 6-8 weeks after completion of CRT and on each consecutive follow-up MRI (3-monthly during the first year of follow-up and 6 monthly during the following years). All MR images were evaluated by an experienced pelvic MR reader, who recorded the size/volume, shape, aspect of the border and signal intensity of the tumour area on the T2-weighted MR images. Images were compared with the earlier follow-up images to establish changes over time. On high b-value diffusion-weighted MRI, the presence (suggestive of tumour) or absence (suggestive of complete response) of high signal intensity within the tumour bed was recorded (figure 1). ${ }^{14,15}$
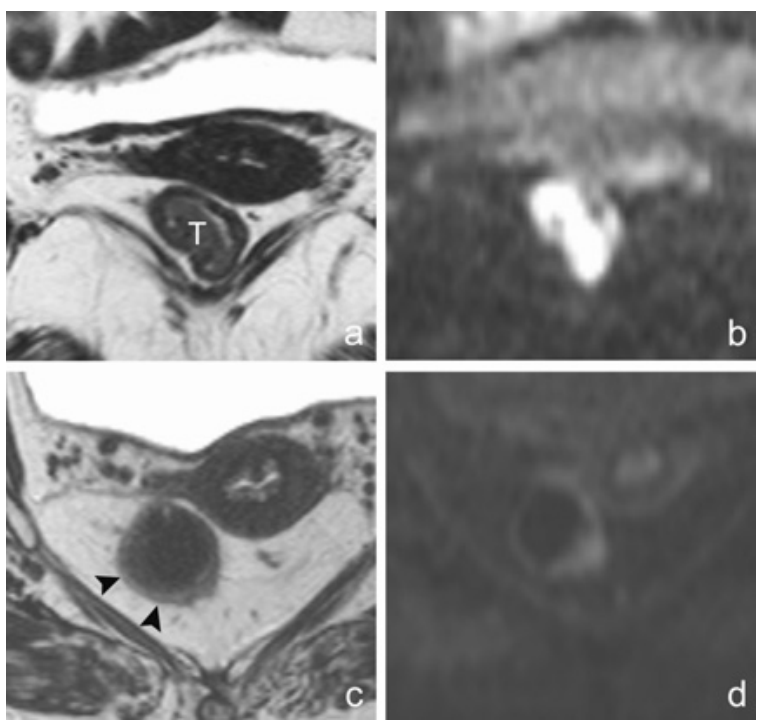

Figure 1. Diffusion-weighted MR Imaging. Axial T2-weighted (a,c) and high b-value (b1000) diffusion-weighted (b, d) images of a patient before and after chemoradiation treatment. Before chemoradiation, a tumour (T) showing intermediate signal intensity is visible on T2-weighted MRI (a). On the corresponding diffusion image (b) the tumour can be identified as a clearly defined area of high signal intensity compared to the low signal intensity of the surrounding tissues. After chemoradiation, a normalised two-layered rectal wall (arrowheads) is visible on T2-weighted MRI (c) and no residual tumour can be detected. On the corresponding diffusion image (d) there is no remaining high signal intensity and the patient was identified as having undergone a complete response. 


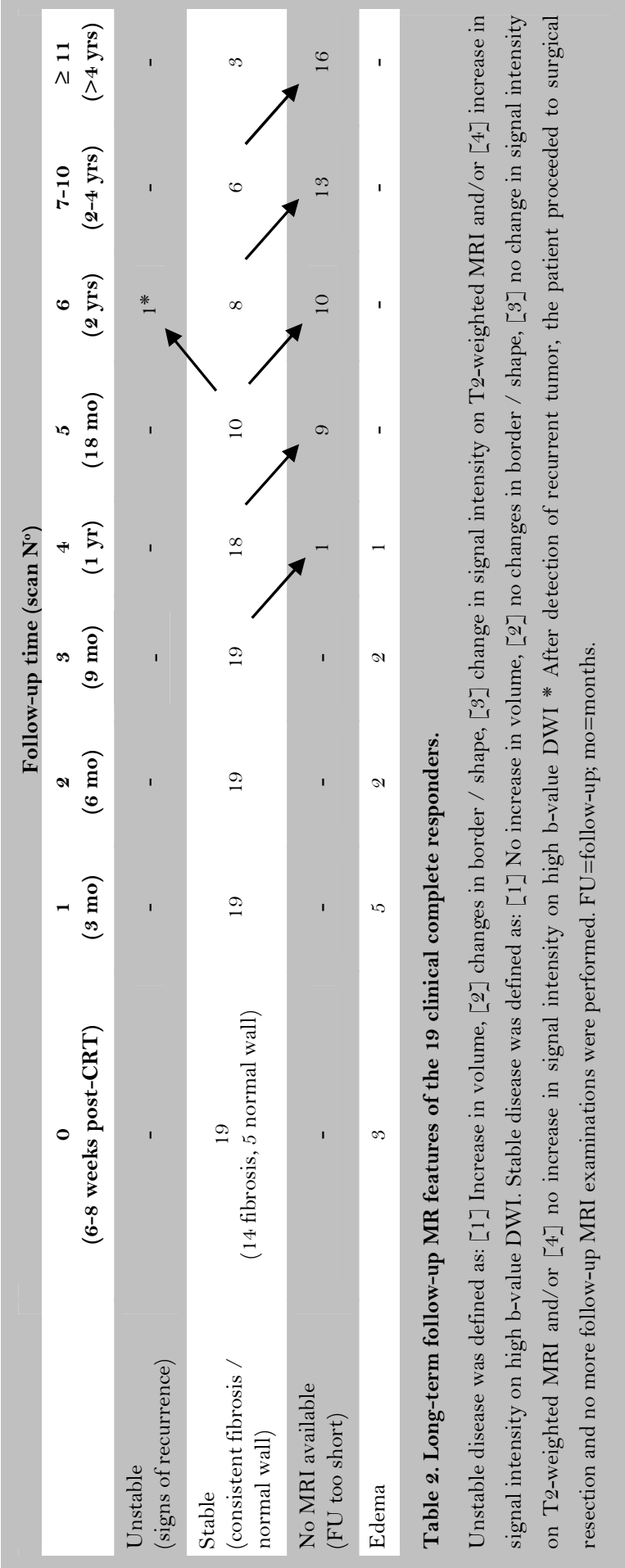




\section{Results}

\section{The study group}

So far, nineteen patients have chosen the non-operative approach and are being followed within a defined study protocol. ${ }^{5}$ The initial tumour stage at primary presentation consisted of cT1-2 in five patients, cT3 in twelve patients and cT4 in two patients. The $\mathrm{cN}$ stage was $\mathrm{No}$ in five patients, $\mathrm{N}_{1}$ in four patients and $\mathrm{N}_{2}$ in ten patients. In thirteen patients the initial tumour was located $<5 \mathrm{~cm}$ from the anorectal junction, in five patients it was located $5-10 \mathrm{~cm}$ from the anorectal junction and in one patient $>10 \mathrm{~cm}$ from the anorectal junction. At the time of writing, the follow-up period ranged between 12 and 60 months (median follow-up 22 months) and the number of follow-up MR examinations ranged accordingly between 3 and 11 (table 2).

\begin{tabular}{|c|c|c|c|c|c|}
\hline & \multicolumn{4}{|c|}{ Post-CRT (6-8 weeks after completion of CRT) } & \multirow[b]{3}{*}{ TOTAL } \\
\hline & & Fibrosis & & No Fibrosis & \\
\hline & Minimal & Full thickness & Irregular & $\begin{array}{c}\text { Normalised wall } \\
\text { wawall wall }\end{array}$ & \\
\hline \multirow{3}{*}{ 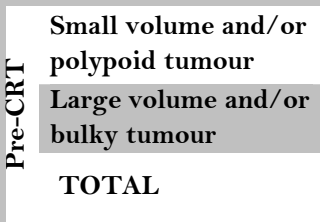 } & $6(32 \%)$ & $\mathrm{O}(0 \%)$ & $1(5 \%)$ & $2(10 \%)$ & $9(43 \%)$ \\
\hline & $1(5 \%)$ & $3(16 \%)$ & $3(16 \%)$ & $3(16 \%)$ & $10(57 \%)$ \\
\hline & $7(37 \%)$ & $3(16 \%)$ & $4(21 \%)$ & $5(26 \%)$ & $\begin{array}{c}19 \\
(100 \%)\end{array}$ \\
\hline \multicolumn{6}{|c|}{$\begin{array}{l}\text { Table 3. Pre- and post-chemoradiation MR morphology of } 19 \text { patients with a clinical complete } \\
\text { response. } \\
\text { Small volume and/or polypoid tumours were defined as T1-2 or borderline T3 tumours with a } \\
\text { maximum tumour length of }<5 \mathrm{~cm} \text {. Large volume and/or bulky tumours were defined as T3 or T4 } \\
\text { tumours with a maximum tumour length of } \geq 5 \mathrm{~cm} \text {. }\end{array}$} \\
\hline
\end{tabular}

\section{MRI findings at short-term ( $\leq 6$ months) follow-up:}

Generally, four distinct groups of MR features could be identified at short-term follow-up (table 3). In 14 of the 19 patients (74\%), at least some area of dark signal intensity was shown on the first MRI performed 6-8 weeks after completion of CRT in the irradiated tumour bed, suggestive for fibrosis. Three patterns of fibrosis could be distinguished, the aspects of which depend on the initial tumour morphology at primary MR staging (figure 2). The fourth pattern, which was observed in 5 of the 19 patients (26\%), consisted of a completely normalised rectal wall. At endoscopy, patients typically showed either a normalised rectal wall or a small white area of scar tissue at the location of the former tumour (figure 3). 

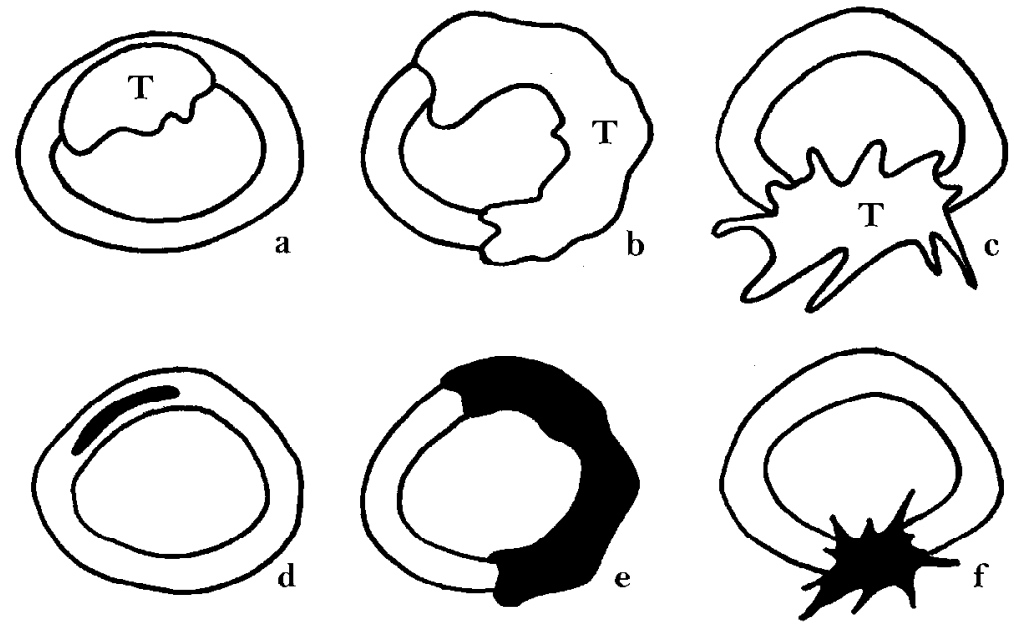

Figure 2. Patterns of fibrosis. Schematic view of three types of tumours $(\mathrm{T})$ before treatment (a-c) and the corresponding patterns of fibrosis (d-f) that were frequently observed after chemoradiation treatment. In patients with relatively small, often polypoid tumours (a), minimal areas of residual fibrosis were mostly observed after CRT, which remained limited to the bowel wall (d: 'minimal fibrosis'). In patients with more bulky tumours, mostly extending over $50 \%$ of the rectal circumference (b), the tumours often underwent massive fibrotic changes, but showed a relatively small decrease in volume (e: 'full thickness fibrosis'). In patients with more irregular, spiculated tumour types (c), varying degrees of volume reduction were observed. The fibrotic residue remained ill-defined and spiculated, similar to the aspect of the primary tumour (f: 'irregular fibrosis').
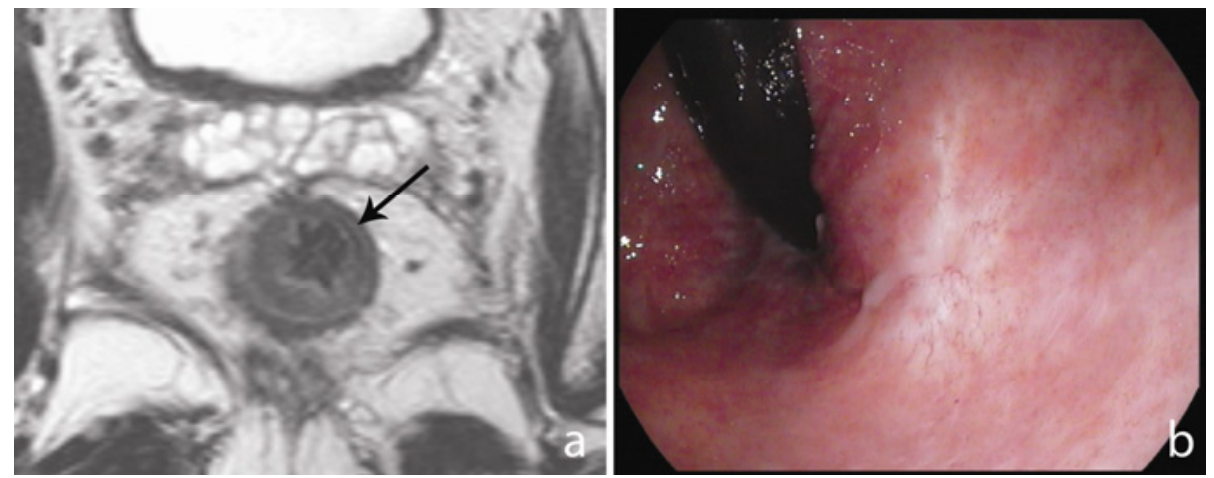

Figure 3. Typical white scar at endoscopy. Axial T2-weighted MR image (a) and corresponding endoscopic view (b) of a patient, managed with a wait-and-see policy, at 1 year after completion of chemoradiation treatment. On the MRI a small fibrotic rim is visible within the rectal wall (arrow). At the corresponding endoscopy, a typical area of white scar tissue is visualised at the location of the former tumour. 


\section{Pattern 1: 'Minimal' fibrosis}

Relatively small volume and/or polypoid tumours (cT1-2 or borderline T3, tumour length $<5 \mathrm{~cm}$ ) predominantly showed a marked decrease in tumour volume. On the restaging scan performed (6-8 weeks) after CRT these tumours typically regressed to a minimal area of residual fibrosis which remained restricted within the layers of the rectal wall, causing minimal local thickening of the rectal wall (figure 4). This type of 'minimal' fibrosis was observed in 7/19 (37\%) of the patients.
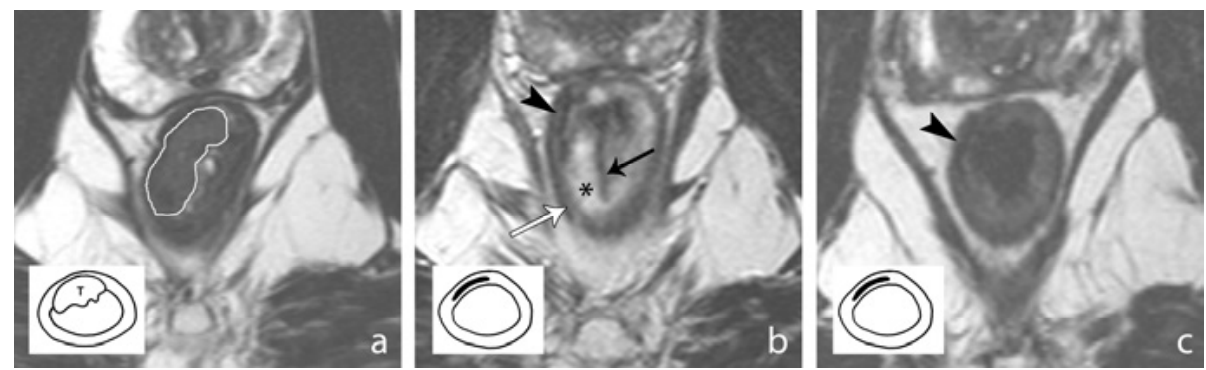

Figure 4. 'Minimal fibrosis' during short-term and long-term follow-up. Axial T2-weighted MR images of a rectal cancer patient before chemoradiation treatment (a), 6-8 weeks after completion of chemoradiation treatment (b) and at two years follow-up (c). A small polypoid tumour is visible in the distal rectum before treatment (a). After chemoradiation (b) the tumour has disappeared. The rectal wall now shows some edematous thickening, which can be recognized as a three layered pattern, consisting of the inner dark layer of mucosa (black arrow), a bright layer of submucosa (*) and the outer dark layer of the muscular rectal wall (white arrow). There is also a small residual dark area of fibrosis (black arrowhead). At two years follow-up (c), the edematous thickening has disappeared and the bowel wall has turned normal, except for at the site of the tumour bed (black arrowhead), which remained dark, indicative of fibrosis.

\section{Pattern 2: 'Full thickness fibrosis'}

In three patients (16\%) with relatively bulky tumour types (T3-4, tumour length $\geq$ $5 \mathrm{~cm}$ ), often growing over a large circumference of the rectal lumen, only little reduction in tumour size was observed. The shape of the irradiated tumour bed followed that of the initial tumour and remained relatively consistent during the follow-up period. The initially grey tumour on MRI became fully dark, suggestive of fibrotic transformation of the tumour. These cases were classified as a 'full thickness' fibrotic transformation of the primary tumour (figure 5). 

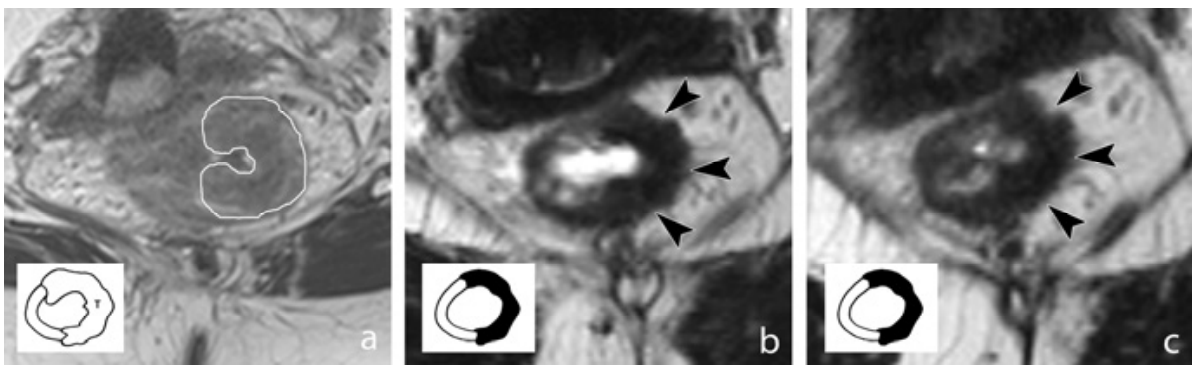

Figure 5. 'Full thickness fibrosis' during short-term and long-term follow-up. Axial T2-weighted MR images of a rectal cancer patient before chemoradiation treatment (a), 6-8 weeks after completion of chemoradiation treatment (b) and at $1 \frac{1 / 2}{2}$ year of follow-up (c). Before treatment (a) there is a tumoural thickening extending over $\pm 50 \%$ of the rectal circumference. After chemoradiation (b),only a small volume reduction has occurred and the shape of the wall thickening remained unchanged. However, the tumour has turned fully dark indicative of fibrosis (black arrowheads). At 1 1/2 year follow-up (c) the fibrotic area remained unchanged and showed only a very subtle further decrease in volume.

\section{Pattern 3: 'Irregular fibrosis'}

In four patients $(21 \%)$ with irregularly shaped, spiculated and ill-defined tumours (T3-4, tumour length $\geq 5 \mathrm{~cm}$ ), varying degrees of volume reduction were observed. In some of these patients there was remarkable reduction in tumour volume, whereas in others there was only small decrease in volume. In all four patients, however, the tumour bed turned dark because of fibrosis. The initial tumour shape with irregular and spiculated borders persisted (figure 6).
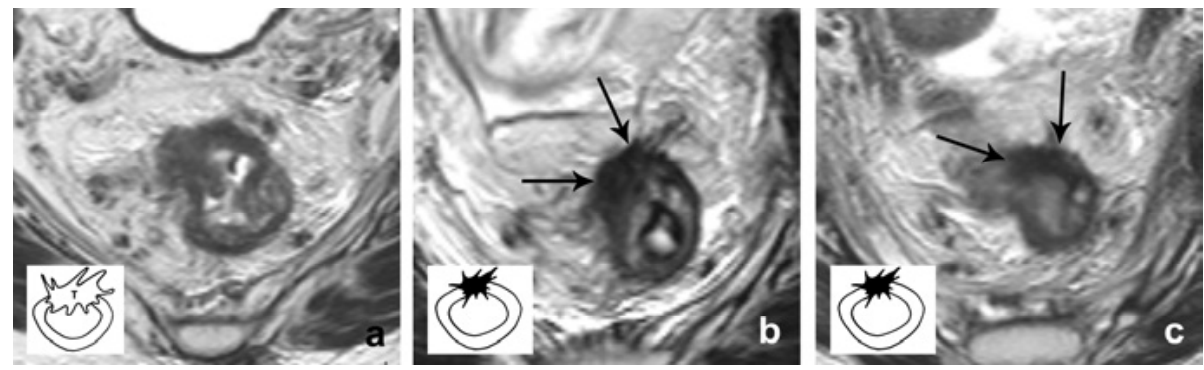

Figure 6. 'Irregular fibrosis' during short-term and long-term follow-up. Axial T2-weighted MR images of a rectal cancer patient before chemoradiation treatment (a) 6-8 weeks after completion of chemoradiation treatment (b) and at 1 year of follow-up (c). Before treatment (a) there is a tumour in the mid-rectum with irregular borders and spiculations into the mesorectal fat. After chemoradiation (b) there is hardly any volume reduction but an area of hypointense signal intensity, suggestive of fibrosis (arrows), has replaced the initially isointense tumour area. This fibrosis follows the shape of the primary tumour with irregularly shaped borders and spiculations. At 1 year of follow-up (c), the shape of the fibrotic thickening persisted and showed only minimal shrinkage. 


\section{Pattern 4: Normalised rectal wall}

In $26 \%$ of the patients the rectal wall was completely normal at MRI performed 6-8 weeks after CRT and no residual tumour mass or fibrosis was detected (figure 1). In contrast to the above mentioned patterns of fibrotic changes, in which there was a clear correlation with the initial tumour size and features at MRI before chemoradiotherapy, no such correlation was found in rectal tumours which fully disappeared after CRT. Some of these patients initially showed relatively large, bulky tumours, while others showed small polypoid tumours (table 3).

\section{MRI findings at long-term (> 6 months) follow-up}

Interestingly, in the 14 patients in whom a residual area of fibrosis was detected after CRT, the aspect of the fibrosis remained largely unaffected during long-term follow-up, the longest follow-up period at the time of writing being 60 months (table 2). No changes were observed regarding the shape, delineation or hypointense signal intensity of the fibrotic areas during repeated follow-up MRIs and a further volume decrease - if any - was only very subtle. In the patients in whom the tumour vanished at MRI and the rectal wall normalized, this normal wall persisted on consecutive MRIs at longer follow-up and no long term evolution into fibrosis was observed (table 3).

\section{Edema}

In the first months after completion of chemoradiation treatment, a small group $(5 / 19 ; 26 \%)$ of the patients showed an edematous rectal wall, visible as a characteristic three layered pattern of dark mucosa, bright submucosa and dark muscular wall. In all patients the edematous thickening gradually decreased during the remaining follow-up period (figure 4).

\section{Persistent complete response versus recurrent tumour}

One patient from the study group developed a small endoluminal recurrence after 22 months of follow-up (table 2). Endorectal ultrasound indicated a T1 tumour and the patient was salvaged with transanal endoscopic microsurgery. At present, this patient is disease free, but only with a follow-up of 2 months after the procedure. For illustrative purposes, we report on two additional patients outside the study group in whom the tumour locally recurred after respectively 17 and 24 months of follow-up. These two patients were not part of the study group as they presented with synchronous distant (liver) metastases at their initial diagnosis. They both received a long-course of neoadjuvant chemoradiation after which they were curatively treated for their liver metastases. On the restaging MRI performed 6-8 weeks after completion of CRT, a dark area of fibrosis was visible in the irradiated tumour bed and no residual tumour could be detected. Both patients chose not to undergo TME surgery. During their long-term follow-up the volume of the previously fibrotic tumour bed increased and the signal intensity changed from black (indicating fibrosis) to grey (indicating tumour) on the T2-weighted MR images. In addition, areas of high signal intensity, 
indicative of recurrent tumour, developed on the diffusion-weighted images (figure 7). In the patient with the small local recurrence in the wait-and-see study group, the T2weighted MR images did not yet reveal any significant changes in the morphology of the rectal wall. The diffusion-weighted MRI, however, showed a small area of high signal intensity, compatible with the tumour recurrence.
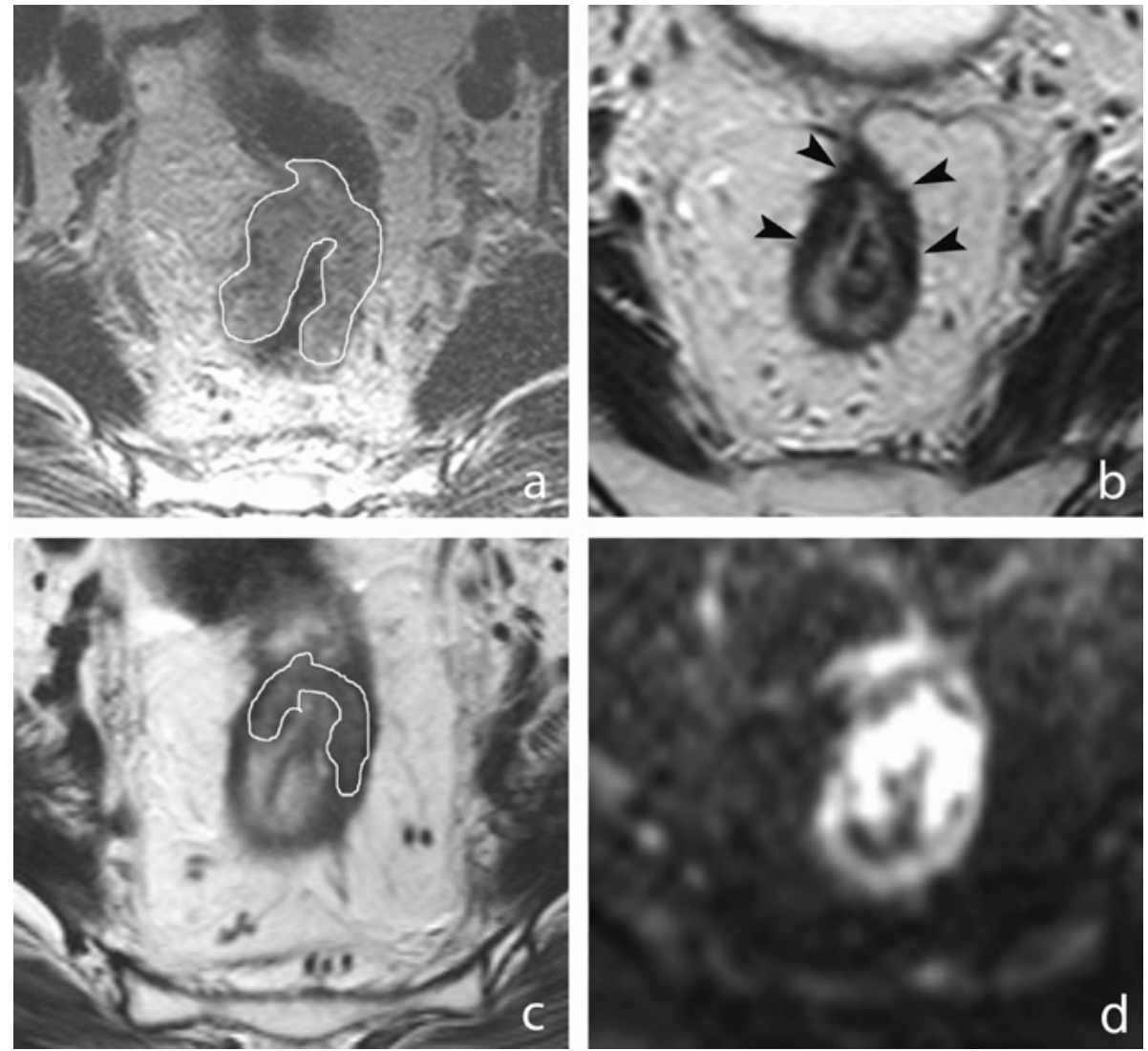

Figure 7. Local tumour recurrence during follow-up. Axial MR images of a patient who was nonoperatively managed but developed a local recurrence during follow-up. The pretreatment T2-weighted MRI (a) shows a grey tumour in the proximal rectum. After chemoradiation, the tumour shrunk and the rectal wall turned fibrotic (b). After two years of follow-up, a grey mass was again visible within the previously fibrotic tumour bed (c), suggestive of a recurrent tumour. On the corresponding high b-value diffusion-weighted MR image (d), the recurrent tumour could easily be recognised as an area of markedly high signal intensity. The presence of recurrent adenocarcinoma was proven by tumour biopsy. 


\section{Discussion}

In many countries, MRI is part of the standard workup for the staging of rectal cancer at primary diagnosis. ${ }^{1}$ In recent years patients with locally advanced rectal cancer who receive preoperative chemo and/or radiation therapy have shown phenomenal response with downstaging and downsizing of the tumour. This opens the debate whether a resection is still necessary in all patients. It is in this setting that a restaging MRI after chemoradiation could be helpful. Until now, the main aim of a restaging MRI has been to provide the surgeon a roadmap to determine his resection plane and to decide whether a less extensive resection can be performed in tumours that have regressed from the mesorectal fascia. ${ }^{16}$ Given the current trend towards minimally invasive treatments for the good responders after CRT, a more precise imaging assessment of response is mandatory in order to improve the selection of these patients and the response monitoring at follow-up. Although selection of patients is generally based on clinical examination and endoscopy with biopsy, imaging could help in increasing the confidence for appropriate selection of the right patients. In our hospital the imaging method used for restaging is MRI. In addition to a restaging MRI shortly after CRT, the study protocol of a wait-and-see approach for a clinical complete tumour response with frequent follow-up ${ }^{5}$ allowed us to also monitor the evolution of MR features during long-term follow-up. We believe that all multidisciplinary team members, including colorectal surgeons, need to understand the MR images and patterns of response.

This study aimed at describing and illustrating the evolution of the tumour bed on consecutive MRIs in a selected group of rectal cancer patients with a clinical complete tumour response after chemoradiation who were managed with a wait-and-see policy. The MRI of the rectum in these patients at the moment of their selection (6-8 weeks after completion of CRT) and the period thereafter showed interesting evolution patterns. The MR morphology of the complete tumour responders 6-8 weeks after CRT was typically that of either a dark fibrotic wall thickening or, in a smaller number of patients, a normalised rectal wall. Given the difficulties of MRI in the interpretation of fibrosis, the feature of a normalised wall on post-CRT MR images will likely be the criterion with the highest positive predictive value for identifying a complete response by imaging. In our study, there was no clear correlation between the initial tumour morphology before treatment and the chance of a completely normalised rectal wall after CRT. It may be that in some tumours the biological tumour profile rather than the morphological characteristics determines the way the tumour will react to chemoradiation. In contrast, the morphological pattern of the fibrotic areas did follow that of the primary tumour before onset of treatment. These patterns could be categorized as 'full thickness', 'minimal' or 'irregular' fibrosis and remained consistent over the years. When the tumour has completely disappeared and the wall returned normal after post-CRT MRI, this normal wall persisted over the years. When during the first months after CRT the wall showed an edematous thickening, this edema 
gradually disappeared during longer follow-up. All together, if the morphology (normalised wall or fibrosis) as identified on the first restaging MRI remained consistent during long-term follow-up, this could be considered a sign of a persistent complete response. Although our study was not designed to systematically compare patients with a complete response to patients with recurrent tumour, we did find that in patients with recurrent disease, areas of intermediate signal intensity began to develop within the fibrotic scar bed on the T2-weighted images. This is in concordance with previous reports that showed that the development of areas of intermediate signal intensity during follow-up was predictive for the presence of a local tumour recurrence. ${ }^{17,18}$ The small recurrence in the wait-and-see patient was noted on diffusionweighted MRI as a newly developed area of high signal intensity, while the T2weighted images did not yet reveal any significant changes in morphology. It has previously been suggested that diffusion-weighted MRI may be superior to conventional MRI in the detection of (small) malignant tumours, particularly within areas of post-radiation fibrosis. ${ }^{14,15,19}$ Diffusion-weighted MRI could thus be a valuable adjunct to standard imaging in the detection of recurrent tumour during the nonoperative follow-up of rectal cancer patients, although the true value of DWI in this particular clinical setting will need to be addressed by further studies.

There are some limitations to our study design. First, a 'definite' histological diagnosis of a complete response could not be obtained since none of the patients underwent surgical resection. In the clinical setting of a wait-and-see approach, the usual gold standard of histology is inherently not available, and an extensive clinical follow-up as applied in our study may serve as a surrogate reference standard. Ideally the follow-up period should have been at least 2 years for all patients, given the fact that the majority of tumour recurrences are known to likely occur within the first two years after treatment. ${ }^{20}$ Our results should therefore be considered preliminary and larger patient groups with longer follow-up are required in order to draw more definite conclusions. Second, the aim of our study was to study the evolution of the MR morphology of patients with a known complete response and not to study the potential of MRI in the initial identification and selection of complete responders, which has already been the subject of previous studies, including a study from our center. ${ }^{14,15}$

\section{Conclusion}

four MR patterns of a persistent complete response of rectal cancer after chemoradiation are identified. These MR features can serve as a reference for the follow-up of patients treated with a wait-and-see policy. 


\section{References}

1. Glimelius B, Oliveira J. Rectal cancer: ESMO clinical recommendations for diagnosis, treatment and follow-up. Ann Oncol. 2009; 20 (Suppl 4):54-56.

2. Habr-Gama A, Perez RO, Proscurshim I, et al. Patterns of failure and survival for nonoperative treatment of stage co distal rectal cancer following neoadjuvant chemoradiation therapy. $J$ Gastrointest Surg 2006; 10:1319-1328; discussion 1328-1319.

3. Lezoche G, Baldarelli M, Guerrieri M, et al. A prospective randomized study with a 5-year minimum follow-up evaluation of transanal endoscopic microsurgery versus laparoscopic total mesorectal excision after neoadjuvant therapy. Surg Endosc 2008; 22:352-358.

4. Borschitz T, Wachtlin D, Mohler M, Schmidberger H, Junginger T. Neoadjuvant chemoradiation and local excision for T2-3 rectal cancer. Ann Surg Oncol 2008; 15:712-720.

5. Maas M, Lambregts DMJ, Van Dam RM, et al. MR-based 'wait-and-see' policy in clinical complete responders to chemoradiation in rectal cancer: A promising alternative. Ann Oncol 2010; 21 (Suppl 1) :i54 [abstract].

6. Yu SK, Brown G, Heald RJ, et al. Deferral of rectal cancer surgery following a continued response to preoperative chemoradiotherapy (Watch and Wait) study: a phase II multicenter study in the United Kingdom. J Clin Oncol 2011; 29 (Suppl 4):abstr 489 [abstract].

7. Carlomagno C, Pepe S, D'Armiento FP, et al. Predictive factors of complete response to neoadjuvant chemoradiotherapy in patients with rectal cancer. Oncology; 78:369-375.

8. Kim SH, Lee JY, Lee JM, Han JK, Choi BI. Apparent diffusion coefficient for evaluating tumor response to neoadjuvant chemoradiation therapy for locally advanced rectal cancer. Eur Radiol 2011; 21:987-995

9. Kim DJ, Kim JH, Lim JS, et al. Restaging of Rectal Cancer with MR Imaging after Concurrent Chemotherapy and Radiation Therapy. Radiographics 2010; 30:503-516.

10. Barbaro B, Vitale R, Leccisotti L, et al. Restaging locally advanced rectal cancer with MR imaging after chemoradiation therapy. Radiographics 2010; 30:699-716.

11. Habr-Gama A, Perez RO, Wynn G, Marks J, Kessler H, Gama-Rodrigues J. Complete clinical response after neoadjuvant chemoradiation therapy for distal rectal cancer: characterization of clinical and endoscopic findings for standardization. Dis Colon Rectum 2010; 53:1692-1698.

12. Janssen MH, Ollers MC, Riedl RG, et al. Accurate Prediction of Pathological Rectal Tumor Response after Two Weeks of Preoperative Radiochemotherapy Using (18)F-FluorodeoxyglucosePositron Emission Tomography-Computed Tomography Imaging. Int J Radiat Oncol Biol Phys 2010;7 7:392-399.

13. van Stiphout RG, Lammering G, Buijsen J, et al. Development and external validation of a predictive model for pathological complete response of rectal cancer patients including sequential PET-CT imaging. Radiother Oncol 201 1; 98:126-133.

14. Kim SH, Lee JM, Hong SH, Kim GH, Lee JY, Han JK, Choi BI. Locally advanced rectal cancer: added value of diffusion-weighted MR imaging in the evaluation of tumor response to neoadjuvant chemo- and radiation therapy. Radiology 2009; 253:116-125

15 Lambregts DM, Vandecaveye V, Barbaro B, et al. Diffusion-weighted MRI for selection of complete responders after chemoradiation for locally advanced rectal cancer: a multicenter study. Ann Surg Oncol 2011; Feb 23 [ePub ahead of print, DOI 10.1245/s10434-011-1607-5]

16. Vliegen RF, Beets GL, Lammering G, et al. Mesorectal fascia invasion after neoadjuvant chemotherapy and radiation therapy for locally advanced rectal cancer: accuracy of MR imaging for prediction. Radiology 2008; 246:454-462. 
17. Blomqvist L, Holm T, Göranson H, Jacobsson H, Ohlsén H, Larsson SA. MR imaging, CT and CEA scintigraphy in the diagnosis of local recurrence of rectal carcinoma. Acta Radiol 1996; 37:779-784

18. Lambregts DM, Cappendijk VC, Maas M, Beets GL, Beets-Tan RGH. Value of MRI and diffusionweighted MRI for the diagnosis of locally recurrent cancer. Eur Radiol 201 1; 21:1250-1258

19. Nishie A, Stolpen AH, Obuchi M, Kuehn DM, Dagit A, Andresen K. Evaluation of locally recurrent pelvic malignancy: performance of T2- and diffusion-weighted MRI with image fusion. J Magn Reson Imaging 2008; 28:705-713

20. Habr-Gama A, Perez RO, Nadalin W, et al. Operative versus nonoperative treatment for stage 0 distal rectal cancer following chemoradiation therapy: long-term results. Ann Surg 2004; 240:711717 ; discussion $717-718$ 

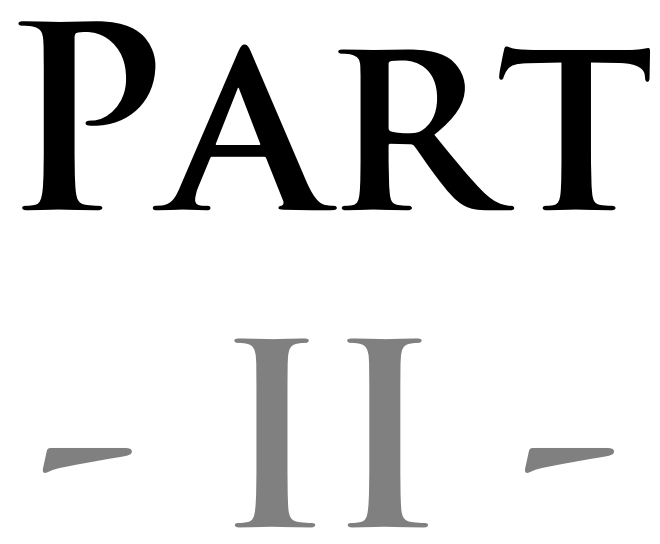

Paradigm shift from local to distant control 



\title{
CHAPTER 5
}

\section{Modern multidisciplinary treatment of rectal cancer based on staging with MRI leads to excellent local control, but distant control remains a challenge}

\author{
M. Maas* \\ S.M.E. Engelen* \\ M.J. Lahaye \\ J.W.A. Leijtens \\ C.L.H. van Berlo \\ R.L.H. Jansen \\ S.O. Breukink \\ C.H.C. Dejong \\ C.J. van de Velde \\ R.G.H. Beets-Tan \\ G.L. Beets
}

* authors contributed equally to the manuscript and therefore share first authorship

Accepted for publication by European Journal of Cancer 


\begin{abstract}
Background. The purpose of this multicenter cohort study was to evaluate whether tailor-made treatment of primary rectal cancer based on MRI can reduce the number of incomplete resections and local recurrences and improve recurrence-free and overall survival.

Methods. From February 2003 until January 2008296 patients were enrolled. All underwent preoperative MRI using a lymph node specific contrast agent to predict CRM, T- and N-stage. Based on expert reading of the MRI, patients were stratified in different risk groups for local recurrence: (a) low risk (CRM >2mm and No status), (b) intermediate risk and (c) high risk (close/involved CRM, N2 status or distal tumours). Mainly based on this MRI risk assessment patients were treated with (a) surgery only (TME or local excision), (b) preoperative 5x5 Gy + TME, and (c) a long course of chemoradiation therapy followed by surgery after a 6-8 week interval. The number of complete resections (CRM $>1 \mathrm{~mm}$ ) was determined by histopathological evaluation of the resection specimen.
\end{abstract}

Findings. Overall 228 patients underwent treatment with curative intent: 49 with surgery only, 86 with 5x5 Gy and surgery and 93 with chemoradiation and surgery. The number of complete resections was 218 (95.6\%). At a median follow-up of 41 months the 3 - year local recurrence rate, disease-free survival rate and overall survival rate is $2.2 \%, 80 \%$ and $84.5 \%$ respectively.

Conclusions. With a differentiated multimodality treatment based on dedicated preoperative MR imaging, local recurrence is no longer the main problem in rectal cancer treatment. The new challenges are early diagnosis and treatment, reducing morbidity of treatment and preferably prevention of metastatic disease. 


\section{Introduction}

In the past decades studies have shown that the risk for recurrence after resection of rectal cancer is substantially reduced with the surgical technique of the Total Mesorectal Excision (TME). In this technique, popularized by Heald, the tumour is removed as a complete package including the surrounding mesorectal fat and lymph nodes. ${ }^{1}$ Additionally, neoadjuvant (chemo)radiation has improved local control and, in some studies, survival ${ }^{2-5}$. Intensifying treatment of rectal cancer however is at the expense of treatment-induced morbidity and even mortality. Therefore, individualization of treatment taking into account characteristics such as age, comorbidity, stage and location of the tumour might provide an optimal balance between minimizing treatment related morbidity and best oncological outcome. Until now, there is however no definite evidence that the outcome is better than applying a single standard treatment for all patients. Subgroup analyses within the large randomized trials can provide clues as to what factors can be used to guide treatment decisions for individual patients. In most of the trials patients with stage I disease (T1-2No) have a negligible risk for local recurrence, and therefore do not need preoperative irradiation ${ }^{6}$. On the other hand, in patients with a combination of unfavorable characteristics like a tumour extending into the mesorectal fascia, positive lymph nodes and a very distal location, a short course of preoperative radiation and immediate surgery does not provide enough protection against local recurrence, and a long course of preoperative chemoradiation is required $^{2,3,6}$.

Reliable preoperative imaging is essential for a differentiated treatment according to risk factors for local recurrence. Although endorectal ultrasound is good in assessing the extent of the primary tumour in small lesions ${ }^{7}$, MRI has repeatedly shown to provide the best information on the relation of the tumour to the mesorectal fascia ${ }^{8-12}$. Assessing nodal involvement however has been suboptimal, and until now all three imaging modalities (EUS, CT and MRI) lack sufficient accuracy for clinical decisionmaking ${ }^{13}$. MRI studies with lymph node-specific contrast agents have shown promising results for prediction of nodal involvement ${ }^{14,}{ }^{15}$. This would enable MRI to assess the two most important risk factors for local recurrence: relation of the tumour to the mesorectal fascia and nodal stage.

The primary aim of our prospective cohort study was to assess the outcome as defined by the number of complete resections of a differentiated treatment protocol for rectal cancer, based on MRI. The secondary aim was the assessment of long-term outcome as defined by three-year local recurrence, disease-free and overall survival, compared to the data of the Dutch TME trial. 


\section{Methods}

\section{Patients}

Between February 2003 and January 2008 a prospective multicentre cohort study was performed in patients with primary rectal cancer in whom a differentiated treatment protocol was primarily based on MRI. In February 2003 the study started as a single centre pilot study at Maastricht University Medical Centre, and was continued as a multicentre study from December 2005 onwards $(n=117)$. Three regional hospitals joined the study: Laurentius Hospital Roermond (start of inclusion: 12-2005, n=38), St. Jans Hospital Weert (start of inclusion: 12-2005, $n=17$ ) and VieCuri Medical Center Venlo (start of inclusion: 02-2006, $\mathrm{n}=58$ ). Institutional review board approval was obtained for all hospitals. All patients gave a written informed consent.

Inclusion criteria: Histologically proven adenocarcinoma of the rectum.

Exclusion criteria: Patients were excluded from the study if they had locally recurrent rectal cancer, were pregnant, were younger than 18 years, had a contraindication for MR imaging (pacemaker, neurostimulator, insulin pump, certain vascular clips (e.g. used in brain surgery), cochlear implants, metal fragments in the eye or any other metal implant not securely fixed or electronic device), or did not give informed consent for participation. For the present analyses that include long-term outcome, patients who received palliative treatment or who had a previous or coexisting malignancy were excluded.

\section{MR imaging}

All patients underwent a pelvic MRI with standard T2W TSE sequences in 3 orthogonal directions (sagittal, axial and coronal) and an axial 3D T1W gradient echo (GRE) sequence. For nodal staging an axial T2*W GRE was performed with Ultrasmall Super Paramagnetic Iron Oxide (USPIO), a lymph node specific contrast agent). The USPIO MR contrast agent (Sinerem, Guerbet Laboratories, Roissy, France) consists of low molecular weight iron oxide coated with dextran. Sinerem was administered at a dose of $2.6 \mathrm{mg} \mathrm{Fe} / \mathrm{kg}$ by slow intravenous infusion during a period of 45 minutes, 24-36 hours before the MRI scan. No side-effects were recorded during or after infusion. Imaging was performed on a 1.0/1.5T MR scanner. Patients did not receive bowel or other preparation. Total scan time was approximately 40 minutes.

\section{Image evaluation}

All MRI scans were read by both a local radiologist and an expert reader, and evaluated for T-stage, N-stage, involvement of the mesorectal fascia and height of the tumour. USPIO images were read for the prediction of nodal status by predefined criteria based on contrast uptake, size and shape. ${ }^{16,17}$ 


\section{Treatment stratification and strategy}

In a multidisciplinary meeting the treatment plan for each individual patient was determined based on the clinical information, MR imaging of local disease and imaging for distant disease. Patients with widespread metastatic disease and/or a very poor general condition that precluded major surgery were considered for palliative treatment only, and are excluded from the present analysis. For the other patients the tumour was classified on the basis of the MR images patients as 'low', 'intermediate', and 'high' risk for local recurrence. Low risk was defined as T1-2No or T3No with a wide CRM ( $>2 \mathrm{~mm}$ ) when localized in the proximal rectum. The definition of a wide CRM was chosen on the basis of the widely recognized $1 \mathrm{~mm}$ at histology with an additional $1 \mathrm{~mm}$ safety margin to compensate for small MR measurement errors. High risk was defined as tumours with circumferential resection margin $<2 \mathrm{~mm}$, distal tumours (i.e. $<5 \mathrm{~cm}$ from the anal verge) or $\mathrm{N} 2$ status. All other tumours were considered as intermediate risk (figure 1). Generally, low risk tumours were treated with surgery only, intermediate risk tumours were treated with 5x5 Gy preoperative radiotherapy followed by surgery within one week after the last radiation fraction, and high risk tumours were treated with a long course of chemoradiation (CRT) and surgery after a 6-8 week interval.

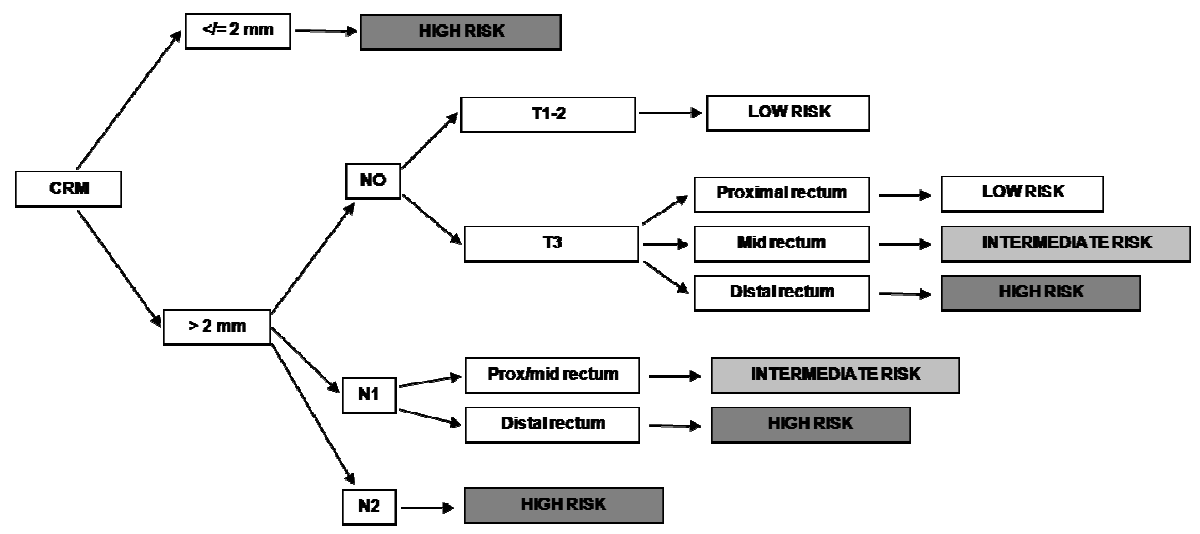

Figure 1. MRI based treatment stratification. $\mathrm{CRM}=$ circumferential resection margin.

This CRT consisted of radiation in 28 fractions of $1.8 \mathrm{~Gy}$, on weekdays combined with oral capecitabine $\left(825 \mathrm{mg} / \mathrm{m}^{2}\right.$, twice a day for seven days a week), or capecitabine with oxaliplatin (oxaliplatin $130 \mathrm{mg} / \mathrm{m}^{2}$ on day one) in patients with synchronous distant metastases. Patients underwent surgery 6-8 weeks after the last fraction of radiation therapy. One to two weeks before surgery patients underwent a new pelvic MRI, to evaluate local status as a roadmap for surgery. 
Surgery consisted of a low anterior resection or abdominoperineal resection according to the TME-principle as described by Heald ${ }^{18}$. All surgeons were trained in high quality TME surgery as a result of the widespread implementation of TME after the results of the Dutch TME trial in The Netherlands. In selected cases of early tumours a local excision (snare polypectomy or transanal endoscopic microsurgery) was performed. For locally advanced tumours, the extent of the resection was based on the MR images. For large tumours the TME sometimes had to be extended beyond the mesorectal fascia, with an en-bloc resection of surrounding organs when required. Adjuvant chemotherapy was generally considered for all locally advanced tumours treated with chemoradiation and for tumours with involved nodes at histology. Chemotherapy consisted of 6 courses of oral capecitabine $\left(1000 \mathrm{mg} / \mathrm{m}^{2}\right.$ twice daily during 2 weeks) with intravenous oxaliplatin $130 \mathrm{mg} / \mathrm{m}^{2}$ at day 1 , or capecitabine $\left(1000 \mathrm{mg} / \mathrm{m}^{2}\right)$ as monotherapy.

\section{Histological evaluation}

The resection specimen was evaluated in a standardized way, as described by Quirke $^{19}$. A complete resection (Ro) was defined as a circumferential resection margin of $\geq 1 \mathrm{~mm}$. For the patients who underwent local excision, a complete resection of the tumour at histology as well as a confirmed No status at follow-up MRI was considered a complete resection.

\section{Follow-up}

Follow-up after treatment for rectal cancer followed the national guidelines: clinical examination every 6 months for the first three years, and yearly until five years of follow-up, CEA measurements every 3 months for the first three years, and every 6 months until five years of follow-up, and liver ultrasonography or CT-scan twice yearly in the first year and yearly thereafter until five years of follow-up. For those patients who underwent a local excision, follow-up MRI was performed at least after six months and one year, in addition to endoscopic follow-up. Local recurrence, distant recurrence, death or event-free interval from the day of surgery were collected for all patients.

\section{Comparison with Dutch TME trial}

Three-year survival data and the number of complete resections were compared to the individual data of the Dutch TME trial that were provided by the Dutch TME trial group. This was considered as the best available comparison as it is a large prospective database in the setting of a randomized controlled trial and reflects the outcome of patients with rectal cancer before the widespread use of MRI. The setting for the Dutch TME trial was comparable to the set-up of the current cohort study and the inclusion and exclusion criteria are very similar. Patients who were in a palliative setting were excluded from the Dutch TME trial. A difference in selection criteria between both studies is that the present study includes all comers, including the very early tumours and the very locally advanced tumours, whereas the Dutch TME trial 
did not include these two groups. The main difference between the two studies was that local staging with MRI was not mandatory in the Dutch TME trial, and was performed only in a minority of patients. ${ }^{6}$ Because of the small but real difference in patient population the outcome results were compared without formal statistical comparison.

\section{Statistical analysis}

Baseline characteristics were prospectively collected. Postoperative course and complications were scored using the Dindo classification ${ }^{20}$. For the estimation of long term outcome Kaplan Meier survival functions were used. Local control was defined as the absence of pelvic recurrence; distant-metastasis free survival as the absence of distant metastasis outside the pelvis; disease-free survival as the absence of a local and distant recurrence and death from cancer-related cause; and overall survival survival as the absence of death from any cause. The chi-square test was used for comparison of proportions. All statistical analyses were performed using Statistical Package for the Social Sciences (SPSS) (version 16.0; SPSS, Chicago, Ill.) and STATA 11.0.

\section{Results}

Overall 296 patients were included. Of these patients, 13 were not evaluable because of MRI-related problems (artifacts, refusal) $(n=5)$ and refusal of treatment $(\mathrm{n}=8)$. Of the remaining 283 patients 5 had a previous malignancy, one had a coexisting malignancy, and 47 were not treated with a curative intent because of widespread unresectable metastatic disease $(n=46)$ and because of very poor general condition $(n=1)$.

Therefore, 230 patients could be included for this study. Sixteen of these patients presented with synchronous metastatic disease that was considered potentially curable. For these patients the three-year survival estimates are reported separately. Of the 230 included patients $134(58 \%)$ were male. Mean age $( \pm \mathrm{SD})$ was $67( \pm 10.6)$ years.

In 31 patients the actual treatment differed from the MRI based proposal. This was most often due to advanced age or poor condition of the patient, illustrated by 20 patients with a locally advanced tumour on MRI who were treated with 5x5 Gy $(n=18)$ or surgery only $(n=2)$. In 7 patients surgery without radiotherapy was chosen whereas MRI advised short course radiotherapy and 4 patients received a short course of radiotherapy whereas MRI advised surgery only. Figure 2 shows the stratification of the actual received treatment. 


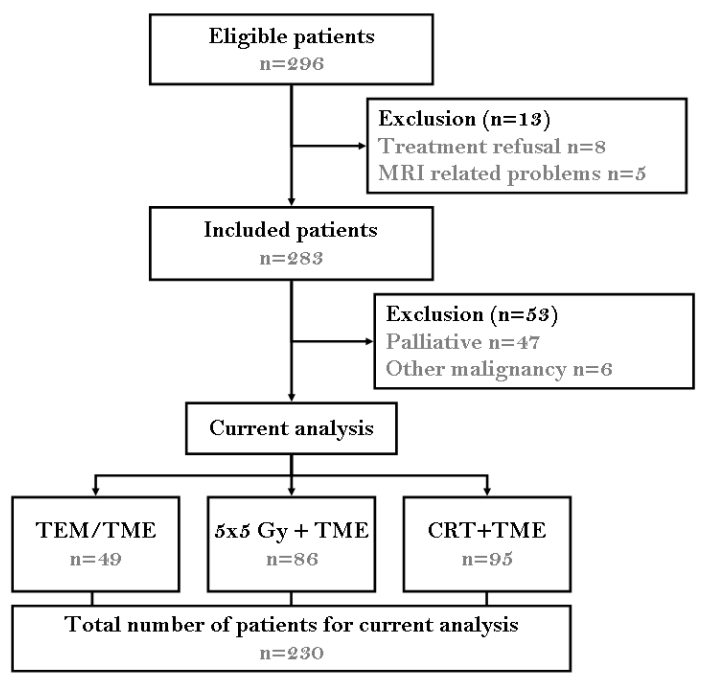

Figure 2. Flowchart of inclusion of patients. TEM=transanal endoscopic microsurgery; TME=total mesorectal excision; $\mathrm{Gy}=\mathrm{Gray}$; $\mathrm{CRT}=$ chemoradiation.

\section{Surgery and perioperative period}

Twenty-one patients underwent a local excision, 134 a low anterior resection (11 of which with an extended TME), 71 an abdominoperineal resection (25 'extended'), 1 patient a total pelvic exenteration, 1 patients a posterior pelvic exenteration and 2 patients an other resection. Furthermore, two patients had a clinical complete response to chemoradiation, confirmed by repeated biopsies and imaging. These patients preferred not to undergo surgery and are currently in a follow-up protocol. They were not included in the analysis for complete resections but were included in the analysis of long-term outcome.

All local excisions $(n=21)$ were performed during a short hospital stay of 2-3 days (TEM) or in the outpatient clinic (snare polypectomy) and were uncomplicated. For the other patients $(n=207)$, median hospital stay was 11 days (range: 4-199). There were 123 patients having one or more post-operative complications. The severity of the complications is graded using the Dindo-classification ${ }^{21}$ in table 1.

As shown in table 1, ten patients died postoperatively during their initial hospital stay (Dindo grade V), six of whom within 30 days. The postoperative mortality of all patients (including local excision) is $4.3 \%$ with a 30 -day mortality of $2.6 \%$. In 4 patients death was directly related to surgical complications, the other 6 patients died of (often multiple) systemic postoperative complications (e.g. myocardial infarction). 


\begin{tabular}{|c|c|}
\hline & $\mathbf{N}$ \\
\hline No complications & $105 / 228$ \\
\hline Grade I & $40 / 228$ \\
\hline Grade II & $22 / 228$ \\
\hline Grade III A & $9 / 228$ \\
\hline Grade III B & $37 / 228$ \\
\hline Grade IV A & $2 / 228$ \\
\hline Grade IV B & $3 / 228$ \\
\hline Grade V & $10 / 228$ \\
\hline \multicolumn{2}{|c|}{$\begin{array}{l}\text { Table 1. Surgical complications according to Dindo et al. Grade 1: any deviation from normal } \\
\text { postoperative course that does not require treatment other than antiemetics/ analgetics etc; grade } \\
\text { 2: complications requiring pharmacological treatment, e.g. urinary tract infection; grade 3: } \\
\text { complications requiring surgical/endoscopic/radiological intervention, (a) without general } \\
\text { anesthesia or (b) with general anesthesia; grade 4: Life threatening complications requiring ICU } \\
\text { admission, (a) with single organ dysfunction or (b) with multiorgan dysfunction; grade 5: } \\
\text { complications leading to death of the patient. }\end{array}$} \\
\hline
\end{tabular}

\section{Histological examination}

The number of complete resections and the distribution in the different stages at histopathological examination after surgery are shown in table 2. The number of complete resections of $95.6 \%$ is much higher than the 84.1 in the Dutch TME trial (unpublished data). The number of complete resections did not differ significantly between the treatment groups in the present trial $(p=0.201)$. An involved margin after surgery was seen in $4.4 \%$ of patients $(n=10)$, and was due to (a combination of) 1) failure in surgical technique: tumour perforation during surgery $(n=5)$ or incomplete removal of the entire mesorectum, and/or 2) surgical planning $(n=8)$ : insufficient attention to MR images after chemoradiation by the surgeon, showing a margin that was still at risk. In none of these patients the cause of the incomplete resection could be traced to an underestimation of the circumferential resection margin on MRI as described by the radiologist. The incomplete resections are summarized in table 3.

\section{Adjuvant chemotherapy}

Adjuvant chemotherapy was administered to all patients who had primary synchronous metastasis $(7 \%, 16 / 230)$. In the other patients who were treated with curative intent adjuvant chemotherapy was administered in $19 \%$ of patients treated with surgery only, in $20 \%$ of patients treated with 5x5 Gy and surgery and in $60 \%$ of the patients treated with chemoradiation and surgery. 


\begin{tabular}{|c|c|c|c|c|c|c|}
\hline & N Ro (\%) & $\mathbf{0}$ & I & II & III & IV \\
\hline Local excision/TME & $49 / 49(100)$ & $\mathrm{O}$ & 34 & 6 & 9 & $\mathrm{O}$ \\
\hline $5 \mathrm{x} 5 \mathrm{~Gy}+\mathrm{TME}$ & $82 / 86$ (95.3) & $\mathrm{O}$ & 29 & 28 & 23 & 6 \\
\hline CRT + surgery ${ }^{1,2}$ & $87 / 93(93.5)$ & 14 & 22 & 23 & 24 & 10 \\
\hline Total & $218 / 228$ (95.6) & 14 & 85 & 57 & 56 & 16 \\
\hline \multicolumn{7}{|c|}{$\begin{array}{l}\text { Table } 2 . \text { Number of complete resections and distribution of AJCC Stage at histology. } \\
{ }^{1} \text { AJCC Stage for these patients is stage after neoadjuvant therapy, ypTNM. } \\
{ }^{2} 2 / 95 \text { patients of the CRT + surgery refused surgery after CRT and were therefore left out of the } \\
\text { analysis of complete resections. }\end{array}$} \\
\hline
\end{tabular}

\section{Follow-up}

The median follow-up was 41 (0-83) months. The three-year local recurrence rate was $2.2 \%$ (95\% C.I.; 0.8-5.7\%) for all patients (figure 3), as compared to $6.2 \%$ (95\% C.I. $5.1-7.6 \%)$ from the individual data of the Dutch TME trial. The seven patients who developed a local recurrence are summarized in table 4. None of the local recurrences occurred in the group of patients with an incomplete resection.

Three-year distant-metastasis-free survival, disease-free survival and overall survival were $85.5 \%$ (95\% C.I.; $80-90 \%)$, $80.2 \%$ (74-85\%) and $84.5 \%(79-89 \%)$, respectively (see figure 3 ). Three-year survival estimates for the primary metastasized patients that were treated with curative intent were $16 \%(3-40 \%), 13 \%(2-35 \%)$ and $44 \%$ (20-66\%), respectively.

The Dutch TME trial shows a three-year distant-metastasis-free, disease-free, and overall survival of $79.1 \%$ (95\% C.I.; $77-81 \%), 76.8 \%(75-79 \%)$ and $81 \%(79-83 \%)$ respectively. Given the fact that in the Dutch TME trial locally very advanced tumours were excluded whereas they were included in the present study, there is a suggestion that the overall results have improved with the current MRI based strategy. 


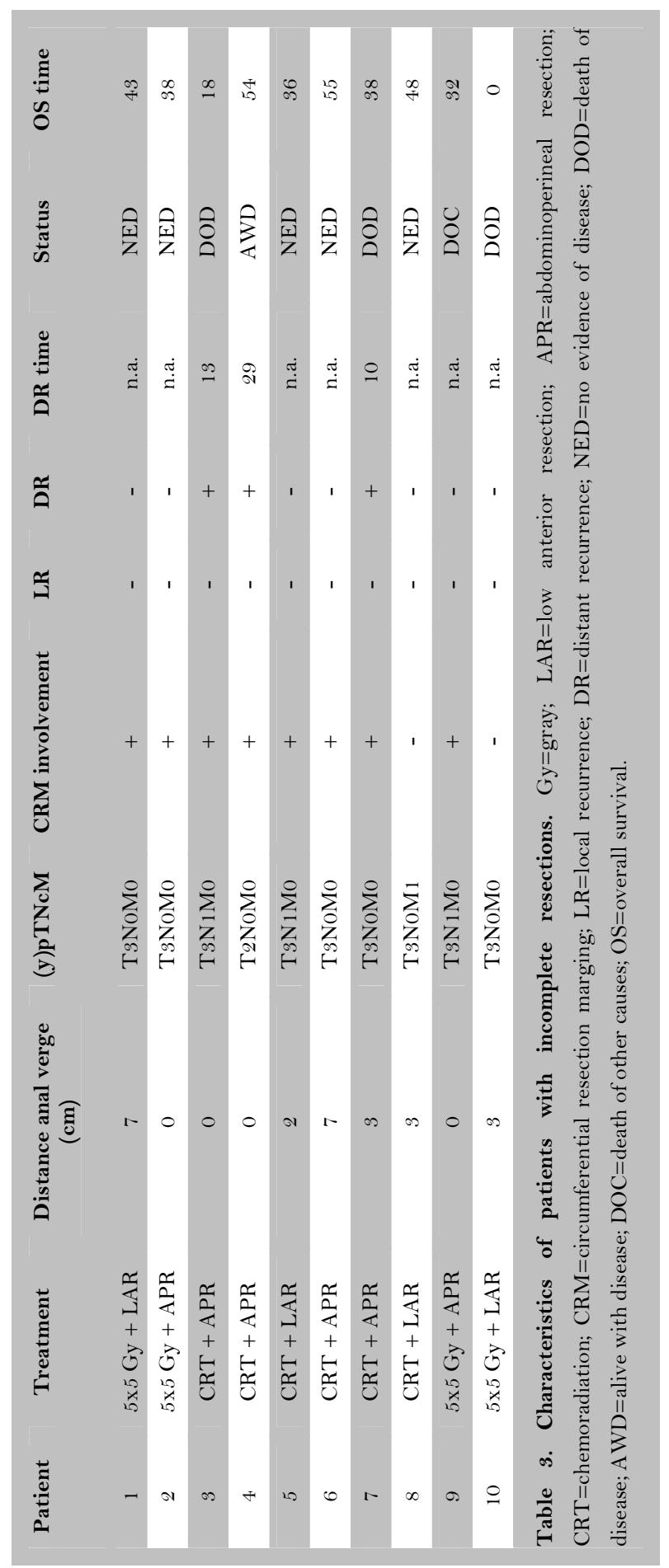




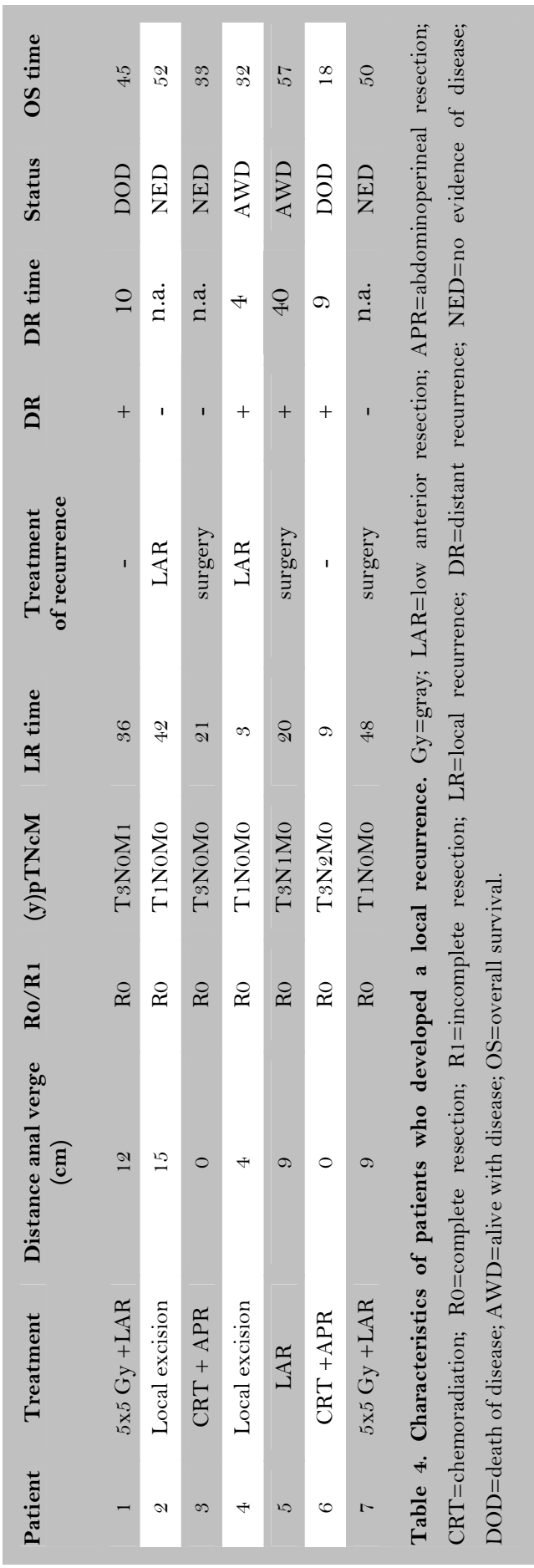




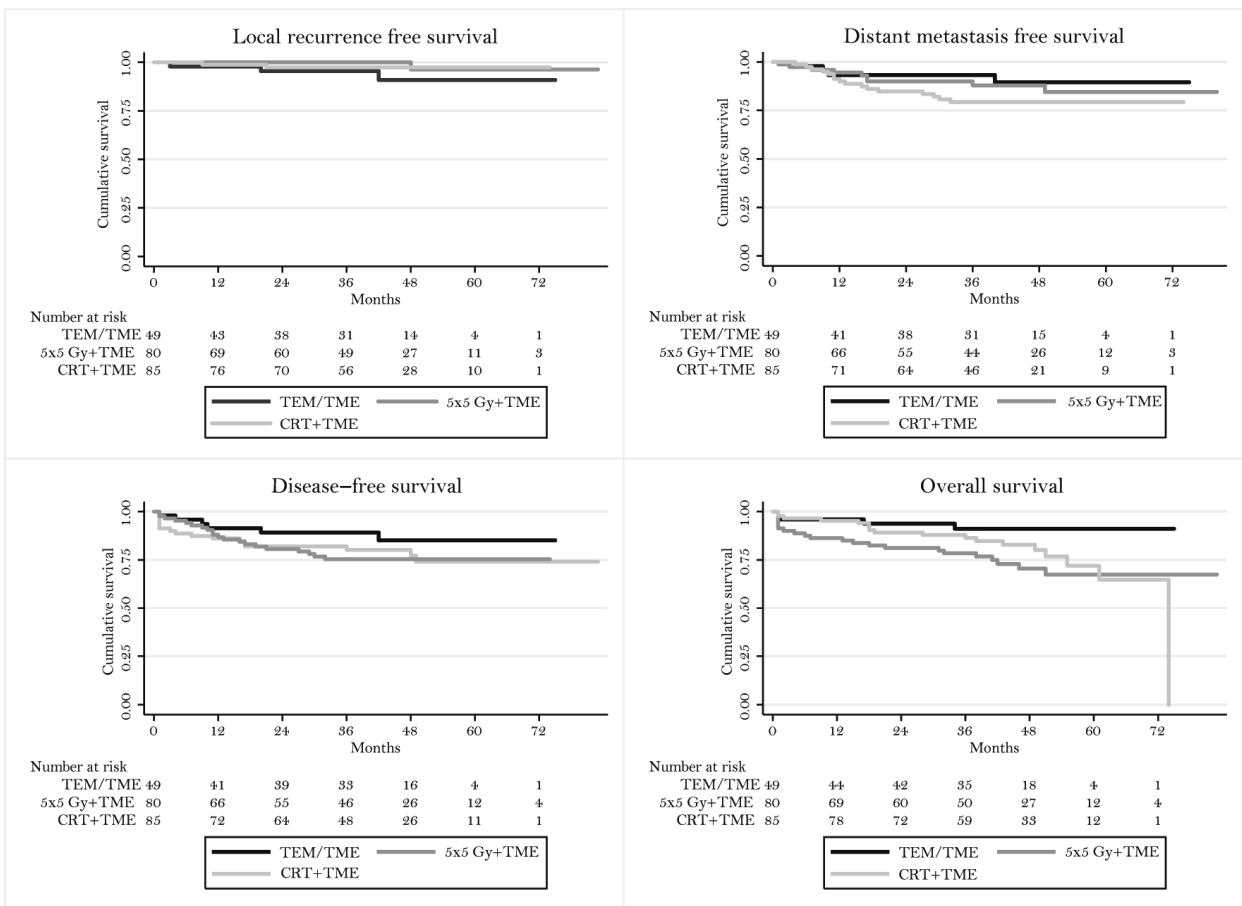

Figure 3. Kaplan Meier survival functions for the three treatment groups.

\section{Discussion}

This study shows that tailored treatment of primary rectal cancer based on preoperative MR imaging leads to a high rate (95.6\%) of complete resections and an excellent 3-year local control with a local recurrence rate of only $2.2 \%$. Overall survival was $84.5 \%$.

The number of complete resections is much better than older series on rectal cancer treatment, and much better than the $84.1 \%$ in the Dutch TME trial. The 2.2\% local recurrence rate also compares favorably with $3.4 \%$ of the $5 \times 5$ Gy radiation group in the Dutch TME trial ${ }^{21}$ and $4.4 \%$ at 3 years in the MRC CRO7 trial ${ }^{22}$. In the trials on neoadjuvant chemoradiation for locally advanced tumours the 5 year local recurrence rates were $7.6 \%$ (Bosset et al) and 6\% (Sauer et al) ${ }^{2,3}$. A strict comparison is however difficult as many series and randomized trials focus on a well-defined group of patients with rectal cancer whereas the present study includes 'all comers' without any selection. It is important to realize that the good results of the current study may be related to a number of recent improvements in the treatment of rectal cancer. In the Dutch TME trial, which ran from 1996 to 1999, a special emphasis was placed on quality assurance of surgical TME technique. With workshops, videos, visits of renowned rectal surgeons and a system of continued proctoring the TME technique 
became standard in most surgical practices. Additionally, up-to-date high resolution MR techniques were standard in the current study. MRI shows the proximity of the tumour to the important surgical planes in distal rectal cancer, and helps the surgeon to perform a complete resection ${ }^{23}$. MRI also identifies tumours that invade or come close to the mesorectal fascia, tumours that are best treated with a long course of neoadjuvant chemoradiation rather than a short course of radiotherapy. The Mercury Study, a multicenter prospective study that used a MRI based selection similar to the present study, reported a 5 year local recurrence rate of $3.3 \%$ for the subgroup of patients (33\% of the entire cohort) with a good prognosis who were treated without neoadjuvant therapy, with an overall and disease free survival of $68 \%$ and $85 \%$ respectively ${ }^{24}$. Although the MR based selection in the Mercury study was similar to our study, their treatment policy that followed this selection was much more restricted regarding the use of neoadjuvant therapy. In the Mercury study only $32 \%$ of patients received neoadjuvant therapy compared to $78 \%$ in our study. The overall long-term outcome results of the Mercury study have not yet been published, and it would be interesting to compare the local recurrence rates of these two policies. Another factor that may have contributed to the good outcome in the current study is the important role in the decision making process of the multidisciplinary team, a factor that is considered to be essential in modern rectal cancer treatment ${ }^{25-27}$.

\section{Positive margins}

An interesting and puzzling finding in this study is the fact that none of the patients with a positive margin at histology developed a local recurrence. A recent review confirmed the earlier observations that a positive margin is a risk factor for local recurrence, even more so when patients are treated with neoadjuvant chemoradiation ${ }^{28}$, 29. The fact that this is not observed in the present study could be just a chance observation, or be caused by a too short follow-up time. The strategy in the present study was specifically aimed at avoiding a positive margin, making optimal use of MRI, sound surgical technique, and with liberal use of chemoradiation for tumours close to the mesorectal fascia and for very distal tumours. Maybe the few tumours with positive margins that result from such a strategy are different from the tumours with positive margins in older series with a much higher rate of incomplete resections. It is therefore unclear whether a positive margin can still be used as a surrogate endpoint for local recurrence.

Abdominoperineal resections in rectal cancer surgery are often associated with a higher percentage of incomplete resections and an adverse outcome ${ }^{30}$. Presently, a wide cylindrical abdominoperineal resection for distal rectal cancer is therefore advocated in literature ${ }^{31,32}$, as it would increase the chance for a complete resection. However, in this study a cylindrical resection for distal rectal tumours was not performed routinely, without apparently compromising outcome, although there were more incomplete resections in the APR group as shown in table 3. Neoadjuvant chemoradiation as well as dedicated MR imaging as a roadmap to the surgeon might again be responsible for 
this result. It is also in line with the retrospective analysis of Messenger et al ${ }^{33}$, in which similar incomplete resection and local recurrence rate were found as compared to studies advocating a wide cylindrical excision, in a group of patients in which $>50 \%$ received neoadjuvant chemoradiation.

This multicentre cohort study of unselected consecutive rectal cancer patients illustrates the morbidity and mortality that is associated with rectal cancer surgery. One out of five patients required an intervention after initial surgery, ranging from drainage of an abscess to relaparotomy because of anastomotic leakage, and the overall postoperative mortality is $4 \%$. Old patients and patients with severe comorbidity were often treated with the short course radiotherapy $(n=20)$ or even no radiotherapy at all $(n=7)$ despite the presence of risk factors for local recurrence, because chemoradiation was considered too toxic. This bias or 'confounding by indication' can explain the higher mortality in the short-course radiotherapy group as compared to the chemoradiation group.

In addition to short-term morbidity, multimodal rectal cancer treatment is also associated with long term functional morbidity. This study did not assess the defecation and urogenital long term function. Undoubtedly the very low local recurrence rate had been achieved at the cost of functional long term morbidity. We have the feeling that many patients have been 'overtreated' with neoadjuvant therapy, and the question is still open how to find the optimal balance between local control and good functional outcome.

\section{Improving survival}

Multidisciplinary efforts to obtain a good local control of rectal cancer have paid off well. However, many patients still die of metastatic disease. In the present cohort $21 \%$ of patients at primary diagnosis presented with metastases, and $15 \%$ of the remaining patients developed metastatic disease at a later stage. Unfortunately only a minority of these patients are ultimately cured, despite aggressive multimodal treatment. Earlier detection of metastatic disease, more active systemic therapy and a more individualised approach using predictive factors could improve not only disease control, but also long term survival, especially when combined with metastasectomies. There is a new tendency to address the metastatic disease simultaneously with the primary tumour or even before the primary tumour, reflected in neoadjuvant systemic therapy protocols and in the surgical 'liver first approach' in which metastatic disease is resected before the primary tumor ${ }^{34}$. A major step forward in improving colorectal cancer survival is expected from large screening programs, that not only lower the overall incidence of colorectal cancer but also the proportion of advanced tumours ${ }^{35,36}$.

\section{Limitations of the study}

The main limitation of this study is that, in contrast to a randomized study, a cohort study cannot provide solid proof that a differentiated approach leads to a better outcome than a more uniform treatment schedule. Besides accurate and high quality 
MR imaging other factors contributed to our good outcome: improved TME surgery and multidisciplinary treatment. The primary aim of this study was, however, to evaluate the outcome of a MRI based treatment approach in this setting of high quality TME and multidisciplinary treatment. The study shows that with this approach in our setting an excellent local control can be achieved, although we cannot exclude that other factors could play a role too. Another limitation is a relatively short median follow-up of 3 years. Although 3 years is a well-accepted end-point in oncological research, late recurrences can occur after neoadjuvant chemoradiation. A further limitation of the study is the practical difficulty of MR staging with the lymph node specific contrast agent Ultrasmall Super Paramagnetic Iron Oxide, an agent that is no longer available on the market despite promising initial results ${ }^{14,15}{ }^{16}$. Although with standard MR imaging without USPIO the accuracy of the predicted nodal status will be slightly lower, the key features in the MR stratification scheme - mesorectal fascia invasion, T-stage, and tumour height will be equally accurate. Recent literature shows that there is a continued search for good lymph node contrast agents. ${ }^{37}$

\section{Conclusion}

With a differentiated multimodality treatment based on dedicated preoperative MR imaging, local recurrence is no longer the main problem in rectal cancer treatment. The new challenges are early diagnosis and treatment, reducing morbidity of treatment and prevention and treatment of metastatic disease. 


\section{References}

1. Heald RJ, Ryall RD. Recurrence and survival after total mesorectal excision for rectal cancer. Lancet 1986;1(8496): 1479-1482.

2. Sauer R, Becker H, Hohenberger W, Rodel C, Wittekind C, Fietkau R, Martus P, Tschmelitsch J, Hager E, Hess CF, Karstens JH, Liersch T, Schmidberger H, Raab R. Preoperative versus postoperative chemoradiotherapy for rectal cancer. N Engl J Med 2004;351(17): 173 1-1740.

3. Bosset JF, Collette L, Calais G, Mineur L, Maingon P, Radosevic-Jelic L, Daban A, Bardet E, Beny A, Ollier JC. Chemotherapy with preoperative radiotherapy in rectal cancer. $N$ Engl J Med 2006;355(11): 1114-1123.

4. Braendengen M, Tveit KM, Berglund A, Birkemeyer E, Frykholm G, Pahlman L, Wiig JN, Bystrom P, Bujko K, Glimelius B. Randomized phase III study comparing preoperative radiotherapy with chemoradiotherapy in nonresectable rectal cancer. J Clin Oncol 2008;26(22): 3687-3694.

5. Gerard JP, Conroy T, Bonnetain F, Bouche O, Chapet O, Closon-Dejardin MT, Untereiner M, Leduc B, Francois E, Maurel J, Seitz JF, Buecher B, Mackiewicz R, Ducreux M, Bedenne L. Preoperative radiotherapy with or without concurrent fluorouracil and leucovorin in T3-4 rectal cancers: results of FFCD 9203. J Clin Oncol 2006;24(28): 4620-4625.

6. Kapiteijn E, Marijnen CA, Nagtegaal ID, Putter H, Steup WH, Wiggers T, Rutten HJ, Pahlman L, Glimelius B, van Krieken JH, Leer JW, van de Velde CJ. Preoperative radiotherapy combined with total mesorectal excision for resectable rectal cancer. N Engl J Med 200 1;345(9): 638-646.

7. Bipat S, Glas AS, Slors FJ, Zwinderman AH, Bossuyt PM, Stoker J. Rectal cancer: local staging and assessment of lymph node involvement with endoluminal US, CT, and MR imaging--a metaanalysis. Radiology 2004;232(3): 773-783.

8. Beets-Tan RG, Beets GL, Vliegen RF, Kessels AG, Van Boven H, De Bruine A, von Meyenfeldt MF, Baeten CG, van Engelshoven JM. Accuracy of magnetic resonance imaging in prediction of tumourfree resection margin in rectal cancer surgery. Lancet 2001;357(9255): 497-504.

9. Brown G, Richards CJ, Newcombe RG, Dallimore NS, Radcliffe AG, Carey DP, Bourne MW, Williams GT. Rectal Carcinoma: Thin-Section MR Imaging for Staging in 28 Patients. Radiology 1999;211(1): 215-222.

10. Bissett IP, Fernando CC, Hough DM, Cowan BR, Chau KY, Young AA, Parry BR, Hill GL. Identification of the fascia propria by magnetic resonance imaging and its relevance to preoperative assessment of rectal cancer. Dis Colon Rectum 2001;44(2): 259-265.

11. Blomqvist L, Rubio C, Holm T, Machado M, Hindmarsh T. Rectal adenocarcinoma: assessment of tumour involvement of the lateral resection margin by MRI of resected specimen. $\mathrm{Br} J$ Radiol 1999;72(853): 18-23.

12. Peschaud F, Cuenod CA, Benoist S, Julie C, Beauchet A, Siauve N, Taieb-Kasbi F, Penna C, Nordlinger B. Accuracy of magnetic resonance imaging in rectal cancer depends on location of the tumor. Dis Colon Rectum 2005;48(8): 1603-1609.

13. Lahaye MJ, Engelen SM, Nelemans PJ, Beets GL, van de Velde CJ, van Engelshoven JM, Beets-Tan RG. Imaging for predicting the risk factors--the circumferential resection margin and nodal disease-of local recurrence in rectal cancer: a meta-analysis. Semin Ultrasound CT MR 2005;26(4): 259-268.

14. Will O, Purkayastha S, Chan C, Athanasiou T, Darzi AW, Gedroyc W, Tekkis PP. Diagnostic precision of nanoparticle-enhanced MRI for lymph-node metastases: a meta-analysis. Lancet Oncol 2006;7(1): 52-60.

15. Lahaye MJ, Engelen SM, Beets GL, de Bruine AP, von Meyenfeldt MF, Van Engelshoven JM, Van de Velde CJ, Beets-Tan RG. How accurate can we predict the nodal status in primary rectal cancer with USPIO MRI? Ann Oncol 2006;17 (suppl): i11-12. 
16. Lahaye MJ, Engelen SM, Kessels AG, de Bruine AP, von Meyenfeldt MF, van Engelshoven JM, van de Velde CJ, Beets GL, Beets-Tan RG. USPIO-enhanced MR imaging for nodal staging in patients with primary rectal cancer: predictive criteria. Radiology 2008;246(3): 804-811.

17. Lahaye MJ, Beets GL, Engelen SM, Kessels AG, de Bruine AP, Kwee HW, van Engelshoven JM, van de Velde CJ, Beets-Tan RG. Locally advanced rectal cancer: MR imaging for restaging after neoadjuvant radiation therapy with concomitant chemotherapy. Part II. What are the criteria to predict involved lymph nodes? Radiology 2009;252(1): 81-91.

18. Heald RJ. A new approach to rectal cancer. Br J Hosp Med 1979;22(3): 277-281.

19. Quirke P, Durdey P, Dixon MF, Williams NS. Local recurrence of rectal adenocarcinoma due to inadequate surgical resection. Histopathological study of lateral tumour spread and surgical excision. Lancet 1986;2(8514): 996-999.

20. Dindo D, Demartines N, Clavien PA. Classification of surgical complications: a new proposal with evaluation in a cohort of 6336 patients and results of a survey. Ann Surg 2004;240(2): 205-2 13.

21. van Gijn W, Marijnen CA, Nagtegaal ID, Kranenbarg EM, Putter H, Wiggers T, Rutten HJ, Pahlman L, Glimelius B, van de Velde CJ. Preoperative radiotherapy combined with total mesorectal excision for resectable rectal cancer: 12-year follow-up of the multicentre, randomised controlled TME trial. Lancet Oncol;12(6): 575-582.

22. Sebag-Montefiore D, Stephens RJ, Steele R, Monson J, Grieve R, Khanna S, Quirke P, Couture J, de Metz C, Myint AS, Bessell E, Griffiths G, Thompson LC, Parmar M. Preoperative radiotherapy versus selective postoperative chemoradiotherapy in patients with rectal cancer (MRC CRo7 and NCIC-CTG Co16): a multicentre, randomised trial. Lancet 2009;373(9666): 811-820.

23. Shihab OC, Heald RJ, Rullier E, Brown G, Holm T, Quirke P, Moran BJ. Defining the surgical planes on MRI improves surgery for cancer of the low rectum. Lancet Oncol 2009;10(12): 1207-1211.

24. Taylor FG, Quirke P, Heald RJ, Moran B, Blomqvist L, Swift I, Sebag-Montefiore DJ, Tekkis P, Brown G. Preoperative high-resolution magnetic resonance imaging can identify good prognosis stage I, II, and III rectal cancer best managed by surgery alone: a prospective, multicenter, European study. Ann Surg 2011;253(4): 711-719.

25. Valentini V, Glimelius B, Minsky BD, Van Cutsem E, Bartelink H, Beets-Tan RG, Gerard JP, Kosmidis P, Pahlman L, Picciocchi A, Quirke P, Tepper J, Tonato M, Van de Velde CJ, Cellini N, Latini P. The multidisciplinary rectal cancer treatment: main convergences, controversial aspects and investigational areas which support the need for an European Consensus. Radiother Oncol 2005;76(3): 241-250.

26. Wiggers T, van de Velde CJ. The circumferential margin in rectal cancer. Recommendations based on the Dutch Total Mesorectal Excision Study. Eur J Cancer 2002;38(7): 973-976.

27. Frasson M, Garcia-Granero E, Roda D, Flor-Lorente B, Rosello S, Esclapez P, Faus C, Navarro S, Campos S, Cervantes A. Preoperative chemoradiation may not always be needed for patients with T3 and T2N+ rectal cancer. Cancer 2012;117(14): 3118-3125.

28. Nagtegaal ID, Marijnen CA, Kranenbarg EK, van de Velde CJ, van Krieken JH. Circumferential margin involvement is still an important predictor of local recurrence in rectal carcinoma: not one millimeter but two millimeters is the limit. Am J Surg Pathol 2002;26(3): 350-357.

29. Nagtegaal ID, Quirke P. What is the role for the circumferential margin in the modern treatment of rectal cancer? J Clin Oncol 2008;26(2): 303-312.

30. den Dulk M, Marijnen CA, Putter H, Rutten HJ, Beets GL, Wiggers T, Nagtegaal ID, van de Velde CJ. Risk factors for adverse outcome in patients with rectal cancer treated with an abdominoperineal resection in the total mesorectal excision trial. Ann Surg 2007;246(1): 83-90. 
31. Kim JS, Hur H, Kim NK, Kim YW, Cho SY, Kim JY, Min BS, Ahn JB, Keum KC, Kim H, Sohn SK, Cho $\mathrm{CH}$. Oncologic outcomes after radical surgery following preoperative chemoradiotherapy for locally advanced lower rectal cancer: abdominoperineal resection versus sphincter-preserving procedure. Ann Surg Oncol 2009;16(5): 1266-1273.

32. West NP, Finan PJ, Anderin C, Lindholm J, Holm T, Quirke P. Evidence of the oncologic superiority of cylindrical abdominoperineal excision for low rectal cancer. J Clin Oncol 2008;26(21): 3517-3522.

33. Messenger DE, Cohen Z, Kirsch R, O'Connor BI, Victor JC, Huang H, McLeod RS. Favorable pathologic and long-term outcomes from the conventional approach to abdominoperineal resection. Dis Colon Rectum;54(7): 793-802.

34. Verhoef C, van der Pool AE, Nuyttens JJ, Planting AS, Eggermont AM, de Wilt JH. The "liver-first approach" for patients with locally advanced rectal cancer and synchronous liver metastases. Dis Colon Rectum 2009;52(1): 23-30.

35. Lieberman D. Colon cancer screening and surveillance controversies. Curr Opin Gastroenterol 2009;25(5): 422-427.

36. Bretthauer M. Evidence for colorectal cancer screening. Best Pract Res Clin Gastroenterol;24(4): 417425.

37. Lambregts DM, Beets GL, Maas M, Kessels AG, Bakers FC, Cappendijk VC, Engelen SM, Lahaye MJ, de Bruine AP, Lammering G, Leiner T, Verwoerd JL, Wildberger JE, Beets-Tan RG. Accuracy of gadofosveset-enhanced MRI for nodal staging and restaging in rectal cancer. Ann Surg $2011 ; 253(3): 539-545$. 



\section{CHAPTER 6}

\section{Neoadjuvant chemoradiation for rectal cancer: defining subgroups who may benefit from further adjuvant chemotherapy after resection}

M. Maas

P.J. Nelemans

V. Valentini

C.H. Crane

C. Capirci

C. Rödel

G.M. Nash

L.J. Kuo

R. Glynne-Jones

J. García-Aguilar

J. Suárez

F.A. Calvo

S. Pucciarelli

S. Biondo

G. Theodoropoulos

D.M.J. Lambregts

R.G.H. Beets-Tan

G.L. Beets 


\begin{abstract}
Background. Recently it was suggested that the benefit of adjuvant chemotherapy for rectal cancer patients might depend on the response to neoadjuvant chemoradiation (CRT). The aim of this study was to evaluate whether the effect of aCT is modified by the response to CRT and to identify which patients benefit from aCT after CRT for rectal cancer and which patients do not.

Methods. A pooled analysis of individual patient data from 13 datasets on the prognostic value of pathologic complete response after CRT was performed. Patients were categorised into 3 response groups: pCR (ypToNo), ypT1-2 tumour and ypT3-4 tumour. Relevant baseline characteristics were available and were used in multivariable regression analyses using Cox proportional hazards models to adjust for differences in prognostic factors between subgroups. The primary outcome measure was relapse-free survival (RFS).
\end{abstract}

Findings. 3313 patients were included of which 1723 (52\%) received adjuvant chemotherapy. 898 patients had a pCR, 966 had a ypT1-2 tumour and 1302 had a ypT3-4 tumour. For 147 patients the response category was missing $(n=122)$ or was ypToN+ $(n=25)$. Median follow-up for all patients was 51 (0-219) months. After adjustment for differences in prognostic factors, the hazard ratios for RFS with $95 \%$ confidence interval (CI) for adjuvant chemotherapy were 1,25 (0,68-2,29), 0,58 (0,37$0,89)$ and $0,83(0,66-1,10)$ for patients with pCR, ypT1-2 tumours and ypT3-4 tumours, respectively.

Conclusions. The results demonstrate an association between adjuvant chemotherapy and outcome in patients treated with CRT for locally advanced rectal cancer. However, the effect of adjuvant chemotherapy differs between subgroups. Patients with a pCR after CRT may not benefit from adjuvant chemotherapy, whereas patients with residual tumour do. The results strongly support the need for prospective studies on an individualized approach to the administration adjuvant chemotherapy, where omission of adjuvant chemotherapy in patients with a pCR after CRT could be considered. 


\section{Introduction}

Currently, adjuvant chemotherapy for colorectal cancer is indicated for patients at increased risk for metastatic disease, typically established through postoperative histopathological risk factors, like involved lymph nodes, poor differentiation grade or lymphatic or venous invasion. ${ }^{1}$ For rectal cancer, the shift from adjuvant to neoadjuvant (chemo)radiation ${ }^{2}$ has complicated the use of postoperative histopathology to determine the indication for adjuvant chemotherapy, as chemoradiation (CRT) often leads to downstaging of tumour and nodes. Thus, the histopathological staging often no longer reflects the initial stage of the rectal cancer before CRT. Therefore, the medical oncologist faces a challenge in deciding which patients with rectal cancer should be treated with adjuvant chemotherapy after CRT. First, the decision could be based on the pre-CRT imaging. However, the available imaging modalities are only moderately accurate in lymph node assessment ${ }^{3,}{ }^{4}$, the risk factor that is considered pivotal in decision making about adjuvant chemotherapy. Another option is to guide the decision on post-CRT histopathological staging, but this strategy carries the risk of undertreating patients whose lymph nodes have been sterilised due to the CRT. Last, for the sake of simplicity one could argue that if a patient is treated with chemoradiation, adjuvant chemotherapy is always warranted, as the patient has locally advanced disease. However, this strategy almost certainly leads to overtreatment.

The question remains as to which patients benefit from adjuvant chemotherapy after CRT for rectal cancer. ${ }^{5}$ A subgroup analysis of a randomized EORTC trial suggested that the effect of adjuvant chemotherapy on disease-free survival (DFS) is correlated with ypT-staging, which is a measure of response to CRT. Patients with ypTo-2 tumours had a significant improvement in DFS when adjuvant chemotherapy was administered, whereas patients with ypT3-4 residual tumours had not. ${ }^{6}$ Another report questioned the benefit of adjuvant chemotherapy for pathologic complete responders (ypToNo) after CRT. ${ }^{7}$

Therefore, the aim of this study was to evaluate whether the effect of adjuvant chemotherapy after CRT is modified by the histopathological stage after CRT using a pooled analysis of individual patient data and to identify which patients benefit from adjuvant chemotherapy.

\section{Methods}

Individual patient data from a previous pooled analysis on the prognostic value of a pCR after CRT for locally advanced rectal cancer were used. The search strategy, identification and selection of these data have been described in detail in an earlier publication. ${ }^{8}$ From the primary literature search, 17 papers were identified of which 14 authors consented to participation in the previous analysis. For the present analysis, information on the administration of adjuvant chemotherapy and/or about the yp $\mathrm{T}$ and 
ypN-stage was missing in three of these 14 datasets. These data could not be provided and thus these datasets were not included for the current analysis. ${ }^{9-11}$

From one of the three datasets that could not be included at the time of the earlier publication, data was available for the current study. ${ }^{12,13}$ Additionally, - to increase the sample of patients with a pCR after CRT - we contacted the first author of a study on the long-term outcome of a large group of patients with a pCR after CRT, who agreed to share the dataset. ${ }^{7}$ Thus, data from 13 centres were included for the present analysis. ${ }^{7}$, 12-24 Baseline staging of patients before treatment consisted of endorectal ultrasound and computed tomography mostly. Interval between chemoradiation and surgery was generally 6-8 weeks. Surgery consisted of total mesorectal excision for all patients. Individual patients were excluded from the current pooled analysis for the following reasons: (1) data about administration of adjuvant chemotherapy was missing, (2) patients were treated with preoperative radiation only without concomitant chemotherapy, (3) radiotherapy dose $\leq 25 \mathrm{~Gy}$, (4) presence of synchronous metastasis, (5) locally recurrent disease or (6) an incomplete resection ( $\mathrm{R} 1$ or $\mathrm{R} 2$ ). Included for analysis were data on gender, age, clinical $\mathrm{T}$ - and $\mathrm{N}$-stage, distance between tumour and anal verge, pathologic $\mathrm{T}$ - and N-stage, type of surgery (low anterior resection, abdominoperineal resection or other surgery e.g. Hartmann's procedure or exenteration), type of adjuvant chemotherapy and information on dates of events and/or follow-up times to events.

Based on histopathology of the resection specimen after CRT patients were categorised into: (1) pCR, defined as ypToNo, (2) ypT1-2 and (3) ypT3-4. For an additional analysis to evaluate the effect of adjuvant chemotherapy in patients with ypNo and ypN+, patients were categorised into subgroups according to pathological $\mathrm{N}$-status (ypN-stage). For 147 patients (4\%) the response category was missing $(n=122)$ or was not consistent with one of the abovementioned categories $(n=25$, ypToN+). These data, however, were included in the analysis to evaluate the effect of adjuvant chemotherapy in the total group of patients.

The primary outcome measure was recurrence-free survival (RFS). Recurrence was defined as a local and/or distant recurrence during follow-up.

\section{Statistical analysis}

Baseline characteristics were compared between patients who did and did not receive adjuvant chemotherapy. Differences in baseline characteristics were tested for statistical significance with the independent samples t-test for the comparison of means and the $\mathrm{X}^{2}$-test for comparison of proportions. Outcome measures were RFS, defined as the absence of any recurrence (local or distant) during follow-up; disease-free survival (DFS), defined as the absence of both local and distant recurrence and death by any cause during follow-up; and overall survival (OS), defined as the absence of death from any cause during follow-up. Follow-up time was calculated from the date of surgery to the date of the event of interest or the date of last follow-up (censoring date). 
Multivariable Cox proportional hazards models with stratification for study centre were used to adjust for differences in baseline characteristics between patients who did and did not receive adjuvant chemotherapy within response groups. The proportional hazard assumption was evaluated graphically with log-minus-log plots. ${ }^{25}$ Trend tests based on Schoenfeld residuals were also used to assess departure of proportionality. ${ }^{25}$ Hazard ratios (HR) with $95 \%$ confidence intervals (CI) were calculated. The HRs that correspond with the variable coding for whether the patient received adjuvant chemotherapy or not indicate the relative risks of having an event during follow-up. A $\mathrm{HR}<1$ indicates that the patients who received adjuvant chemotherapy had a lower probability of having an event.

To evaluate whether the effect of adjuvant chemotherapy was modified by the degree of response to CRT an interaction term for adjuvant chemotherapy and response to CRT was entered into the multivariable model. The three response groups were coded by two dummy variables using the response group with pCR as reference group. The HR associated with the interaction terms represent the ratio between the HR for response group ypT1-2 (or response group ypT3-4) and the HR of the reference group of patients with a pCR, indicating to what extent the effect of adjuvant chemotherapy is modified by the response to CRT. A similar analysis was performed with an interaction term for ypN-stage and adjuvant chemotherapy.

Analyses were performed with SPSS 16.0 and STATA 11.0. P-values $<0.05$ were considered statistically significant.

\section{Results}

In total 3313 patients were included, of whom 1723 (52\%) underwent adjuvant CT. There were 898 patients with a pCR, 966 with ypT1-2 tumours and 1302 with ypT3-4 tumours. Approximately half of the patients with pCR (441/898) came from the study by Capirci et al.23 Median follow-up for all patients was 51 (range 0-219) months. Median follow-up time for patients with adjuvant CT was 55 months (range 0-188) and for patients without adjuvant CT it was 46 months (range 0-219). For patients with pCR median follow-up was 47 months (range 0-187), for patients with ypT1-2 tumours 61 months (range 1-219) and for patients with ypT3-4 tumours it was 49 months (range 0-201). Additional information and baseline characteristics per study are shown in table 1.

Baseline characteristics for all patients and patients who did and did not undergo adjuvant CT are shown in table 2. Patients who underwent adjuvant CT were significantly younger that patients who did not undergo adjuvant CT, a larger proportion of patients who underwent adjuvant CT had more distally located tumours, underwent a low anterior resection and had more advanced pathologic stages (higher ypT- and ypN-stage) than patients who did not undergo adjuvant CT (all p<0.0001). 


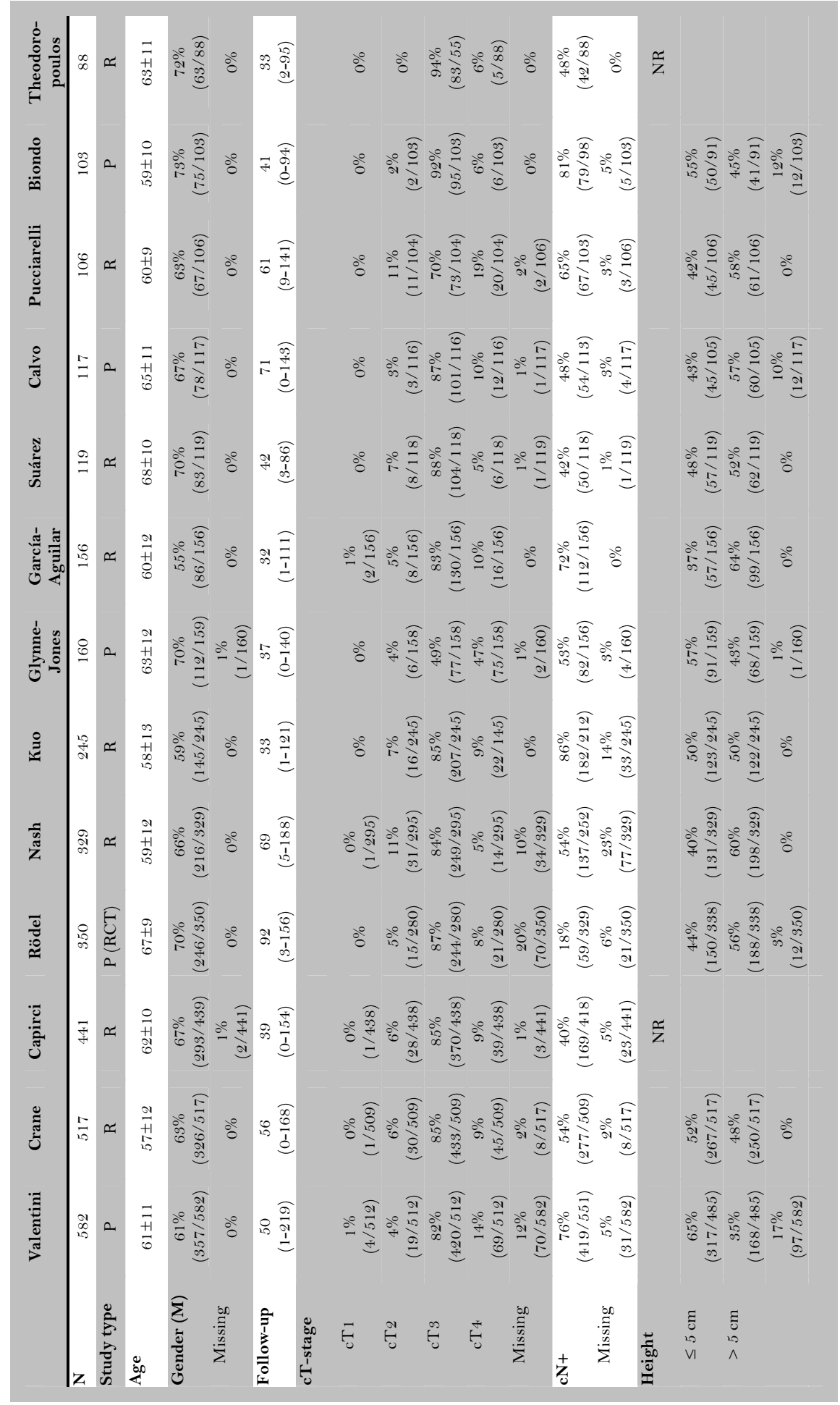




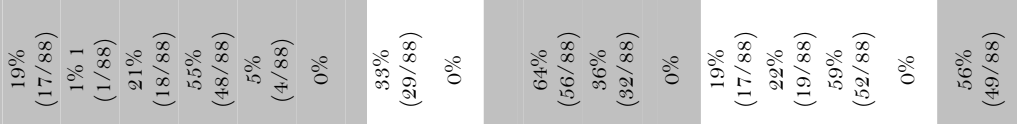

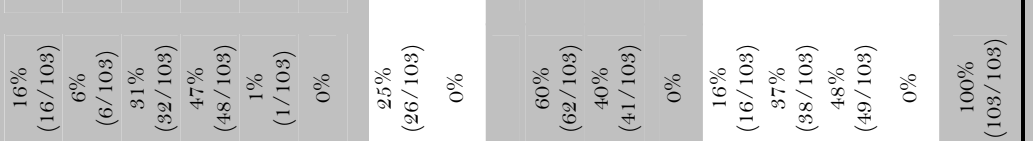

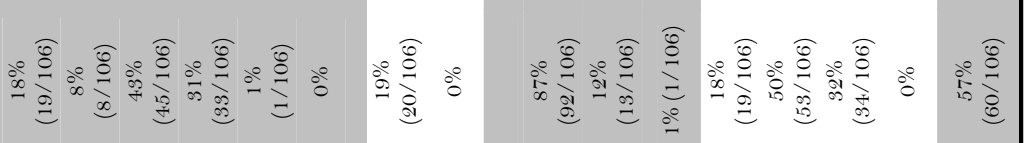

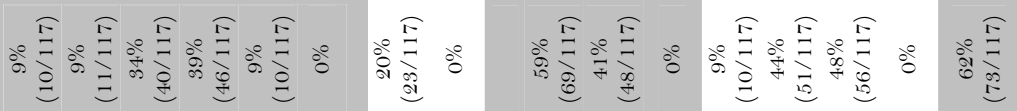

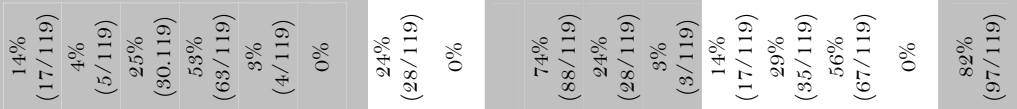

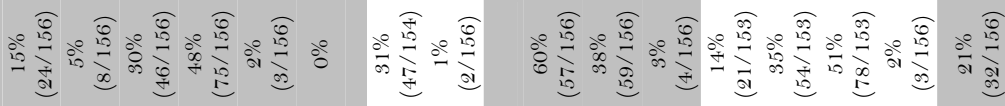

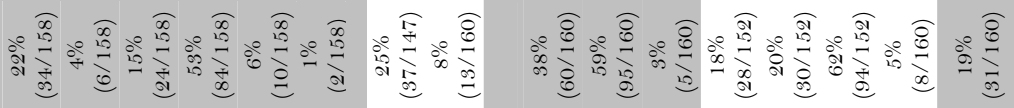

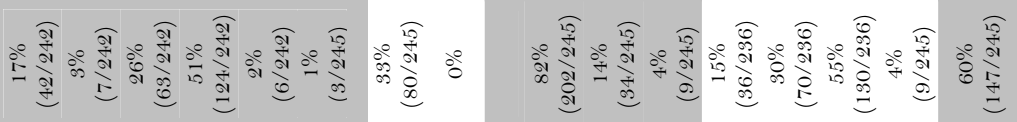

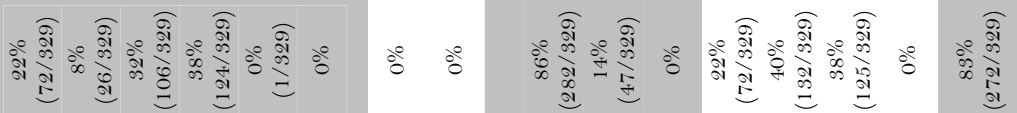

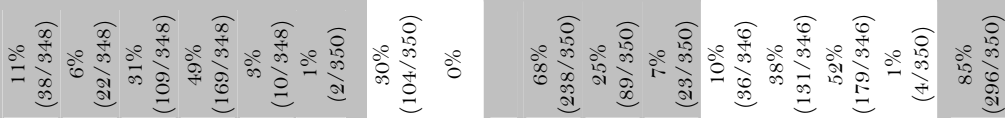

辛昰

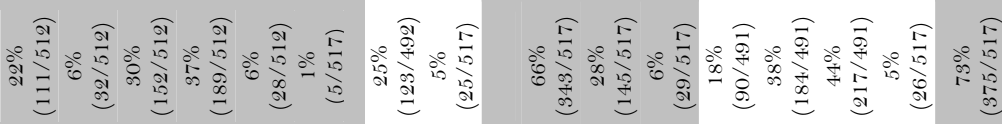

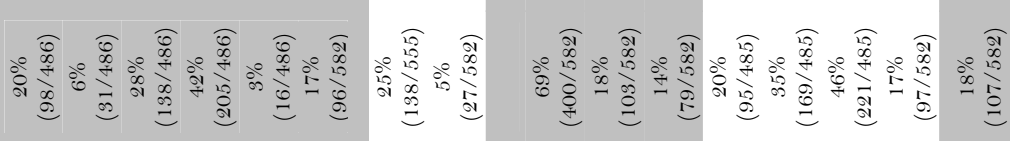

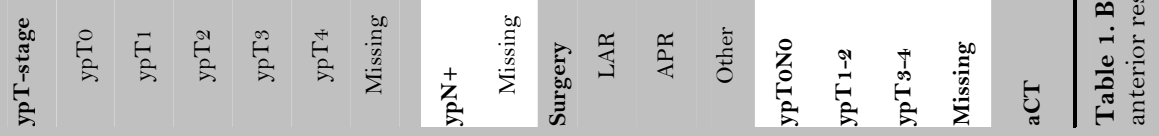




\begin{tabular}{|c|c|c|c|c|}
\hline & All & $\begin{array}{l}\text { No aCT } \\
(n=1590)\end{array}$ & $\begin{array}{c}\mathrm{aCT} \\
(\mathrm{n}=1723)\end{array}$ & p-value \\
\hline Age (years) & $61(12)$ & $63(11)$ & $60(12)$ & $\mathrm{p}<0.0001$ \\
\hline Gender (male) & $64 \%(2119 / 3313)$ & $63 \%(1001 / 1590)$ & $65 \%(1118 / 1723)$ & 0.258 \\
\hline Missing & $0 \%(3 / 3298)$ & $0 \%(2 / 1575)$ & $0 \%(1 / 1723)$ & \\
\hline \multicolumn{5}{|l|}{ Clinical T-stage } \\
\hline cT1 & $0 \%(9 / 3122)$ & $1 \%(7 / 1489)$ & $0 \%(2 / 1618)$ & \\
\hline $\mathrm{cT} 2$ & $6 \%(177 / 3122)$ & $6 \%(93 / 1489)$ & $5 \%(84 / 1618)$ & 0.093 \\
\hline cT3 & $83 \%(2586 / 3122)$ & $81 \%(1225 / 1489)$ & $84 \%(1361 / 1618)$ & \\
\hline $\mathrm{cT} 4$ & $11 \%(350 / 3122)$ & $12 \%(179 / 1504)$ & $11 \%(171 / 1618)$ & \\
\hline Missing & $6 \%(191 / 3313)$ & $5 \%(86 / 1590)$ & $6 \%(105 / 1723)$ & \\
\hline \multicolumn{5}{|l|}{ Clinical N-stage } \\
\hline $\mathrm{cN}+$ & $56 \%(1729 / 3103)$ & $56 \%(846 / 1508)$ & $55 \%(883 / 1595)$ & 0.678 \\
\hline Missing & $6 \%(210 / 3313)$ & $5 \%(82 / 1590)$ & $7 \%(128 / 1723)$ & \\
\hline \multicolumn{5}{|l|}{ Tumour height (cm) } \\
\hline$\leq 5 \mathrm{~cm}$ & $50 \%(1333 / 2650)$ & $55 \%(606 / 1099)$ & $47 \%(727 / 1551)$ & $<0.0001$ \\
\hline$>5 \mathrm{~cm}$ & $50 \%(1317 / 2650)$ & $45 \%(493 / 1099)$ & $53 \%(824 / 1551)$ & \\
\hline Missing & $20 \%(663 / 3313)$ & $31 \%(491 / 1590)$ & $10 \%(172 / 1723)$ & \\
\hline \multicolumn{5}{|l|}{ Type of surgery } \\
\hline LAR & $70 \%(2324 / 3313)$ & $68 \%(1073 / 1590)$ & $73 \%(1251 / 1723)$ & \\
\hline APR & $25 \%(834 / 3298)$ & $26 \%(416 / 1590)$ & $24 \%(418 / 1723)$ & $<0.0001$ \\
\hline Other & $5 \%(155 / 3298)$ & $6 \%(101 / 1590)$ & $3 \%(54 / 1723)$ & \\
\hline Missing & $0 \%$ & $0 \%$ & $0 \%$ & \\
\hline \multicolumn{5}{|l|}{ Response category } \\
\hline pCR (ypToNo) & $28 \%(898 / 3166)$ & $41 \%(608 / 1478)$ & $17 \%(290 / 1688)$ & \\
\hline урТ 1-2 & $31 \%(966 / 3166)$ & $27 \%(400 / 1478)$ & $34 \%(566 / 1688)$ & $<0.0001$ \\
\hline урТ $3-4$ & $41 \%(1302 / 3166)$ & $32 \%(470 / 1478)$ & $49 \%(832 / 1688)$ & \\
\hline Missing & $4 \%(147 / 3313)$ & $7 \%(112 / 1590)$ & $2 \%(35 / 1723)$ & \\
\hline \multicolumn{5}{|l|}{ Pathological N-stage } \\
\hline $\mathrm{N}+$ & $20 \%(655 / 3246)$ & $13 \%(194 / 1538)$ & $27 \%(461 / 1708)$ & $<0.0001$ \\
\hline Missing & $2 \%(67 / 3313)$ & $3 \%(52 / 1590)$ & $1 \%(15 / 1723)$ & \\
\hline Median FU time (mo) & $51(0-219)$ & $47(0-219)$ & $55(\mathrm{O}-188)$ & $<0.0001$ \\
\hline
\end{tabular}




\begin{tabular}{|c|c|c|c|c|}
\hline & $\begin{array}{c}\text { pCR } \\
(n=898)\end{array}$ & $\begin{array}{l}\text { урТ 1-2 } \\
(\mathrm{n}=966)\end{array}$ & $\begin{array}{c}\text { урТ3-4 } \\
(n=1302)\end{array}$ & p-value \\
\hline Age (years) & $61( \pm 11)$ & $61( \pm 11,5)$ & $61( \pm 12,0)$ & $\mathrm{p}=0.819$ \\
\hline Gender (male) & $66 \%(589 / 896)$ & $65 \%(632 / 966)$ & $65 \%(843 / 1302)$ & $\mathrm{p}=0.894$ \\
\hline Missing & $0,2 \%(2 / 898)$ & $0 \%$ & $0 \%(1 / 1302)$ & \\
\hline \multicolumn{5}{|l|}{ Clinical T-stage } \\
\hline cT1 & $0,5 \%(4 / 878)$ & $0,3 \%(3 / 924)$ & $0,1 \%(1 / 1215)$ & \multirow{5}{*}{$\mathrm{p}<0.0001$} \\
\hline $\mathrm{cT} 2$ & $8 \%(71 / 878)$ & $9 \%(81 / 924)$ & $2 \%(21 / 1215)$ & \\
\hline cT3 & $82 \%(723 / 878)$ & $84 \%(776 / 924)$ & $82 \%(999 / 1215)$ & \\
\hline $\mathrm{cT} 4$ & $9 \%(80 / 878)$ & $6 \%(64 / 924)$ & $16 \%(194 / 1215)$ & \\
\hline Missing & $2 \%(20 / 898)$ & $4 \%(42 / 966)$ & $7 \%(87 / 1302)$ & \\
\hline \multicolumn{5}{|l|}{ Clinical N-stage } \\
\hline $\mathrm{cN}+$ & $50 \%(431 / 855)$ & $55 \%(501 / 907)$ & $59 \%(486 / 1198)$ & \multirow[t]{2}{*}{$\mathrm{p}<0.0001$} \\
\hline Missing & $5 \%(43 / 898)$ & $6 \%(59 / 966)$ & $8 \%(104 / 1302)$ & \\
\hline \multicolumn{5}{|c|}{ Tumour height (cm) } \\
\hline$\leq 5 \mathrm{~cm}$ & $53 \%(230 / 434)$ & $54 \%(491 / 912)$ & $45 \%(545 / 1201)$ & \multirow{3}{*}{$\mathrm{p}<0.0001$} \\
\hline$>5 \mathrm{~cm}$ & $47 \%(204 / 434)$ & $46 \%(421 / 912)$ & $55 \%(656 / 1201)$ & \\
\hline Missing & $52 \%(464 / 898)$ & $6 \%(54 / 966)$ & $8 \%(102 / 1302)$ & \\
\hline \multicolumn{5}{|l|}{ Type of surgery } \\
\hline LAR & $76 \%(680 / 898)$ & $71 \%(686 / 966)$ & $68 \%(882 / 1302)$ & \multirow{4}{*}{$\mathrm{p}=0.001$} \\
\hline APR & $22 \%(196 / 898)$ & $25 \%(238 / 966)$ & $28 \%(367 / 1302)$ & \\
\hline Other & $2 \%(22 / 898)$ & $4 \%(42 / 966)$ & $4 \%(53 / 1302)$ & \\
\hline Missing & $0 \%$ & $0 \%$ & $0 \%$ & \\
\hline $\begin{array}{l}\text { Table 3. Ba } \\
\text { chemoradiation } \\
\text { pCR=pathologic }\end{array}$ & $\begin{array}{l}\text { eristics for } p \\
\text { etre; } L A R=l o w \\
\text { onse. }\end{array}$ & $\begin{array}{l}\text { categorized } \\
\text { ior resection; }\end{array}$ & $\begin{array}{l}\text { ling to their } \mathbf{r} \\
\text { abdominoperinea }\end{array}$ & $\begin{array}{l}\text { ponse to } \\
\text { resection; }\end{array}$ \\
\hline
\end{tabular}


In table 3 information on baseline characteristics are shown and compared between response categories. Almost all patients had cT3 tumours before CRT ( $82 \%$ in the pCR group, $84 \%$ in the ypTo- 2 group and $82 \%$ in the ypT $3-4$ group). In every of the 3 groups approximately half of patients had involved nodes before CRT.

Table 4 provides information on the prognostic value of ypT- and ypN-staging by showing the 5-year Kaplan Meier estimates of RFS, DFS and OS for patients not treated with adjuvant chemotherapy according to histological ypTN categories.

\begin{tabular}{|c|c|c|c|}
\hline pCR & $\begin{array}{l}\text { Recurrence free survival } \\
\qquad 90 \%(87-93)\end{array}$ & $\begin{array}{c}\text { Disease-free survival } \\
87 \%(84-90)\end{array}$ & $\begin{array}{c}\text { Overall survival } \\
87 \%(83-90)\end{array}$ \\
\hline \multicolumn{4}{|c|}{ According to $y p T$-stage } \\
\hline урТ1-2 & $84 \%(79-87)$ & $78 \%(74-83)$ & $86 \%(81-89)$ \\
\hline урТ3-4 & $60 \%(55-65)$ & $52 \%(46-57)$ & $63 \%(58-68)$ \\
\hline \multicolumn{4}{|c|}{ According to ypN-stage } \\
\hline ypNo & $81 \%(79-84)$ & $76 \%(73-79)$ & $81 \%(79-84)$ \\
\hline ypN+ & $52 \%(43-60)$ & $47 \%(38-55)$ & $59 \%(50-67)$ \\
\hline \multicolumn{4}{|c|}{ According to combined $y p T$ - and $y p N$-stage } \\
\hline ypT1-2No & $85 \%(80-88)$ & $79 \%(74-83)$ & $86 \%(81-90)$ \\
\hline yp $11-2 \mathrm{~N}+$ & $78 \%(59-89)$ & $76 \%(58-88)$ & $88 \%(70-95)$ \\
\hline урT3-4No & $68 \%(62-74)$ & $59 \%(52-64)$ & $69 \%(63-75)$ \\
\hline урТ3-4N+ & $43 \%(32-53)$ & $36 \%(26-46)$ & $50 \%(38-60)$ \\
\hline
\end{tabular}

Table 4. 5-year Kaplan Meier estimates (wih 95\% confidence intervals) of patients with varying response to $\mathrm{CRT}$ with regard to $\mathrm{T}$ - and $\mathrm{N}$-stage who were not treated with adjuvant chemotherapy. $\mathrm{pCR}=$ pathologic complete response; $\mathrm{RFS}=$ relapse-free survival; $\mathrm{DFS}=$ disease-free survival; OS=overall survival.

\section{Multivariable analyses}

Multivariable Cox regression analyses were performed with inclusion of the following factors as independent variables: age, gender, clinical T-stage and clinical Nstage before CRT, type of surgery, administration of adjuvant chemotherapy. The proportional hazards assumption was not violated. When analyzing the combined data of all patients, the adjusted HRs indicated a better prognosis for patients who received adjuvant chemotherapy than for patients who did not. The adjusted HR for the effect of adjuvant chemotherapy on RFS was 0.81 (95\%CI 0.66-0.99), for DFS the HR was 0.75 (95\%CI 0.62-0.90) and for OS the HR was 0.69 (95\%CI 0.56-0.85).

Figure 1 shows the forest plots displaying the HRs and 95\%CIs for administration of adjuvant chemotherapy per ypT and per ypN-stage for RFS, DFS and OS. For patients with a pCR, the hazard ratios vary around ' 1 ' with wide $95 \%$ CIs. 

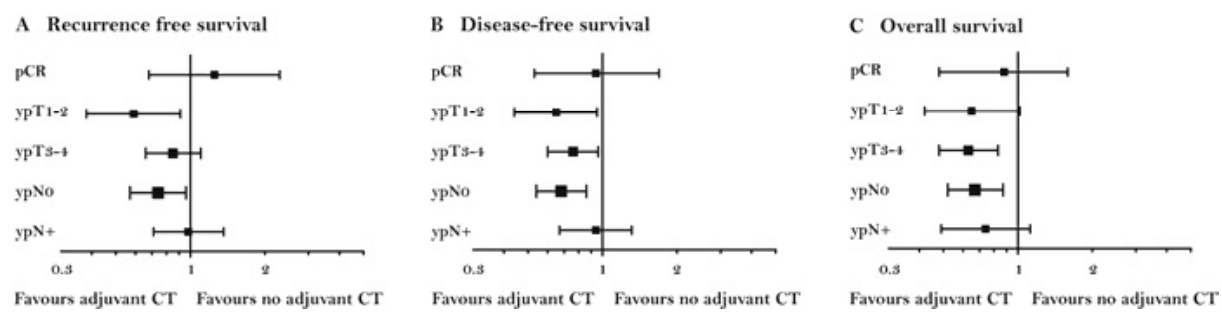

Figure 1. Forest plots displaying the hazard ratios with $95 \%$ confidence interval derived from the comparison of patients treated with adjuvant chemotherapy and not treated with adjuvant chemotherapy (reference group) for the three response groups and for patients with ypNo and ypN+. (a) Relapse-free survival, (b) disease-free survival and (c) overall survival.

For RFS, the HR was 1.25 (95\%CI: 0.68-2.29). For DFS and OS the HRs for this response group were 0.94 (95\%CI: 0.53-1.69) and 0.88 (95\%CI: 0.48-1.59), respectively. For patients with ypT1-2 and ypT3-4 the HR was $<1$ for all outcome measures, indicating a statistically significant association of adjuvant chemotherapy with an improved outcome. For patients with ypNo the HR for adjuvant chemotherapy on RFS was 0.74 (95\%CI: $0.57-0.96)$, while in patients with ypN+ the HR was 0.98 (95\%CI: 0.71-1.36). For DFS similar results were found and for OS the difference in the HRs for adjuvant chemotherapy between patients with ypNo and ypN+ was less pronounced: HR 0.67 (95\%CI: 0.52-0.87) for ypNo and HR 0.74 (95\%CI: 0.49-1.12) for ypN+.

To evaluate the robustness of the results for patients with $\mathrm{pCR}$, we repeated the analysis without the patients with pCR from Capirci et al. ${ }^{7}$ The resulting HR of 1.24 (95\%CI: 0.52-2.97) for RFS again suggested no benefit from adjuvant chemotherapy for this subgroup.

\section{Interaction}

For RFS, the HRs for the interaction terms suggest a stronger effect of adjuvant chemotherapy in the response groups ypT1-2 (HR=0.71 with 95\%CI:0.38-1.33, $\mathrm{p}=0.280)$ and ypT3-4 $(\mathrm{HR}=0.80$ with $95 \% \mathrm{CI}: 0.45-1.42, \mathrm{p}=0.450)$ than in the subgroup with pCR, but the estimated interaction effects do not reach statistical significance. This analysis was repeated with an interaction term for ypN status and adjuvant chemotherapy. For RFS, the HR for the interaction term was 0.80 (95\%CI:0.55-1.16, $\mathrm{p}=0.241$ ), indicating a larger effect of adjuvant chemotherapy in patients with ypNo stage. For DFS and OS the interaction HRs were also non-significant. 


\section{Discussion}

The results indicate that the effect of adjuvant chemotherapy after CRT and surgery for rectal cancer depends on the final histological staging. Patients with a pCR after CRT do not seem to benefit from adjuvant chemotherapy and as these patients already have an excellent prognosis ${ }^{8}$ there is little or no room for improvement with adjuvant chemotherapy. For patients with residual tumour adjuvant chemotherapy does improve the long-term outcome, with the largest benefit for the patients with ypT1-2 tumours after CRT.

Although adjuvant chemotherapy is common in many clinical practices, there is still no definite answer to the question whether it is effective in patients with locally advanced rectal cancer after treatment with CRT. In a recent systematic review of randomized trials it was reported that the effect of adjuvant chemotherapy in patients with rectal cancer treated with CRT might be limited. ${ }^{26}$ As no single trial was large enough to detect a $5 \%$ improvement in 5-year survival, it was recommended to perform a meta-analysis using individual patient data to resolve the issue of whether adjuvant 5FU-based chemotherapy produces worthwhile benefit in patients who have been treated with neoadjuvant CRT and surgery. The results of this present pooled analysis with a HR for RFS of 0.81 (95\%CI:0.66-0.99) are suggestive of a benefit of adjuvant chemotherapy in the total group of patients who received neoadjuvant CRT. This finding is in accordance with a trend towards a survival benefit from adjuvant chemotherapy that was shown in two randomized trials. From subgroup analyses of the QUASAR trial that focused on patients with rectal cancer only a HR of $0.60(95 \% \mathrm{CI}$ : 0.30-1.20) was reported, in favor of adjuvant chemotherapy. ${ }^{27}$ The previously mentioned EORTC trial reported a HR of 0.87 (95\%CI:0.72-1.04) for DFS and a HR of 0.84 (95\%CI:0.78-1.13) for OS in favor of adjuvant chemotherapy. ${ }^{28}$

Our finding that the effect of aCT is stronger in the ypT1-2 group than in the ypT3-4 group is consistent with the results from the subgroup analysis of the EORTC trial. ${ }^{28}$ These subgroup analyses showed a beneficial effect of adjuvant chemotherapy in patients with ypTo-2 tumours (HR for DFS=0.64 with 95\%CI:0.45-0.91 and HR for $\mathrm{OS}=0.64$ with $95 \% \mathrm{CI}$ 0.42-0.96), and no benefit in patients with ypT3-4 tumours (HR 1.18 with 95\%CI:0.89-1.57 for DFS and 1.19 with 95\%CI:0.84-1.68 for OS, p>0.05). The authors put forward the hypothesis that the same prognostic factors drive both tumour sensitivity for the primary treatment with chemoradiation and sensitivity for adjuvant chemotherapy aimed at microscopic distant disease. ${ }^{6}$ The finding in this pooled analysis that adjuvant chemotherapy seems to have an effect in patients with ypNo tumours, but not in patients with ypN+ tumours also supports the hypothesis from Collette et al.: when the primary tumour does not respond well to the chemoradiation, the micrometastases in the nodes will also lack response to adjuvant chemotherapy. ${ }^{6}$ These findings point to a policy for administration of adjuvant chemotherapy in patients with rectal cancer treated with CRT which is at odds with the usual approach in colorectal cancer. Currently, in colorectal cancer the decision to 
administer adjuvant chemotherapy is guided by the pathologic N-stage, where patients with pathologic $\mathrm{N}+$ stage have an indication for adjuvant chemotherapy. Unlike patients not treated with neoadjuvant CRT, patients with rectal cancer who have been treated with CRT and still have a pathologic $\mathrm{N}+$ status do not seem to benefit from adjuvant chemotherapy. In these patients adjuvant chemotherapy might be omitted or a different chemotherapeutic agent (not 5-FU based) could be considered.

\section{Limitations}

The results of this pooled analysis should be interpreted with caution because data were not derived from randomized trials. Due to confounding by indication the distribution of prognostic factors for survival may have differed between patients who received adjuvant chemotherapy and those who did not. An attempt was made to eliminate this bias by adjustment for these differences in a multivariable Cox regression model, but it is possible that some relevant prognostic factors were not captured in these multivariable analyses. For instance, no information was available on postoperative complications or co-morbidity of patients. Both factors may have guided the decision to withhold adjuvant chemotherapy. As a result, the group of patients who did not receive adjuvant chemotherapy may have had an elevated risk of death due to other diseases than rectal cancer. Such an imbalance would result in bias towards favoring adjuvant chemotherapy for the outcomes DFS and OS. However, the HRs for RFS are less likely to be biased, because this outcome does not comprise deaths and can therefore be considered a more valid and thus reliable estimate of effectiveness of adjuvant chemotherapy.

A second limitation is that the majority of patients received 5-FU-based adjuvant chemotherapy. It remains unclear whether the results of the present study are reproducible with a regimen that includes oxaliplatin.

A third limitation is that, although the results of the current pooled analysis support the presence of differential effects of adjuvant chemotherapy within different subgroups, there is no definite proof of treatment-by-response interaction. The HRs for the interaction terms suggest a stronger effect of adjuvant chemotherapy in the response groups ypT1-2 and ypT3-4 than in the subgroup with pCR, but the estimated interaction effects do not reach statistical significance. However, it cannot be concluded that lack of statistical significance indicates absence of interaction. Tests for interaction are known to have limited power. A sample size calculation showed that to achieve a significant interaction effect a sample size of approximately 13000 patients would be needed. The substantial differences in effect of adjuvant chemotherapy between the response groups strongly suggest the presence of effect modification by response to CRT.

Limitations that are inherent to pooled analyses of non-randomized individual patient data can be circumvented by a randomized controlled trial (RCT) or a pooled analysis of data from RCTs, However, a very large sample size would be needed to detect small but clinically relevant differences in effect between groups who respond 
differently to CRT, particularly in view of the low prevalence of pCR (15-20\%). ${ }^{8}$ Therefore, to provide definite evidence with a RCT will be very challenging. Whilst awaiting the results of such a RCT, the results of the current pooled analysis might therefore be used when contemplating on the use of adjuvant chemotherapy after CRT in individual patients.

\section{Conclusion}

The results indicate that the effect of adjuvant chemotherapy after CRT and surgery for rectal cancer depends on the final histological staging. Patients with a pCR after CRT may not benefit from adjuvant chemotherapy, whereas patients with residual tumour do. Although the test for interaction did not reach statistical significance, the results strongly support further investigation of a more individualized approach to administer adjuvant chemotherapy after CRT and surgery based on final pathologic staging, where omission of adjuvant chemotherapy in patients with a pCR after CRT could be considered. 


\section{References}

1. Jonker DJ, Spithoff K, Maroun J. Adjuvant Systemic Chemotherapy for Stage II and III Colon Cancer after Complete Resection: An Updated Practice Guideline. Clin Oncol ( $R$ Coll Radiol) 2011;23(5): 314-322.

2. Sauer R, Becker H, Hohenberger W, Rodel C, Wittekind C, Fietkau R, Martus P, Tschmelitsch J, Hager E, Hess CF, Karstens JH, Liersch T, Schmidberger H, Raab R. Preoperative versus postoperative chemoradiotherapy for rectal cancer. N Engl J Med 2004;351(17): 1731-1740.

3. Bipat S, Glas AS, Slors FJ, Zwinderman AH, Bossuyt PM, Stoker J. Rectal cancer: local staging and assessment of lymph node involvement with endoluminal US, CT, and MR imaging--a metaanalysis. Radiology 2004;232(3): 773-783.

4. Lahaye MJ, Engelen SM, Nelemans PJ, Beets GL, van de Velde CJ, van Engelshoven JM, Beets-Tan RG. Imaging for predicting the risk factors--the circumferential resection margin and nodal disease-of local recurrence in rectal cancer: a meta-analysis. Semin Ultrasound CT MR 2005;26(4): 259-268.

5. Valentini V, van Stiphout RG, Lammering G, Gambacorta MA, Barba MC, Bebenek M, Bonnetain F, Bosset JF, Bujko K, Cionini L, Gerard JP, Rodel C, Sainato A, Sauer R, Minsky BD, Collette L, Lambin P. Nomograms for predicting local recurrence, distant metastases, and overall survival for patients with locally advanced rectal cancer on the basis of European randomized clinical trials. $J$ Clin Oncol 2011;29(23): 3163-3172.

6. Collette L, Bosset JF, den Dulk M, Nguyen F, Mineur L, Maingon P, Radosevic-Jelic L, Pierart M, Calais G. Patients with curative resection of cT3-4 rectal cancer after preoperative radiotherapy or radiochemotherapy: does anybody benefit from adjuvant fluorouracil-based chemotherapy? A trial of the European Organisation for Research and Treatment of Cancer Radiation Oncology Group. $J$ Clin Oncol 2007;25(28): 4379-4386.

7. Capirci C, Valentini V, Cionini L, De Paoli A, Rodel C, Glynne-Jones R, Coco C, Romano M, Mantello G, Palazzi S, Mattia FO, Friso ML, Genovesi D, Vidali C, Gambacorta MA, Buffoli A, Lupattelli M, Favretto MS, La Torre G. Prognostic value of pathologic complete response after neoadjuvant therapy in locally advanced rectal cancer: long-term analysis of 566 ypCR patients. Int $J$ Radiat Oncol Biol Phys 2008;72(1): 99-107.

8. Maas M, Nelemans PJ, Valentini V, Das P, Rodel C, Kuo LJ, Calvo FA, Garcia-Aguilar J, GlynneJones R, Haustermans K, Mohiuddin M, Pucciarelli S, Small W, Jr., Suarez J, Theodoropoulos G, Biondo S, Beets-Tan RG, Beets GL. Long-term outcome in patients with a pathological complete response after chemoradiation for rectal cancer: a pooled analysis of individual patient data. Lancet Oncol 2010;11(9): 835-844.

9. Goethals L, Haustermans K, Perneel C, Bussels B, D'Hoore A, Geboes K, Ectors N, Van Cutsem E, Van den Bogaert W, Penninckx F. Chemo-radiotherapy versus radiotherapy alone in the preoperative treatment of resectable rectal cancer. Eur J Surg Oncol 2005;3 1(9): 969-976.

10. Mohiuddin M, Hayne M, Regine WF, Hanna N, Hagihara PF, McGrath P, Marks GM. Prognostic significance of postchemoradiation stage following preoperative chemotherapy and radiation for advanced/recurrent rectal cancers. Int J Radiat Oncol Biol Phys 2000;48(4): 1075-1080.

11. Shivnani AT, Small W, Jr., Stryker SJ, Kiel KD, Lim S, Halverson AL, Talamonti MS. Preoperative chemoradiation for rectal cancer: results of multimodality management and analysis of prognostic factors. Am J Surg 2007;193(3): 389-393; discussion 393-384.

12. Guillem JG, Chessin DB, Cohen AM, Shia J, Mazumdar M, Enker W, Paty PB, Weiser MR, Klimstra D, Saltz L, Minsky BD, Wong WD. Long-term oncologic outcome following preoperative combined modality therapy and total mesorectal excision of locally advanced rectal cancer. Ann Surg 2005;241(5): 829-836. 
13. Govindarajan A, Reidy D, Weiser MR, Paty PB, Temple LK, Guillem JG, Saltz LB, Wong WD, Nash GM. Recurrence Rates and Prognostic Factors in ypNo Rectal Cancer After Neoadjuvant Chemoradiation and Total Mesorectal Excision. Ann Surg Oncol 2011.

14. Biondo S, Navarro M, Marti Rague J, Arriola E, Pares D, Del Rio C, Cambray M, Novell V. Response to neoadjuvant therapy for rectal cancer: influence on long-term results. Colorectal Dis 2005;7(5): 472-479.

15. Diaz-Gonzalez JA, Calvo FA, Cortes J, Garcia-Sabrido JL, Gomez-Espi M, Del Valle E, MunozJimenez F, Alvarez E. Prognostic factors for disease-free survival in patients with T3-4 or N+ rectal cancer treated with preoperative chemoradiation therapy, surgery, and intraoperative irradiation. Int J Radiat Oncol Biol Phys 2006;64(4): 1122-1128.

16. Garcia-Aguilar J, Hernandez de Anda E, Sirivongs P, Lee SH, Madoff RD, Rothenberger DA. A pathologic complete response to preoperative chemoradiation is associated with lower local recurrence and improved survival in rectal cancer patients treated by mesorectal excision. Dis Colon Rectum 2003;46(3): 298-304.

17. Hughes R, Glynne Jones R, Grainger J, Richman P, Makris A, Harrison M, Ashford R, Harrison RA, Livingstone JI, McDonald PJ, Meyrick Thomas J, Mitchell IC, Northover JM, Phillips R, Wallace M, Windsor A, Novell JR. Can pathological complete response in the primary tumour following pre-operative pelvic chemoradiotherapy for T3-T4 rectal cancer predict for sterilisation of pelvic lymph nodes, a low risk of local recurrence and the appropriateness of local excision? Int $J$ Colorectal Dis 2006;21(1): 11-17.

18. Janjan NA, Crane C, Feig BW, Cleary K, Dubrow R, Curley S, Vauthey JN, Lynch P, Ellis LM, Wolff R, Lenzi R, Abbruzzese J, Pazdur R, Hoff PM, Allen P, Brown T, Skibber J. Improved overall survival among responders to preoperative chemoradiation for locally advanced rectal cancer. $\mathrm{Am} J$ Clin Oncol 2001;24(2): 107-112.

19. Kuo LJ, Liu MC, Jian JJ, Horng CF, Cheng TI, Chen CM, Fang WT, Chung YL. Is final TNM staging a predictor for survival in locally advanced rectal cancer after preoperative chemoradiation therapy? Ann Surg Oncol 2007;14(10): 2766-2772.

20. Pucciarelli S, Toppan P, Friso ML, Russo V, Pasetto L, Urso E, Marino F, Ambrosi A, Lise M. Complete pathologic response following preoperative chemoradiation therapy for middle to lower rectal cancer is not a prognostic factor for a better outcome. Dis Colon Rectum 2004;47(11): 17981807.

21. Rodel C, Martus P, Papadoupolos T, Fuzesi L, Klimpfinger M, Fietkau R, Liersch T, Hohenberger W, Raab R, Sauer R, Wittekind C. Prognostic significance of tumor regression after preoperative chemoradiotherapy for rectal cancer. J Clin Oncol 2005;23(34): 8688-8696.

22. Suarez J, Vera R, Balen E, Gomez M, Arias F, Lera JM, Herrera J, Zazpe C. Pathologic response assessed by Mandard grade is a better prognostic factor than down staging for disease-free survival after preoperative radiochemotherapy for advanced rectal cancer. Colorectal Dis 2008;10(6): 563-568.

23. Theodoropoulos G, Wise WE, Padmanabhan A, Kerner BA, Taylor CW, Aguilar PS, Khanduja KS. T-level downstaging and complete pathologic response after preoperative chemoradiation for advanced rectal cancer result in decreased recurrence and improved disease-free survival. Dis Colon Rectum 2002;45(7): 895-903.

24. Valentini V, Coco C, Picciocchi A, Morganti AG, Trodella L, Ciabattoni A, Cellini F, Barbaro B, Cogliandolo S, Nuzzo G, Doglietto GB, Ambesi Impiombato F, Cosimelli M. Does downstaging predict improved outcome after preoperative chemoradiation for extraperitoneal locally advanced rectal cancer? A long-term analysis of 165 patients. Int J Radiat Oncol Biol Phys 2002;53(3): 664-674.

25. Bellera CA, MacGrogan G, Debled M, de Lara CT, Brouste V, Mathoulin-Pelissier S. Variables with time-varying effects and the Cox model: some statistical concepts illustrated with a prognostic factor study in breast cancer. BMC Med Res Methodol 2010;10: 20. 
26. Bujko K, Glynne-Jones R, Bujko M. Does adjuvant fluoropyrimidine-based chemotherapy provide a benefit for patients with resected rectal cancer who have already received neoadjuvant radiochemotherapy? A systematic review of randomised trials. Ann Oncol 2010;21(9): 1743-1750.

27. Gray R, Barnwell J, McConkey C, Hills RK, Williams NS, Kerr DJ. Adjuvant chemotherapy versus observation in patients with colorectal cancer: a randomised study. Lancet 2007;370(9604): 20202029.

28. Bosset JF, Collette L, Calais G, Mineur L, Maingon P, Radosevic-Jelic L, Daban A, Bardet E, Beny A, Ollier JC. Chemotherapy with preoperative radiotherapy in rectal cancer. $N$ Engl $\mathrm{J} \mathrm{Med}$ 2006;355(11): 1114-1123. 



\section{CHAPTER 7}

What is the most accurate whole-body imaging modality for assessment of local and distant recurrent disease in colorectal cancer? A meta-analysis

Imaging for recurrent colorectal cancer

M. Maas

I.J.G. Rutten

P. Nelemans

D.M.J. Lambregts

V.C. Cappendijk

G.L. Beets

R.G.H. Beets-Tan

Eur J Nucl Med Mol Imaging 2011;38:1560-1571 


\begin{abstract}
Background. To compare the diagnostic performance of PET, PET/CT, CT and MRI as whole-body imaging modalities for the detection of local and/or distant recurrent disease in colorectal cancer (CRC) patients who have a (high) suspicion of recurrent disease, based on clinical findings or rise in carcinoembryogenic antigen (CEA).

Methods. A meta-analysis was undertaken. Pubmed and Embase were searched for studies on the accuracy of whole-body imaging for patients with suspected local and/or distant recurrence of their CRC. Additionally, studies had to have included at least 20 patients with CRC and $2 \times 2$ contingency tables had to be provided or derivable. Articles evaluating only local recurrence or liver metastasis were excluded. Summary receiver operator characteristics (ROC) curves were constructed from the data on sensitivity and specificity of individual studies and pooled estimates of diagnostic odds ratios (DORs) and areas under the ROC curve (AUCs) were calculated. To test for heterogeneity the Cochran Q-test was used.

Findings. 14 observational studies were included which evaluated PET, PET/CT, CT and/or MRI. Study results were available in 12 studies for PET, in 5 studies for CT, in 5 studies for PET/CT and in one study for MRI. AUCs for PET, PET/CT and CT were 0.94 (0.90-0.97), 0.94 (0.87-0.98) and 0.83 (0.72-0.90), respectively. In patient based analyses PET/CT had higher diagnostic performance than PET with an AUC of 0.95 (0.89-0.97) for PET/CT vs. 0.92 (0.86-0.96) for PET.

Conclusions. Both whole-body PET and PET/CT are very accurate for the detection of local and/or distant recurrent disease in CRC patients with a (high) suspicion of recurrent disease. CT has lowest diagnostic performance. This difference is probably mainly due to the lower accuracy of CT for detection of extrahepatic metastases (including local recurrence). For clinical practice PET/CT might be the modality of choice when evaluating patients with a (high) suspicion for recurrent disease, because of its best performance in patient based analyses and confident prediction of disease status.
\end{abstract}




\section{Introduction}

Nineteen percent of patients with colorectal cancer are diagnosed with distant metastasis at initial presentation, which (when undertreated) is associated with a 5 -year survival rate of $7 \% .{ }^{1}$ Furthermore, local and distant recurrences occur in $30-50 \%$ of patients during follow-up after primary surgery. ${ }^{2}$ Whereas in many patients metastatic disease cannot be cured, in carefully selected patients a resection of the metastases has been reported to result in 5-year survival rates up to $30-40 \% .^{3}$ The therapeutic options for colorectal metastases - including surgery and chemotherapy - as well as the clinical outcome depend strongly on accurate evaluation and early identification of recurrent lesions.

Metastatic disease in colorectal cancer is most common in liver and lung, but can affect the whole body. Whole-body imaging is important in different clinical settings. First, at primary staging of colorectal cancer it is important to determine the local and distant spread of the tumour to determine the risk profile and the indicated treatment. Second, whole body imaging can be used either as part of a surveillance programme after surgery for colorectal cancer or when a recurrence is suspected on the basis of clinical examinations. In the clinical setting in which patients have suspected recurrence, it is unclear which whole-body staging modality is most accurate for the detection of a recurrence. Currently, in this specific setting, computed tomography (CT) is used to detect recurrence, even though CT has a high false-positive rate for pulmonary lesions and high false-negative rate for extrahepatic intra-abdominal lesions (e.g. para-aortic nodes)., ${ }^{5}$ Several studies have reported good results for whole-body staging with $18 \mathrm{~F}$-fluorodeoxyglucose (FDG) positron emission tomography (PET) and FDG PET/CT. ${ }^{6-8}$ The experience with magnetic resonance imaging (MRI) is limited.

So far, there is no consensus on which is the most accurate whole body imaging technique for colorectal cancer patients who have a suspicion for recurrence based on clinical findings or rise in CEA. Therefore, the objective of the present study is to perform a meta-analysis of published studies in order to determine what is the most accurate whole-body imaging modality for the detection of recurrent disease in patients with colorectal cancer who have suspected local and/or distant recurrent disease and to advise which modality is most suitable in clinical practice.

\section{Methods}

A literature search was performed in Pubmed/MEDLINE and Embase up to May 2010 using the following search terms: 'colorectal neoplasm or carcinoma or cancer', 'whole-body imaging or staging', 'neoplasm staging', 'colorectal', 'metastasis', 'recurrence', 'positron-emission tomography' or 'PET', 'magnetic resonance imaging' or 'MRI', 'computed tomography' or 'CT' and 'PET-CT' or 'PET/CT'. PET refers to FDG-PET. No language restriction was used. Studies were included when they met 
the following criteria: (a) focus on metastasis and/or recurrence detection in patients with suspected recurrence in the follow-up for colorectal cancer, (b) study population included more than 20 patients with colorectal cancer, (c) results were given in a $2 \times 2$ contingency table or this table could otherwise be derived from the article, and (d) reference standard combined histology with follow-up. Case reports, reviews, articles that evaluated local staging only or detection of liver metastases only, and studies that evaluated whole-body imaging at primary staging or for patients with known hepatic metastases were excluded. Last, studies which evaluated response to therapy only were also excluded.

Two reviewers (IJGR and MM) independently searched the databases for eligible studies. The reviewers checked the titles and abstracts of the identified studies in order to select studies which potentially met the inclusion criteria. Thereafter they independently studied full text copies of the selected studies to make a decision as to which studies met the inclusion criteria. In case of disagreement, consensus was reached. Reference lists were checked to find additional eligible studies. Data which were extracted from the studies were: (1) number, gender and age of patients, (2) study objective, (3) type of reference standard, (4) unit of analysis (lesion or patient based analysis), (5) degree of blinding, (6) duration of follow-up, and (7) prevalence of disease. Study quality was assessed with the QUADAS checklist for studies of diagnostic accuracy included in systematic reviews. ${ }^{9}$

\section{Statistical analysis}

Preferably, results from lesion based analyses were used for this meta-analysis, but part of the studies only reported data on a patient basis. Based on the results from the (derived) $2 \times 2$ contingency tables, pooled measures for diagnostic performance, such as sensitivity, specificity, diagnostic odds ratio (DOR) and area under the receiver operator characteristics curve (AUC), were calculated using random effects models. The pooled DOR for each imaging modality was used for the construction of summary receiver operating characteristic (SROC) curves. SROC curves account for the so-called threshold effect in diagnostic studies, which arises when studies use different cut-off points or thresholds to define a positive or negative test result. The DORs combine sensitivity and specificity into one measure for diagnostic performance. A DOR of 1 means that the test has no ability to discriminate. The higher the DOR, the better the ability of a test to discriminate between subjects with and without the disease of interest. To test differences in diagnostic performance between modalities for statistical significance, the relative DOR of one modality compared to another was calculated with its corresponding p-value.

The Cochran $Q$ test was used to test for heterogeneity between individual study results. Significance of this test indicates that differences between study results cannot solely be attributed to sampling variation. The p-value for heterogeneity was considered significant when $\mathrm{p}<0.10$, because heterogeneity tests are known for its lack of statistical power. Differences in DORs between studies can also result from 
differences in design, case mix and analysis. To account for heterogeneity, the DOR and AUC for the imaging modalities under study were pooled within subgroups of studies. These subgroups were made according to the presence or absence of a specific study characteristic that can affect the estimate of the diagnostic performance of a modality.

Pooled estimates of diagnostic performance and relative DORs were calculated with MetaDiSc version $1.4^{10}$, a software programme which implements metaregression using a generalization of a model that was proposed by Moses et al. ${ }^{11}$

\section{Results}

With the search 82 studies were retrieved, of which a total of 60 articles potentially met the inclusion criteria after selection based on titles and abstracts. Out of these 60 articles, 46 were excluded ${ }^{12-56}$, leaving 14 articles for inclusion. ${ }^{2,}$ 6-8, 57-66 The 45 articles were excluded because of the following reasons. Nineteen articles studied

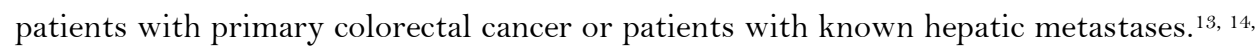
16, 18, 20, 21, 23, 25, 29, 30, 33-36, 38, 40, 41, 44, 55, 56 Nine studies were excluded because they included less than 20 patients with colorectal cancer. ${ }^{12}$, 15, 19, 22, 24, 26, 31, 32, 50 Six articles were excluded because a $2 \times 2$ contingency table could not be constructed $^{28,39,43,45,53,54}$, five evaluated patients after recent treatment with chemotherapy or evaluated response after treatment and were therefore excluded $17,27,37,42,49$ and three were a meta-analysis and/or review. ${ }^{47,48,52}$ One was a case report. ${ }^{51}$ One article evaluated the accuracy of a combination of diagnostic modalities to detect lesions without specifying individual accuracies per modality and was thus excluded. ${ }^{46}$ Finally, one study was excluded because it only evaluated the clinical reports for PET and did not re-evaluate the images for the study. ${ }^{67}$ Study identification and inclusion are shown in a flowchart in figure 1. Results of the quality assessment with the QUADAS checklist are shown in table 1.

Individual study characteristics are presented in table 2. Of the 14 articles included, three studied a single modality $2,8,62$ and eleven compared two or three different modalities.6, 7, 57-61, 63-66 Grouping the articles according to investigated imaging modality, 12 articles studied the performance of PET 


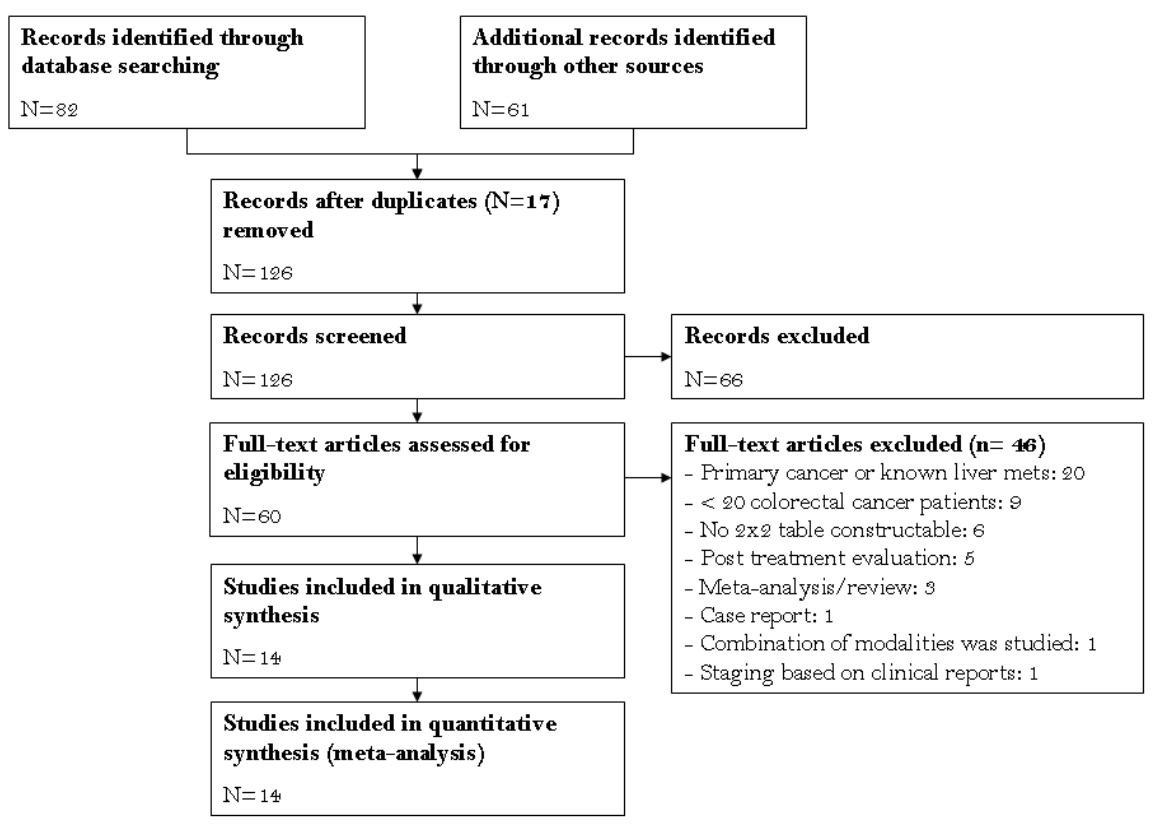

Figure 1. PRISMA flowchart describing the identification and inclusion of studies.

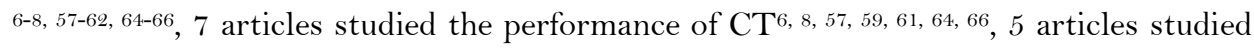
the performance of $\mathrm{PET} / \mathrm{CT}^{2,7,58,61,63}$ and one article studied the performance of MRI. ${ }^{63}$ In two studies which evaluated both PET and CT only part of the thorax and abdomen was imaged with $\mathrm{CT}$ and therefore only the results for PET were included from these studies. ${ }^{59,66}$ So, in total results from 5 studies were available for CT. All CT studies used intravenous contrast. The number of patients ranged from 24 to 115 patients per study, with a total of 871 patients evaluated in all included studies. The percentage of male patients varied from $46 \%$ to $71 \%$ and the mean or median or mean age ranged from 58-68 years. All studies used histopathology or a combination of histopathology, clinical and radiological follow-up, conventional diagnostic modalities (X-ray, endoscopy, ultrasound) and surgical exploration as reference method. The indication for whole-body imaging was suspected local or distant recurrence based on clinical symptoms, rise in carcinoembryonic antigen (CEA) levels, endoscopy findings or findings from other imaging methods in all studies for all or the majority of patients.

Estimates of diagnostic performance, such as sensitivity, specificity, positive and negative predictive value, accuracy, DOR and AUC, for all individual studies are shown in table 3. 


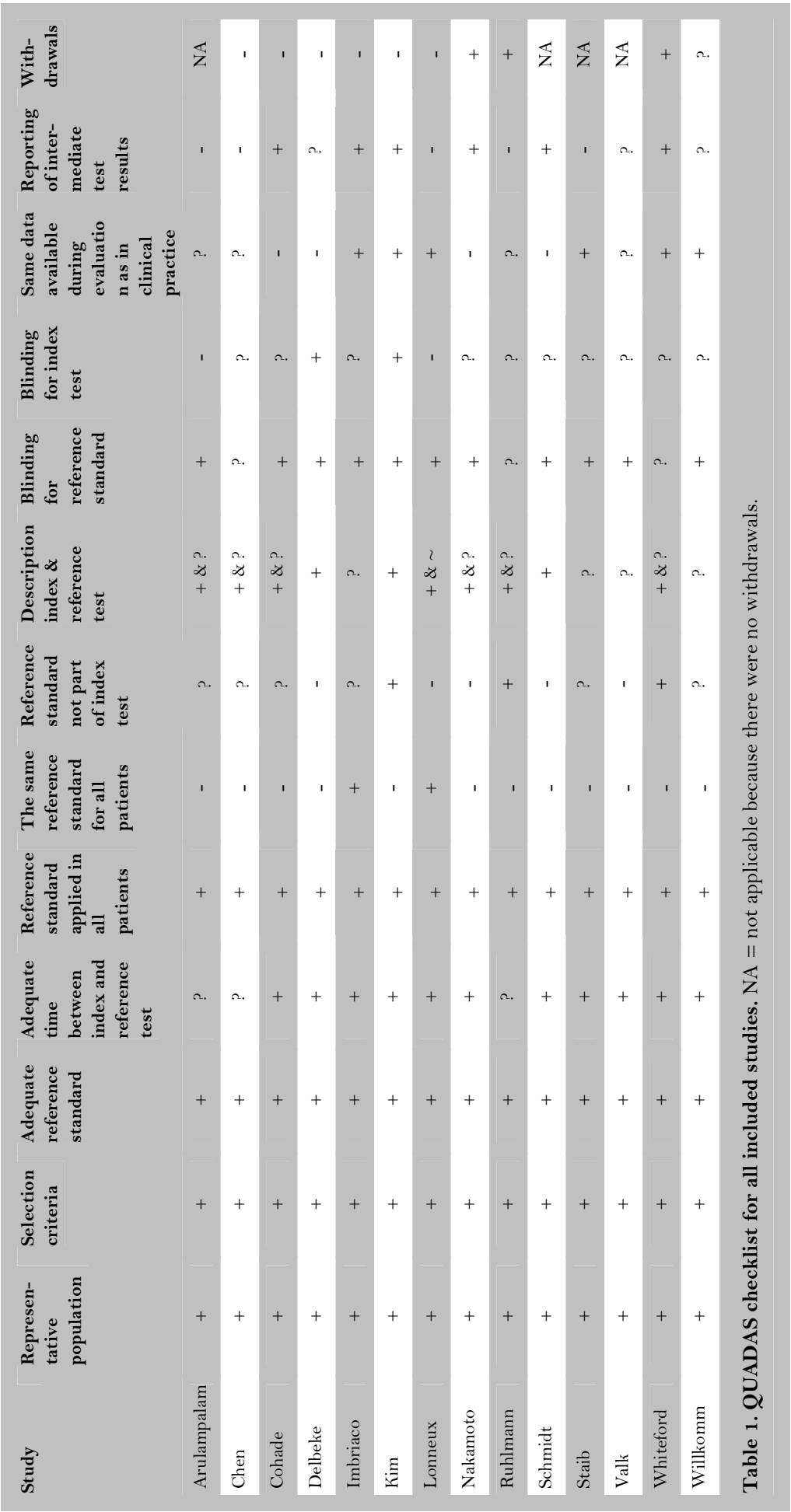




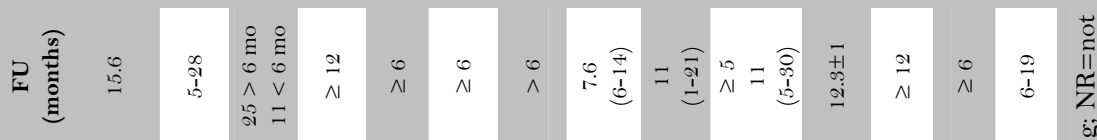

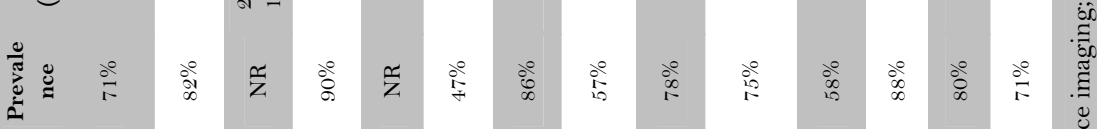

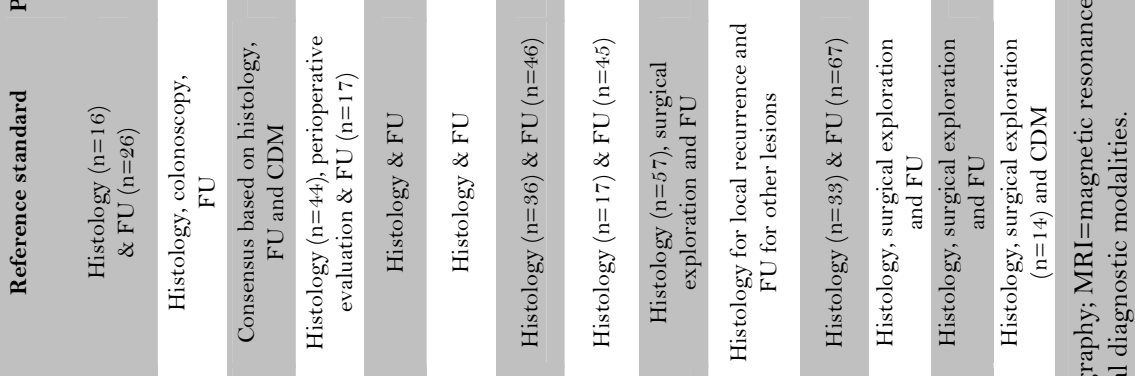

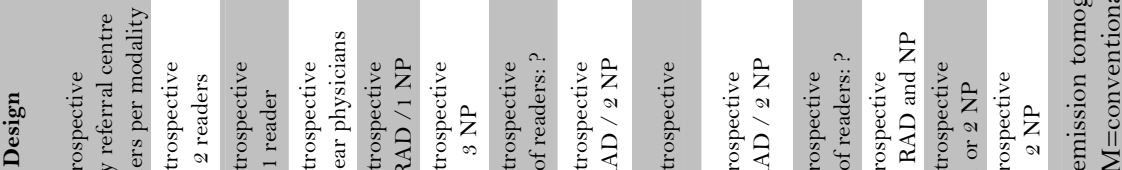

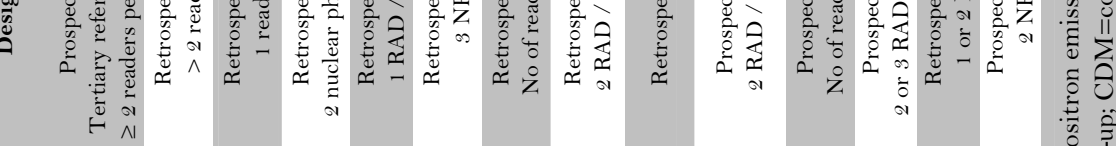

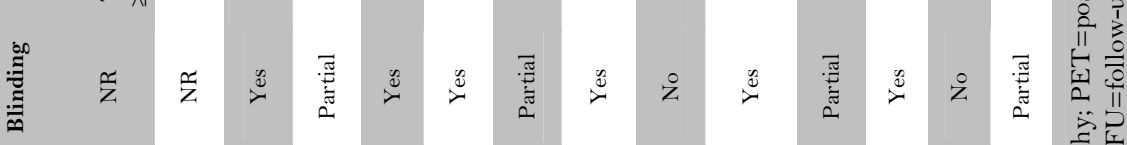

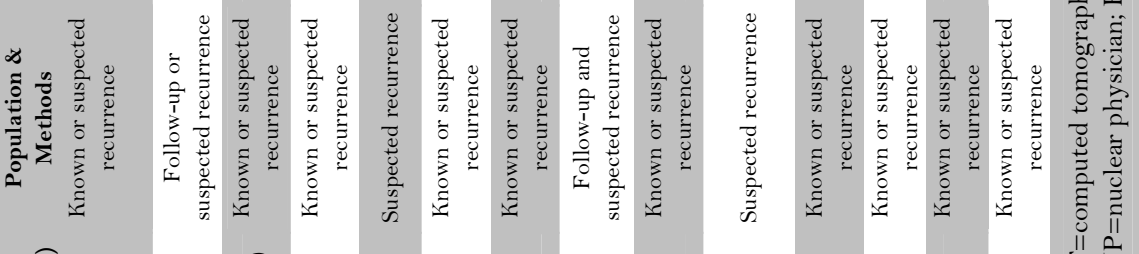

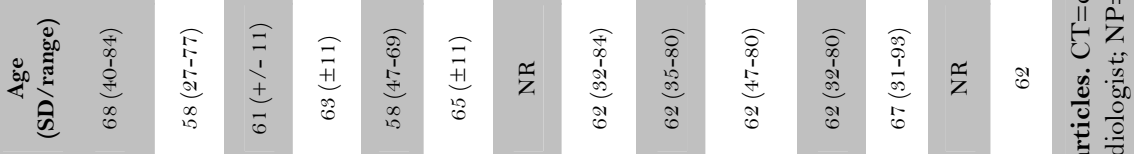
䒕

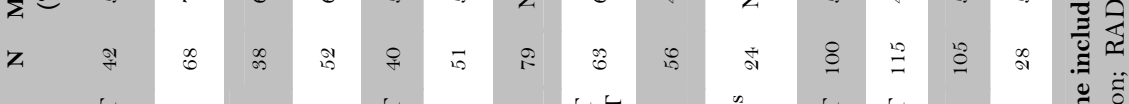

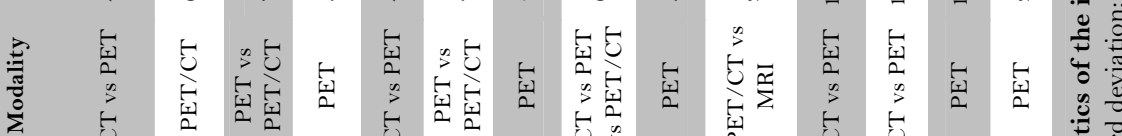

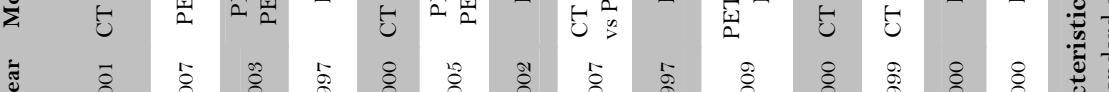

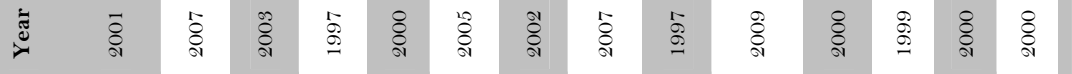

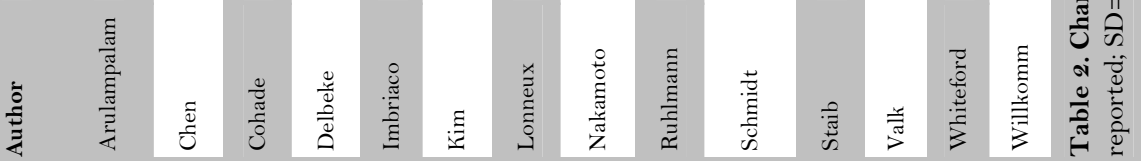




\begin{tabular}{|c|c|c|c|c|c|c|c|c|}
\hline Author & Modality & Unit of Analysis & Sensitivity & Specificity & PPV & NPV & Accuracy & DOR \\
\hline Arulampalam 2001 & PET & $\mathrm{PbP}$ & 93 & 58 & 85 & 78 & 83 & 16 \\
\hline Cohade 2003 & PET & LbL & 88 & 56 & 92 & 43 & 83 & 8 \\
\hline Delbeke 1997 & PET & Both & 94 & 86 & 97 & 73 & 92 & 74 \\
\hline Imbriaco 2000 & PET & LbL & 94 & 95 & 96 & 93 & 95 & 222 \\
\hline Kim 2005 & PET & Both & 74 & 93 & 77 & 92 & 88 & 33 \\
\hline Lonneux 2002 & PET & Both & 97 & 73 & 96 & 80 & 94 & 465 \\
\hline Nakamoto 2007 & PET & $\mathrm{PbP}$ & 75 & 82 & 84 & 71 & 78 & 12 \\
\hline Ruhlmann 1997 & PET & $\mathrm{PbP}$ & 100 & 75 & 94 & 100 & 95 & 236 \\
\hline Staib 2000 & PET & $\mathrm{PbP}$ & 98 & 91 & 93 & 98 & 95 & 328 \\
\hline Valk 1999 & PET & $\mathrm{PbP}$ & 96 & 71 & 96 & 71 & 93 & 51 \\
\hline Whiteford 2000 & PET & $\mathrm{PbP}$ & 87 & 68 & 92 & 58 & 84 & 697 \\
\hline Willkomm 2000 & PET & $\mathrm{PbP}$ & 100 & 100 & 100 & 100 & 100 & 14 \\
\hline Arulampalam 2001 & CT & $\mathrm{PbP}$ & 73 & 75 & 88 & 53 & 74 & 7 \\
\hline Imbriaco 2000 & CT & LbL & 74 & 70 & 77 & 67 & 72 & 6 \\
\hline Nakamoto 2007 & CT & $\mathrm{PbP}$ & 69 & 93 & 93 & 69 & 79 & 51 \\
\hline Staib 2000 & CT & $\mathrm{PbP}$ & 91 & 72 & 80 & 87 & 82 & 22 \\
\hline Valk 1999 & $\mathrm{CT}$ & $\mathrm{PbP}$ & 78 & 50 & 92 & 24 & 75 & 4 \\
\hline Chen 2007 & $\mathrm{PET} / \mathrm{CT}$ & $\mathrm{PbP}$ & 95 & 83 & 96 & 77 & 93 & 64 \\
\hline Cohade 2003 & $\mathrm{PET} / \mathrm{CT}$ & $\mathrm{LbL}$ & 86 & 67 & 94 & 44 & 83 & 11 \\
\hline Kim 2005 & $\mathrm{PET} / \mathrm{CT}$ & Both & 89 & 98 & 94 & 96 & 96 & 298 \\
\hline Nakamoto 2007 & $\mathrm{PET} / \mathrm{CT}$ & $\mathrm{PbP}$ & 75 & 96 & 96 & 74 & 84 & 23 \\
\hline Schmidt 2009 & $\mathrm{PET} / \mathrm{CT}$ & Both & 86 & 97 & 96 & 88 & 91 & 136 \\
\hline Schmidt 2009 & MRI & Both & 73 & 93 & 90 & 79 & 83 & 35 \\
\hline \multicolumn{9}{|c|}{$\begin{array}{l}\text { Table 3. Diagnostic performance for all the included studies, sorted by modality. PET = positron emission } \\
\text { tomography, } \mathrm{CT}=\text { computed tomography, } \mathrm{PET} / \mathrm{CT}=\text { positron emission tomography combined with computed } \\
\text { tomography, } \mathrm{MRI}=\text { magnetic resonance imaging. } \mathrm{PPV}=\text { positive predictive value, } \mathrm{NPV}=\text { negative predictive value, } \\
\mathrm{PbP}=\text { patient-by-patient based analysis, } \mathrm{LbL}=\text { lesion-by-lesion based analysis. If both lesion based and patient based } \\
\text { results were provided, results for lesion based analyses are shown in this table. }\end{array}$} \\
\hline
\end{tabular}

\section{Summary Receiver Operator Characteristic curves}

SROC curves for the diagnostic performance of PET, PET/CT, and CT and the individual study results are shown in figure 2. PET and PET/CT had the best diagnostic performance for recurrence detection, with DORs of 55.2 (95\%CI 23.2131.2 ) and 55.3 (95\%CI 15.9-191.8), respectively, compared to a DOR of 9.8 (95\%CI 4.2-22.8) for CT. The single study concerning MRI was not included in the regression analysis but the results are shown in the graph as a single value. The DOR for this MRI study was 35.1 (95\%CI 13.5-90.4). The corresponding AUCs for PET, PET/CT 


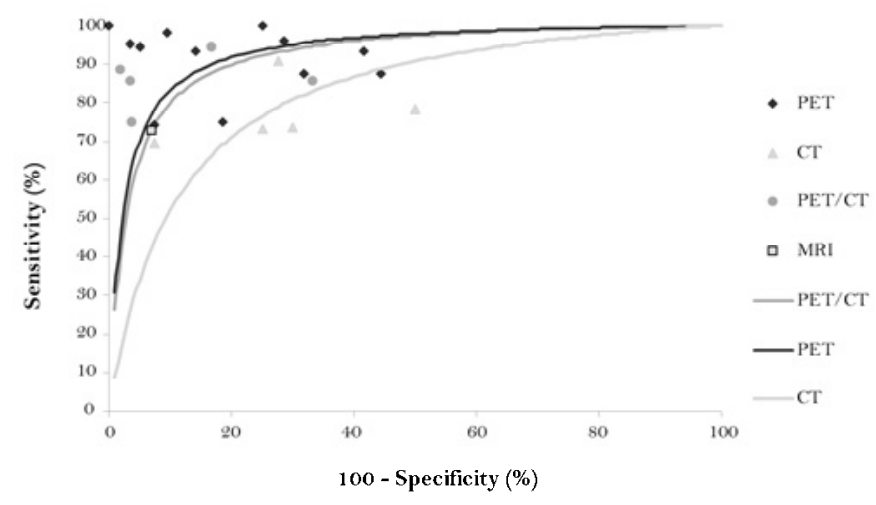

Figure 2. Summary ROC curves with all individual study results for all modalities. The single study on MRI is displayed as a single value in the graph. PET = positron emission tomography $(\mathrm{n}=12)$, $\mathrm{CT}=$ computed tomography $(\mathrm{n}=5), \mathrm{PET} / \mathrm{CT}=$ combined positron emission tomography and computed tomography $(\mathrm{n}=5), \mathrm{MRI}=$ magnetic resonance imaging $(\mathrm{n}=1)$

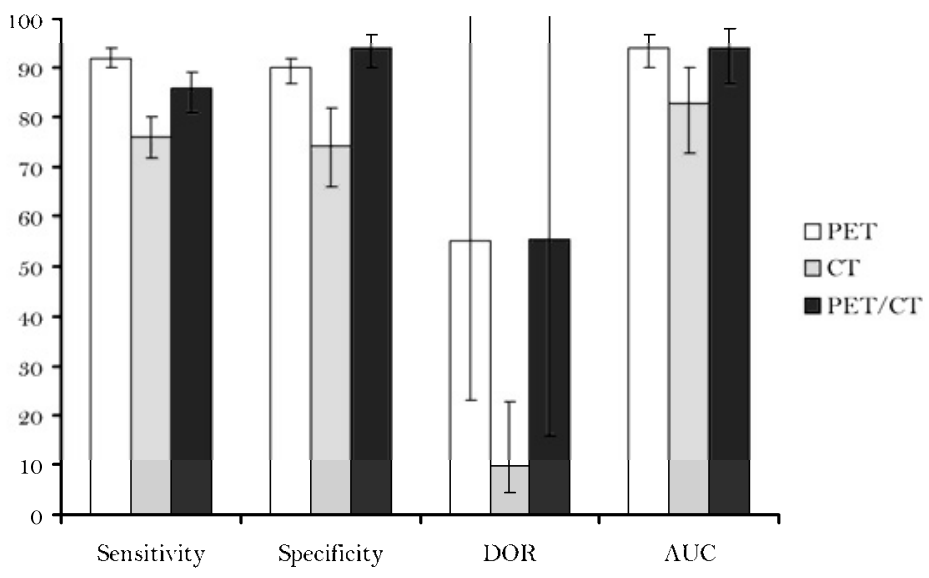

Figure 3. Pooled sensitivity (\%) and specificity (\%), area under the receiver operator characteristics curve (AUC, \%) and diagnostic odds ratio (DOR) for computed tomography (CT), positron emission tomography (PET) and PET/CT with 95\% confidence intervals indicated by error bars. 
and CT for recurrence detection were 0.94 (95\%CI 0.90-0.97), 0.94 (95\%CI 0.87-0.98) and 0.83 (95\%CI 0.72-0.90), respectively. CT had a significantly lower diagnostic performance than PET $(\mathrm{p}=0.021)$. Between CT and PET/CT the difference was not significant $(\mathrm{p}=0.10)$. The difference between PET and PET/CT was not significant either $(p=0.66)$. AUC for the single MRI study was 0.92 (95\%CI 0.86-0.96). Pooled sensitivity and specificity, AUC and DOR for the modalities are shown in figure 3.

\section{Subgroup analyses}

The Cochran $Q$ test showed that there is significant heterogeneity between study results for each imaging modality $(\mathrm{p}<0.10)$. This heterogeneity is also illustrated in figure 2, which shows substantial scatter of observed pairs of sensitivity and specificity of individual studies around the fitted SROC curves. To correct for potential sources of heterogeneity subgroup analyses were performed. Pooled estimates of diagnostic performance were calculated within subsets of studies that differed with respect to factors that potentially can affect diagnostic performance: 1) unit of analysis (patient based versus lesion based), 2) prevalence (percentage of patients with malignant disease in the studied population) as an indicator of disease spectrum ( $<75 \%$ versus $\geq 75 \%), 3$ ) blinding to clinical information (yes versus no), 4) design (retrospective versus prospective), and 5) year of publication (<2003 versus $\geq 2003$ ). Full blinding was defined as blinding to both clinical information and other imaging results. Partial blinding was defined as blinding for other imaging results only. In all subgroups CT remained the modality with the lowest diagnostic performance. The results of the subgroup analyses are displayed in figure 4. PET had significantly lower diagnostic performance when a study was published after 2003: AUC was 0.96 (95\%CI 0.92-0.98) before 2003 vs. 0.87 (95\%CI 0.78-0.92) after 2003, $\mathrm{p}=0.013$.

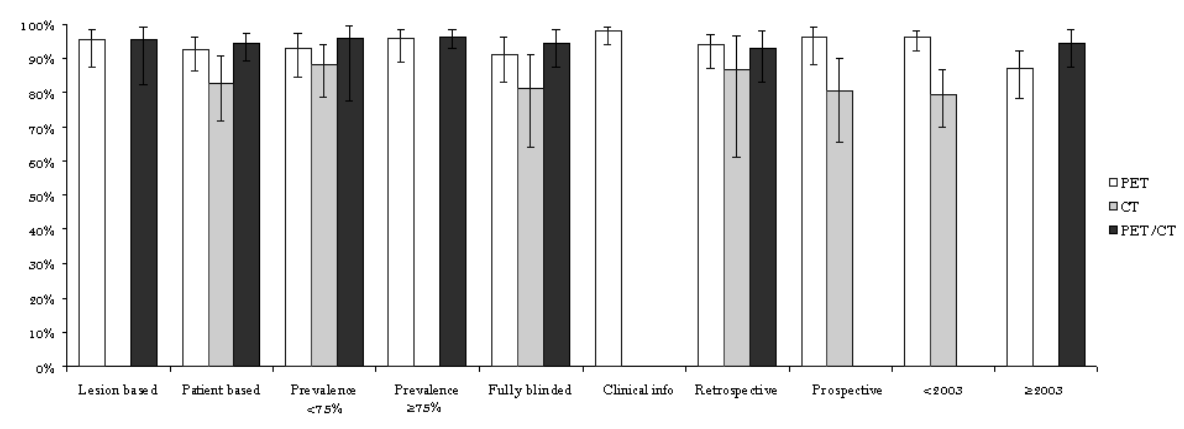

Figure 4. Areas under the summary receiver operator characteristics curve with $95 \%$ confidence intervals (error bars) per modality for subgroups. Prevalence refers to the prevalence of disease in the studied population. Fully blinded is defined as reading the images without any knowledge about the patient. Clinical info indicates that readers were aware of clinical information about the patients, but had no knowledge about results from other imaging studies. In some subgroups columns are missing for one or more modalities, because no or only one study was available for that subgroup and thus the subgroup analysis could not be performed 


\section{Discussion}

In this meta-analysis we compared PET, PET/CT, CT and MRI for whole-body staging in patients who have suspected recurrence in the follow-up for curatively treated colorectal cancer. We found that PET and PET/CT have high diagnostic performance with an AUC of 0.94 for both PET and PET/CT. CT had a significantly lower diagnostic performance than PET or PET/CT with an AUC of 0.83. This lower diagnostic performance persisted after correction for differences in design and analysis of studies. The subgroup analyses showed that in studies in which readers were fully blinded (to both clinical information and other imaging results) or in studies which were published after 2003 diagnostic performance was lower for PET. The single study evaluating MRI showed a high AUC of 0.92.

$\mathrm{PET}$ and PET/CT were the most accurate modalities. PET and PET/CT are metabolic imaging techniques that provide information on the nature of a lesion based on differences in glucose metabolism. Malignant lesions have a higher glucose metabolism and thus a higher uptake of FDG. These changes in metabolism are known to precede changes in morphology (which are evaluated with $\mathrm{CT}$ ), hence the higher sensitivity for PET or PET/CT than for CT in the detection of small malignant lesions. In figure $\mathrm{V}$ an illustration is given of a lesion with high FDG uptake (and thus detection with PET) which could not (yet) be identified with CT. FDG uptake is also increased in inflammatory tissue and in normal organs such as the brain, the urinary tract and bowel, causing false-positive findings. By combining the functional information of PET with the morphological information of CT false-positive errors can be reduced and superior performance of PET/CT over PET and CT as stand alone techniques is expected. Nevertheless, the results of our meta-analysis do not confirm superior performance for PET/CT over PET. There are some methodological issues related to this finding. Only three studies compared PET/CT with PET within the same patient group and therefore most of the data originated from studies without direct comparison of both modalities in the same patients. $7,58,61$ Differences in study designs between the PET and PET/CT studies could have influenced the results and this may have favoured the performance of PET. The results of the three studies that did compare PET with PET/CT in the same study population showed a superior performance for PET/CT, especially in the patient based analyses. ${ }^{7}, 58,61$ In our subgroup analyses of patient based study results we could confirm the higher performance of PET/CT over PET on a patient basis (AUC 0.95 for PET/CT vs. 0.92 for PET, figure IV). The three studies also found that readers were more confident in their diagnosis of lesions with PET/CT than with PET only. Kim et al. reported highest confidence level scores for PET/CT (91\%) compared to $61 \%$ for PET and $50 \%$ for CT. ${ }^{7}$ 


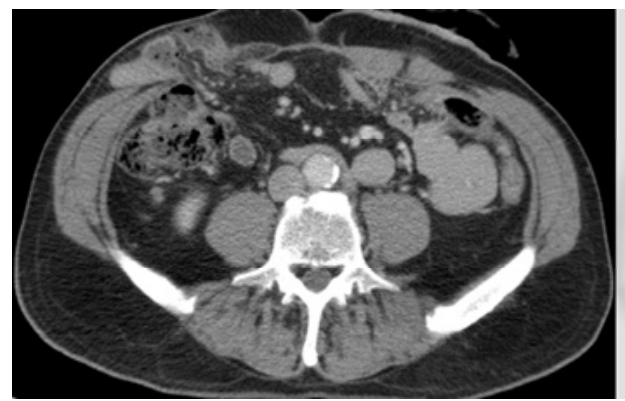

Figure 5. Diagnostic computed tomography (CT)-image (left) and positron emission tomography (PET)-image (right) of a patient who has a clearly visualised para-aortic lesion on PET (arrow), which cannot be discerned on CT.
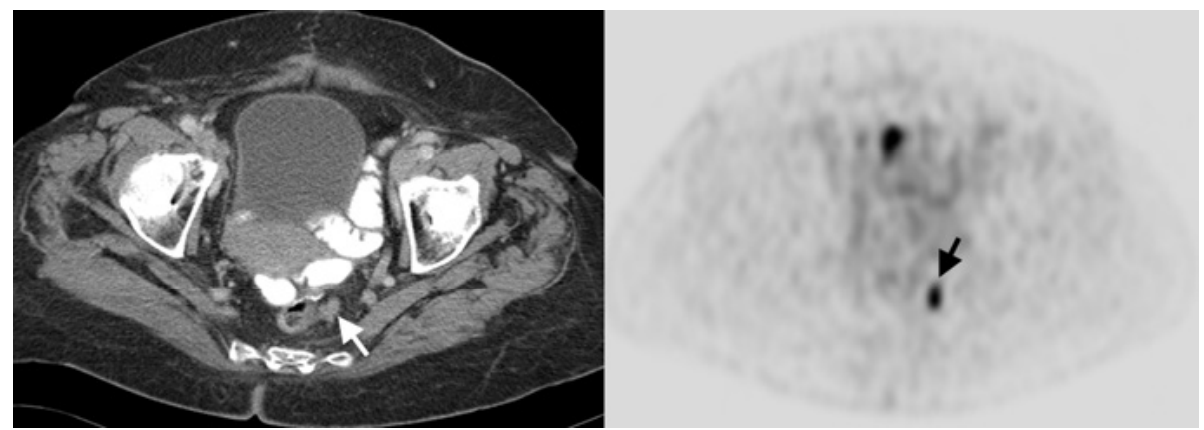

Figure 6. CT-image (left) and PET-image (right) of a patient with locally recurrent colorectal cancer after a sigmoid resection. On PET a clear hot spot (arrow) is found with increased FDG uptake, while on CT it was not recognised as a local recurrence (arrow).

CT had a lower diagnostic performance than PET/CT and PET. The cause may be that the accuracy of $\mathrm{CT}$ for extrahepatic metastasis detection is lower than that of $\mathrm{PET}$ and PET/CT. CT is known to be more accurate in the detection of hepatic than in the detection of extrahepatic metastases (including local recurrence), making it less ideal for whole-body staging. Studies in this meta-analysis have shown that with respect to the detection of extrahepatic lesions CT performs worse (sensitivities 53$71 \%$ and specificities 50-85\%) than PET (sensitivities $70-100 \%$ and specificities $40-$ $100 \%){ }^{59,} 61,66$ Several older reports have reported low diagnostic performance for the detection of local recurrence with CT. ${ }^{68,69} \mathrm{~A}$ more recent study by Stückle et al. with multi-slice CT acknowledged the low sensitivity (38-82\%) for local recurrence detection but reported high specificity (97-100\%) in the follow-up after surgery. ${ }^{70}$ Because the studied populations in our meta-analysis comprised of patients who had both local and distant recurrence the diagnostic performance of $\mathrm{CT}$ can be influenced by the fact that local recurrence detection is difficult with CT (figure VI). 
Finally, most included studies evaluating whole-body CT were performed around the year 2000 and it should be taken into account that since then quality of CT may have improved considerably. This may have caused underestimation of the diagnostic performance of CT in this meta-analysis. However, a more recent study (2007) comparing modern CT technique with PET and PET/CT within the same patient population by Nakamoto et al. still showed that CT had lowest diagnostic performance, while PET/CT was the most accurate modality.

An interesting finding in this meta-analysis is that in more recently published studies diagnostic performance of PET was significantly worse than in earlier publications. This phenomenon is observed more often in diagnostic studies and may be explained by publication bias. In the late nineties PET was a relatively new modality, so the chance for acceptance for publication was higher for positive study results. Another possible explanation is that study design and methodology have improved over time leading to more critical evaluation of the modality and thus possibly lower diagnostic performance of a modality.

Awareness of clinical information clearly improved performance. Diagnostic performance of studies in which readers were fully blinded was lower than in studies in which readers were aware of all clinical information except for results of other imaging modalities. The largest difference was observed for PET (AUC 0.91 for full blinding vs. 0.98 in case of awareness of clinical data). This finding is in agreement with clinical experience that knowledge of the clinical information of the patient is considered crucial to achieve sufficient diagnostic performance, particularly for PET. These findings underline the necessity for clinicians to provide radiologists and nuclear physicians with full information about the patient's clinical status and the importance for radiologists and nuclear physicians to be involved in multidisciplinary management teams, where they are confronted with the clinical situation.

One established modality that has been used increasingly in the last decade - in particular for the follow-up of patients with suspected local recurrence after surgery for rectal cancer - is MRI.71 Although MRI has shown to be feasible for the detection of local recurrences, its yield is not high enough to warrant routine use in the follow-up of rectal cancer patients. ${ }^{72,}$, 33 The single study that evaluated whole-body MRI showed good results, but more evidence is needed to establish the role of MRI in whole-body imaging for colorectal cancer.

\section{Limitations}

There are some limitations to this study. The first important issue is that this is a meta-analysis of published studies and therefore heterogeneity between studies is present. To account for this heterogeneity we performed subgroup analyses according to factors that were likely to cause heterogeneity and still found that CT had lower diagnostic performance than PET and PET/CT. However, because of the relatively small number of studies per modality, simultaneous correction for more than one study factor was not feasible, making our level of evidence less robust. Moreover, residual 
heterogeneity may have remained unexplained due to some unmeasured or unreported study characteristics, which is inherent to meta-analysis based on published data.

Second, in all studies a combination of pathology and follow-up was used as the reference standard. However, undetected lesions will not be discovered until they become visible with imaging and therefore there is a chance for verification bias. Most studies that used follow-up as the reference standard had a follow-up time of at least 6 months. However, small missed lesions might become visible after a longer interval. Verification bias could then lead to overestimations of accuracy.

Third, because we aimed to evaluate whole-body staging for the detection of both local and distant recurrences of colorectal cancer in patients with suspected recurrence based clinical findings or rise in CEA, we excluded studies which merely provided data on liver recurrence or local recurrence only.

Last, most PET/CT studies in our meta-analysis used side-by-side comparison of single PET and single CT, and fused PET/CT was only scarcely used.

\section{Conclusion}

Our study suggests that for whole-body imaging of patients with a (high) suspicion for recurrent CRC during follow-up PET/CT is the most accurate imaging modality, closely followed by PET, which performs slightly lower than PET/CT on a patient basis. CT has lowest diagnostic performance.

This meta-analysis explored diagnostic performance in the clinical setting in which patients had suspected local and/or distant recurrence based on clinical findings or rise in CEA. In current clinical practice CT is the mostly used modality for this type of patients and only when CT findings are equivocal PET or PET/CT is performed. Our meta-analysis shows that instead of CT as the first line imaging modality, PET/CT might be the recommended modality for patients with suspected local or distant recurrence based on clinical findings or rise in CEA. In such patients, a negative CT result does not seem to help in excluding a recurrence and should be followed by PET/CT anyhow. Furthermore, when CT findings are equivocal, PET/CT is needed to further characterise lesions and when CT detects malignant lesions, PET/CT is obligatory to search for additional metastases when curative surgery of the malignant lesions is considered. However, while interpreting these results one should keep in mind that there were some limitations of this meta-analysis with regard to heterogeneity and number of studies, which make the estimate of diagnostic performance less precise and less definitive. Furthermore, whether implementation of this recommended diagnostic strategy is feasible in clinical practice will also depend on the cost-effectiveness of this approach. 


\section{References}

1. Glimelius BL. The role of preoperative and postoperative radiotherapy in rectal cancer. Clin Colorectal Cancer 2002;2(2): 82-92.

2. Chen LB, Tong JL, Song HZ, Zhu H, Wang YC. (18)F-DG PET/CT in detection of recurrence and metastasis of colorectal cancer. World J Gastroenterol 2007;13(37): 5025-5029.

3. Elias D, Sideris L, Pocard M, Ouellet JF, Boige V, Lasser P, Pignon JP, Ducreux M. Results of Ro resection for colorectal liver metastases associated with extrahepatic disease. Ann Surg Oncol 2004;11(3): 274-280.

4. Pfannschmidt J, Bischoff M, Muley T, Kunz J, Zamecnik P, Schnabel PA, Hoffmann H, Dienemann H, Heussel CP. Diagnosis of pulmonary metastases with helical CT: the effect of imaging techniques. Thorac Cardiovasc Surg 2008;56(8): 471-475.

5. Wiering B, Ruers TJ, Krabbe PF, Dekker HM, Oyen WJ. Comparison of multiphase CT, FDG-PET and intra-operative ultrasound in patients with colorectal liver metastases selected for surgery. Ann Surg Oncol 2007;14(2): 818-826.

6. Imbriaco M, Akhurst T, Hilton S, Yeung HW, Macapinlac HA, Mazumdar M, Pace L, Kemeny N, Erdi Y, Cohen A, Fong Y, Guillem J, Larson SM. Whole-Body FDG-PET in Patients with Recurrent Colorectal Carcinoma. A Comparative Study with CT. Clin Positron Imaging 2000;3(3): 107-114.

7. Kim JH, Czernin J, Allen-Auerbach MS, Halpern BS, Fueger BJ, Hecht JR, Ratib O, Phelps ME, Weber WA. Comparison between 18F-FDG PET, in-line PET/CT, and software fusion for restaging of recurrent colorectal cancer. $J$ Nucl Med 2005;46(4): 587-595.

8. Willkomm P, Bender H, Bangard M, Decker P, Grunwald F, Biersack HJ. FDG PET and immunoscintigraphy with $99 \mathrm{mTc}$-labeled antibody fragments for detection of the recurrence of colorectal carcinoma. J Nucl Med 2000;41(10): 1657-1663.

9. Whiting P, Rutjes AW, Reitsma JB, Bossuyt PM, Kleijnen J. The development of QUADAS: a tool for the quality assessment of studies of diagnostic accuracy included in systematic reviews. BMC Med Res Methodol 2003;3: 25.

10. Zamora J, Abraira V, Muriel A, Khan K, Coomarasamy A. Meta-DiSc: a software for meta-analysis of test accuracy data. BMC Med Res Methodol 2006;6: 31.

11. Moses LE, Shapiro D, Littenberg B. Combining independent studies of a diagnostic test into a summary ROC curve: data-analytic approaches and some additional considerations. Stat Med 1993;12(14): 1293-1316.

12. Antoch G, Vogt FM, Freudenberg LS, Nazaradeh F, Goehde SC, Barkhausen J, Dahmen G, Bockisch A, Debatin JF, Ruehm SG. Whole-body dual-modality PET/CT and whole-body MRI for tumor staging in oncology. Jama 2003;290(24): 3199-3206.

13. Butch RJ, Stark DD, Wittenberg J, Tepper JE, Saini S, Simeone JF, Mueller PR, Ferrucci JT, Jr. Staging rectal cancer by MR and CT. AJR Am J Roentgenol 1986;146(6): 1155-1160.

14. Furukawa H, Ikuma H, Seki A, Yokoe K, Yuen S, Aramaki T, Yamagushi S. Positron emission tomography scanning is not superior to whole body multidetector helical computed tomography in the preoperative staging of colorectal cancer. Gut 2006;55(7): 1007-1011.

15. Goshen E, Davidson T, Aderka D, Zwas ST. PET/CT detects abdominal wall and port site metastases of colorectal carcinoma. Br J Radiol 2006;79(943): 572-577.

16. Pijl ME, Wasser MN, Joekes EC, van de Velde CJ, Bloem JL. Metastases of colorectal carcinoma: comparison of soft- and hard-copy helical CT interpretation. Radiology 2003;227(3): 747-751. 
17. Selzner M, Hany TF, Wildbrett P, McCormack L, Kadry Z, Clavien PA. Does the novel PET/CT imaging modality impact on the treatment of patients with metastatic colorectal cancer of the liver? Ann Surg 2004;240(6): 1027-1034; discussion 1035-1026.

18. Squillaci E, Manenti G, Mancino S, Ciccio C, Calabria F, Danieli R, Schillaci O, Simonetti G. Staging of colon cancer: whole-body MRI vs. whole-body PET-CT--initial clinical experience. Abdom Imaging 2008;33(6): 676-688.

19. Thomson V, Pialat JB, Gay F, Coulon A, Voloch A, Granier A, Guerin JC, Viallon M, Berthezene Y. Whole-body MRI for metastases screening: a preliminary study using $3 \mathrm{D}$ VIBE sequences with automatic subtraction between noncontrast and contrast enhanced images. Am J Clin Oncol 2008;31(3): 285-292.

20. Veit P, Kuhle C, Beyer T, Kuehl H, Herborn CU, Borsch G, Stergar H, Barkhausen J, Bockisch A, Antoch G. Whole body positron emission tomography/computed tomography (PET/CT) tumour staging with integrated PET/CT colonography: technical feasibility and first experiences in patients with colorectal cancer. Gut 2006;55(1): 68-73.

21. Abdel-Nabi H, Doerr RJ, Lamonica DM, Cronin VR, Galantowicz PJ, Carbone GM, Spaulding MB. Staging of primary colorectal carcinomas with fluorine-18 fluorodeoxyglucose whole-body PET: correlation with histopathologic and CT findings. Radiology 1998;206(3): 755-760.

22. Brauck K, Zenge MO, Vogt FM, Quick HH, Stock F, Trarbach T, Ladd ME, Barkhausen J. Feasibility of whole-body MR with T2- and T1-weighted real-time steady-state free precession sequences during continuous table movement to depict metastases. Radiology 2008;246(3): 910-916.

23. Kantorova I, Lipska L, Belohlavek O, Visokai V, Trubac M, Schneiderova M. Routine (18)F-FDG PET preoperative staging of colorectal cancer: comparison with conventional staging and its impact on treatment decision making. J Nucl Med 2003;44(11): 1784-1788.

24. Komori T, Narabayashi I, Matsumura K, Matsuki M, Akagi H, Ogura Y, Aga F, Adachi I. 2[Fluorine-18]-fluoro-2-deoxy-D-glucose positron emission tomography/computed tomography versus whole-body diffusion-weighted MRI for detection of malignant lesions: initial experience. Ann Nucl Med 2007;21(4): 209-215.

25. Kong G, Jackson C, Koh DM, Lewington V, Sharma B, Brown G, Cunningham D, Cook GJ. The use of $18 \mathrm{~F}-\mathrm{FDG} \mathrm{PET} / \mathrm{CT}$ in colorectal liver metastases--comparison with CT and liver MRI. Eur $J$ Nucl Med Mol Imaging 2008;35(7): 1323-1329.

26. Lonneux M, Delval D, Bausart R, Moens R, Willockx R, Van Mael P, Declerck P, Jamar F, Zreik H, Pauwels S. Can dual-headed 18F-FDG SPET imaging reliably supersede PET in clinical oncology? A comparative study in lung and gastrointestinal tract cancer. Nucl Med Commun 1998;19(11): 10471054.

27. Lubezky N, Metser U, Geva R, Nakache R, Shmueli E, Klausner JM, Even-Sapir E, Figer A, BenHaim M. The role and limitations of 18-fluoro-2-deoxy-D-glucose positron emission tomography (FDG-PET) scan and computerized tomography (CT) in restaging patients with hepatic colorectal metastases following neoadjuvant chemotherapy: comparison with operative and pathological findings. J Gastrointest Surg 2007;1 1(4): 472-478.

28. Ogunbiyi OA, Flanagan FL, Dehdashti F, Siegel BA, Trask DD, Birnbaum EH, Fleshman JW, Read TE, Philpott GW, Kodner IJ. Detection of recurrent and metastatic colorectal cancer: comparison of positron emission tomography and computed tomography. Ann Surg Oncol 1997;4(8): 613-620.

29. Rosa F, Meimarakis G, Stahl A, Bumm R, Hahn K, Tatsch K, Dresel S. Colorectal cancer patients before resection of hepatic metastases. Impact of (18)F-FDG PET on detecting extrahepatic disease. Nuklearmedizin 2004;43(4): 135-140.

30. Ruers TJ, Langenhoff BS, Neeleman N, Jager GJ, Strijk S, Wobbes T, Corstens FH, Oyen WJ. Value of positron emission tomography with [F-18]fluorodeoxyglucose in patients with colorectal liver metastases: a prospective study. J Clin Oncol 2002;20(2): 388-395. 
31. Schlemmer HP, Schafer J, Pfannenberg C, Radny P, Korchidi S, Muller-Horvat C, Nagele T, Tomaschko K, Fenchel M, Claussen CD. Fast whole-body assessment of metastatic disease using a novel magnetic resonance imaging system: initial experiences. Invest Radiol 2005;40(2): 64-71.

32. Stecco A, Romano G, Negru M, Volpe D, Saponaro A, Costantino S, Sacchetti G, Inglese E, Alabiso $\mathrm{O}$, Carriero A. Whole-body diffusion-weighted magnetic resonance imaging in the staging of oncological patients: comparison with positron emission tomography computed tomography (PETCT) in a pilot study. Radiol Med 2009;114(1): 1-17.

33. Topal B, Flamen P, Aerts R, D'Hoore A, Filez L, Van Cutsem E, Mortelmans L, Penninckx F. Clinical value of whole-body emission tomography in potentially curable colorectal liver metastases. Eur J Surg Oncol 2001;27(2): 175-179.

34. Falk PM, Gupta NC, Thorson AG, Frick MP, Boman BM, Christensen MA, Blatchford GJ. Positron emission tomography for preoperative staging of colorectal carcinoma. Dis Colon Rectum 1994;37(2): 153-156.

35. Gearhart SL, Frassica D, Rosen R, Choti M, Schulick R, Wahl R. Improved staging with pretreatment positron emission tomography/computed tomography in low rectal cancer. Ann Surg Oncol 2006;13(3): 397-404.

36. Khan S, Tan YM, John A, Isaac J, Singhvi S, Guest P, Mirza DF. An audit of fusion CT-PET in the management of colorectal liver metastases. Eur J Surg Oncol 2006;32(5): 564-567.

37. Nahas CS, Akhurst T, Yeung H, Leibold T, Riedel E, Markowitz AJ, Minsky BD, Paty PB, Weiser MR, Temple LK, Wong WD, Larson SM, Guillem JG. Positron emission tomography detection of distant metastatic or synchronous disease in patients with locally advanced rectal cancer receiving preoperative chemoradiation. Ann Surg Oncol 2008;15(3): 704-711.

38. Ono K, Ochiai R, Yoshida T, Kitagawa M, Omagari J, Kobayashi H, Yamashita Y. Comparison of diffusion-weighted MRI and 2-[fluorine-18]-fluoro-2-deoxy-D-glucose positron emission tomography (FDG-PET) for detecting primary colorectal cancer and regional lymph node metastases. J Magn Reson Imaging 2009;29(2): 336-340.

39. Schiepers C, Penninckx F, De Vadder N, Merckx E, Mortelmans L, Bormans G, Marchal G, Filez L, Aerts R. Contribution of PET in the diagnosis of recurrent colorectal cancer: comparison with conventional imaging. Eur J Surg Oncol 1995;21(5): 517-522.

40. Tateishi U, Maeda T, Morimoto T, Miyake M, Arai Y, Kim EE. Non-enhanced CT versus contrastenhanced CT in integrated PET/CT studies for nodal staging of rectal cancer. Eur J Nucl Med Mol Imaging 2007;34(10): 1627-1634.

41. Tsunoda Y, Ito M, Fujii H, Kuwano H, Saito N. Preoperative diagnosis of lymph node metastases of colorectal cancer by FDG-PET/CT. Jpn J Clin Oncol 2008;38(5): 347-353.

42. Veit P, Antoch G, Stergar H, Bockisch A, Forsting M, Kuehl H. Detection of residual tumor after radiofrequency ablation of liver metastasis with dual-modality PET/CT: initial results. Eur Radiol 2006;16(1): 80-87.

43. Vitola JV, Delbeke D, Sandler MP, Campbell MG, Powers TA, Wright JK, Chapman WC, Pinson CW. Positron emission tomography to stage suspected metastatic colorectal carcinoma to the liver. Am J Surg 1996;171(1): 21-26.

44. Zerhouni EA, Rutter C, Hamilton SR, Balfe DM, Megibow AJ, Francis IR, Moss AA, Heiken JP, Tempany CM, Aisen AM, Weinreb JC, Gatsonis C, McNeil BJ. CT and MR imaging in the staging of colorectal carcinoma: report of the Radiology Diagnostic Oncology Group II. Radiology 1996;200(2): 443-451.

45. Zhuang H, Sinha P, Pourdehnad M, Duarte PS, Yamamoto AJ, Alavi A. The role of positron emission tomography with fluorine-18-deoxyglucose in identifying colorectal cancer metastases to liver. Nucl Med Commun 2000;21(9): 793-798. 
46. Ntinas A, Zambas N, Al Mogrambi S, Petras P, Chalvatzoulis E, Frangandreas G, Tsantilas D, Spiridis C, Gerasimidis T. Postoperative follow-up of patients with colorectal cancer: a combined evaluation of CT scan, colonoscopy and tumour markers. Tech Coloproctol 2004;8 Suppl 1: s190-192.

47. Saunders TH, Mendes Ribeiro HK, Gleeson FV. New techniques for imaging colorectal cancer: the use of MRI, PET and radioimmunoscintigraphy for primary staging and follow-up. Br Med Bull 2002;64: 81-99.

48. Shin SS, Jeong YY, Min JJ, Kim HR, Chung TW, Kang HK. Preoperative staging of colorectal cancer: CT vs. integrated FDG PET/CT. Abdom Imaging 2008;33(3): 270-277.

49. Wong CY, Salem R, Raman S, Gates VL, Dworkin HJ. Evaluating 90Y-glass microsphere treatment response of unresectable colorectal liver metastases by [18F $]$ FDG PET: a comparison with CT or MRI. Eur J Nucl Med Mol Imaging 2002;29(6): 815-820.

50. Yang QM, Bando E, Kawamura T, Tsukiyama G, Nemoto M, Yonemura Y, Furukawa H. The diagnostic value of PET-CT for peritoneal dissemination of abdominal malignancies. Gan To Kagaku Ryoho 2006;33(12): 1817-1821.

51. Yoshioka T, Fukuda H, Fujiwara T, Iwata R, Ido T, Murakawa Y, Gamo M, Ishioka C, Kanamaru R. FDG PET evaluation of residual masses and regrowth of abdominal lymph node metastases from colon cancer compared with CT during chemotherapy. Clin Nucl Med 1999;24(4): 261-263.

52. Zhang C, Chen Y, Xue H, Zheng P, Tong J, Liu J, Sun X, Huang G. Diagnostic value of FDG-PET in recurrent colorectal carcinoma: a meta-analysis. Int J Cancer 2009;124(1): 167-173.

53. Flamen P, Stroobants S, Van Cutsem E, Dupont P, Bormans G, De Vadder N, Penninckx F, Van Hoe L, Mortelmans L. Additional value of whole-body positron emission tomography with fluorine18-2-fluoro-2-deoxy-D-glucose in recurrent colorectal cancer. J Clin Oncol 1999;17(3): 894-901.

54. Johnson K, Bakhsh A, Young D, Martin TE, Jr., Arnold M. Correlating computed tomography and positron emission tomography scan with operative findings in metastatic colorectal cancer. Dis Colon Rectum 2001;44(3): 354-357.

55. Fong Y, Saldinger PF, Akhurst T, Macapinlac H, Yeung H, Finn RD, Cohen A, Kemeny N, Blumgart LH, Larson SM. Utility of $18 \mathrm{~F}-\mathrm{FDG}$ positron emission tomography scanning on selection of patients for resection of hepatic colorectal metastases. Am J Surg 1999;178(4): 282-287.

56. Veit-Haibach P, Kuehle CA, Beyer T, Stergar H, Kuehl H, Schmidt J, Borsch G, Dahmen G, Barkhausen J, Bockisch A, Antoch G. Diagnostic accuracy of colorectal cancer staging with wholebody PET/CT colonography. Jama 2006;296(21): 2590-2600.

57. Arulampalam T, Costa D, Visvikis D, Boulos P, Taylor I, Ell P. The impact of FDG-PET on the management algorithm for recurrent colorectal cancer. Eur J Nucl Med 200 1;28(12): 1758-1765.

58. Cohade C, Osman M, Leal J, Wahl RL. Direct comparison of (18)F-FDG PET and PET/CT in patients with colorectal carcinoma. J Nucl Med 2003;44(11): 1797-1803.

59. Delbeke D, Vitola JV, Sandler MP, Arildsen RC, Powers TA, Wright JK, Jr., Chapman WC, Pinson CW. Staging recurrent metastatic colorectal carcinoma with PET. J Nucl Med 1997;38(8): 11961201.

60. Lonneux M, Reffad AM, Detry R, Kartheuser A, Gigot JF, Pauwels S. FDG-PET improves the staging and selection of patients with recurrent colorectal cancer. Eur J Nucl Med Mol Imaging 2002;29(7): 915-921.

61. Nakamoto Y, Sakamoto S, Okada T, Senda M, Higashi T, Saga T, Togashi K. Clinical value of manual fusion of PET and CT images in patients with suspected recurrent colorectal cancer. AJR Am J Roentgenol 2007;188(1): 257-267. 
62. Ruhlmann J, Schomburg A, Bender H, Oehr P, Robertz-Vaupel GM, Vaupel H, Wolter H, Kozak B, Biersack HJ. Fluorodeoxyglucose whole-body positron emission tomography in colorectal cancer patients studied in routine daily practice. Dis Colon Rectum 1997;40(10): 1195-1204.

63. Schmidt GP, Baur-Melnyk A, Haug A, Utzschneider S, Becker CR, Tiling R, Reiser MF, Hermann KA. Whole-body MRI at $1.5 \mathrm{~T}$ and $3 \mathrm{~T}$ compared with FDG-PET-CT for the detection of tumour recurrence in patients with colorectal cancer. Eur Radiol 2009;19(6): 1366-1378.

64. Staib L, Schirrmeister H, Reske SN, Beger HG. Is (18)F-fluorodeoxyglucose positron emission tomography in recurrent colorectal cancer a contribution to surgical decision making? Am J Surg $2000 ; 180(1): 1-5$.

65. Valk PE, Abella-Columna E, Haseman MK, Pounds TR, Tesar RD, Myers RW, Greiss HB, Hofer GA. Whole-body PET imaging with $[18 \mathrm{~F}]$ fluorodeoxyglucose in management of recurrent colorectal cancer. Arch Surg 1999;134(5): 503-511; discussion 51 1-503.

66. Whiteford MH, Whiteford HM, Yee LF, Ogunbiyi OA, Dehdashti F, Siegel BA, Birnbaum EH, Fleshman JW, Kodner IJ, Read TE. Usefulness of FDG-PET scan in the assessment of suspected metastatic or recurrent adenocarcinoma of the colon and rectum. Dis Colon Rectum 2000;43(6): 759767; discussion 767-770.

67. Kamel IR, Cohade C, Neyman E, Fishman EK, Wahl RL. Incremental value of CT in PET/CT of patients with colorectal carcinoma. Abdom Imaging 2004;29(6): 663-668.

68. Blomqvist L, Holm T, Goranson H, Jacobsson H, Ohlsen H, Larsson SA. MR imaging, CT and CEA scintigraphy in the diagnosis of local recurrence of rectal carcinoma. Acta Radiol 1996;37(5): 779784 .

69. Pema PJ, Bennett WF, Bova JG, Warman P. CT vs MRI in diagnosis of recurrent rectosigmoid carcinoma. J Comput Assist Tomogr 1994;18(2): 256-261.

70. Stuckle CA, Haegele KF, Jendreck M, Kickuth R, Schneider O, Hohlbach G, Liermann D. [Improvements in detection of rectal cancer recurrence by multiplanar reconstruction]. Radiologe 2005;45(10): 930-934, 936.

71. Valentini V, Aristei C, Glimelius B, Minsky BD, Beets-Tan R, Borras JM, Haustermans K, Maingon P, Overgaard J, Pahlman L, Quirke P, Schmoll HJ, Sebag-Montefiore D, Taylor I, Van Cutsem E, Van de Velde C, Cellini N, Latini P. Multidisciplinary Rectal Cancer Management: 2nd European Rectal Cancer Consensus Conference (EURECA-CC2). Radiother Oncol 2009;92(2): 148-163.

72. Titu LV, Breen DJ, Nicholson AA, Hartley J, Monson JR. Is routine magnetic resonance imaging justified for the early detection of resectable liver metastases from colorectal cancer? Dis Colon Rectum 2006;49(6): 810-815.

73. Titu LV, Nicholson AA, Hartley JE, Breen DJ, Monson JR. Routine follow-up by magnetic resonance imaging does not improve detection of resectable local recurrences from colorectal cancer. Ann Surg 2006;243(3): 348-352. 

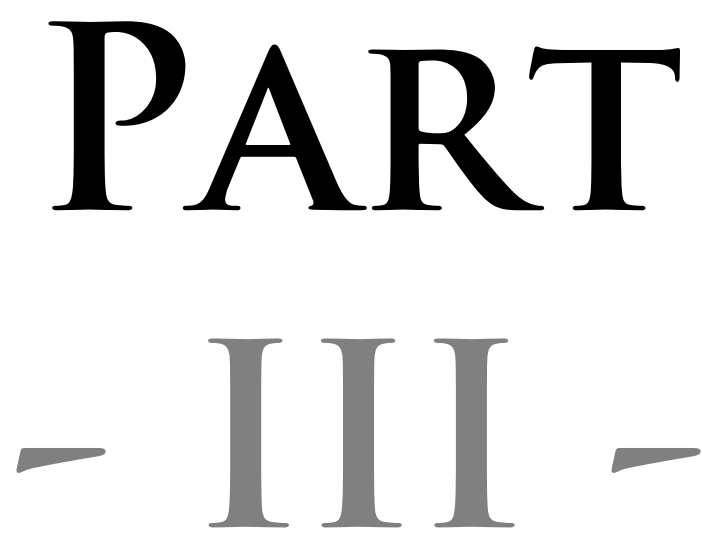

A patient's perspective 

CHAPTER 8

\section{Patiënteninterview}

M Maas

W Savelberg-Pasmans

GL Beets 
CHAPTER 8 


\section{Wait-and-see studie: visie van de patiënt}

Deze thesis is voornamelijk gericht op de wetenschappelijk en medische kant van wait-and-see policy na chemoradiatie. Echter, de mening en visie van de patiënt is ook erg belangrijk. Tijdens de studies is het opgevallen dat de patiënt een heel andere mening heeft dan de betrokken behandelend arts. Om aandacht te besteden aan dit zeer belangrijke patiëntenperspectief hebben we een interview afgenomen bij een patiënte die nu 2,5 jaar aan de wait-and-see studie deelneemt. Zij had een lage T3N2 rectumtumor die geheel in remissie is gegaan na chemoradiatie, waarop ze vanuit een ander ziekenhuis naar het MUMC werd verwezen om te evalueren of ze zou kunnen deelnemen aan de wait-and-see studie.

\section{Eerste reactie}

De eerste reactie van patiënte toen ze te horen kreeg dat haar tumor door de chemoradiatie verdwenen leek te zijn: 'Fantastisch! Maar eigenlijk geloof je het niet meteen.' Vooral in de omgeving werd er nuchter gereageerd en er werd zelfs gesuggereerd dat er misschien wel nooit sprake van een tumor was geweest. De bevinding had veel impact op patiënte omdat het pad eigenlijk al uitgestippeld was: 'Alles zou weggehaald worden en ik zou een stoma krijgen, het stoma was al aangetekend op mijn buik. Dan hoor je dat het waarschijnlijk weg is en dan weet je het niet meer. Je durft eigenlijk niet te hopen dat het zou kunnen zonder operatie. Ik had er via mijn radiotherapeut al wat over gehoord, maar die had duidelijk gemaakt dat het nog in de kinderschoenen stond'.

Vervolgens werd ze naar Maastricht verwezen, omdat de behandelend arts het erg interessant vond dat de tumor weg was. Hij belde 's avonds en zei: 'Ga maar gewoon naar Maastricht'. Ze was wel angstig dat de behandelend arts haar toch gewoon ging opereren, terwijl dit volgens patiënte 'eigenlijk altijd later nog kan'.

In de periode tussen verwijzing en de afspraken in Maastricht was er eigenlijk weinig tijd om na te denken. 'Je kent de ins en outs niet, je bent een leek. Je bent ook erg gereserveerd om je aan de optie over te geven, je beschermt jezelf tegen te veel hoop, ondanks dat stemmetje in je hoofd'.

In Maastricht bleek na een aantal onderzoeken dat ze in aanmerking kwam voor deelname aan de studie. In Maastricht werden voor- en tegens van deelname aan de studie uitgebreid besproken, deze informatie werd als heel objectief ervaren. 'Het was zo veel logischer wat in Maastricht werd verteld, dan wat er in mijn andere ziekenhuis (bij diagnose) was gezegd. Daar werd een radicale operatie geboden met een stoma en misschien was een anussparende operatie mogelijk, wat allemaal gepaard zou gaan met veel langdurige complicaties, zoals incontinentie. Maar ik dacht: het is weg, waarom ga je dan opereren? Je wordt zo vaak gecontroleerd en daar voel je je safe bij. Ze zitten er 
zo kort bovenop, als het weer de kop op steekt, dan kan het dán weggehaald worden, maar dat is dán. Je leeft van tevoren.'

\section{Voor- en nadelen}

Als we haar vragen naar de nadelen en risico's van de studie, die ook uitgebreid aangekaart werden bij de uitleg over de studie, geeft ze aan dat de voordelen duidelijk opwegen tegen de nadelen. 'Die informatie heeft me niet argwanend of angstig gemaakt. Er waren zo veel voordelen. Die kans laat je niet lopen.' Desgevraagd geeft ze aan wat de voordelen zijn. 'Je wordt zo vaak en met korte tussentijd gecontroleerd en dan ga je weer blij de deur uit. Dan heb je thuis geen zorgen meer als je gecontroleerd bent. Ik heb heel erg genoten van de dingen na een controle. Je weet: ze hebben me binnenstebuiten gekeerd. En natuurlijk is het vermijden van een stoma een ander voordeel.' We zien vaak in de praktijk dat mensen het vermijden van een stoma (tijdelijk of permanent) een belangrijk voordeel vinden. Als we de patiënte vragen of ze bij een hoger gelegen tumor, waarbij geen permanent stoma nodig is, ook voor deelname aan de studie had gekozen, antwoordt ze met overtuiging dat ze nog steeds had deelgenomen. 'Het is toch een zware operatie. Ik heb familieleden die dit ook ervaren hebben met veel ellende achteraf.'

Een belangrijk risico van de studie is dat het niet met $100 \%$ zekerheid is vast te stellen dat de tumor echt weg is door de chemoradiatie. 'Daar denk je heel even over na, maar daar geef je niet aan toe. Wat heeft dat voor zin? Je hebt gekozen voor deze weg en het geeft zoveel meer comfort in je leven. Ik heb er zo weinig last van ondervonden, van de behandeling, van alles. Ik heb altijd gewoon door kunnen werken. Anderen hebben zoveel ellende en dan weegt dat zo op tegen de risico's. Misschien is het dan wel gezond om een heel klein beetje struisvogel te spelen en te denken: als het teruggroeit, dat zien we dan wel weer. Ik denk dat niemand zekerheid heeft.'

Wanneer slaat de balans van voordelen en nadelen om? 'Als de artsen zouden zeggen dat de kans groot of reëel is dat er ergens iets anders de kop op steekt of dat er hoge risico's waren. Dan heb ik een grotere kans om met een stoma te blijven leven dan om zonder stoma te leven. Maar jullie waren wel erg voorzichtig en duidelijk. Ik heb daar vertrouwen in gehad.' Ze geeft wel aan dat patiënten het goed moeten begrijpen en ook moeten weten waar ze aan beginnen. 'Uitleg is heel belangrijk. Je moet het als patiënt wel afwegen. Als die mensen hiervoor kiezen zonder erover na te denken en het komt terug, dan heb je straks een patiënt aan je tafel zitten, die zegt: “ja, als je me dat had gezegd...” Maar het is je eigen verantwoording en je eigen lijf. Dat kan niemand voor je beslissen. Je moet de mensen de mogelijkheid geven en that's it.'

De familie speelt ook een rol in de keuze. 'Je staat ook niet alleen voor die keuze. Ik ben best eigenzinnig, ik doe precies wat ik zelf wil. Mijn familie weet gewoon dat je dat besluit neemt voor jezelf. Ondanks dat ze wel wat bang waren, accepteerden ze dat wel. Maar als de balans van voordelen en nadelen minder gunstig was geweest, dan had ik waarschijnlijk ook geen steun van mijn man en kinderen gekregen.' 


\section{Huidige situatie}

Het gaat nu heel goed en ze voelt zich nog steeds erg tevreden met haar deelname aan de studie. 'Ik ben actief en we wandelen veel met de honden. Ik heb nog wel soms pijn rond mijn bekken, maar dat zal wel van de bestraling zijn. Dat zijn dingen daar moet je mee leren leven, dan ga ik even zitten.’ Deelname aan een experimentele studie voelt voor haar heel speciaal. 'Ik denk dan een stapje verder: hoeveel mensen lopen dadelijk onnodig rond met een stoma? Na een zware operatie. Hoe meer mensen aan die studie mee doen, hoe bereikbaarder het wordt, toch? Ik heb zoveel goede reacties gehad van andere mensen: “wauw, hoe kom je daar terecht?" Ik zou het anderen ook adviseren. Ik weet ook wel dat ik geluk heb gehad. Mensen waarbij de tumor niet weg is, die kunnen niet voor deze keuze staan.'

\section{Deelname en controles}

De controles maakten haar alleen in het begin wat onzeker, maar dat is met de tijd langzaam verdwenen. De controles zijn niet echt zwaar, maar de endoscopie vind ze vreselijk. 'Daar heb ik tot de dag erna last van. Van de scans heb ik totaal geen last. Na de controle kan ik het helemaal loslaten. Als de uitnodigingen weer kwamen, dan werd je er weer mee geconfronteerd, dan ga je er over nadenken. Maar ik ben nooit echt bang geweest. Ik ben wel blij als je bevestigd hebt gekregen dat het nog altijd prima is. Ik ben nog nooit naar een controle gekomen met het idee: het zit helemaal fout. Daarnaast was de begeleiding geweldig, op een gelijk niveau met mij. Het beestje werd bij de naam genoemd en er was geen afstand tussen de artsen en mij. Ik kreeg in een ander ziekenhuis alleen te horen wat de arts goed vond voor me, maar dat is toch onzin, het is mijn lijf. Er is ook veel begrip vanuit de artsen, je wordt gebeld met een uitslag in de avond als het ziekenhuis eigenlijk al dicht is, omdat ze weten dat je onzeker bent. Dat geeft je een goed gevoel.' Ook haar familie maakt zich geleidelijk minder zorgen. 'De aandacht verslapt, de angst en onzekerheid zijn weg. De gedachte eraan gaat weg. Dat gaat geleidelijk en komt ook door de begeleiding.'

De duur en frequentie van de follow-up is prima, maar af en toe had ze toch ook fasen dat ze er een hekel aan had om naar het ziekenhuis te gaan. 'Je hebt al zoveel in het ziekenhuis gezeten.' Dan was ze blij dat ze weer drie maanden niet meer naar het ziekenhuis hoefde te gaan. 'Maar later als het allemaal zijn gangetje gaat, dan heb je daar geen moeite meer mee. Dan is het wel lekker, dan kan ik er weer een half jaar tegen. Dat geeft een goed gevoel. Ik zou niet willen stoppen met de controles, dat geeft toch geen lekker gevoel. Het doet je toch goed als het goed gaat en je gerustgesteld bent.' Desgevraagd geeft ze aan dat ze momenteel nergens zorgen over heeft: 'Eerlijk niet'.

\section{Nieuwe opties en de perceptie van artsen}

We vertellen dat er andere manieren (bijvoorbeeld hogere doses bestraling of andere chemotherapie) zijn om de kans op een complete respons te verhogen, echter dit gaat gepaard met meer bijwerkingen en/of complicaties. Ze geeft aan dat dit iets is wat 
we zeker moeten gaan aanbieden aan patiënten. Ze is zelfs erg verbaasd dat we het niet al aanbieden, ook al hebben de patiënten dan toch nog kans dat het niet helemaal weggaat en alsnog een operatie nodig is. 'Als je de kans hebt dat je de meest voordelige uitkomst hebt, dan ga je daar toch voor! Ondanks de bijwerkingen. De operatie is toch een veel ingrijpendere bijwerking met dat stoma. Ik zou altijd hiervoor kiezen! Ben ik daar apart in?'

We geven aan dat artsen dit over het algemeen geen goed idee vinden en dat waitand-see überhaupt door veel artsen argwanend wordt bekeken. Hierop reageert ze vol verbazing: 'Echt waar? Ik vind het belangrijkst wat de patiënt ervan vindt. Waar slaat dat nou op! Je kwaliteit van leven ervaar je toch zelf, daar kan een dokter toch niks over zeggen. Ik bepaal zelf wat ik belangrijk vind.'

De wait-and-see optie wordt dus zelden aan patiënten aangeboden en er zijn weinig patiënten van op de hoogte. Dat merkt ze ook aan de reacties van anderen aan wie ze haar verhaal verteld. 'Zulke mensen zeggen dan “dat kan niet!”, maar het is wel zo! Eigenlijk is het raar dat dat bestaat. Het is niet eerlijk, deze mogelijkheid wordt andere mensen onthouden. Het is ieders eigen keus, maar er zijn vast ook mensen die misschien zo bang zijn dat ze toch voor een operatie kiezen.'

We leggen uit dat de terughoudendheid van de artsen vooral wordt veroorzaakt door de angst dat het toch niet helemaal weg is en er dus een risico is op teruggroei en eventueel ook uitzaaiingen in de tussentijd. 'Ik kan er niet bij dat jullie zoveel moeite moeten doen om dokters te overtuigen. Waarom? Met mijn simpele verstand kan ik me daar niks bij voorstellen. Het is toch een veel voordeligere, gunstigere, minder belastende behandeling dan een operatie? Wat nou als het bij mij terugkomt als een erwt, dan zit het er niet langer dan 3 maanden. Maar ik heb maanden daarmee rondgelopen bij de diagnose tijdens de behandeling en daar maken ze zich dan geen zorgen over! Ja, het is te druk en er is te weinig personeel en er zijn wachtlijsten en in die tijd mag je wel met een tumor rondlopen. Van dat risico ben ik me altijd bewust van geweest. In theorie kan er toentertijd al iets in je lichaam verspreid zijn. Dan zeg ik: ik ben nu drie jaar verder en gezond.'

De artsen willen graag definitief bewijs dat wait-and-see policy veilig is. Om dergelijk definitief bewijs te leveren voor wait-and-see zou in de toekomst een onderzoek nodig zijn waarin deelnemers via loting worden toegewezen aan de behandeling die $\mathrm{u}$ nu volgt of toch een operatie. Er is dan dus een kans van $50 \%$ om voor de wait-and-see groep te loten en er is dan dus ook $50 \%$ kans dat u voor de operatieve behandelingsgroep loot. We vragen haar wat ze hiervan vindt en of ze daaraan mee zou doen. 'Dat zou voor mij niks zijn. Ik zou er niet aan meedoen. Bij mij zou niet worden geopereerd, ik wil geen kans lopen om geopereerd te worden.'

$\mathrm{Ze}$ is nu al 2,5 jaar recidiefvrij en dat zou haar visie op de studie kunnen beïnvloeden. Zou ze indien ze opnieuw voor de keuze zou staan, echt niet aan een dergelijke gerandomiseerde studie deel willen nemen, zeker bij twijfel? 'Je prakkiseert er zo lang over en dan weet je wat je wilt. Ik kan me dat niet voorstellen, ik vind het 
een beetje raar. Ik kan me niet voorstellen dat als je dat aan iemand voorlegt, misschien een enkeling, dat die dan zegt: 'oké, nou dan trek maar een lootje en dan zien we wel wat je met me doet.'

We vragen haar hoe we die dokters kunnen overtuigen van het feit dat ze niet zo terughoudend hoeven te zijn. 'Ze moeten gewoon reëel zijn, ze doen alsof ze alles in de hand hebben en alsof ze alle angst en onzekerheid kunnen voorkomen door heel rigoureus in te grijpen. Maar als puntje bij paaltje komt, als je een oncoloog $100 \%$ zekerheid vraagt, waar je dan ook in je lichaam kanker hebt, dat krijg je niet! Dat zegt hij nooit. Waarom weigeren ze je dan nou zo'n gunstige behandeling, met als reden dat de arts geen angst en onzekerheid meer heeft. Je hebt altijd angst en onzekerheid en er is altijd een risico. Is dat risico dan groter met jullie behandeling?' We geven aan dat de artsen denken dat het risico op een slechtere oncologische uitkomst groter is met waitand-see policy, doordat je niet $100 \%$ zeker kan weten dat het weg is na de chemoradiatie. 'Je kunt ook overdrijven, of niet? Heeft je leven dan nog kwaliteit als je uit angst zo ver gaat? Door angst gedreven, is dat kwaliteit? Als je een tijdje zonder stoma kan leven en je door teruggroei van de tumor later een stoma krijgt, dan heb je toch langer zonder stoma geleefd. Ik heb een voorbeeld in de familie met een vergelijkbare tumor, die heel veel ellende heeft na de operatie. Ook emotioneel komt hij dat wereldje van het ziekenhuis niet uit. Hij is al 4 jaar een patiënt, en ik heb daar geen last van. Dat is zo'n verschil in kwaliteit.'

\section{Conclusie}

Uit het relaas van deze patiënte merken we dat het perspectief van de patiënten vrijwel haaks op het perspectief van de meeste artsen staat. Blijkbaar liggen de prioriteiten voor patiënten anders dan voor hun artsen. Een belangrijk aspect is controle: een patiënt moet zelf de controle houden en zelf keuzes kunnen maken. Ondanks de uitleg over de vele onzekerheden en risico's die de artsen zo argwanend maken, geeft ze aan dat de onzekerheden en risico's van de artsen voor haar niet meetellen, het is immers haar leven en zij wil zelf beslissen. Daarom is uitleg en communicatie zo belangrijk, waarbij ook alle opties, inclusief wait-and-see policy, aan bod moeten komen.

Opvallend is dat de frequente controles als een duidelijk voordeel van de studie worden ervaren. Het geeft de patiënt veel geruststelling en zelfs meer geruststelling dan de wetenschap dat alles weggehaald is. Deze overweging ervaren we vaker bij andere patiënten.

Een gerandomiseerde studie lijkt haar niet haalbaar, want slechts enkelingen zouden de keuze uit handen willen geven. De kans op het achterwege laten van een operatie is te aantrekkelijk om dit over te laten aan het lot. 

CHAPTER 9

Discussion 
CHAPTER 9 


\section{Discussion}

During the last decades progress in the treatment of rectal cancer has resulted in a very effective local control. This excellent local control is mainly due to an optimal surgical technique, the total mesorectal excision, and the introduction of neoadjuvant (chemo)radiation. ${ }^{1-3}$ In our region, the 5-year probability for a local recurrence for all tumours, including the locally advanced tumours, is approximately $2-3 \%$. However, the combination of total mesorectal excision and (chemo)radiation leads to a high rate of treatment related morbidity and mortality and to substantial changes in bowel, urinary and sexual function. ${ }^{4,5}$ Also, a (temporary or permanent) colostomy is often necessary. It has been observed that some patients respond very well to chemoradiation and the probability of pathologic complete response (ypToNo) is approximately $15-20 \%{ }^{6}$ Several studies suggested that such a complete response to chemoradiation is indicative of a favourable biological tumour profile and is associated with excellent prognosis. ${ }^{7-9}$ Therefore, the question can be raised whether it is feasible to reduce morbidity without compromising local (or distant) control by treating complete responders to chemoradiation with less invasive surgery or even omission of surgery (combined with intensive follow-up), the so-called wait-and-see policy.

\section{Paradigm shift to less invasive treatment}

The first main aim of this thesis was to evaluate the feasibility, safety and potential benefits of a wait-and-see policy for complete responders to chemoradiation. The feasibility of a wait-and-see policy depends on a set of prerequisites, which were addressed in this thesis and will be discussed.

The first prerequisite is to verify that patients with complete pathologic response have a better prognosis than patients who have remaining tumour after chemoradiation. In this respect, results from previous studies were equivocal, with some reporting significantly better survival ${ }^{8}, 10,11$, whereas others failed to find statistically significant differences in long-term outcome. ${ }^{12-14}$ This variation in results may be due to small sample sizes and for this reason a pooled analysis was performed with individual patient data from multiple studies (chapter 2). Included were studies that evaluated prognosis of patients with locally advanced rectal cancer, who were treated with total mesorectal excision and chemoradiation. Such a pooled analysis has more power than individual studies to detect relevant differences in long-term survival according to response to chemoradiation and can also provide a reliable estimate of the long-term survival of complete pathologic responders. This estimate can serve as a benchmark for comparison of the results of a wait-and-see policy with standard treatment by total mesorectal excision. The pooled analysis of individual patient data from 14 international centres established that local control, distant-metastasis free survival, disease-free survival and overall survival are excellent for complete responders treated with surgery. Their prognosis is significantly better than patients 
with residual tumour after CRT. ${ }^{6}$ The prognosis of patients with a complete response after CRT and surgery for rectal cancer should be used as a reference when evaluating less invasive treatment after CRT in clinical complete responders. With such an excellent prognosis for complete responders treated with surgery, the bars are set high for less invasive treatment after CRT.

A second important prerequisite is accurate identification of patients eligible for a wait-and-see policy, i.e. the clinical complete responders to chemoradiation. In chapter 4 the selection of patients with a complete tumour response for a wait-and-see policy in our pilot study is described. MRI played a central role in our response assessment strategy. The main issue of restaging rectal cancer after CRT is that many physicians are worried that unrecognized residual tumour after chemoradiation will lead to local recurrences. Standard T2-weighted MRI can identify complete responders after chemoradiation, but only when the rectal wall has regained its normal aspect (which occurs only in $25 \%$ of the patients ${ }^{15}$ ); when there is residual fibrosis or thickening of the rectal wall, T2-weighted MRI cannot discern small nests of residual tumour. Standard MRI misses only $2-8 \%$ of tumour remnants, which is relatively low. ${ }^{16,}{ }^{17}$ But radiologists tend to overstage the presence of residual tumour because they do not want to run the risk of missing residual tumour. ${ }^{16,18-20}$ Therefore, there is a tendency towards underestimation rather than overestimation of the number of patients with a complete response with standard T2-weighted MRI. Due to this cautious approach many patients with a complete response are missed (60-100\%). ${ }^{17}$ With the addition of diffusion-weighted sequences to standard MRI it can be more accurately assessed whether the residual hypo-intense mass in the rectal wall on T2-weighted MRI indicates true residual tumour (as indicated by high signal on b1000 diffusion-weighted imaging) or fibrosis only (absence of signal on b1000 diffusion-weighted imaging). As a consequence, the risk of missing residual tumour remains low, whereas the percentage of missed complete responses decreases to $36-44 \% .{ }^{17}$ During the wait-and-see study we experienced that endoscopy is an excellent tool for tumour response evaluation after chemoradiation. ${ }^{21,22}$ Endoscopy has the ability to correct both over- and understaging of MRI. Therefore, we feel that endoscopy is an indispensable tool in response evaluation when one is considering less invasive treatment after chemoradiation.

In addition to the evaluation of the response of the primary tumour it is important to evaluate the lymph nodes, which are often involved at diagnosis. Whereas for primary nodal staging standard MRI is only moderately accurate, nodal restaging after CRT has been reported to be more reliable and therefore facilitates selection of patients with a negative node status after CRT.20, ${ }^{23}$ Therefore, the combination of standard MRI, diffusion-weighted MRI and endoscopy seems sufficiently accurate to identify complete responders eligible for wait-and-see policy, with an acceptable small risk of overlooking residual tumour.

The third prerequisite is to provide an effective but also tolerable follow-up strategy. The follow-up strategy in the pioneer study from Habr-Gama et al. was 
mainly based on very frequent endoscopic examinations: up to monthly in the first year. ${ }^{24}$ We chose a follow-up strategy with a lower frequency but incorporated MRI in addition to endoscopy. Patients did not object to this follow-up strategy, which was reflected in the $100 \%$ compliance. During follow-up we found that when the typical white scar with teleangiectasia (typical endoscopic feature of a complete response) remains unchanged during follow-up, it can be assumed that there is a sustained complete response. ${ }^{21}$ MR follow-up features of sustained complete response are hypointense bowel wall thickening that does not change over time or a persistent normalized rectal wall. ${ }^{15}$ The only thing that often does change and is not associated with a recurrence is the gradual decrease in submucosal edema. ${ }^{15}$ Chapter 3 describes the experience and results of this follow-up strategy. Until February 2013, 44 patients with complete response had been included in a prospective pilot study on the effects of a wait-and-see policy. After a follow-up period of 19 (1-91) months, two patients had a recurrence that could be detected early and radically resected based on relevant features at endoscopy and MRI. One other patient developed peritonitis carcinomatosa after 2,5 years of follow-up.

When considering omitting a treatment for cancer, this should lead to benefits in other aspects. As mentioned earlier, total mesorectal excision is associated with potentially dangerous surgical complications and morbidity on the long term. ${ }^{25}$ Also, there is a substantial mortality risk from this surgery, particularly in the elderly. ${ }^{26}$ The benefits of wait-and-see policy should be derived from gain in functional outcome. It is obvious that surgery-related mortality will be absent when leaving out surgical treatment. With regard to urogenital and bowel function it is not clear whether omission of surgery indeed leads to improvement of residual function compared to surgery. It is possible that the chemoradiation has long-term side effects on bowel function, which normally go undetected, because the rectum is resected. Moreover, a substantial benefit that can be gained from omission of surgery is avoidance of a colostomy. Our pilot study showed that in patients following wait-and-see policy a permanent colostomy could be avoided in half of the paints and a temporary colostomy in the other half (based on height of the tumour). On the contrary, all control patients with a complete response who were treated with TME needed a colostomy, of which almost half were permanent. When comparing the surgically treated patients without a colostomy with the patients who followed wait-and-see, the wait-and-see patients had significantly better bowel function and less urogenital problems. Compared to baseline the complete responders following wait-and-see policy experienced less alterations in bowel function. Furthermore, patients who undergo wait-and-see felt less impaired in daily activities by their bowel function than the operated patients with a complete response. ${ }^{21}$

Following the previous paragraphs, physicians and patients considering a waitand-see policy face a trade-off between oncological control and functional gain. On the 
one hand, surgery-related morbidity and mortality will be absent when leaving out surgical treatment. On the other hand, a wait-and-see policy will inevitably harbour the risk of recurrence in some patients, given the fact that staging will never be entirely perfect. The decision on this trade-off is a shared decision made by both the physician and the patient, since only the patient can decide which risk he or she is willing to take for how much functional gain. Shared decision making, is increasingly implemented in clinical practice and is based on several ethical principles, such as a patient's autonomy, benefits and risk assessment and information to the patient. ${ }^{27}$ The interview with a patient in chapter 8 illustrates how valuable this shared decision making is for the patient and that this patient was willing to accept a certain risk to win functional gain. The risk that this particular patient was willing to take was much higher than her primary treating physician deemed acceptable. The acceptable risk will be different for each patient and therefore intensive informing of the patient is very important to come to an individual decision.

\section{Paradigm shift from local to distant control}

The second main aim of this thesis was to identify areas for further improvement of prognosis of patients with rectal cancer. From chapters 5-7 can be concluded that for improvement of prognosis distant control is crucial. Chapter 5 shows that MRI-based differentiated treatment according to the risk of a patient for a local recurrence results in excellent local control. However, the risk for distant metastasis is rather high. Adjuvant chemotherapy is one of the mainstays of distant control in patients with locally advanced rectal cancer. Patients who are treated with neoadjuvant chemoradiation usually have involved nodes at diagnosis and are therefore often treated with adjuvant chemotherapy. Given the absence of involved lymph nodes in complete responders and the relatively low risk for distant metastasis, the benefit of adjuvant chemotherapy might be limited in these patients. Chapter 7 presents the results from a pooled analysis of individual patient data from observational studies, which compared prognosis in patients with and without treatment with adjuvant chemotherapy. The results point in the direction that in patients with a complete response the benefit from adjuvant chemotherapy is considerably smaller than in patients with residual disease after chemoradiation. Given the fact that the absolute risk for metastasis in patients with a complete response is already very low ${ }^{6}$, the use of adjuvant chemotherapy is questionable. Unfortunately, the data in chapter 7 are not derived from randomized trials and therefore, there is a risk for confounding by indication. The results are in accordance with a paper by Capirci et al. that questioned the benefit of adjuvant CT for complete responders after $\mathrm{CRT}^{7}$, but contradict findings from a subgroup analysis of a randomized EORTC trial. ${ }^{28}$ Definite answers on the benefit of adjuvant chemotherapy in patients treated with neoadjuvant CRT will have to be provided by new randomized studies or from pooled analysis of randomized data. 


\section{Future perspectives}

This thesis provides preliminary evidence on the feasibility and safety of less invasive treatment for complete responders after CRT for locally advanced rectal cancer. The preliminary results from this thesis will have to be confirmed in larger studies and after a longer period of follow-up. A randomized controlled trial would be the preferred study design to provide definite evidence, but it is unlikely that a randomized controlled trial will be feasible. First, there is the unwillingness of patients to take part in a study in which chance will determine whether they would be treated with or without surgery because patients often like to be involved in such a decision. Second, an equivalence trial will be necessary, which requires a very large sample size. ${ }^{29}$ It is unrealistic to expect that such a large sample size can be obtained, given the low prevalence of a complete response. ${ }^{6}$ Probably, a large prospective observational multicenter study will be the most feasible design to obtain evidence.

The role of MRI in selecting patients with a complete response has been studied quite extensively, but there is only limited evidence for the validity of diagnosis using endoscopy. ${ }^{30}$ Therefore, studies will have to address the additional diagnostic value of endoscopy to MRI for selection of complete responders. Additionally, the role of endoscopy and MRI in the follow-up during wait-and-see policy should be consolidated, as the currently available evidence is limited.21, 30 Also, as described earlier we still miss some residual tumours in a small number of patients. This occurs in most cases in patients with only small islets of microscopic residual tumour which are not picked up by (diffusion-weighted) MRI. To further reduce this small risk, more functional types of imaging (e.g. molecular imaging or perfusion based imaging) can probably be of help on this issue and sould be the focus of future research.

The option of transanal endoscopic microsurgery (TEM) after chemoradiation for good and complete responders was not addressed in this thesis, but is of major importance. Several studies are currently recruiting patients to evaluate the complication rates and local control after TEM in irradiated patients. ${ }^{31}$ Future studies will have to show which patients are likely to benefit from TEM and which patients can be treated with wait-and-see policy.

There is a rising interest in techniques to increase complete response rates after chemoradiation. The main rationale for this interest is to increase the number of patients who might be eligible for less invasive treatment. However, it is yet unclear whether patients who achieve a complete response after a different radiation schedule than is currently applied have the same prognosis as patients who achieve a complete response after standard chemoradiation (capecitabine with 28x1.8 Gy or 25x2 Gy). When less invasive treatment after chemoradiation is proven to be safe the first step would therefore be to evaluate the prognosis of patients with a complete response after alternative radiation schedules, before considering to offer less invasive treatment to these patient groups. 
With regard to the benefit of adjuvant chemotherapy, it would be an important next step to pool data from randomized trials in which the administration of adjuvant chemotherapy was randomized in patients treated with neoadjuvant chemoradiation. Such a pooled analysis (as recently suggested in a systematic review by Bujko et al. ${ }^{32}$ ) could provide more robust evidence on the value of adjuvant chemotherapy in complete, good and poor responders to chemoradiation. However, given the increasing number of trials evaluating neoadjuvant chemotherapy, the question whether the administration of adjuvant chemotherapy should depend on the degree of response to CRT might not be of the same relevance in the future.

\section{Recommendations}

\section{For clinical practice}

This thesis has shown that a wait-and-see policy can be considered in strictly selected patients with a complete response. It can only be applied when the combination of high quality MRI with accurate nodal staging and endoscopy is available for selection and follow-up. During follow-up any change in MR images or at endoscopy should be considered a recurrence. Data on patients with a complete response who follow a wait-and-see policy should be prospectively and precisely collected, to assure adequate follow-up and monitoring of patients. It can be considered to pool data from patients following a wait-and-see policy from multiple centers in one dataset, as has been recently suggested by a Danish study group.

For patients with a complete response the absolute risk for metastasis is small and therefore the relative effect of adjuvant chemotherapy is limited. It can thus be considered to omit adjuvant chemotherapy for these patients. Conversely, in patients with residual disease there is a potential benefit of adjuvant chemotherapy and this option should be discussed with these patients.

\section{For research}

\section{Staging}

There is a need for an improvement of the detection of low volume residual cancer. Because of limitations of morphological imaging, new studies on imaging should focus on functional imaging modalities (e.g. dynamic-contrast enhanced MRI, perfusion CT) which can provide information with for example targeted markers and detect changes in texture of tissues, which cannot be discerned visually.

Furthermore, this thesis supports the initiation of a prospective study to evaluate the value of endoscopy in response evaluation after CRT.

\section{Treatment}

More evidence in a larger patient sample should be obtained on the safety of less invasive treatment after CRT. The results as presented in this thesis can be used in the 
set-up of a large prospective multicentre study. Although a randomized study would theoretically be the desired study design, a prospective observational study will probably be the most feasible design.

Because of the lack of sufficient evidence on the effect of adjuvant chemotherapy in rectal cancer, a meta-analysis of data from the large randomized trials on adjuvant chemotherapy (EORTC trial, QUASAR study) should be performed to determine the value of adjuvant chemotherapy after (chemo)radiation for patients with rectal cancer and identify factors that determine the benefit of adjuvant chemotherapy for different patient groups. 


\section{References}

1. Landelijke_Werkgroep_Gastro-Intestinale_Tumoren. Landelijke Richtlijn Rectumcarcinoom (versie 2.1). wwwoncolinenl 2008 .

2. Richtlijn Rectumcarcinoom. www.oncoline.nl 2009].

3. Quirke P, Durdey P, Dixon MF, Williams NS. Local recurrence of rectal adenocarcinoma due to inadequate surgical resection. Histopathological study of lateral tumour spread and surgical excision. Lancet 1986;2(8514): 996-999.

4. Heald RJ, Ryall RD. Recurrence and survival after total mesorectal excision for rectal cancer. Lancet 1986;1(8496): 1479-1482.

5. Improved survival with preoperative radiotherapy in resectable rectal cancer. Swedish Rectal Cancer Trial. N Engl J Med 1997;336(14): 980-987.

6. Kapiteijn E, Marijnen CA, Nagtegaal ID, Putter H, Steup WH, Wiggers T, Rutten HJ, Pahlman L, Glimelius B, van Krieken JH, Leer JW, van de Velde CJ. Preoperative radiotherapy combined with total mesorectal excision for resectable rectal cancer. N Engl J Med 2001;345(9): 638-646.

7. Sauer R, Becker H, Hohenberger W, Rodel C, Wittekind C, Fietkau R, Martus P, Tschmelitsch J, Hager E, Hess CF, Karstens JH, Liersch T, Schmidberger H, Raab R. Preoperative versus postoperative chemoradiotherapy for rectal cancer. N Engl J Med 2004;351(17): 173 1-1740.

8. Tytherleigh MG, Warren BF, Mortensen NJ. Management of early rectal cancer. Br $J$ Surg 2008;95(4): 409-423.

9. Rectal Cancer. www.emedicine.com.

10. Marijnen CA, Kapiteijn E, van de Velde CJ, Martijn H, Steup WH, Wiggers T, Kranenbarg EK, Leer JW. Acute side effects and complications after short-term preoperative radiotherapy combined with total mesorectal excision in primary rectal cancer: report of a multicenter randomized trial. $J$ Clin Oncol 2002;20(3): 817-825.

11. Guillem JG, Chessin DB, Cohen AM, Shia J, Mazumdar M, Enker W, Paty PB, Weiser MR, Klimstra D, Saltz L, Minsky BD, Wong WD. Long-term oncologic outcome following preoperative combined modality therapy and total mesorectal excision of locally advanced rectal cancer. Ann Surg 2005;241(5): 829-836.

12. Ruo L, Tickoo S, Klimstra DS, Minsky BD, Saltz L, Mazumdar M, Paty PB, Wong WD, Larson SM, Cohen AM, Guillem JG. Long-term prognostic significance of extent of rectal cancer response to preoperative radiation and chemotherapy. Ann Surg 2002;236(1): 75-81.

13. Lezoche G, Baldarelli M, Guerrieri M, Paganini AM, De Sanctis A, Bartolacci S, Lezoche E. A prospective randomized study with a 5-year minimum follow-up evaluation of transanal endoscopic microsurgery versus laparoscopic total mesorectal excision after neoadjuvant therapy. Surg Endosc 2008;22(2): 352-358.

14. Habr Gama A, Perez RO, Nadalin W, Nahas SC, Ribeiro U, Jr., Silva E Sousa AH, Jr., Campos FG, Kiss DR, Gama Rodrigues J. Long-term results of preoperative chemoradiation for distal rectal cancer correlation between final stage and survival. J Gastrointest Surg 2005;9(1): 90-99.

15. Habr Gama A, Perez RO, Nadalin W, Sabbaga J, Ribeiro U, Jr., Silva e Sousa AH, Jr., Campos FG, Kiss DR, Gama Rodrigues J. Operative versus nonoperative treatment for stage o distal rectal cancer following chemoradiation therapy: long-term results. Ann Surg 2004;240(4): 711-717.

16. Habr Gama A, Perez RO, Proscurshim I, Campos FG, Nadalin W, Kiss D, Gama Rodrigues J. Patterns of Failure and Survival for Nonoperative Treatment of Stage co Distal Rectal Cancer Following Neoadjuvant Chemoradiation Therapy. J Gastrointest Surg 2006;10(10): 1319-1329. 
17. Habr Gama A, de Souza PM, Ribeiro U, Jr., Nadalin W, Gansl R, Sousa AH, Jr., Campos FG, Gama Rodrigues J. Low rectal cancer: impact of radiation and chemotherapy on surgical treatment. Dis Colon Rectum 1998;41(9): 1087-1096.

18. Gavioli M, Luppi G, Losi L, Bertolini F, Santantonio M, Falchi AM, D'Amico R, Conte PF, Natalini $\mathrm{G}$. Incidence and clinical impact of sterilized disease and minimal residual disease after preoperative radiochemotherapy for rectal cancer. Dis Colon Rectum 2005;48(10): 1851-1857.

19. Group SRC. Improved survival with preoperative radiotherapy in resectable rectal cancer. Swedish Rectal Cancer Trial. N Engl J Med 1997;336(14): 980-987.

20. Glynne-Jones R, Mathur P, Elton C, Train ML. The multidisciplinary management of gastrointestinal cancer. Multimodal treatment of rectal cancer. Best Pract Res Clin Gastroenterol 2007;21(6): 1049-1070.

21. Dindo D, Demartines N, Clavien PA. Classification of surgical complications: a new proposal with evaluation in a cohort of 6336 patients and results of a survey. Ann Surg 2004;240(2): 205-213.

22. Bellera CA, MacGrogan G, Debled M, de Lara CT, Brouste V, Mathoulin-Pelissier S. Variables with time-varying effects and the Cox model: some statistical concepts illustrated with a prognostic factor study in breast cancer. BMC Med Res Methodol 2010;10: 20.

23. Capirci C, Valentini V, Cionini L, De Paoli A, Rodel C, Glynne-Jones R, Coco C, Romano M, Mantello G, Palazzi S, Mattia FO, Friso ML, Genovesi D, Vidali C, Gambacorta MA, Buffoli A, Lupattelli M, Favretto MS, La Torre G. Prognostic value of pathologic complete response after neoadjuvant therapy in locally advanced rectal cancer: long-term analysis of 566 ypCR patients. Int $J$ Radiat Oncol Biol Phys 2008;72(1): 99-107.

24. Bujko K, Glynne-Jones R, Bujko M. Does adjuvant fluoropyrimidine-based chemotherapy provide a benefit for patients with resected rectal cancer who have already received neoadjuvant radiochemotherapy? A systematic review of randomised trials. Ann Oncol 2010;2 1(9): 1743-1750.

25. Gray R, Barnwell J, McConkey C, Hills RK, Williams NS, Kerr DJ. Adjuvant chemotherapy versus observation in patients with colorectal cancer: a randomised study. Lancet 2007;370(9604): 20202029.

26. Bosset JF, Collette L, Calais G, Mineur L, Maingon P, Radosevic-Jelic L, Daban A, Bardet E, Beny A, Ollier JC. Chemotherapy with preoperative radiotherapy in rectal cancer. $N$ Engl $\mathrm{J} \mathrm{Med}$ 2006;355(11): 1114-1123.

27. Collette L, Bosset JF, den Dulk M, Nguyen F, Mineur L, Maingon P, Radosevic-Jelic L, Pierart M, Calais G. Patients with curative resection of cT3-4 rectal cancer after preoperative radiotherapy or radiochemotherapy: does anybody benefit from adjuvant fluorouracil-based chemotherapy? A trial of the European Organisation for Research and Treatment of Cancer Radiation Oncology Group. $J$ Clin Oncol 2007;25(28): 4379-4386.

28. Maas M, Nelemans PJ, Valentini V, Das P, Rodel C, Kuo LJ, Calvo FA, Garcia-Aguilar J, GlynneJones R, Haustermans K, Mohiuddin M, Pucciarelli S, Small W, Jr., Suarez J, Theodoropoulos G, Biondo S, Beets-Tan RG, Beets GL. Long-term outcome in patients with a pathological complete response after chemoradiation for rectal cancer: a pooled analysis of individual patient data. Lancet Oncol 2010;11(9): 835-844.

29. Wolpin BM, Meyerhardt JA, Mamon HJ, Mayer RJ. Adjuvant treatment of colorectal cancer. $C A$ Cancer J Clin 2007;5 7(3): 168-185. 

Summary 
CHAPTER 9 


\section{Summary}

The main aims of this thesis are (1) to evaluate the feasibility of a shift towards less invasive local treatment of rectal cancer in patients with complete response to neoadjuvant chemoradiation and (2) to identify areas for further improvement of the prognosis of patients with rectal cancer. The currently available evidence and status with regard to these aims are summarised in chapter 1, the introduction.

\section{Part I - Paradigm shift to less invasive treatment}

To be able to treat selected patients with less invasive treatment it is important to have a reliable estimate of the prognosis of patients who have undergone standard treatment (TME) in order to compare outcome after less invasive treatment with. In chapter 2 a pooled analysis of individual patient data is described with the aim to determine the long-term outcome of patients with a pathologic complete response (pCR after chemoradiation (CRT) and standard resection. These patients with a pCR are compared with patients with residual tumour after CRT. From 14 international hospitals 3105 patients were included, of which 484 had a pCR after CRT and surgery. Multivariable analyses showed that patients with a pCR have an excellent and significantly better prognosis than patients with residual tumour, with regard to local control, distant-metastasis free survival, disease-free survival and overall survival. When it is considered to offer less invasive treatment to these patients with a pCR, this less invasive treatment will have to compete with this excellent long-term outcome after standard treatment.

In chapter 3 less invasive treatment is evaluated in a pilot study. In 21 patients with a clinical complete response after CRT wait-and-see policy was performed. With waitand-see policy surgery is omitted and regular follow-up is performed. Patients were identified to have a clinical complete response with T2-weighted, diffusion-weighted and gadofosveset-enhanced MRI combined with endoscopy. Follow-up consisted of the same modalities, with additional CEA measurements and CTs of the thorax and abdomen. As a control group patients with a pCR after CRT and TME were identified from a prospective cohort study.

After a mean follow-up of more than 2 years, only one patient who followed waitand-see policy had a small local tumour regrowth, that could be completely resected by transanal endoscopic microsurgery (ypT2). All other patients following wait-and-see policy are alive and disease-free. In the control group two patients died; one died from distant metastases and the other died as a consequence of complications from colostomy closure surgery.

With questionnaires bowel function and quality of life were measured, which showed that both were significantly better in patients following wait-and-see policy than in the control group of patients with pCR after CRT and surgery. 
Chapter 4 describes the MRI morphology of the rectum during follow-up of patients following a wait-and-see policy. Four distinct patterns could be identified, of which three comprised of fibrosis (minimal, full thickness and irregular fibrosis) and the fourth was characterised by a normalised rectal wall. These patterns do not show change during follow-up in case of a sustained complete response. In $26 \%$ of the patients edema was present in the first months after CRT. This edema normalised after longer follow-up times. In a patient who developed a local recurrence no specific changes were visible on T2-weighted MRI, but a subtle increase in signal intensity was identified at diffusion-weighted MRI.

\section{Part II - Paradigm shift from local to distant control}

In chapter 5 the results of a multicentre study are reported in which treatment stratification was based on the risk for local recurrence as assessed with MRI. Patients were categorised into three groups according to their risk for a recurrence: early tumour, intermediate tumour and locally advanced tumour, which were treated with surgery only, surgery immediately after $5 \times 5$ Gy of radiation or surgery after 6-8 weeks of neoadjuvant CRT, respectively. The results show an excellent local control with a local recurrence rate of only $2.2 \%$. However, the incidence of metachronous distant metastases was $16 \%$ and the incidence of death was $15 \%$ after a median follow-up of 41 months. Therefore, it can be concluded that the MRI-based treatment strategies led to an excellent local control, but the main threat for prognosis is distant metastasis.

The benefit of adjuvant chemotherapy for patients who have been treated with neoadjuvant CRT is evaluated in chapter 6. A specific interest was the benefit of adjuvant chemotherapy for patients with a pCR after CRT. This study is a continuation of the study as described in chapter 2. Again a pooled analysis of individual patient data was performed with data from 13 international hospitals. In total, 3313 patients were included. Multivariable analyses showed a probable absence of effect of adjuvant chemotherapy on long-term outcome in patients with a pCR. Probably, these results are linked to the excellent prognosis of these specific patients. Patients with residual tumour did have a clear benefit of adjuvant chemotherapy. Subgroup analyses showed that patients without involved nodes after CRT do benefit from adjuvant chemotherapy, whereas patients with involved nodes after CRT do not. These findings are in agreement with the hypothesis that the same factors that predict response to CRT are responsible for the sensitivity of tumour cells for adjuvant chemotherapy as well. This hypothesis has also been reported in the literature.

Chapter 7 discusses which whole-body imaging modality is most accurate in detecting a recurrence in patients with a suspicion of a recurrence during follow-up of colorectal cancer. A meta-analysis was performed including 14 studies that evaluated whole-body PET, PET-CT and/or CT for recurrence detection in patients with suspected recurrent colorectal cancer. Only 1 study on whole-body MRI was identified. 
The meta-analysis shows that PET-CT is the most accurate whole-body imaging modality to detect a local or distant recurrence in patients with colorectal cancer. PETCT detects almost all recurrences, is more reliable in case of a negative CT and is necessary when hepatic metastases are found to exclude the presence of extrahepatic metastases (which is an important flaw of CT).

\section{Part III - A patient's perspective}

Chapter 8 is an interview with a patient who is following the wait-and-see policy, which allows us see a patient's perspective on this treatment strategy. This is an interesting point of view, because doctors generally regard the wait-and-see policy with great reserve. The aim of the interview was to evaluate the pros and cons of wait-andsee policy for patients and to also examine the burden of the risk and follow-up. In our experience patients have a very positive attitude towards wait-and-see policy. They also bear the possible risks associated with wait-and-see policy consciously. Furthermore, the patient was asked whether she, if she again faced the choice to follow the wait-and-see policy or not, would agree to participate in a randomised controlled trial (in which she would be randomly assigned to surgery or the wait-and-see policy). She indicated to not be willing to participate in such a randomised trial, because she would then risk to be appointed to the surgery arm. This interview suggests that the most reliable method to provide definite evidence for the wait-and-see policy, the randomised trial, is not appreciated by patients. Therefore, before embarking on a randomised trial, its feasibility will have to be examined and alternative study designs should be explored. 

Dutch summary 
CHAPTER 9 


\section{Nederlandse samenvatting}

De voornaamste doelen van dit proefschrift zijn (1) om de haalbaarheid van minder invasieve behandeling van patiënten met een complete respons na neoadjuvante chemoradiatie te evalueren en (2) gebieden te identificeren om de prognose van patiënten met een rectumcarcinoom te verbeteren. De huidige bewijslast en status met betrekking tot deze doelen staan in hoofdstuk 1, de introductie, beschreven.

\section{Deel I - Focus verschuiving naar minder invasieve lokale behandeling}

Om minder invasief te kunnen behandelen bij een geselecteerde patiëntengroep is het van belang om ter vergelijking een indicatie van de prognose te hebben van patiënten die wel de standaard invasieve behandeling (TME) hebben ondergaan. In hoofdstuk 2 wordt daarom een gepoolde analyse van individuele patiëntendata beschreven met als doel de prognose van patiënten die een pathologisch complete respons (pCR) hebben na behandeld te zijn met chemoradiatie (CRT) en standaard resectie. Deze uitkomst wordt vergeleken met die van patiënten die wel resttumor hadden na CRT en standaard resectie. Vanuit 14 internationale centra werd de data van 3105 patiënten geïncludeerd, waarvan er 484 een pCR hadden door de CRT. De multivariabele analyses toonden aan dat patiënten met een pCR een uitstekende en significant betere prognose hadden dan patiënten die resttumor hadden na de CRT, met betrekking tot lokale controle, metastasevrije overleving, ziektevrije overleving en algehele overleving. Als dus wordt overwogen om aan deze patiëntengroep een minder invasieve behandeling aan te bieden, moet deze minder invasieve behandeling concurreren met deze uitstekende prognose na CRT en standaard resectie.

In hoofdstuk 3 wordt de proef op de som genomen: bij 21 patiënten met een klinisch complete respons na CRT wordt wait-and-see policy toegepast. Bij wait-and-see policy wordt geen operatie uitgevoerd, maar wordt de patiënt regelmatig gecontroleerd. De patiënten werden geselecteerd als klinisch complete responders met T2-gewogen, diffusie-gewogen en gadofosveset-versterkte MRI en endoscopie. De follow-up bestond ook uit deze modaliteiten gecombineerd met bepaling van het CEA en CT-scans van de thorax en het abdomen. Als controlegroep werden patiënten met een pCR na CRT en standaard resectie geïdentificeerd uit een andere prospectieve studie. $\mathrm{Na}$ een gemiddelde follow-up van meer dan 2 jaar was er één wait-and-see patiënt met een klein recidief na 22 maanden follow-up, dat met transanale endoscopische microchirurgie kon worden verwijderd (ypT2). Alle overige patiënten die wait-and-see policy volgen waren ziektevrij in leven. In de controlegroep zijn twee patiënten overleden; één als gevolg van metastasen en de ander door een complicatie na het sluiten van het colostoma.

Met vragenlijsten werd de darmfunctie en daaraan gerelateerde kwaliteit van leven gemeten, waaruit bleek dat deze uitkomstmaten bij de wait-and-see patiënten significant beter waren dan bij de patiënten met een pCR na chirurgie. 
Hoofdstuk 4 gaat in detail in op de MRI morfologie van het rectum tijdens followup van de wait-and-see patiënten. Er werden vier MRI patronen geïdentificeerd bij patiënten met een klinisch complete respons. Drie van deze patronen bestaan uit fibrose: minimale fibrose, fibrose door de hele rectumwand heen en irregulaire fibrose. De vierde groep bestaat uit patiënten met een genormaliseerde rectumwand. De patronen ondergaan vrijwel geen verandering gedurende de follow-up bij persisterende complete respons. $\mathrm{Bij} 26 \%$ van de patiënten was in de eerste maanden van follow-up ook sprake van oedeem dat normaliseerde na langere follow-up duur. Bij de patiënt met een lokale teruggroei van de tumor werd op T2-gewogen MRI geen verandering gezien, echter op diffusie-gewogen MRI werd een subtiele toename in signaal gezien.

\section{Deel II - Focus verschuiving van lokale controle naar controle van afstandsmetastasen}

In hoofdstuk 5 worden de resultaten van een multicentrische studie gerapporteerd waarbij de behandeling van patiënten werd bepaald door het risico op lokaal recidief zoals beoordeeld met behulp van MRI. Patiënten werden in drie groepen ingedeeld naar gelang het risico op een recidief: vroege tumor, intermediaire tumor en lokaal uitgebreide tumor, welke respectievelijk met alleen chirurgie, chirurgie direct na 5x5 Gy bestraling en chirurgie 6-8 weken na neoadjuvante CRT werden behandeld. Mediane follow-up was 41 maanden. De resultaten tonen een excellente lokale controle met een lokaal recidiefpercentage van slechts 2.2\%. Daar staat een incidentie van metachrone metastasen van $16 \%$ en sterfte van $15 \%$ tegenover. De op MRI gebaseerde behandelstrategie heeft dus een zeer gunstig effect op de lokale controle, echter metastasen vormen de belangrijkste bedreiging voor de prognose.

Het belang van adjuvante chemotherapie voor patiënten die behandeld zijn met CRT wordt in hoofdstuk 6 behandeld. Specifiek wordt in dit hoofdstuk gekeken naar de waarde van adjuvante chemotherapie voor patiënten met een pCR na CRT. Deze studie is een vervolgstudie op de studie in hoofdstuk 2. Wederom werd er een gepoolde analyse verricht van verzamelde individuele patiëntendata, ditmaal uit 13 internationale centra. In totaal werden 3313 patiënten geïncludeerd. Met behulp van multivariabele analyses werd gevonden dat patiënten met een pCR na CRT en standaard resectie waarschijnlijk geen baat hebben van adjuvante chemotherapie. Vermoedelijk hangen deze resultaten samen met de uitstekende prognose van deze specifieke patiëntengroep. Patiënten met resttumor na CRT hebben duidelijk wel baat van adjuvante chemotherapie. Bij subgroep analyses van patiënten met negatieve en positieve klierstatus na CRT blijkt dat patiënten met negatieve klierstatus na CRT wel baat hebben van adjuvante chemotherapie en mensen met positieve klierstatus na CRT niet. Deze resultaten lijken overeen te komen met de hypothese dat dezelfde factoren die predictief zijn voor de respons op CRT ook de gevoeligheid voor adjuvante chemotherapie bepalen. Deze hypothese is al eerder in de literatuur geponeerd. 
Hoofdstuk 7 onderzoekt welke whole-body beeldvormende techniek het meest accuraat is voor (lokaal of afstands-) recidiefdetectie bij patiënten met een verdenking op recidief colorectaal carcinoom. Met een meta-analyse worden de resultaten van 14 studies gepoold die whole-body PET, PET-CT en/of CT voor recidiefdectectie na colorectaal carcinoom evalueren. Er wordt slechts 1 studie geïdentificeerd die wholebody MRI onderzocht. Uit de meta-analyse blijkt dat PET-CT de meest accurate techniek is. PET-CT detecteert de meeste recidieven, is betrouwbaarder dan CT als er geen afwijkingen op CT gevonden worden en is vrijwel altijd geïndiceerd als er levermetastasen gevonden worden op CT om extrahepatische metastasen uit te sluiten (de achilleshiel van CT).

\section{Deel III - Patiëntenperspectief}

In hoofdstuk 8 wordt een patiënt die wait-and-see policy volgt geïnterviewd om een kijkje vanuit het patiëntenperspectief te nemen. Het doel van het interview was om de voor- en nadelen van wait-and-see policy te onderzoeken en om een idee te krijgen van de last van de risico's en de intensieve follow-up voor de patiënt. Vanuit het doktersperspectief is er vooralsnog veel terughoudendheid met betrekking tot waitand-see policy. In onze ervaring is dit voor patiënten omgekeerd: zij staan juist zeer positief tegenover minder invasieve behandeling en dragen zeer bewust het risico op teruggroei van de tumor. De patiënt beaamde dit. De patiënt werd ook gevraagd of zij, als ze wederom voor de beslissing stond om wel of niet wait-and-see policy te volgen, deel zou nemen aan een gerandomiseerde studie, waarbij ze zou moeten loten tussen wait-and-see policy en chirurgie. $\mathrm{Zij}$ gaf aan niet deel te willen nemen aan een gerandomiseerde studie, aangezien ze niet het risico wilde lopen om te loten voor chirurgie. Dit interview suggereert dat de meest betrouwbare methode om definitief bewijs te leveren voor wait-and-see policy, de gerandomiseerde studie, weinig draagvlak heeft onder patiënten. Voor het starten van een gerandomiseerde studie zal de uitvoerbaarheid aldus onderzocht moeten worden en is onderzoek naar een alternatieve studie-opzet van belang. 

Dankwoord 
CHAPTER 9 


\section{Dankwoord}

Allereerst wil ik graag alle patiënten bedanken die mee hebben gewerkt aan mijn onderzoek. Zonder jullie deelname was dit proefschrift niet mogelijk geweest. Mijn waardering voor jullie inzet en motivatie om deze uitdaging samen met mij aan te gaan is onbeschrijflijk. Veel dank!

Dr. Beets, Lieve Geerard. Door jou ben ik dit onderzoek ingerold en daar ben ik je ongelooflijk dankbaar voor. Ik heb altijd heel erg prettig met je samengewerkt. Je begeleiding was relaxed maar tegelijkertijd ook directief. Hierdoor kan ik nu ook heel zelfstandig met het onderzoek aan de slag. Ook heb ik geleerd van jou om door de bomen het bos weer te zien als ik vastliep. Jij was ook de reden dat ik graag chirurg wilde worden; jij was mijn grote voorbeeld. Gaandeweg kwam ik er echter achter dat het niet bij me paste. Gelukkig kon ik toen ook op jouw steun rekenen en heb je me geholpen om de moeilijke carrièrekeus te maken. Veel dank voor je steun en motiverende begeleiding!

Prof. Beets-Tan, Lieve Regina. Via Geerard rolde ik het onderzoek in en daardoor kwam ik ook direct onder jouw vleugels terecht. Je bezielende begeleiding heeft me extra gemotiveerd voor het onderzoek. Mijn onderzoek nam hierdoor een vlucht. Je stond altijd voor me klaar zowel voor werk- als privégerelateerde kwesties. Ik kan altijd bij je binnenlopen en waardeer je toegankelijkheid en vertrouwen in mij enorm. Lieve Regina, ik vertrouw jou ook.

Dr. Nelemans, Lieve Patty. Samen hebben we bergen werk verzet. Jij hebt bij mij een vuurtje aangewakkerd voor de methodologie en statistiek (iets wat weinig mensen echter begrijpen). Ik heb altijd prettig samengewerkt met je en ben dan ook trots dat jij mijn copromotor geworden bent! We zitten vrijwel altijd op één lijn. Bij dilemma's of ingewikkelde kwesties had je altijd een nieuwe invalshoek om tot een oplossing te komen. Heel veel dank voor je steun, begeleiding en luisterend oor. Ik hoop nog lange tijd met je te kunnen samenwerken.

Lieve Doenja. We werden zonder elkaar ooit eerder gezien te hebben bij elkaar gezet. Wie had ooit gedacht dat we zo'n dreamteam zouden worden! Met veel plezier en ook enige heimwee kijk ik terug naar onze onderzoekstijd. Naast een top samenwerking hebben we ook een fantastische klik qua humor en persoonlijkheid. Onze vrijdagmiddagmeligheden herinner ik me als de dag van gisteren. Vooral het incident met de perforator en de telefoonlijn staat me nog helder voor de ogen. Ook hebben we samen veel gereisd: Wenen (4x!), Valencia, Venetië (heel romantisch ;-)), Dresden... Ik vergeet jouw snooze-gewoonten nooit meer... Eén van onze hoogtepunten was onze succesvolle deelname aan LINGO! $\mathrm{Nu}$ zitten we samen in opleiding, wat ook heel gezellig is, waardoor we elkaar wel minder vaak zien. Daarom denk ik nog vaak terug 
aan onze toptijd! Lieve Doenja, bedankt voor onze leuke en gezellige tijd! Je bent een superlieve meid en ik ben blij dat ik met jou heb kunnen samenwerken. Ik kan het me niet voorstellen zonder jou. Mogen we samen nog veel meer leuke tijden beleven!

Lieve Max, Sanne en Elleke. Jullie waren mijn voorgangers. Vooral met Sanne heb ik nog veel en intensief samengewerkt na haar promotietijd. Sanne, ik ben blij dat je me je onderzoek hebt laten opvolgen. Ik heb ontzettend veel plezier met je en onze samenwerking is top! Max en Elleke, jullie zijn nu ook mijn collega-assistenten en ik heb het erg naar mijn zin met jullie. Jullie ook veel dank voor de samenwerking!

Beste Milou en Luc. Als onze opvolgers hadden jullie direct een belangrijke taak: alle lopende onderzoeken leren kennen en voortzetten en tegelijkertijd een multicentrische studie opzetten. Jullie zitten er nu helemaal in en ik heb er vertrouwen in dat jullie een prachtig proefschrift zullen krijgen!

Beste prof. de Haan, beste Michiel. Als opleider is je betrokkenheid bij mijn proefschrift beperkt, maar ik ben je toch erg dankbaar. Je flexibiliteit voor het vrijmaken van tijd voor onderzoek tijdens de opleiding, maar ook je toegankelijkheid zijn voor mij erg belangrijk. Ik vind het fijn om jou als opleider te hebben.

Beste prof. Wildberger, beste Joachim. Je maakt deel uit van mijn leescommissie, maar bent in de eerste plaats natuurlijk afdelingshoofd van de afdeling Radiologie in het MUMC. Je hebt me geholpen bij mijn carrièrekeus voor de Radiologie. Gelukkig maar, want ik ben erg blij met mijn keuze! Dank voor je steun en begeleiding!

Beste professor von Meyenfeldt, beste Maarten. Als voorzitter van mijn leescommissie heb je een belangrijke taak vervuld! Je bent ook betrokken geweest bij mijn onderzoek en ik heb veel van je geleerd. Hartelijk dank voor het leiden van mijn leescommissie, ik ben blij dat je bij mijn verdediging aanwezig kan zijn. Beste prof. Tjan-Heijnen, prof. de Wilt en prof. Lambin, hartelijk dank dat jullie deel uit wilden maken van mijn leescommissie.

Beste collega's, ik ga jullie niet allemaal opnoemen, maar ik vind dat we een superleuke groep assistenten vormen! Van samenwerken tot samen wintersport: ik heb het erg naar mijn zin met jullie!

Beste collega-onderzoekers van de MRI3-gang. Ik heb met jullie een leuke tijd gehad. Marc en Jos, zonder jullie had ik het niet gered! Dank voor al jullie hulp maar ook voor jullie gezelligheid. Walter, Eline en Cécile, dank voor jullie hulp bij onoplosbare technische problemen! Beste Stefan, met jou heb ik oeverloos veel lol gehad. Marc, Jos en Stefan nog heel veel dank voor jullie steun bij LINGO! 
Beste Jan (Verwoerd), hartelijk dank voor je hulp bij het leren begrijpen van de MRI en je motiverende en enthousiasmerende uitleg! Ik heb veel van je opgestoken.

Beste Jaap, we hebben heel wat uurtjes doorgebracht achter de pc om mijn cover te ontwerpen. Het heeft wat voeten in aarde gehad, maar het resultaat is prachtig! Ik ben je eeuwige dank verschuldigd. Beste Ine, jij hebt het binnenwerk van mijn boekje in elkaar gezet, wat me een hoop werk heeft bespaard! Veel dank hiervoor.

I would also like to thank all my foreign colleagues for their generosity to share data with me and their faith in my research! It was a pleasure to work with you and hopefully our collaboration will be continued in the future.

Ook wil ik mijn dank betuigen aan alle collega's van de afdelingen chirurgie, radiologie, radiotherapie, medische oncologie en maag-darm-leverziekten waarmee ik heb samengewerkt buiten het MUMC. Zonder jullie participatie en hulp was dit onderzoek niet mogelijk geweest.

Lieve Nicole, jij bent mijn paranimf geworden. Je bent een lieve schat en altijd in voor een date of feestje! Jij biedt altijd een luisterend oor en kan me altijd weer met beide benen op de grond zetten ;-). Lieve Jules, onze vriendschap is heel sterk en hecht, ik ben er trots op dat jij mijn vriend bent. Ik weet dat je altijd voor me klaar staat. Lieve Marianne, sinds onderwijsgroep 1 zijn we vriendinnen en we hebben veel meegemaakt. We raken nooit uitgepraat! Hopelijk blijven we nog lang vriendinnen en misschien kunnen we ons 10-jaren-stad-plan nieuw leven inblazen! Lieve Kelly, je bent er altijd voor me en ik ben heel blij dat ik jou als vriendin heb! Lieve Sanne (Postma), we zien elkaar niet zo vaak, maar als we dan afspreken is het altijd weer reuze gezellig! Ik heb veel plezier met je en hoop dat we nog vele eetdates gaan hebben. Lieve Ilknur, samen stonden we sterk in Sittard. We zijn inmiddels allebei een andere richting opgegaan en ik hoop dat jouw toekomst vol geluk is en dat je de baan mag krijgen die je graag wil! Lieve Nathalie, ik hoop dat je vrede en rust hebt gevonden.

Lieve Dennis, je hebt mijn promotietijd niet meegemaakt maar wel de nasleep ervan en de totstandkoming van dit boekje. Jij hebt me gesteund en geholpen en me de ruimte gegeven. Je hebt me veranderd en mijn hart ingenomen. Ik kan me het leven niet meer voorstellen zonder je.

Lieve papa en mama, zonder jullie was dit allemaal niet mogelijk geweest. Ik kan met geen woorden beschrijven hoeveel jullie voor me betekenen en hoeveel ik aan jullie steun heb. Ik kan me geen betere ouders wensen. Lieve mama, ik ben blij dat je er bij bent.

Liefs, Monique 

Curriculum vitae 
CHAPTER 9 


\section{Curriculum vitae}

Monique Maas was born on the 5th of January 1983 in Eindhoven, The Netherlands. She went to primary school 'Nutsschool Hanevoet' and secondary school 'S.G. Augustinianum (gymnasium)', both in Eindhoven. She graduated with distinction in 2001 and started medical training at Maastricht University in the same year. She obtained her medical degree in 2007, with distinction. During her study she participated in research from 20042007 at the Department of Rheumatology MUMC, supervised by dr. Annelies Boonen. It was in this period that she gained a large interest in research.

She participated in several elective internships at the Department of Surgery at the MUMC from 2004 to 2007. In 2004 she followed an elective internship at the Traumatology unit. From 2006 to 2007 she did an elective internship at the Department of Gastro-intestinal and Oncological Surgery at the MUMC, combining clinical experience with research under supervision of dr. Geerard Beets and drs. Ronald van Dam. In this period she got acquainted with the rectal cancer research team. She became very enthusiastic about their research. In 2007 she went to Salta (Argentina) to follow an extra-curricular internship at the Department of General and Paediatric Surgery and the Neonatal Intensive Care Unit. When she returned, she started working as a resident of Surgery at the Orbis Medical Centre, Sittard, The Netherlands.

After having worked for almost one year in Sittard, she returned to Maastricht to work at Maastricht University (GROW) as a PhD student under supervision of dr. Geerard Beets and prof. dr. Regina Beets-Tan at the Departments of Surgery and Radiology. During this period she won several prizes, among which the Incentive Prize of the Pélerin Symposium (2007), a travel grant for best abstract for GASTRO 2009 and 2012, and prize for best research paper from the ESSO 2010. Also she received a grant from the Profileringsfonds MUMC in 2009 and an AGIKO-grant from ZonMW in 2011. In 2011 she co-authored a proposal for a Dutch Cancer Society grant on rectal cancer staging of approximately 500,000 euros, which was awarded to the rectal cancer team at MUMC in the Spring of 2012.

In September 2011 she started her residence at the Department of Radiology at the Maastricht University Medical Centre (prof. dr. Michiel de Haan, prof. dr. J.E. Wildberger). During her residency she is continuing her research on rectal cancer and is co-supervising the current $\mathrm{PhD}$ students in the rectal cancer research team. 


\section{List of publications}

1. Gollub MJ, Maas M, Weiser M, Beets GL, Goodman K, Berkers L, Beets-Tan RG. Recognition of the anterior peritoneal reflection at rectal MRI. AJR Am J Roentgenol 2013;200(1): 97-101. IF 2.8

2. Kluza E, Rozeboom ED, Maas M, Martens M, Lambregts DM, Slenter J, Beets GL, Beets-Tan RG. T2 weighted signal intensity evolution may predict pathological complete response after treatment for rectal cancer. Eur Radiol 2013;23(1): 253-261. IF 3.2

3. Maas M, Lambregts DM, Lahaye MJ, Beets GL, Backes W, Vliegen RF, Osinga-de Jong M, Wildberger JE, Beets-Tan RG. T-staging of rectal cancer: accuracy of 3.0 Tesla MRI compared with 1.5 Tesla. Abdom Imaging 2012;37(3): 475-481. IF 1.7

4. Lambregts DM, Heijnen LA, Maas M, Rutten IJ, Martens MH, Backes WH, Riedl RG, Bakers FC, Cappendijk VC, Beets GL, Beets-Tan RG. Gadofosveset-enhanced MRI for the assessment of rectal cancer lymph nodes: predictive criteria. Abdom Imaging; epub 18 September 2012: DOI:10.1007/s00261-012-9957-4. IF 1.7

5. Curvo-Semedo L, Lambregts DM, Maas M, Beets GL, Caseiro-Alves F, Beets-Tan RG. Diffusionweighted MRI in rectal cancer: apparent diffusion coefficient as a potential noninvasive marker of tumor aggressiveness. J Magn Reson Imaging 2012;35(6): 1365-1371. IF 2.7

6. Maas M, Rutten IJ, Nelemans PJ, Lambregts DM, Cappendijk VC, Beets GL, Beets-Tan RG. What is the most accurate whole-body imaging modality for assessment of local and distant recurrent disease in colorectal cancer? A meta-analysis : imaging for recurrent colorectal cancer. Eur J Nucl Med Mol Imaging 201 1;38(8): 1560-1571. IF 5.0

7. Maas M, Beets-Tan RG, Lambregts DM, Lammering G, Nelemans PJ, Engelen SM, van Dam RM, Jansen RL, Sosef M, Leijtens JW, Hulsewe KW, Buijsen J, Beets GL. Wait-and-see policy for clinical complete responders after chemoradiation for rectal cancer. J Clin Oncol 2011;29(35): 4633-4640. IF 18.3

8. Lambregts DM, Vandecaveye V, Barbaro B, Bakers FC, Lambrecht M, Maas M, Haustermans K, Valentini V, Beets GL, Beets-Tan RG. Diffusion-weighted MRI for selection of complete responders after chemoradiation for locally advanced rectal cancer: a multicenter study. Ann Surg Oncol 2011;18(8): 2224-2231. IF 4.2

9. Lambregts DM, Maas M, Riedl RG, Bakers FC, Verwoerd JL, Kessels AG, Lammering G, Boetes C, Beets GL, Beets-Tan RG. Value of ADC measurements for nodal staging after chemoradiation in locally advanced rectal cancer-a per lesion validation study. Eur Radiol 201 1;21(2): 265-273. IF 3.2

10. Lambregts DM, Maas M, Cappendijk VC, Prompers LM, Mottaghy FM, Beets GL, Beets-Tan RG. Whole-body diffusion-weighted magnetic resonance imaging: current evidence in oncology and potential role in colorectal cancer staging. Eur J Cancer 201 1;47(14): 2107-2116. IF 5.5

11. Lambregts DM, Maas M, Bakers FC, Cappendijk VC, Lammering G, Beets GL, Beets-Tan RG. Long-term follow-up features on rectal MRI during a wait-and-see approach after a clinical complete response in patients with rectal cancer treated with chemoradiotherapy. Dis Colon Rectum 2011;54(12): 1521-1528. IF 3.1

12. Lambregts DM, Cappendijk VC, Maas M, Beets GL, Beets-Tan RG. Value of MRI and diffusionweighted MRI for the diagnosis of locally recurrent rectal cancer. Eur Radiol 201 1;2 1(6): 1250-1258. IF 3.2

13. Lambregts DM, Beets GL, Maas M, Kessels AG, Bakers FC, Cappendijk VC, Engelen SM, Lahaye MJ, de Bruine AP, Lammering G, Leiner T, Verwoerd JL, Wildberger JE, Beets-Tan RG. Accuracy of gadofosveset-enhanced MRI for nodal staging and restaging in rectal cancer. Ann Surg 2011;253(3): 539-545. IF 7.5 
14. Lambregts DM, Beets GL, Maas M, Curvo-Semedo L, Kessels AG, Thywissen T, Beets-Tan RG. Tumour ADC measurements in rectal cancer: effect of ROI methods on ADC values and interobserver variability. Eur Radiol 2011;21(12): 2567-2574. IF 3.2

15. de Jong MC, van Dam RM, Maas M, Bemelmans MH, Olde Damink SW, Beets GL, Dejong CH. The liver-first approach for synchronous colorectal liver metastasis: a 5-year single-centre experience. $H P B$ (Oxford) 2011;13(10): 745-752. IF 1.6

16. Curvo-Semedo L, Lambregts DM, Maas M, Thywissen T, Mehsen RT, Lammering G, Beets GL, Caseiro-Alves F, Beets-Tan RG. Rectal cancer: assessment of complete response to preoperative combined radiation therapy with chemotherapy--conventional MR volumetry versus diffusionweighted MR imaging. Radiology 2011 ;260(3): 734-743. IF 5.7

17. Maas M, Nelemans PJ, Valentini V, Das P, Rodel C, Kuo LJ, Calvo FA, Garcia-Aguilar J, GlynneJones R, Haustermans K, Mohiuddin M, Pucciarelli S, Small W, Jr., Suarez J, Theodoropoulos G, Biondo S, Beets-Tan RG, Beets GL. Long-term outcome in patients with a pathological complete response after chemoradiation for rectal cancer: a pooled analysis of individual patient data. Lancet Oncol 2010;1 1(9): 835-844. IF 22.6

18. Maas M, Taal E, van der Linden S, Boonen A. A review of instruments to assess illness representations in patients with rheumatic diseases. Ann Rheum Dis 2009;68(3): 305-309. IF 8.7 